\begin{tabular}{|c|c|c|}
\hline Beitr. Ent. & Keltern & ISSN 0005-805X \\
\hline $\mathbf{5 5}(2005) 1$ & S. $1-107$ & 01.07 .2005 \\
\hline
\end{tabular}

\title{
Revision of the New World species of Stiphrosoma CZERNY
}

\section{(Diptera: Anthomyzidae)}

With 215 figures

\author{
JINDŘICH ROHÁČEK and KeVIN N. BARBER
}

Summary

The species of the genus Stiphrosoma Czerny, 1928 found in the New World are revised. Fourteen species are recognized, including the type species of the genus, S. sabulosum (HaLIDAY, 1837), and 13 new species, viz. S. pectinatum sp. n. (Canada: Ontario, Quebec; USA: District of Columbia, Georgia, Illinois, Indiana, Maryland, Massachusetts, Michigan, New York, North Carolina, Pennsylvania, Tennessee, Virginia, West Virginia), S. lucipetum sp. n. (Bahamas; Belize; Costa Rica; Cuba; USA; Florida), S. pullum sp. n. (Costa Rica), S. setipleurum sp. n. (Canada: New Brunswick, Nova Scotia, Ontario, Quebec; USA: Illinois, Indiana, Massachusetts, Michigan, New York, Pennsylvania, West Virginia), S. balteatum sp. n. (Canada: Ontario, Quebec; USA: District of Columbia, Illinois, Massachusetts, Michigan, New York, Ohio, Tennessee, Wisconsin), S. birtum sp. n. (Canada: Alberta, Manitoba, Ontario, Saskatchewan; USA: Colorado, Minnesota, Montana, North Dakota, Utah), S. artum sp. n. (Canada: Alberta, Saskatchewan; USA: North Dakota), S. helvum sp. n. (Canada: Alberta; USA: Montana), S. stylatum sp. n. (Canada: Manitoba, Ontario; USA: Minnesota, Utah), S. minor sp. n. (USA: Arizona), S. vittatum sp. n. (USA: California), S. sororium sp. n. (Mexico) and S. humerale sp. n. (Canada: Alberta, British Columbia, Manitoba, Newfoundland, Nova Scotia, Ontario, Quebec, Saskatchewan; USA: Michigan, New Hampshire, North Carolina, Tennessee, Vermont, Virginia, Washington; in the Palaearctic - Latvia; North Korea; Russia: Siberia). Descriptions of all species are given along with illustrations of male and female terminalia and other diagnostic structures, and their relationships, biology and distribution are discussed. Occurrence of $S$, sabulosum in the Nearctic Region is discussed but its presupposed introduction from Europe has not been demonstrated. The Holarctic distribution of $S$. bumerale is regarded as natural; the E. Palaearctic populations of $S$. humerale were formerly erroneously ascribed to $S$. laetum (MEIGEN, 1830). Wing polymorphism is described in two new species, viz. S. hirtum sp. n. and $S$. artum sp. n., as well as in S. sabulosum. The genus Stiphrosoma is newly diagnosed on the basis of all known species and its relationships are discussed. A key to world species of Stiphrosoma is presented.

\section{Zusammenfassung}

Die neuweltlichen Arten der Gattung Stiphrosoma CzERNY, 1928 werden revidiert. Vierzehn Arten werden festgestellt, darunter der Gattungstypus, S. sabulosum (HALIDAY, 1837), sowie 13 neue Arten: S. pectinatum sp. n. (Kanada: Ontario, Quebec; USA: District of Columbia, Georgia, Illinois, Indiana, Maryland, Massachusetts, Michigan, New York, North Carolina, Pennsylvania, Tennessee, Virginia, West Virginia), S. lucipetum sp. n. (Bahamas; Belize; Costa Rica; Kuba; USA: Florida), S. pullum sp. n. (Costa Rica), S. setipleurum sp. n. (Kanada: Neubraunschweig, Neuschottland, Ontario, Quebec; USA: Illinois, Indiana, Massachusetts, Michigan, New York, Pennsylvania, West Virginia), S. balteatum sp. n. (Kanada: Ontario, Quebec; USA: District of Columbia, Illinois, Massachusetts, Michigan, New York, Ohio, Tennessee, Wisconsin), S. hirtum sp. n. (Kanada: Alberta, Manitoba, Ontario, Saskatchewan; USA: Colorado, Minnesota, Montana, North 
Dakota, Utah), S. artum sp. n. (Kanada: Alberta, Saskatchewan; USA: North Dakota), S. helvum sp. n. (Kanada: Alberta; USA: Montana), S. stylatum sp. n. (Kanada: Manitoba, Ontario; USA: Minnesota, Utah), S. minor sp. n. (USA: Arizona), S. vittatum sp. n. (USA: Kalifornien), S. sororium sp. n. (Mexiko) und S. humerale sp. n. (Kanada: Alberta, Britisch Kolumbien, Manitoba, Neufundland, Neuschottland, Ontario, Quebec, Saskatchewan; USA: Michigan, New Hampshire, North Carolina, Tennessee, Vermont, Virginia, Washington; in der Paläarktis: - Lettland; Nord-Korea; Russland: Sibirien). Alle Arten werden beschrieben unter Abbildung der männlichen und weiblichen Genitalien sowie anderer diagnostischer Merkmale, und ihre Verwandtschaftsverhältnisse, Biologie und Verbreitung werden diskutiert. Das Vorkommen von S. sabulosum in der nearktischen Region wird erörtert aber ihre vermutete Einschleppung aus Europa ist unbewiesen. Die holarktische Verbreitung von S. humerale wird als natürlich erachtet; ostpaläarktische Populationen von $S$. humerale wurden früher irttümlich für $S$. laetum (MEIGEN, 1830) gehalten. Flügelpolymorphismus wird von zwei neuen Arten beschrieben, $S$. hirtum sp. n. und S. artum sp. n., sowie von S. sabulosum. Eine neue Gattungsdiagnose für Stiphrosoma wird erstellt unter Berücksichtigung aller bekannten Arten, und die Verwandtschaftsverhältnisse der Gattung werden diskutiert. Ein Schlüssel für alle Arten von Stiphrosoma weltweit wird vorgestellt.

Keywords

Taxonomy, Stiphrosoma, generic diagnosis, 13 new species, key, relationships, biology, distribution, wing polymorphism, New World

\section{Introduction}

Czerny (1928) described the genus Stiphrosoma to include only two European species, S. oldenbergi CzERNY, 1928 and S. sabulosum (HALIDAY, 1837), and characterized by incomplete venation and/or reduced wings. Several years later ENDERLEIN (1936) placed the brachypterous $S$. sabulosum in his new monotypic genus Ptenotaenia and reduced Stiphrosoma to another monotypic genus containing S. oldenbergi as type species. However, the latter species was found to be a macropterous form and hence synonym of S. sabulosum by STACKELBERG $(1958,1970)$ and Stiphrosoma was subsequently treated either as a monotypic genus (Soós 1981; RoHÁčEK 1983, 1984, 1987; ROHÁČEK \&. Freidberg 1993), as a subgenus of Anthomyza Fallén, 1810 (Stackelberg 1958), or, following Collin (1944), as its synonym (STACKelberg 1970; ANDERsson 1984; VOCKEROTH 1987).

Based on the revision of Palaearctic species RонÁčeK (1996) redefined and reclassified the genus Stiphrosoma to include species of the Anthomyza laeta-group in addition to S. sabulosum. In this broadened generic concept, Stiphrosoma contained only 4 species in the Palaearctic Region but also a number of undecribed species in the Nearctic Region which are the subject of the present revision. Additional research by the junior author revealed further Stiphrosoma species in the Neotropical Region (Central America) and, therefore, this study has been expanded to cover all New World representatives of the genus. Moreover, re-examination of the Stiphrosoma species from the E. Palaearctic area resulted in the finding that specimens considered by RoHÁčEK (1996) to belong to S. laetum (MeIGeN, 1830) are, in fact, conspecific with a new but closely allied species which is widespread in North America. True $S$. laetum is probably restricted to the W. Palaearctic area. With this new species (recently also found to occur in Latvia and described as S. humerale sp. n. below), the Palaearctic fauna now includes 5 species of Stiphrosoma. 
In contrast, as many as 14 species have been recognized in North and Central America, none of which has been formally recorded from the area, although the occurence of S. sabulosum in Canada (Ontario) and the USA (Massachusetts) has long been known (Vockeroth 1987). Only two of the New World species of Stiphrosoma are shared with the Palaearctic Region, viz. S. humerale sp. n. mentioned above and S. sabulosum whose distribution in N. America may be the result of relatively recent introduction from Europe and rapid spreading by human activities.

All New World species are described, illustrated and keyed, with discussion of their relationships and synopsis of their biology and distribution. The genus Stiphrosoma is redescribed to encompass the world fauna of the group and the key includes all species known worldwide. The phylogeny and biogeography are discussed with particular reference to the most recent knowledge of the New World fauna of Anthomyzidae.

\section{Material and methods}

The material examined during this study is deposited in a number of collections. The following codens, representing institutions, are used throughout the manuscript to indicate deposition of specimens:

AMNH American Museum of Natural History, Division of Invertebrate Zoology, New York, NY, U.S.A.

CASC California Academy of Sciences, Department of Entomology, San Francisco, CA, U.S.A.

CMNH Carnegie Museum of Natural History, Section of Invertebrate Zoology, Pittsburg, PA, U.S.A.

CNCI Canadian National Collection of Insects, Biodiversity (Entomology) and Integrated Pest Management, Ottawa, ON, Canada.

DEBU University of Guelph - Insect Collection, Department of Environmental Biology, University of Guelph, Guelph, ON, Canada.

DEIC Deutsches Entomologisches Institut, Eberswalde, Germany.

EMEC Essig Museum of Entomology, University of California - Berkeley, Berkeley, CA, U.S.A.

EMUS Entomological Museum, Department of Biology, Utah State University, Logan, UT, U.S.A.

IBUL Institute of Biology, University of Latvia, Salaspils, Latvia.

INBC Instituto Nacional de Biodiversidad (INBio), Santo Domingo de Heredia, Costa Rica.

INHS Illinois Natural History Survey, Insect Collection, Champagne, IL, U.S.A.

LEMQ Lyman Entomological Museum, McGill University, Macdonald Campus, Ste.-Anne-deBellevue, QC, Canada.

MBP Collection of M. Barták, Praha, Czech Republic.

MZLU Museum of Zoology, Lund University, Lund, Sweden.

NMID National Museum of Ireland, Dublin, Ireland.

SEMC Snow Entomological Museum, University of Kansas, Lawrence, KS, U.S.A.

SMOC Silesian Museum, Opava, Czech Republic.

UBCZ Spencer Entomological Museum, Department of Zoology, University of British Columbia, Vancouver, BC, Canada.

UCRC Entomology Research Museum, Department of Entomology, University of California Riverside, Riverside, CA, U.S.A.

USNM National Museum of Natural History, Smithsonian Institution, Department of Entomology, Washington, DC, U.S.A.

ZMHB Museum für Naturkunde der Humboldt-Universität zu Berlin, Berlin, Germany.

ZSMC Zoologische Staatsammlung München, München, Germany.

The presentation of label data is strictly verbatim for type specimens but standardized for other material examined. Abdomens of many specimens were detached and genitalia dissected. After examination, all dis- 
sected parts were put into plastic tubes containing glycerine and pinned below the respective specimens; this is indicated by the abbreviation "genit. prep." in the text.

The genus Stiphrosoma is diagnosed following a sequence of characters of RoHáčEK (1999). Morphological terminology follows that used in the most recent papers by RoHÁčEK (e.g. 1998, 1999, 2004a) including terms of the male hypopygium. The "hinge" hypothesis of the origin of the eremoneuran hypopygium, re-discovered and documented recently by ZATWARNICKI (1996), has been accepted and, therefore, the following alterations of terms of the male genitalia from RoHÁČEK (1996) need to be listed (new term first): ejacapodeme $=$ ejaculatory apodeme, epandrium $=$ periandrium, medandrium $=$ intraperiandrial sclerite, phallapodeme $=$ aedeagal apodeme, transandrium $=$ posterior hypandrial bridge. Morphological terms of the male genitalia are displayed in Figs 2-4, 7, 9-12, 23, 26, of the female postabdomen and genitalia in Figs $5,12-19,105,116-117,177$. Digital wing images are of the left wing, dorsal view, and then reversed for conventional orientation.

The cladistic analysis of the phylogenetic relationships of Stiphrosoma has been produced manually. Because of the absence of a clearly defined sister taxon, character polarity was determined using a hypothetical taxon summarizing plesiomorphic characters of the related genera Chamaebasca, Mumetopia, Cercagnota and Apterosepsis as a generalized outgroup. A character-weighting approach has been applied to recognize distinctly monophyletic clades and the most parsimonious cladogram has been selected from alternatives available.

Abbreviations of morphological terms used in text and/or figures:

\begin{tabular}{|c|c|c|c|}
\hline$A_{1}$ & anal vein & occe & external occipital (seta) \\
\hline$a c$ & acrostichal (seta) & ors & orbital (seta) \\
\hline afa & aedeagal part of folding apparatus & pa & postalar (seta) \\
\hline ag & accessory gland & pg & postgonite \\
\hline $\mathrm{bm}$ & basal membrane & pha & phallapodeme \\
\hline $\mathrm{C}$ & costa & $\mathrm{pp}$ & phallophore \\
\hline ce & cercus & $\mathrm{ppl}$ & propleural (= proepisternal) (seta) \\
\hline$c p$ & caudal process of transandrium & prg & pregonite \\
\hline cs & connecting sclerite & prs & presutural (seta) \\
\hline $\mathrm{Cs}_{3}, \mathrm{Cs}_{4}$ & $3 \mathrm{rd}, 4$ th costal section & pvt & postvertical (seta) \\
\hline & ctenidial spine & $\mathrm{R}_{1}$ & 1st branch of radius \\
\hline $\mathrm{CuA}_{1}$ & cubitus & $\mathrm{R}_{2+3}$ & 2nd branch of radius \\
\hline & dorsocentral (seta) & $\mathrm{R}_{4+5}$ & 3 rd branch of radius \\
\hline $\mathrm{dm}$ & discal medial cell & $\mathrm{r}-\mathrm{m}$ & radial-medial $\left(=\right.$ anterior, $\mathrm{t}_{\mathrm{a}}$ ) cross-vein \\
\hline $\mathrm{dm}-\mathrm{cu}$ & $\begin{array}{l}\text { discal medial-cubital ( }=\text { posterior, } \mathrm{t}_{\mathrm{p}} \text { ) } \\
\text { cross-vein }\end{array}$ & $\mathrm{r}-\mathrm{m} \backslash \mathrm{dm}$ & $\begin{array}{l}\mathrm{cu}: \mathrm{dm}-\mathrm{cu} \text { - ratio of length of sector of } \\
\mathrm{M} \text { between cross-veins and length of pos- }\end{array}$ \\
\hline ea & ejacapodeme & & terior cross-vein \\
\hline ep & epandrium & s & saccus of distiphallus \\
\hline$f$ & filum of distiphallus & S2-S10 & abdominal sterna \\
\hline$f_{1}, f_{2}, f_{3}$ & fore, mid, hind femur & sa & supraalar (seta) \\
\hline & fulcrum of phallapodeme & sc & scutellar (seta) \\
\hline gs & gonostylus & Sc & subcosta \\
\hline hl & hypandrial lobe & $\mathrm{sp}$ & spermatheca \\
\hline hu & humeral (= postpronotal) (seta) & stpl & sternopleural (= katepisternal) (seta) \\
\hline hy & hypandrium & $\mathrm{T} 1-\mathrm{T} 10$ & abdominal terga \\
\hline is & internal sclerite(s) & $t_{1}, t_{2}, t_{3}$ & fore, mid, hind tibia \\
\hline M & media & ta & transandrium \\
\hline ma & medandrium & vi & vibrissa \\
\hline mspl & mesopleural (= anepisternal) (seta) & vr & ventral receptacle \\
\hline npl & notopleural (seta) & vte & outer vertical (seta) \\
\hline oc & ocellar (seta) & vti & inner vertical (seta) \\
\hline
\end{tabular}




\section{Genus Stiphrosoma Czerny, 1928}

Stiphrosoma Czerny, 1928: 6; Frey, 1958: 31 (key); Trojan, 1962: 35; Soós, 1981: 114; Roháček \& Freidberg, 1993: 63 (key); Roháček, 1996: 90 (redescription). Gender: neuter.

Type species: Stiphrosoma oldenbergi Czerny, 1928: 6 (des. by Enderlein 1936: 167, by elimination) = S. sabulosum (Haliday, 1837).

Ptenotaenia Enderlein, 1936: 167. Gender: feminine.

Type species: Opomyza (Geomyza) sabulosa Haliday, 1837: 151 (by monotypy).

Diagnosis: (1) Head about as long as high or slightly higher than long. (2) Eye large, suboval, with longest diameter oblique. (3) Frons relatively wide, frontal triangle more or less distinct. (4) Frontal lunule minute, very reduced. (5) Occiput medially with a pair of convergent silvery white microtomentose stripes above foramen. (6) Antenna kneelike bent between pedicel and 1st flagellomere, the latter laterally compressed. (7) Arista distinctly (short to very long) pectinate. (8) Palpus yellow, with 1 dark terminal seta. Cephalic chaetotaxy: (9) pvt short, convergent or crossed; (10) vte, vti (usually longest), and oc long; (11) 2 long ors, the anterior shorter than posterior; 1-2 microsetulae in front of anterior ors; (12) a row of very short postocular setulae; (13) 1 long vi and 1 shorter but well developed subvibrissa; (14) peristomal setulae small or anterior ones as long as subvibrissa.

(15) Thorax slightly to distinctly narrower than head. Thoracic chaetotaxy: (16) 1 short hu, $2 \mathrm{npl}$ (anterior longer); (17) 1 small prs or reduced to microseta; (18) 1 short sa, 1 longer pa; (19) 2 long postsutural dc (posterior longer than apical sc, anterior substantially shorter); (20) ac microsetae in $4-6$ rows on suture, fewer between dc; (21) 2 sc (apical long, basal short and weak); (22) 1 minute ppl; (23) 2 stpl (posterior always longer) and 1 microseta in front of anterior stpl. (24) Legs usually yellow, often with brown apical tarsal segment, rarely also femora and tibiae brown; (25) $f_{1}$ with long to very short or lacking ctenidial spine; (26) $t_{2}$ with distinct ventroapical seta; (27) male $f_{3}$ with posteroventral row of shortened and thickened setae. (28) Wing relatively short (often shorter than body length) and narrow, sometimes greatly reduced with modified venation; (29) wing membrane unicolorous. (30) $\mathrm{C}$ with distinct spinulae between apices of $\mathrm{R}_{1}$ and

$R_{2+3}$; (31) $R_{2+3}$ long, parallel to $C$, apically straight or slightly upcurved to $C$; (32) $R_{4+5}$ parallel or slightly divergent from apical part of $\mathrm{M}$; (33) cell $\mathrm{dm}$ relatively short and narrow; cross-vein $\mathrm{r}-\mathrm{m}$ situated in proximal third to two-fifths of $\mathrm{dm}$ cell; (34) CuA not reaching wing margin, $A_{1}$ ending far from it. (35) Alula small and very narrow.

Abdomen. (36) T1 separate from T2; (37) T2-T5 large and broad; (38) preabdominal sterna (S2-S5) narrow, markedly paler than associated terga, becoming wider posteriorly. Male postabdomen: (39) T6 reduced, bare, shortly transverse, often partly (medially or one side) or completely unpigmented; (40) S6 and S7 strongly asymmetrical, partly fused and situated laterally (Fig. 137), each usually with a few setae; (41) S8 medium sized, less asymmetrical, situated dorsally and setose.

Male genitalia. (42) Epandrium relatively broad, always wider than long, moderately to densely setose, with 1-3 pairs of setae longer than others. (43) Medandrium (Fig. 3) simple, moderate to comparatively large, dorsally broad. (44) Cercus simply lobate, of moderate size, weakly sclerotized. (45) Gonostylus finely setose at anterior margin of inner side, densely micropubescent externally. (46) Hypandrium without anterior dorsally 
projecting flat internal lobes; (47) transandrium (Figs 12, 25) simple, transverse, without caudal process, ventrally with only basal membrane. (48) Pregonite (Figs 10-11) small (low), inconspicuous, fused to hypandrium, setulose. (49) Postgonite (Figs 23, 37) medium sized, usually slender, slightly bent to S-shaped, with 1 seta. (50) Phallapodeme (Figs 6-7) with deeply forked base and usually widened apex having downwardly curved corners. (51) Aedeagus with small framed phallophore connected by ventral band-like sclerites with distiphallus. (52) Distiphallus composed of voluminous membranous saccus and slender sclerotized filum. (53) Saccus armed with spinulae, strong spines, thorns or only hyaline tubercles. (54) Filum formed by 2 longitudinal band-like, more or less fused sclerites and its unpigmented apex terminated in various sharp processes, teeth, spinulae and/or setulae. (55) Aedeagal part of folding apparatus with well developed connecting sclerite and its external wall provided with various sculpturing (dense spinelike or tuberculiform excrescences - Figs 7, 26). (56) Basal membrane (Fig. 25) below transandrium with small hyaline transverse tubercles or spinulae, at least ventromedially. (57) Ejacapodeme small, with usual digitiform process having various apex.

(58) Female abdomen with broader terga and narrower sterna than in male. (59) Postabdomen relatively broad, short but telescopically retractable from 7 th segment. (60) T6 and S6 normal, T6 particularly large. (61) T7 and S7 fused to form distinctive tergosternum characterized by dark, medially divided or unpigmented, dorsal part (cf. Fig. 13) and by (usually distinctly paler) ventral part with a small remnant of original S7 (Figs 15, 33, 66). (62) T8 plate-shaped, of variable shape and pigmentation, sparsely setulose; (63) S8 short, transverse, with a posteromedial cleft, or medially membranous to divided. (64) Internal sclerotization of female genital chamber (uterus) formed by 1 to 3 pairs of crooked and partly fused posterior sclerites and (65) 1 anterior very narrow and very transversely looped sclerite (Figs 5, 16). (66) Anterior part of uterus provided with a small, sclerotized, shortly subcylindrical ventral receptacle (Fig. 19) and short and broad duct. (67) Accessory glands of usual form (Fig. 120), on ringed, terminally somewhat dilated ducts. (68) Spermathecae $(1+1)$ shortly to elongately pyriform, with surface covered by dark curved spines which may be transversely attached to surface and carrying minute pale globulae. (69) T10 small, short and transverse, or its posterior part membranous, with 1 pair of medial dorsal setae; (70) $\$ 10$ relatively short, wider than long, and considerably wider than T10, micropubescent. (71) Cerci short to very short and with relatively short fine setae.

\section{Discussion:}

The combination of the following features (see above) is considered to be particularly diagnostic of Stiphrosoma: 5, 7, 11, 13, 17, 19, 20, 28, 33, 39, 43, 46, 47, 54-56, 59, 61, 63-66, 68-71. Stiphrosoma can be distinguished from Anthomyza (genus to which most Stiphrosoma members would be formerly placed) by the pectinate arista (7), well developed subvibrissa (13), reduced prs seta (17), wing relatively short (28) and cross-vein $\mathrm{r}-\mathrm{m}$ situated more proximally (33) and markedly different male genitalia (cf. characters 43 , $47,54-56)$ and female terminalia $(59,61,63-66,68,71)$.

However, the genus Stiphrosoma proved to be related to other genera, particularly to those known from the New World. Its seems almost certain that at least Chamaebosca SpeIser, 1903 and Mumetopia Melander, 1913 belong to the same clade as Stiphrosoma. The relationships of Chamaebosca to the latter genus was discussed by RoHÁčeK (1998: 
151) on the basis of the redescription of the type species Ch. microptera SPEISER, 1903. Chamaebosca not only has a similarly reduced wing as brachypterous forms of Stipbrosoma species, but also shares cephalic and thoracic chaetotaxies and similar male internal genitalia, the latter considered to demonstrate probable sister-group relationships of Stiphrosoma and Chamaebosca (see RoHÁčEK 1998). This statement is to be verified by synapomorphies in the female postabdominal structures in future, because the female is unknown in Ch. microptera. Chamaebosca differs from Stiphrosoma by its short-haired arista, palpus with several setulae, male $\mathrm{f}_{3}$ without thickened and shortened setae, short male S6-S8, epandrium without long setae, gonostylus partly fused with epandrium and lacking micropubescence, and basal membrane with tooth-like spines.

Mumetopia (in narrower sense, see BARBER \& ROHÁČEK, in litt.) externally resembles the macropterous form of $S$. sabulosum and may be closely related as shown by similarities in the female postabdomen of $M$. occipitalis MELANDER, 1913 and Stiphrosoma species (e.g. same structure of T8, S8, spermatheca - shortly pyriform as in S. sabulosum and some other Stiphrosoma species, practically identical ventral receptacle). However, Mumetopia differs from Stiphrosoma not only in external features (e.g. usually only 1 long ors, shorthaired arista, small subvibrissa) but especially also in the male genitalia (e.g. T6, cerci and medandrium heavily sclerotized and dark; postgonite short and robust with several setulae; saccus unusually sclerotized; filum bifid) and female abdomen (e.g. sterna very narrow, only S6 and S7 large and broad; S7 disparate, large, heavily sclerotized; genital chamber and posterior internal sclerites very long, looped sclerite very attenuated, tape-like). It is probable that besides Chamaebosca and Mumetopia some other unnamed Neotropical genera also belong to the Stiphrosoma clade.

Of the Palaearctic genera only Cercagnota RoHÁčex \& Frenoberg, 1993 is probably related to Stiphrosoma. It has a similar antenna with pectinate arista, thoracic and leg chaetotaxies and wing venation resembling that of the macropterous form of $S$. sabulosum. Also its saccus of distiphallus, aedeagal part of folding apparatus, basal membrane and female tergosternum T7+S7 are reminiscent of those of Stiphrosoma but Cercagnota obviously is not very closely allied to the latter genus because it possesses only 1 long ors, weak subvibrissa, angular postgena, peculiarly modified and projecting male cerci, transandrium with weakly sclerotized bipartite caudal process, different sclerotization of basal part and saccus of distiphallus, female tergosternum $T 7+S 7$ short and compact, also dark ventrally, S8 not incised posteromedially, female genital chamber membranous, without internal sclerites and spermathecae simply spherical, with smooth surface.

The highly modified apterous genus Apterosepsis Rrchards, 1962 (Tanzania) may also belong to the Stiphrosoma clade (also see the discussion under $S$. setipleurum below) judging from the similarly constructed female postabdomen (including S8 and ventral receptacle). Unfortunately, the male of its only species (A. basilewskyi Richards, 1962) is unknown, and, consequently its relationships to Stiphrosoma cannot be definitely confirmed.

At present, the genus Stiphrosoma includes 17 species: S. sabulosum (Haliday, 1837), S. fissum RoHÁČEK, 1996, S. cingulatum (HALIDAY, 1855), S. laetum (MEIGEN, 1830) and 13 new species described here. All these 17 species are keyed below. The synopsis of the New World species is arranged in systematic order, according to presumed relationships of the species. 


\section{Key to world species of Stiphrosoma}

1 Wing reduced (Figs 180-183, 195-198, 207) or at least dm-cu lacking (Figs 184, 206) ..

_- Wing fully developed and dm-cu always present (Figs 190-194) ............................... 4

2(1) Thorax with dark brown notum and dorsal half of pleuron (Fig. 1); f lacking ctenidial spine (Fig. 8); preabdominal terga brown; gonostylus short (Fig. 2); female $T 7+S 7$ dark brown, with distinctive pattern ventrally (Fig. 15); T8 dark brown, almost triangular, anteriorly strongly tapered (Fig. 13) S. sabulosum (HALIDAY)

-- Thorax yellow to ochreous, at most with darker ochreous areas at dorsal margin of pleuron; $\mathrm{f}_{1}$ with short but distinct ctenidial spine; gonostylus elongate; preabdominal terga yellow with brown stripe along posterior margin; female $T 7+S 7$ yellow to ochreous, with poorly delimited remnant of S7 (Fig. 92) and T8 pale ochreous-yellow slightly tapered anteriorly ... 3

3(2) $t_{3}$ without ventroapical seta, hind basitarsus with only fine setulae ventrobasally (Fig. 89); male preabdominal sterna with dense groups of thickened setae (Fig. 93); male S6 and S7 bare; gonostylus shorter (Fig. 86); postgonite longer and with dilated apex (Fig. 83); female S6 narrower and remnant of S7 with only 4 setae (Fig. 92); spermatheca elongate and slender (Fig. 88) S. hirtum sp. n.

-- $\quad t_{3}$ with short ventroapical seta, hind basitarsus with 2-3 dark ventrobasal setae (Fig. 102); male preabdominal sterna with fine setae (Fig. 108); male S6 and S7 with 2-3 setae each; gonostylus longer (Fig. 97); postgonite shorter and with tapered apex (Fig. 96); female S6 wider and remnant of S7 with more (7-9) setae (Fig. 107); spermatheca shorter and broader (Fig. 103) S. artum sp. n.

4(1) Notum brown to dark brown, at most humeral and/or notopleural areas yellow; preabdominal terga of both sexes uniformly brown 5

-- Notum yellow to ochreous or bicolorous, yellow and brown, with longitudinal vittae; preabdominal terga variously coloured (yellow, bicolorous or brown)

5(4) Arista long-pectinate (cf. Fig. 42); pleural part of thorax brown, only small areas above fore coxa and around base of haltere yellow; legs with femora and tibiae largely brown; ctenidial spine on $\mathrm{f}_{1}$ small, shorter than maximum width of $\mathrm{t}_{1}$; wing dark, with membrane brown (Fig. 192); gonostylus (Fig. 49) with apex bent anteriorly; pregonite with only 2 setae (Fig. 50) and hypandrium with 1-2 setae posteroventrally on each side (Figs 50, 54); aedeagal complex heavily sclerotized including aedeagal part of folding apparatus (Fig. 53). Female unknown S. pullum sp. $\mathrm{n}$.

-- Arista shortly pectinate; pleural part of thorax yellow, with only dorsal longitudinal band dark brown; legs uniformly yellow; ctenidial spine on $f_{1}$ robust and longer than maximum width of $\mathrm{t}_{1}$; wing pale, with membrane hyaline (Fig. 214); gonostylus (Fig. 169) with apex rounded and straight; pregonite with numerous setae (Fig. 170) and hypandrium bare; aedeagal complex weakly sclerotized (except for phallapodeme, phallophore and filum) and pale pigmented (Fig. 173). Female terminalia as in Figs 175-179.

S. humerale sp. n.

6(4) Thorax largely yellow, at most with ochreous areas at dorsal margin of pleuron; notum without dark longitudinal vittae or spots

S. hirtum sp. n. and S. artum sp. n., f. macropt., go to couplet 3 
-- Thorax bicolorous, yellow and brown (or pale brown), its pleural part with dark dorsal band reaching from propleuron to haltere or to base of abdomen; notum with at least lateral dark vittae or with more longitudinal yellow or brown stripes

7(6) Mesopleuron with a group of setulae (Fig. 63); saccus of distiphallus with 3 robust spines but without fine setulae (Fig. 61); filum with distinctive apex (Fig. 60); female spermatheca elongately pyriform, with small spines on surface (Fig. 67) ............ S. setipleurum sp. n.

- $\quad$ Mesopleuron always bare; saccus of distiphallus and filum with different armature; female spermatheca with larger and differently arranged spines or shortly pyriform (Figs 17, 46, 129)

8(7) Peristomal setae (Fig. 42) unusually strong, 1-4 anterior as long as subvibrissa; ac microsetae in 6 rows in front of suture; mesonotum with numerous microsetae between dc line and prs-pa line; hypandrium with a pair of posterolateral setae (Figs 37-38); basal part of distiphallus (Fig. 40) densely finely setulose; female T6 very broad and densely setose (Fig. 43); $T 7+S 7$ short, with entirely integrated original S7 (Fig. 45); T8 with distinctive $\mathrm{X}$-shaped dark pattern (Fig. 43); spermathecae very shortly pyriform and with extremely robust dark spines (Fig. 46) S. lucipetum sp. n.

-- Peristomal setae weak, all smaller than subvibrissa; ac microsetae in 4 rows in front of suture; area between dc line and prs-pa line with a few microsetae (cf. Fig. 77); hypandrium without setae; basal part of distiphallus bare (see Fig. 126) or with hyaline spinulae (Fig. 173); female $T 6$ narrower and longer, less densely setose; $T 7+S 7$ longer, with remnant of original S7 more or less distinctly delimited; T8 without X-shaped dark pattern; spermathecae longer to elongately pyriform and with more slender spines

9(8) Ctenidial spine on $f_{1}$ strongly reduced, minute (Fig. 29); arista long-pectinate (Fig. 32); mesonotum brown with yellow humeral-notopleural area and a pair of yellow longitudinal bands between dc lines separated by a narrow brown medial stripe; gonostylus very short, its length less than half of epandrial height (Fig. 21); female terminalia as in Figs 27-34.

S. pectinatum sp. n.

- Ctenidial spine on $\mathrm{f}_{1}$ well developed although sometimes shorter than maximum width of $t_{1}$; arista shortly to moderately pectinate, if long-pectinate then gonostylus long; mesonotum largely yellow (or ochreous-orange) with brown pattern

10(9) Arista densely long-pectinate; ors shifted anteriorly and anterior ors very shortened (RoHÁčEK 1996: Fig. 36); gonostylus long and slender but apically rounded (RoHÁčEK 1996: Fig. 24); saccus of distiphallus without spines and filum with slender pointed preapical projection (RoHÁč́EK 1996: Fig. 21); female T7+S7 with short transverse remnant of S7 (ROHÁčEK 1996: Fig. 32) and spermatheca shortly pyriform (RонÁčEx 1996: Fig. 33)

\section{S. fissum RoHÁČEK}

-- Arista shortly or medium-long pectinate; ors in normal position and anterior ors long. Male genitalia and female postabdomen different

11(10) Preabdominal terga of both sexes uniformly brown; saccus of distiphallus with numerous short spines and spinulae (RонÁčEK 1996: Fig. 58); apex of filum provided with fine curved setae (RоHÁČEK 1996: Fig. 62); female genital chamber reinforced by strong and dark internal sclerites (RoHáček 1996: Figs 67, 69) S. laetum (MEIGEN)

-- At least some of preabdominal terga bicolorous, with yellow and brown pattern; saccus of distiphallus with sparse robust spines combined with fine pilosity or without any armature; apex of filum armed by fine teeth or short spinulae; female internal sclerites weakly sclerotized and pale pigmented 
12(11) Occiput largely brown, only medial area above foramen and ventral marginal area yellow or ochreous; mesonotum yellow to orange-ochreous with 3 brown longitudinal bands (medial broad)

-- Occiput yellow or ochreous-yellow, medially usually lighter; mesonotum yellow or ochreous-yellow, with only lateral brown or pale brown vittae (see Fig. 77) and sometimes with a very narrow medial dark stripe between medial sc microsetae 14

13(12) Frontal triangle yellow and poorly delimited from rest of frons; tarsi yellow, only last tarsal segments with apex sometimes darker yellow to pale brown; epandrium wider (Fig. 142); gonostylus with simply tapered apex (Fig. 148); transandrium with distinctly bent posterior ledge (Fig. 145); saccus of distiphallus with 4 central and 2 subapical short spines (Fig. 147); female T8 with T-shaped pigmentation (Fig. 149); S10 very short (Fig. 153)

S. vittatum sp. n.

-- Frontal triangle laterally delimited by narrow brownish stripes; tarsi yellow but last tarsal segments brown (Fig. 163); epandrium narrower (Fig. 155); gonostylus tapered in the middle and its apex widened and rounded (Fig. 157); transandrium simple (Fig. 160); saccus with only 2 robust spines (Fig. 161); female T8 with posteromedial pale area leaving the dark pattern resembling a broad Y (Fig. 162); S10 distinctly longer (Fig. 166)

S. sororium sp. n.

14(12) Mesonotum with only lateral brown vittae (Fig. 77); $t_{3}$ with short but distinct ventroapical seta (cf. Fig. 102); gonostylus shorter and wider (Figs 72, 115)

-- Mesonotum with a narrow dark stripe between medial ac microsetae in addition to lateral brown vittae; $t_{3}$ without ventroapical seta (cf. Fig. 89); gonostylus slender and long (Figs $127,141)$

15(14) Gonostylus very short (its length slightly more than half of epandrial height, see RoHÁČEK 1996: Fig. 40); saccus of distiphallus with a number of dark robust spines (RонÁčEK 1996: Fig. 42); filum with a group of small spiniform tubercles and apex with 2 lanceolate processes (RoHÁČ́E 1996: Fig. 43); entire female T6 yellow (RoHÁČEK 1996: Fig. 47); spermatheca (RoHÁčeK 1996: Fig. 49) with spines oriented longitudinally ... S. cingulatum (HaLIDAY)

-- Gonostylus longer (slightly shorter than height of epandrium); saccus with fewer or without robust spines; filum differently formed; female T6 yellow but with distinct brown posterior marginal stripe; spermatheca with spines oriented transversely, attached to surface ..... 16

16(15) Ctenidial spine on $f_{1}$ twice or more as long as maximum width of $t_{1}$; arista longer pectinate; epandrium broad (Fig. 68); gonostylus wider and with more rounded apex (Fig. 72); postgonite simply bent (Fig. 71); saccus without sclerotized spines and filum with slender curved projection in distal third and dilated spinulose apex (Fig. 73); female $\mathrm{S} 6$ broad (Fig. 79); $T 7+S 7$ dorsomedially with triangular unpigmented area (Fig. 75); remnant of $S 7$ with only 4 setae; S8 long and divided medially (Fig. 79) S. balteatum sp. $\mathrm{n}$.

Ctenidial spine on $f_{1}$ slightly longer than maximum width of $t_{1}$; arista shortly pectinate; epandrium narrow (Fig. 109); gonostylus more slender and with more tapered apex (Fig. 115); postgonite short and $S$-shaped in profile (Fig. 112); saccus with several strong dark spines and filum slender, without projection in apical third, with curved narrowed apex terminated by fine spinulae (Fig. 111); female 66 narrower (Fig. 117); T7+S7 dorsomedially broadly unpigmented (Fig. 116); remnant of $S 7$ with a number of setae; S8 very short and incised posteromedially (Fig. 117) 
17(14) Last tarsal segments yellow, with distal half brown; male S6 with very slender ventral projection; gonostylus longer and apically less tapered (Fig. 127); pregonite larger and postgonite with distinctly widened and rounded apex (Fig. 123); apex of filum with less dense fine teeth (Fig. 125). Female terminalia as in Figs 128-133 S. stylatum sp. n.

-- Last tarsal segments yellow, at most with ochreous apex; male 56 with thick ventral projection (Fig. 137); gonostylus shorter and strongly tapered apically (Fig. 141); pregonite smaller (Fig. 136) and postgonite with simple apex (Fig. 140); apex of filum densely finely dentate (Fig. 138). Female unknown S. minor sp. n.

\section{Stiphrosoma sabulosum (HALIDAY, 1837)}

(Figs 1-19, 180-189)

Opomyza (Geomyza) sabulosa Haliday, 1837: 151.

Anthomyza sabulosa: Czerny, 1902: 251; Collin, 1944: 267, 268; Stackelberg, 1970: 326 (key); Andersson, 1984: 52 (catalog).

Stiphrosoma sabulosum: Czerny 1928: 6; Séguy, 1934: 304 (key); Trojan, 1962: 36; Soós, 1981: 115 (key);

Roháček, 1996: 95 (redescription)

Geomyza brevipennis Zetterstedt, 1852: 4335.

Anthomyza saliens Loew, 1866: 5.

Stiphrosoma Oldenbergi Czerny, 1928: 6; Trojan, 1962: 36.

Anthomyza oldenbergi: Andersson, 1984: 52 (catalog).

Opomyza apterina Ruthe in litt.: Czerny, 1902: 251 (nom. nudum).

Type material:

Opomyza (Geomyza) sabulosa Haliday: Lectotype female (designated by Roháček, 1996: 95) labelled „Killina“ (handwritten), „Haliday 20.2.'82“ (registration label), "Type“ (red printing), „sabulos" (handwritten), „Fide, Dale. seen, Collin" (handwritten), „Opomyza (G.) sabulosa Halid. ๆ, J. Roháček des. 1994, Lectotypus“ (red), „Stiphrosoma sabulosum (Hal.) ㅇ, J. Roháček det. 1994“. For paralectotypes see Roháček (1996) (all type specimens in NMID, examined). Comments: „Killina“ = Bay of Killiney (cf. Haliday 1837:151 and Roháček 1996).

Geomyza brevipennis Zetterstedt: Holotype female labelled „Ekeby in Ln. Börshult den 24 Juli 24", „Geomyza brevipennís $9 . .$. Holmgr.", „G. brevipennis Zett.", „Holotypus Geomyza brevipennis Zetterstedt, 1852, des. H. And. 1987“ (red), „Anthomyza sabulosa Hal., det. H. Andersson 1987“, "Stiphrosoma sabulosum (Hal.) ๆ , J. Roháček det. 1994" (MZLU, examined).

Anthomyza saliens Loew: Lectotype female (designated by Roháček, 1996: 95) labelled „9/5 41", „Typus“ (red), „saliens“, „Anthomyza saliens Loew o , J. Roháček des. 1994, Lectotypus" (red), Stiphrosoma sabulosum (Hal.) q, J. Roháček det. 1994 (ZMHB). Comments: The lectotype originates from „Posen“ (= Poznaň, Poland) and were collected by H. Loew himself in May 1841 (see Loew 1866: 4).

Stiphrosoma oldenbergi Czerny: Holotype female labelled „Berlin 27.V. 26“, „Albrechts Tierofen“, „coll. Oldenberg“, „Stiphrosoma Oldenbergi Czerny“, „Holotypus" (red), „Coll. DEI Eberswalde“, „Stiphrosoma sabulosum (Hal.) \& f.macropt., J. Roháček det. 1994 " DEIC, examined). Comments: the specimen is in very poor condition, headless, without legs and wings; genit. prep. 


\section{New World material examined:}

(all f. brach. unless noted otherwise) CANADA: Ontario: 3 mi W Arthur, 11.vii.1985, grass edge of canola field, 3 females (DEBU); Burlington, edge Tuck Ck., $43^{\circ} 21.2^{\prime} \mathrm{N}$ $79^{\circ} 46.6^{\prime} \mathrm{W}$, pooter, base of grasses, 23.v.1998, 2 males 6 females. (DEBU, SMOC), 15.viii.2000, 3 males 5 females (DEBU); same locality but 19.viii.1998, sweeps / pooter, grasses edge of park, 1 male (SMOC); Chapleau, $47^{\circ} 50.32^{\prime} \mathrm{N} 83^{\circ} 23.89^{\prime} \mathrm{W}$, 18.vi.2004, long grasses, pooter, 1 male (DEBU); $-7.2 \mathrm{~km} \mathrm{E} \mathrm{Deux} \mathrm{Rivieres,} \mathrm{Hwy \# 17,} \mathrm{rest} \mathrm{area,}$ $46^{\circ} 14.90^{\prime} \mathrm{N} 78^{\circ} 10.82^{\prime} \mathrm{W}, 12 . v i .2004$, long grasses, pooter, 9 males 14 females (DEBU) all K. N. Barber leg.; Fergus, 27.v.1991, on lawn, 1 female (DEBU); Guelph, 3.vii.1980, 11 males 13 females (DEBU) all S. A. Marshall leg.; Guelph, 3.vii.1980, 4 males 7 females (CNCI), 2.viii.1980, 4 males 7 females, 3.viii.1980, 6 males 10 females, 9.vii.1981, 1 female, 23.vii.1982, 2 males (DEBU); same locality but 27-30.vi.1980, pans, 1 female, 1-5.vii.1980, 1 male, 15-24.viii.1980, 1 male, 24.viii-4.ix.1980, 1 female, 1.v4.vi.1982, 3 males 10 females (DEBU); same locality but pan traps, 5-18.vii.1980, 1 male (DEBU), 1-20.vii.1980, 6 males 10 females (DEBU), 22.v-7.vi.1981, 46 males 55 females (DEBU, CNCI), 8-24.vi.1981, 27 males 48 females, 1 female f. macropt. (DEBU, CNCI), 24.vi-14.vii.1981, 9 males 12 females (DEBU), 14.vii-16.viii.1981, 1 female (DEBU); same locality but 7.v-4.vi.1982, Malaise trap, 1 female (DEBU) all K. N. Barber leg.; Guelph, Arboretum, 21-24.vii.1984, field, mushroom traps, 1 male, Brian V. Brown leg. (DEBU); Halton Reg., Milton, Derry Rd. \& $4^{\text {th }}$ Line, 9-11.vii.2001, grass field, yellow pans, 1 female (DEBU - 00172103), 12-16.vii.2001, 1 male (DEBU - 00172177) S. Paiero leg.; Hamilton, R[oyal] B[otanical] G[ardens], 12.vi.1982, 1 female, A. W. Schaafsma leg. (DEBU); Hawk Jct., Community Centre, $48^{\circ} 05.39^{\prime} \mathrm{N}$ $84^{\circ} 33.62^{\prime} \mathrm{W}, 17 . v i .2004$, long grasses, pooter, 1 male 1 female (DEBU); Iron Bridge, $46^{\circ} 17.00^{\prime} \mathrm{N} 83^{\circ} 13.14^{\prime} \mathrm{W}, 12 . v i .2004$, long grasses at ball field, pooter, 2 males 1 female (DEBU) all K. N. Barber leg.; Kemptville, 25.v.1978, 1 female, L. Masner leg. (CNCI); London, 420 Coombs Ave., 42 $59.74^{\prime} \mathrm{N} 81^{\circ} 16.86^{\prime} \mathrm{W}, 23 . v .2004$, long lawn grass, pooter, 2 females (DEBU); Manitoulin Is., $3.3 \mathrm{~km}$ E Spring Bay, Hwy $542 @$ Tracy Rd., $45^{\circ} 43.90^{\prime} \mathrm{N} 82^{\circ} 16.48^{\prime} \mathrm{W}$, 30.viii.2004, pooter, roadside/fenceline grasses, 1 female, (DEBU); Massey, $46^{\circ} 12.80^{\prime} \mathrm{N} 82^{\circ} 04.44^{\prime} \mathrm{W}, 12$.vi.2004, long lawn grass, pooter, 26 males

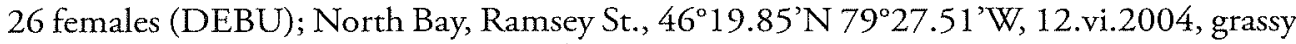
edge of bike path, pooter, 14 males 20 females (DEBU) all K. N. Barber leg.; Ottawa, 30.vi.1987, in copula on ground among grass roots, 1 male 1 female (CNCI); Ottawa nr. Uplands Airport, 7.viii.1987, ex. Malaise trap, 1 male (CNCI) all J. M. Cumming leg.; P[oin]t Pelee, 7.vii.1980, 1 female (CNCI); Prescott, water tower property, $44^{\circ} 42.75^{\prime} \mathrm{N}$ $75^{\circ} 31.15^{\prime} \mathrm{W}, 7-8 . v i .2004$, long lawn grass, pooter, 8 males 6 females (DEBU); $10 \mathrm{~km}$ W S [ault] S[te.] Marie, Airport Rd., airport entrance, 46²9.7’ N 84²9.2'W, 19.vi.2000, sweeps, mowed grass, 1 female (DEBU); S[ault] S[te.] Marie, Bellevue Pk., $46^{\circ} 30.1^{\prime} \mathrm{N}$ 84⒙1'W, 7-8.vii.2000, sweeps, mostly Calamagrostis, 1 female (DEBU); S[ault] S[te.]

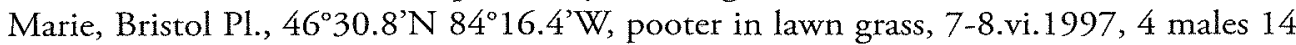
females, 22.vi.1997, 8 males 2 females (DEBU, SMOC); S[ault] S[te.] Marie, Bristol Pl. Pk., 46 $30.8^{\prime} \mathrm{N} 84^{\circ} 16.6^{\prime} \mathrm{W}$, 13.vi.1998, sweeps / pooter, mixed grasses, 1 female; same locality but 6.vi.2001, pooter, base of mixed grasses, 1 male 1 female (DEBU); S[ault] S[te.] Marie, Finn Hill, $46^{\circ} 31.67^{\prime} \mathrm{N} 84^{\circ} 17.32^{\prime} \mathrm{W}$, pooter, Calamagrostis canadensis, 10.viii.2003, 1 female, 19.vii.2004, 3 males 3 females, 30.vii.2004, 1 male (DEBU); same locality but $46^{\circ} 31.65^{\prime} \mathrm{N} 84^{\circ} 17.34^{\prime} \mathrm{W}, 30 . v i i .2004$, pooter, Carex stipata stipata, 2 
males 1 female (DEBU); same locality but $46^{\circ} 31.63^{\prime} \mathrm{N} 84^{\circ} 17.33^{\prime} \mathrm{W}$, pooter, Carex stipata stipata, 20.vii.2004, 5 males 7 females, 21.vii.2004, 2 males, 23.vii.2004, 1 male 2 females, 25.vii. 2004,2 males 2 females; same locality but $46^{\circ} 31.60^{\prime} \mathrm{N} 84^{\circ} 17.30^{\prime} \mathrm{W}$, pooter, Carex stipata stipata, 23.vii.2004, 1 male, 27.vii.2004, 1 male 1 female (DEBU); S[ault] S[te.] Marie, Min. of Transportation office, $46^{\circ} 32.9^{\prime} \mathrm{N} 84^{\circ} 19.0^{\prime} \mathrm{W}, 11 . v i .2001$, pooter, base of grasses, 15 males 30 females (DEBU), AMNH, EMUS; Wahnapitae, Lions Club Park, $46^{\circ} 29.22^{\circ} \mathrm{N} 80^{\circ} 47.29^{\prime} \mathrm{W}, 12 . v i .2004$, long grasses, pooter, 5 males 16 females (DEBU); Wawa, Visitor Centre, $47^{\circ} 58.49^{\prime} \mathrm{N} 84^{\circ} 46.99^{\prime} \mathrm{W}, 15 . v i .2004$, long grasses, pooter, 2 males 2 females (DEBU) all K. N. Barber leg. Quebec: Ste.-Anne-deBellevue, Stoneycroft Pond, $45^{\circ} 25.8^{\prime} \mathrm{N} 73^{\circ} 56.4^{\prime} \mathrm{W}$, pan trap in old field, 20-27.vi.1996, 1 male 3 females, T. A. Wheeler leg. (LEMQ). USA: Massachusetts: Belmont, Rock Meadow, 10.vi.1982, 3 males, 8 females, N. E. Woodley leg. (USNM); same locality but 25.vi.1982, 7 females (CNCI), 30.vi.1982, 7 males 17 females (CNCI), 2 males 2 females (CASC) all J. R. Vockeroth leg. Michigan: nr. Capac, Hwy\#69, rest area $1.2 \mathrm{~km} \mathrm{~W}$ mile $175,42^{\circ} 59.63^{\prime} \mathrm{N} 82^{\circ} 57.46^{\prime} \mathrm{W}, 24 . v .2004$, long grasses, pooter, 4 females (DEBU); w. of Linwood, Hwy I-75, rest area, mile $175,43^{\circ} 45.63^{\prime} \mathrm{N} 84^{\circ} 00.99^{\prime} \mathrm{W}, 24 . v .2004$, pooter, long grasses, 1 female, 1 female $f$ macropt., 1 female with 1 brach. wing and 1 macropt. wing (DEBU) all K. N. Barber leg. New York: Ogdensburg, Bridge Port Authority, $44^{\circ} 42.95^{\prime} \mathrm{N} 75^{\circ} 27.22^{\prime} \mathrm{W}, 11 . v i .2004$, edge of nature trail, long grasses, pooter, 13 males 9 females, K. N. Barber leg. (DEBU).

Description [based on RoHáčEK (1996) and modified to include Nearctic material listed above]:

Male. Total body length 1.45-1.66 mm (f. macropt.), 1.18-1.55 mm (f. brach.); general colour brown to dark brown. Head only slightly higher than long, bicoloured (Fig. 1). Posterior part (from posterior ors) of orbits, frontal (incl. ocellar) triangle, lateral parts of occiput and dorsal part of postgena brown to dark brown; rest of head yellow. Frontal triangle extending to anterior third of frons, somewhat shining despite sparse pale microtomentum. Pale anterior half of orbits whitish, anterior half of frons and stripes between frontal triangle and orbits yellowish microtomentose and dull. Face (prefrons) and gena whitish to pale yellow. Cephalic chaetotaxy: pvt minute, convergent, with tips meeting medially; 2 ors, posterior as long as oc, anterior about two-thirds of posterior ors; 2-4 microsetulae medially, in front of frontal triangle; subvibrissa one to two-thirds of vi length; 3-4 peristomal setulae. Eye with longest diameter about 1.5 times as long as shortest; gena narrow, its smallest height 0.1 times as long as shortest eye diameter. Antenna ochreous yellow; 1st flagellomere with darkened dorsal area surrounding base of arista, otherwise yellow, with medium-long hairs on anterodorsal corner. Arista dark brown, about 1.9 times as long as antenna, with thickened basal segment and with short but distinct pectination (Fig. 1).

Thorax slightly (f. macropt.) to distinctly (f. brach.) narrower than head, brown to dark brown, sparsely greyish microtomentose and subshiny; only pleura (usually) ventrally (i.e. sternopleuron and hypopleuron) brown-ochreous to yellow (Fig. 1). Thoracic chaetotaxy: prs reduced to microseta; only 2-3 dc microsetae in front of anterior $\mathrm{dc}$; ac sparse (only 2-4), in 2 rows between dc, not extending to posterior third of mesonotum; basal sc very small in contrast to related species; anterior stpl much smaller than posterior; posterior margin and ventral part of sternopleuron with a few additional microsetae, some- 
times 1 microseta also in front of anterior stpl. Scutellum somewhat trapezoidal, dorsally convex and with rounded posterior corners.

Legs yellow, only apical tarsal segments or their tips darkened. $f_{1}$ (Fig. 8) without ctenidial spine, only with usual posteroventral and posterodorsal rows of thin setae. $f_{3}$ with posteroventral row of rather sparse setae, $4-5$ in distal half of $f_{3}$ shortened and somewhat thickened. Hind basitarsus with only short setulae ventrally.

Wing dimorphic (see RoHÁčEK 1996) but macropterous specimens are much rarer in populations (not yet known in North America). Very rarely, specimens with unevenly developed wings are found (RoHÁčEK 1996: Fig. 1). Wing of macropterous form (Figs 184-185) relatively short, with pale ochreous membrane and veins. $R_{2+3}$ apically slightly bent to $\mathrm{C}$ but often incomplete, not reaching $\mathrm{C}$. $\mathrm{R}_{4+5}$ not straight, apically slightly divergent from $M$. Cross-vein $r-m$ situated proximally, slightly basal to junction of $R_{1}$ and $\mathrm{C} . \mathrm{M}$ reaching wing margin. Discal $(\mathrm{dm})$ cell open, $\mathrm{dm}-\mathrm{cu}$ absent. $\mathrm{CuA}_{1}$ almost straight or slightly sinuous and, like $A_{1}$ not reaching wing margin. Wing measurements (f. macropt.): length $1.45 \mathrm{~mm}$, width $0.58 \mathrm{~mm}, \mathrm{Cs}_{3}: \mathrm{Cs}_{4}$ and $\mathrm{r}-\mathrm{mldm}-\mathrm{cu}: \mathrm{dm}-\mathrm{cu}$ not measurable because $\mathrm{R}_{2+3}$ incomplete and dm-cu absent respectively. Wing of brachypterous form greatly shortened and narrowed (Figs 180-183, 186-189). Only $R_{1}$ and $R_{4+5}$ complete; $R_{2+3}, M, C u A_{1}$ and $A_{1}$ reduced to short remnants or entirely absent; $r-m$ always preserved. Alula very reduced, often almost indistinct. Wing measurements (f. brach.): length $0.39-0.83 \mathrm{~mm}$, width $0.10-0.13 \mathrm{~mm}$. Haltere with dark yellow stem and whitish knob, in $\mathrm{f}$. brach. greatly reduced.

Abdomen. Preabdominal terga dark brown and sparsely greyish microtomentose, subshining; the associated sterna pale brown to ochreous. T6 reduced to a short, medially unpigmented stripe, thus appearing like two small sclerites. S2-S5 narrow and becoming slightly wider posteriorly, more densely setulose than terga; $\mathrm{S} 5$ the widest but much shorter than S4. Postabdominal sterna dark brown, asymmetrical; S8 about as long as epandrium.

Genitalia. Epandrium (Figs 2-3) higher and much broader than long, with sparse setae, 2 dorsolateral of which longer than others. Dorsal side of epandrium relatively straight; anal fissure subtriangular. Cercus (Figs 2-3) large in comparison with epandrium. Medandrium (Fig. 3) relatively broad but weakly sclerotized. Gonostylus (Figs $2,4)$ short, rhomboid in lateral view, with rounded anteroventral corner and diagonal keel-like ledge on outer surface. Hypandrium (Figs 10-11) frame-like, pale, weakly sclerotized. Transandrium (Fig. 12) simple, basal membrane ventrally provided with a few transverse tubercles. Pregonite (Figs 10-11) small, pale pigmented, with some 10 setulae; postgonite also very weakly sclerotized and poorly differentiated from basal membrane, with 1 usual seta (Fig. 10). Aedeagal complex. Phallapodeme with widened apex and broadly forked base (Fig. 6). Aedeagal part of folding apparatus laterally sculptured by rounded flat excrescences; its ventral part connected with basal membrane of transandrium (Figs 7, 10). Connecting sclerite poorly differentiated, pale. Aedeagus (Fig. 7) with relatively small phallophore; distiphallus composed of a voluminous, sparsely and finely spinulose saccus and rather robust, heavily sclerotized filum. Distal end of filum split in a pointed dark process and flattened, strongly bent, pale apex provided with fine teeth (Figs 7,9 ). Ejacapodeme small, pale pigmented, mainly formed by terminal projection.

Female. Similar to male unless mentioned otherwise. Total body length $1.70-1.98 \mathrm{~mm}$ 
(f. macropt.), 1.35-1.87 $\mathrm{mm}$ (f. brach.). $\mathrm{f}_{3}$ without shortened and thickened posteroventral setae. Wing of brachypterous form usually somewhat longer and narrower than in male. Wing measurements (f. macropt.): length $1.50-1.79 \mathrm{~mm}$, width $0.56-0.66 \mathrm{~mm}$, $\mathrm{Cs}_{3}: \mathrm{Cs}_{4}=1.64-1.83$ (wing depicted in Fig. 185 aberrant with apex of $\mathrm{R}_{4+5}$ deflected toward $M$ not included in these measurements). Wing measurements (f. brach.): length $0.50-1.03 \mathrm{~mm}$, width $0.09-0.17 \mathrm{~mm}$.

Abdomen. Preabdominal terga somewhat wider, sterna narrower and paler than in male. S4 and S5 subequal in size.

Postabdomen (Figs 13-15). T6 dark brown, posteriorly narrowed. S6 much smaller than T6, posteriorly wider than anteriorly. Tergosternum $T 7+S 7$ divided dorsomedially (Fig. 13) and with characteristic pigmentation ventrally (Fig. 15; dark ventromedial part (corresponding to original S7) separated by pale pigmented tongue-shaped areas from lateral parts. T8 (Fig. 13) also distinctive, of triangular shape, with angularly tapered anterior corner and with setae in posterior corners. S8 (Figs 15, 18) short, transverse and convex, with narrow posteromedial cleft and short setulae. Internal sclerotization of female genital chamber composed of only one pair of posterior flat sclerites connected to S8 (Fig. 18) and 1 anterior, transverse, looped sclerite (Figs 5, 16). Anterior part of uterus with small but subcylindrical ventral receptacle (Fig. 19) borne on a relatively wide duct. Spermathecae (Fig. 17) shortly pyriform, covered with dense dark spines. T10 unusually short and transverse (Fig. 13), with a pair of setae. S10 longer than T10, anteriorly emarginate (Fig. 15). Cerci short and short-haired.

\section{Discussion:}

Stiphrosoma sabulosum is a distinctive wing polymorphic species with the brachypterous form strongly predominating in European populations. In the Nearctic only two macropterous female specimens are known while a third specimen has only one macropterous wing. The long series collected in pan traps (Guelph, ON) spanning 22.v. to 16.viii.1981 yielded a total of 82 male and 116 female brachypterous specimens and only 1 macropterous female - macroptery in at least some populations occurs in fewer than $1 \%$ of the females trapped this way. The occurrence of rare specimens with unevenly developed wings (long known in Europe - see Collin 1944; StaCkelberg 1958; Roháček 1996) is thus also confirmed in the Nearctic populations. Interestingly, this phenomenon was otherwise only recorded for Conioscinella zetterstedti Andersson, 1966 (Chloropidae) in a Canadian population (WHEeLER 1994). The wing of the rare macropterous form resembles those of $S$. hirtum sp. n., $S$. artum sp. n. (two forms with dm-cu usually lacking) and also of Cercagnota collini (CzERNY, 1928) in the position of $\mathbf{r}-\mathbf{m}$ and in the absence of $\mathrm{dm}$-cu. The narrow wing of the brachypterous form is very similar to those of shortwinged specimens of $S$. hirtum sp. n. and $S$. artum sp. n. and also of Chamaebosca species but the reduction of veins is somewhat different (see Figs 195-198, 201-205, 207).

S. sabulosum can be easily distinguished from all other New World congeners in having a dark mesonotum combined with reduced wings and the ctenidial spine on $f_{1}$ lacking. Its relationships remain obscure. No closely allied species has been recognized among known species of Stiphrosoma. S. sabulosum is the only species of the genus without ctenidial spine on $f_{1}$, with uniquely reduced (weakly sclerotized) postgonite, indistinct connecting sclerite, only sparsely and finely spinulose saccus, distally split filum, female $\mathrm{T} 7+\mathrm{S} 7$ also ventrally dark but with separated remnant of S7, triangular (anteriorly ta- 
pered) female $T 8$ and with only 1 pair of internal sclerites of the female genital chamber. In the very short gonostylus with lateral keel and shortly pyriform spermatheca of primitive type (the same type is also known in Mumetopia) it resembles S. pectinatum sp. n. (which has $f_{1}$ with very shortened ctenidial spine, thus most similar to $f_{1}$ of $S$. sabulosum) but some of these features probably are (at least spermathecae) plesiomorphic or (reduction of ctenidial spine) evolved in parallel. In habitus $S$. sabulosum differs significantly from $S$. pectinatum sp. n. (see key).

\section{Biology:}

In Europe, $S$. sabulosum is associated with grassland habitats, mainly in lowlands. Its larvae develop in leaf sheaths of grasses near the ground (breeding records from Arrhenatherum elatius, Lolium perenne - NYE 1958; also reared from tufts of Dactylis glomerata, Holcus lanatus and Poa nemoralis - RoHÁČEK 1996) and are probably (micro)phytosaprophagous; 3rd instar larvae overwinter and pupate in May, but because mature larvae were also found in June, it is probable that the species has 2 or more generations (NYE 1958). There is a breeding record (Richards 1932) also from a nest of Microtus agrestis, apparently from grass brought into the nest by the rodent. Adults were mostly recorded in May-June but they also occur in July-August (cf. Soós 1981; RoHÁČEK 1983). They live (often in numbers) in grass tufts near the roots and were also collected using pitfall traps (BÄHRMANN 1987; ROHÁČEK 1996). Interestingly, macropterous specimens may sometimes occur in sweep samples and Malaise traps although they are otherwise rare in populations.

In North America, disturbed habitats are the most likely places to find this species. It has been taken from mowed, urban lawns but the largest densities are found in uncut edges or untended areas of these same urban or semi-urban settings (i.e., residential and commercial properties, roadsides, parking lots, greenbelts). It also occurs in relatively low densities in successional graminoid meadows in association with other Stiphrosoma species and other anthomyzids. This apparentassociation with disturbed habitats may be an artifact of selective sampling but nonetheless suggests this is an introduced species (but see below). Not surprisingly, there are only two specimens taken in Malaise traps (Ottawa, Guelph, ON) but neither was a macropterous specimen. The single collection in a mushroom trap (Guelph, ON) is more likely the result of the use of a recessed cup (pitfall) rather than the bait component of the trap.

\section{Distribution:}

Widespread in North and Central Europe (all records are summarized in the Fauna Europaea database, see RoHáčEK 2004b). The species was long (since 1978) known from the Nearctic Region, but no records have been published. In North America, S. sabulosum has been collected almost exclusively in Ontario, Canada ranging from Point Pelee National Park and Prescott in the south to Wawa and Chapleau in the north. First collected in 1978 in Kemptville (likely a pan trap), it was subsequently found in Ottawa (Ontario), Belmont (Massachusetts) and in large numbers in Guelph (Ontario), in the early 1980s. Subsequent collections in the late-1990s confirmed its presence in Sault Ste. Marie, Ontario (although previously observed but not collected in 1986). The only specimens obtained outside of this province (southern Quebec, Massachusetts, New York, and Michigan) were made by collectors associated or previously associated with $\mathrm{CNCI}$ or 
DEBU suggesting experiential effects on collection effort (J.R.Vockeroth first identified the Kemptville specimen and informed other dipterists). No doubt this species is much more widely distributed than these records indicate and has been for some time.

Because of the extensive collections of Geomyza species by aspirator (pooter) (VoCKEROTH 1961) for many years prior to 1978, and as G. apicalis (MEIGEN) often co-habits with S. sabulosum (personal observations), it is tempting to suggest that $S$. sabulosum was not present in Ontario much before this. However, it is just as plausible that this small, cryptic species did in fact go undetected until 1978. Witness the absence of recent collections in both Canada and the USA and this likely speaks more to the habitat and cryptic habits of this small fly than to its absence. The discussions and arguments revolving around the interpretation of data such as these in the Opomyzidae (Vockeroth 1961, Wheeler et al. 1999) and Chloropidae (WheELER 1994) emphasize this ambiguity. It is interesting to note that two eastern species discussed (G. apicalis and C. zetterstedti) are often sympatric with $S$. sabulosum, have a propensity for wing-reduction, and are generally associated with grasses. Both have been argued to be naturally holarctic. On the other hand, G. tripunctata FALLÉN is interpreted to be recently adventive and is already known from some of the same specific localities as S. sabulosum in southern Ontario (Burlington and Fergus, see WHeELER et al. 1999) but not yet known north and west of North Bay, Ontario (unpublished record). Perhaps the most useful information would be gained with the discovery of $S$. sabulosum from western or northwestern Canada.

The possibility that $S$. sabulosum (and perhaps some of these co-occurring species) has been assisted in its spread with transport by commercial turf grass operations cannot be discounted.

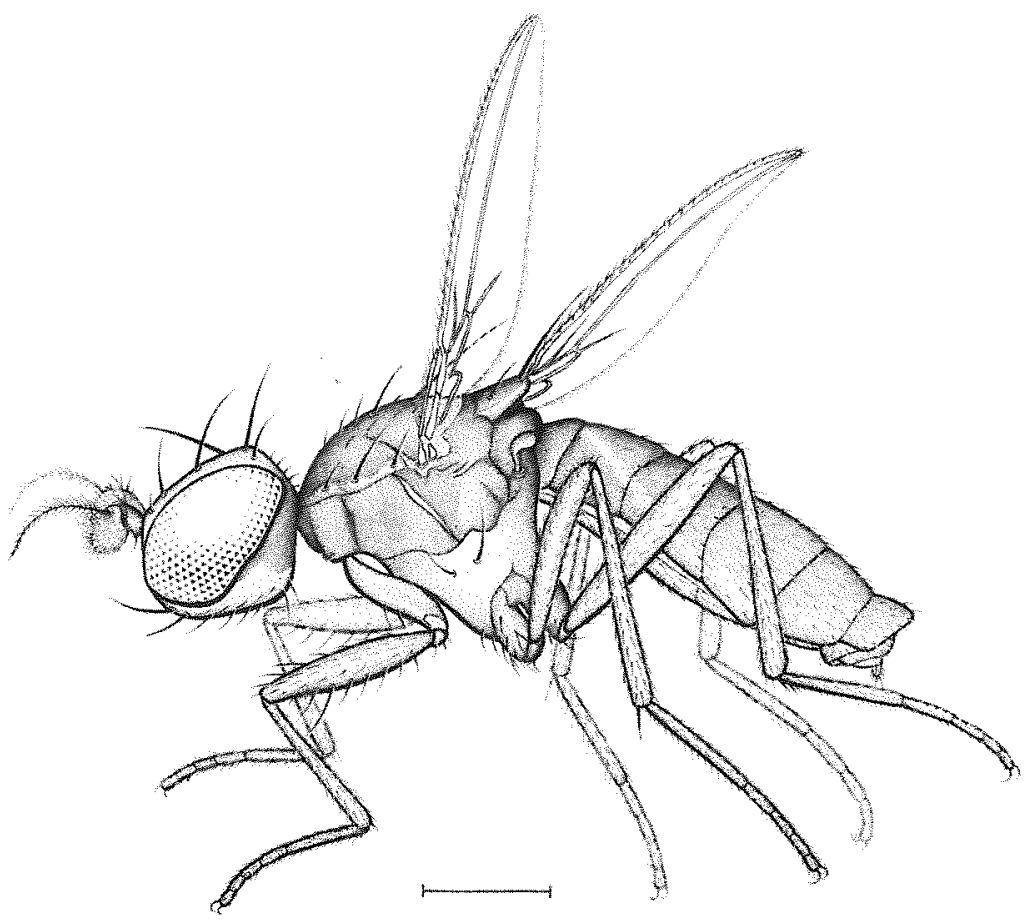

Fig. 1: Stiphrosoma sabulosum (Haudday), female f. brach. (Czech Republic). Scale $=0.3 \mathrm{~mm}$. 


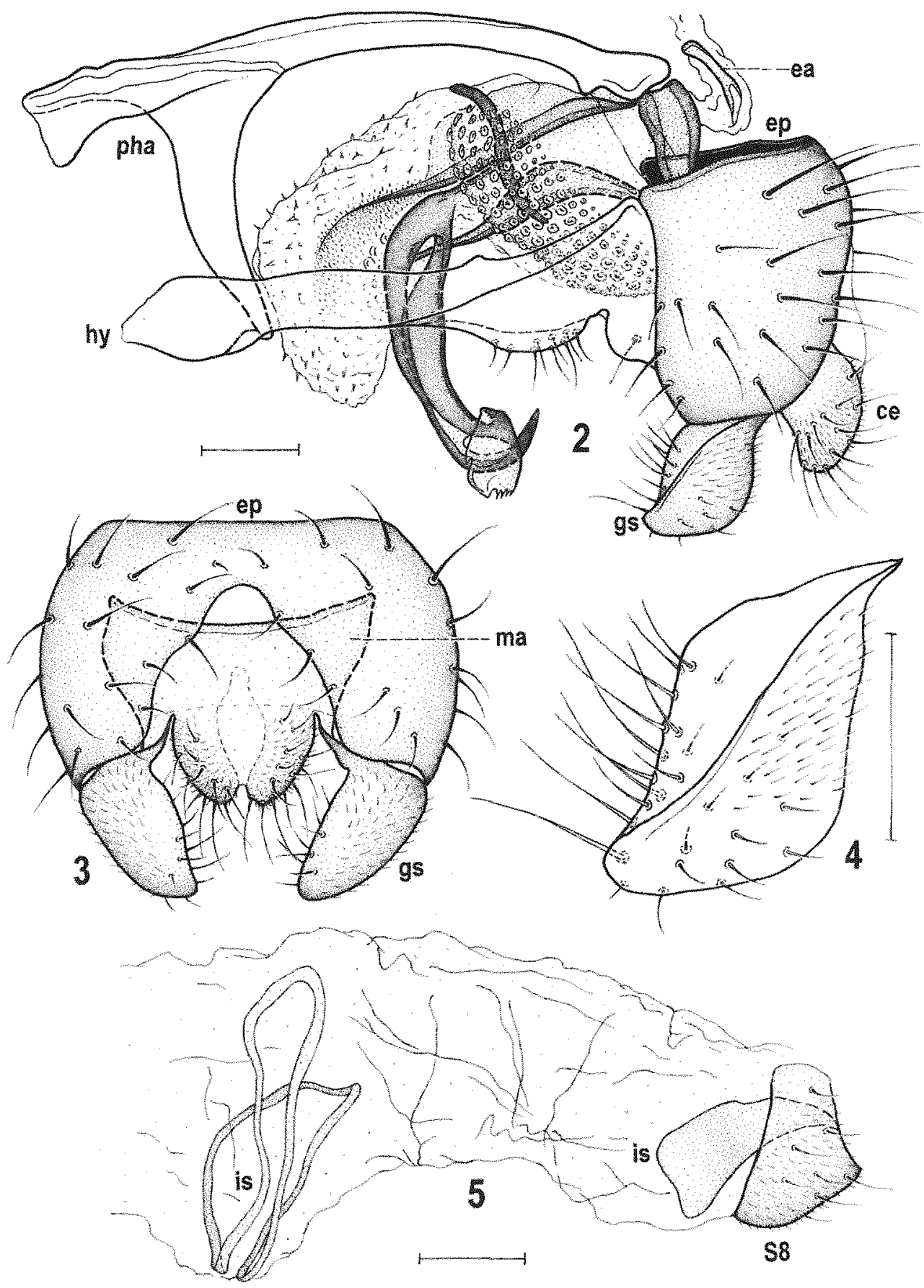

Figs 2-5: Stiphrosona sabulosum (HaLrdax), male (2-4), female (5) (Slovakia). 2 - male genitalia laterally (phallapodeme, hypandrium and associated structures not dotted); 3 - external genitalia caudally; 4 - gonostylus laterally; 5 -internal sclerites of female genital chamber laterally. Scales $=0.05 \mathrm{~mm}$. For abbreviations see text. All after RoHÁčé (1996). 


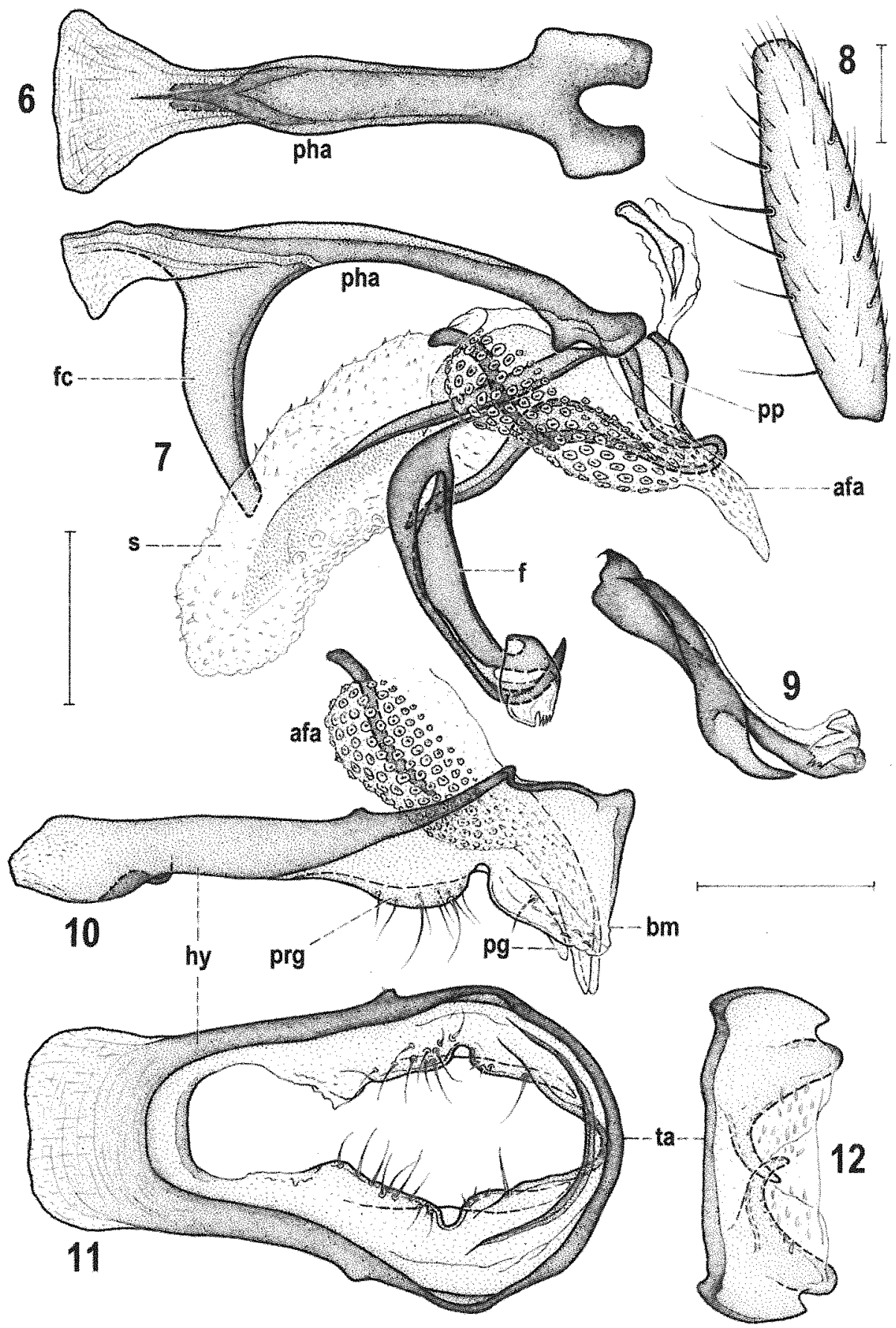

Figs 6-12: Stiphrosoma sabulosum (HALIDAY), male (Slovakia). 6 - phallapodeme dorsally; 7 - aedeagal complex laterally; 8 - left $\mathrm{f}_{1}$ posteriorly; 9 - filum of distiphallus ventrally; 10 - hypandrium and associated structures laterally; 11 - ditto ventrally; 12 - transandrium and basal membrane caudally. Scales $=0.1 \mathrm{~mm}$. For abbreviations see text. All after RoHÁčEK (1996). 


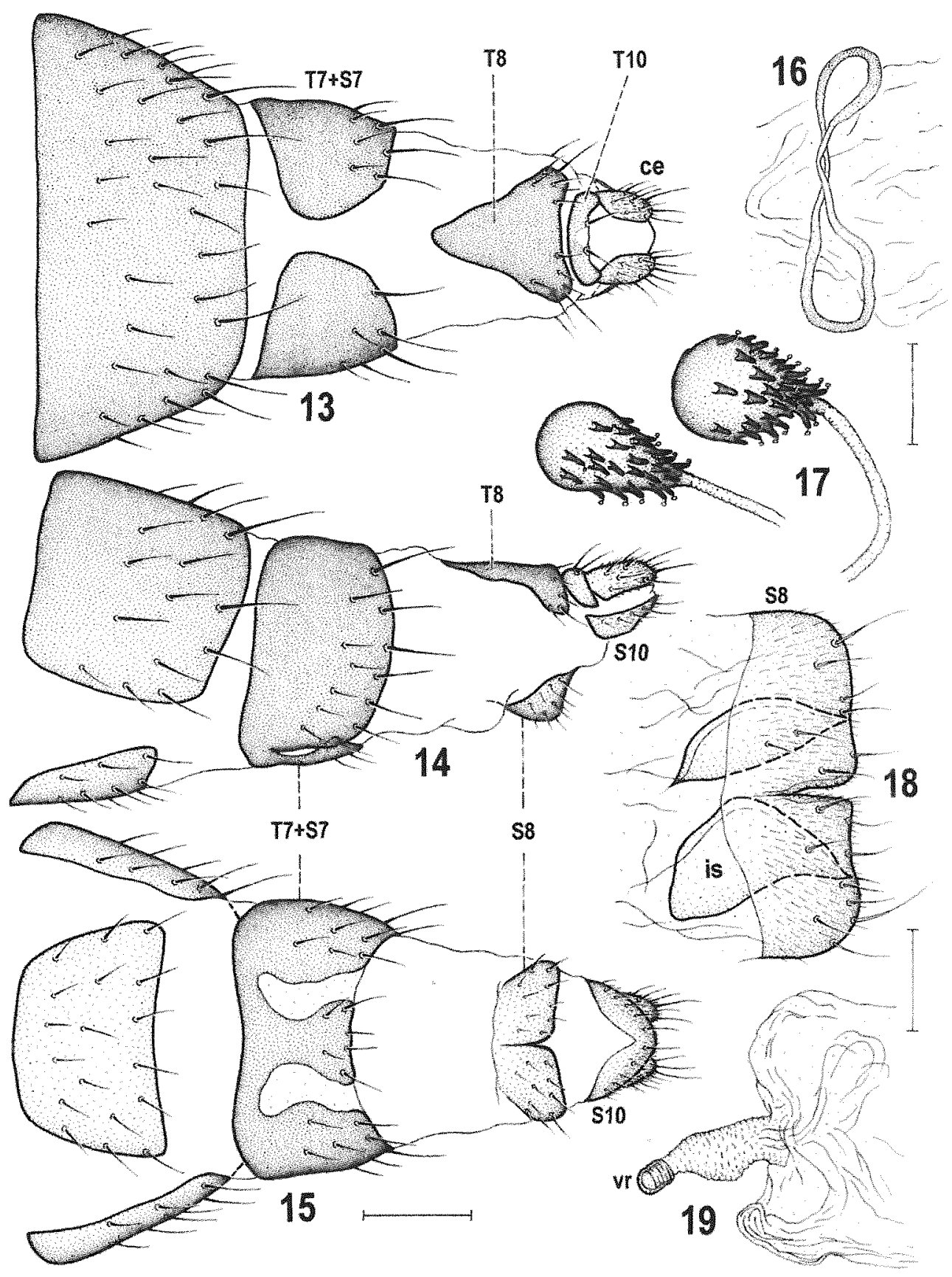

Figs 13-19: Stiphrosoma sabulosum (HALIDAY), female (Slovakia). 13 - postabdomen dorsally; 14 - ditto laterally; 15 - ditto ventrally; 16 - looped internal sclerite ventrally; 17 - spermathecae; 18 - S8 and internal sclerites ventrally; 19 - ventral receptacle laterally. Scales: Figs $13-15=0.1 \mathrm{~mm}$; others $=0.05 \mathrm{~mm}$. For abbreviations see text. All after RoHÁčeK (1996). 
Stiphrosoma pectinatum sp. n.

(Figs 20-34, 190)

\section{Type material:}

Holotype male labelled: „TENN: Cades Cove, GSMNP, 5.vi.1979, M. J. Sharkey, sweeps" (DEBU, intact). Paratypes: CANADA: Nova Scotia: West end Sable Is., 11.vii.1967, 2 females, D. M. Wood leg. (CNCI). Ontario: Fuller, 11.vii.1971, 1 female, C. D. Rollo leg. (DEBU); Guelph, Malaise trap, 1-7.vii.1985, 1 male, 23-30.vi.1985, 1 female, 15-21.vii.1985, 1 female, K. N. Barber leg. (DEBU); Ottawa, 30.vi.1963, 1 male, 6.vii.1963, 1 female, 13.vii.1963, 1 male 2 females (CNCI); Marmora, 4.vii.1952, 1 female (CNCI) all J. R. Vockeroth leg.; S[ault] S[te.] Marie, S. of Algoma U. College, $46^{\circ} 29.88^{\prime} \mathrm{N} 84^{\circ} 17.19^{\prime} \mathrm{W}, 5.1 x .2004$, sweeps, trampled graminoids, mostly Carex aquatilis, 1 female, K. N. Barber leg. (DEBU); S[ault] S[te.] Marie, Birchwood Park, 28.vi.1986, mixed forest, 1 female; same locality but $46^{\circ} 30.7^{\prime} \mathrm{N} 84^{\circ} 15.6^{\prime} \mathrm{W}, 23 . v i i i .2002$, sweeps, graminoids/ Impatiens, 1 female (DEBU); S[ault] S[te.] Marie, Bristol Pl. Pk., $46^{\circ} 30.8^{\prime} \mathrm{N} 84^{\circ} 16.6^{\prime} \mathrm{W}^{\prime \prime}$, sweeps/pooter, Phalaris arundinacea, 1.viii.1997, 1 male $1 \mathrm{fe}-$ male, 8.viii.1997, 1 female; same locality but 13.vi.1998, sweeps/pooter, mixed grasses, 1 female; same locality but 15.viii.1998, sweeps, Impatiens under Betula/Populus, 1 female (DEBU) all K. N. Barber leg. Quebec: Herrington Lk., Gatineau Pk., 3.vii.1963, 1 female, J. R. Vockeroth leg. (CNCI). USA: District of Columbia: Washington, Deanwood, nr. brook, 9.vi.1991, 1 female, M. Barták leg. (MBP); Georgia: Prattsburg, 25.vii.1930, 1 female, Paul W. Oman leg. (SEMC). Illinois: Union Co., Shawnee NF. Pine Hills Cpgd., 9.vi.1983, \# 83039-042, 1 male, I. S. Askevold leg. (DEBU). Indiana: LaFayette, 22.viii.1916, 1 male, [-] leg. (USNM). Maryland: Cabin John Br., 6.vi.[-], 1 male, J. M. Aldrich leg. (USNM); Glen Echo, 15.x.1952, 1 female, A. Stone leg. (USNM); Montgomery Co., 4 mi SW of Ashton, 14.v.1985, 2 males 2 females, 19.v.1985, 1 male; same locality but 3.vi.1981, Malaise trap, 1 female, all G. F. \& J. F. Hevel leg. (USNM); Montgomery Co., Bethesda, 23.v.1970, 1 male, 22.viii.1970, 1 male, G. Steyskal leg. (USNM); Montgomery Co., Colesville, Malaise trap, 20.viii.1973, 1 female, 4.vii.1976, 1 female, 28.v.1977, 1 female, 13.viii.1977, 1 male, 18.ix.1977, 1 male, 3.viii.1979, 1 male, W. W. Wirth leg. (USNM); near Plummers Is., 5.viii.1914, 2 males; same locality but at light, 8.viii.1914, 2 males 2 females, 12.viii.1914, 1 male 1 female, 17.viii.1914, 2 females, 22.viii.1914, 1 male, R. C. Shannon leg. (USNM). Massachusetts: Catoctin, Mt. Park (Lantz), 15.vi.1991, edge of wood, 1 male 1 female, meadow nr pond, 1 male (MBP, SMOC); Catoctin, Mt. Park, Chestnut wood, 15.vi.1991, 2 males 3 females (MBP, SMOC), all M. Barták leg. Michigan: Midland Co., 17.vi.1943, o, 1 male, R. R. Dreisbach leg. (USNM). New York: Tompkins Co., Danby, 18.vi.1963, 1 male, W. W. Wirth leg. (USNM). North Carolina: Graham Co., Robbinsville, 9.vi.1979, 1 male 3 females, G. E. Bohart leg. (EMUS). Pennsylvania: Dauphin Co., Grantville, 24.v.1962, 1 female, J. R. Vockeroth leg. (CNCI). Tennessee: same data as for holotype, 27 males 41 females (DEBU, AMNH, SMOC); same data but 2.vi.1979, 1 male 3 females (DEBU); Great Smoky Mts. National Park, Chimneys Camp, 11.vi.1946, 1 female, G. Steyskal leg. (USNM); Townsend, 2.vi.1979, sweeps, 5 males 6 females, M. J. Sharkey leg. (DEBU, SMOC). Virginia: Clarke Co., 3 mi E Berryville, Shenandoah River, 24.vii.1977, 1 female, N. L. Herman leg. (AMNH); Fairfax Co., Dead Run, 28.vii.1915, 1 male, R. C. Shannon leg. (USNM); Great Falls, 21.vi.1931, 1 male, A. L. Melander leg. (USNM); 
Shenandoah Co., Mt. Jackson, 25.v.1962, 2 males 4 females, J. R. Vockeroth leg. (CNCI); Shenandoah N [ational] P[ark], mi. 65-100, 29.v.1979, sweeps, 1 female, M. J. Sharkey leg. (DEBU). West Virginia: Franklin, 26.vi.1951, stream margin, 1 female, W. W. Wirth leg. (USNM). Some paratypes with genit. prep.

\section{Other $S$. pectinatum material not designated as paratypes:}

USA: Indiana: LaFayette, 27.vi.1916, 1 female, [-] leg. (USNM). North Carolina: Cherokee, 4.vi.1979, sweeps, 1 male, M. J. Sharkey leg. (DEBU). Tennessee: same data as for holotype, 9 males 12 females; same data but 2.vi.1979, 1 female (DEBU); East Ridge, 6.v.1952, 1 female, O. Peck leg. (CNCI); Smokies, Chimneys, 30.vi.1941, 1 female, A. L. Melander leg. (USNM); Townsend, 2.vi.1979, sweeps, 4 males 5 females, M. J. Sharkey leg. (DEBU).

Etymology: The species is named for its strikingly long-pectinate (Amygdalops-like) arista.

\section{Description:}

Male. Total body length 1.54-1.81 mm. Body bicoloured, yellow and brown. Head as long as high. Frons yellow, with whitish yellow and white microtomentose orbits, narrow frontal triangle reaching to anterior third, 2 small pale brown triangular spots behind frontal lunule and darker brown ocellar triangle. Occiput pale yellow medially, ochreous brown laterally and with narrow brown stripe at posterior margin of eye. Face with 4 more or less coalesced brown stripes contrasting with yellowish white remainder of face, parafacialia, gena and mouthparts (including palpus). Cephalic chaetotaxy: pvt small but crossed; vte markedly shorter than vti; oc and posterior ors often slightly longer than vti; anterior ors distinctly shorter than posterior; usually 2 microsetulae in front of anterior ors but the foremost very minute to indistinct; only 1 medial pair of minute setulae in front of frontal triangle; vi long, subvibrissa distinctly shorter and weaker; peristomal setulae fine and few in number (4-5); postocular setulae shorter than peristomals, in single row. Eye elongately ellipsoid; its longest diameter about 1.6 times as long as shortest. Gena very narrow, its smallest height 0.1 times as long as shortest eye diameter. Antenna (Fig. 32) with ochreous pedicel and yellowish white 1 st flagellomere with brown darkened anterodorsal area surrounding base of arista. Arista brown, about 1.6-1.7 times as long as antenna, long-pectinate, particularly dorsally; 1 st flagellomere with long white cilia on apex.

Thorax slightly narrower than head, yellow and brown. Mesonotum largely brown to pale brown, with a pair of yellow bands between dorsocentral lines usually reaching from fore margin of mesonotum to anterior $\mathrm{dc}$ and being separated by narrow brown medial stripe; also lateral band covering humeral and notopleural areas pale yellow. Pleural part of thorax whitish yellow except for dorsal brown band extending from anterior margin of propleuron to haltere. Mesonotum subshining, with sparse micropubescence. Thoracic chaetotaxy: 1 small prs, hardly longer than ac setulae; $2 \mathrm{dc}$, anterior variable in length, posterior long and strong; 3-5 dc setulae in front of anterior dc seta, hindmost distinctly longer than others; ac microsetae usually in 2 rows of variable length (at most reaching slightly behind anterior dc), sometimes with a few additional (lateral) setulae presuturally; basal sc short and weak, apical as long as posterior dc; 2 stpl (anterior markedly shorter) and 1 microseta in front of anterior stpl; $2-3$ additional setulae in dorsal half of sternopleuron and several longer setae ventrally. Scutellum rounded triangular, relatively flat, entirely brown but with whitish grey microtomentum on disc. 
Legs slender, entirely pale yellow. $f_{1}$ with strongly reduced ctenidial spine (Fig. 29) and very long posteroventral setae, that near ctenidial spine longest. $f_{3}$ with short but slightly thickened posteroventral setae (only 5-7) restricted to distal half of femur; $t_{3}$ and hind basitarsus simply finely setulose.

Wing (Fig. 190) with pale ochreous membrane and yellowish brown veins. $R_{2+3}$ slightly sinuous; $R_{4+5}$ slightly bent or sinuous; $M$ almost straight. Discal (dm) cell relatively short, gradually widened distally; $\mathrm{r}-\mathrm{m}$ situated in basal two-fifths of $\mathrm{dm}$ cell; dm-cu relatively long. CuA variable in length, ending far from or close to wing margin (in the latter case slightly curved); $A_{1}$ short; alula and anal lobe small but distinct. Wing measurements: length $1.56-1.75 \mathrm{~mm}$, width $0.51-0.64 \mathrm{~mm}, \mathrm{Cs}_{3}: \mathrm{Cs}_{4}=1.70-2.11, \mathrm{r}-\mathrm{mldm}-\mathrm{cu}: \mathrm{dm}-\mathrm{cu}$ $=2.69-3.00$. Haltere pale ochreous brown, stem darker than knob.

Abdomen brown and whitish yellow. T1-T3 largely brown, at most anteromedially paler ochreous; T4 and T5 yellow, with broad brown band along posterior and lateral margins. T2-T5 only setose in posterior half. S2-S5 whitish yellow, narrow, becoming wider posteriorly, finely setulose. T6 bare, reduced to small transverse strip, unpigmented and weakly sclerotized. S6 and S7 pale ochreous, S6 with brown anterior margin and 2 setae; S7 with 1-3 setae. S8 much darker than S7, brown and dorsally setose, contrasting with yellow epandrium.

Genitalia. Epandrium (Figs 20-21) almost as long as high and very broad, with relatively sparse long setae, 1 dorsomedial pair longer than others. Dorsal side of epandrium straightened, ventral part of epandrium protruding ventrally on each side; anal fissure rounded triangular. Cercus (Figs 20-21) relatively large and broad. Medandrium (Fig. 20) large, broad, weakly sclerotized. Gonostylus (Fig. 24) short, broad, of ellipsoid outline in widest extension view, laterally with keel-like ledge separating bare anterior part and micropubescent posterior part (Fig. 21) and internally with long setae. Hypandrium (Fig 23) slender and very weakly sclerotized. Transandrium simple, straight; basal membrane ventrally with a group of transverse tubercles (Fig. 25). Pregonite (Fig. 23) reduced and hardly projecting ventrally, with only fine setulae (9-10); postgonite (Fig. 23) strongly sinuous, with broad and flat anteroproximal process and 1 longer seta hidden behind the latter; its apical part narrow, flat, unpigmented. Aedeagal complex. Phallapodeme with widened apex projecting in flattened lateral lobes and with broad, deeply forked base. Aedeagal part of folding apparatus laterally sculptured by small spine-like tubercles; connecting sclerite long and relatively broad (Fig. 26). Aedeagus (Fig. 26) composed of short, frame-like phallophore and robust distiphallus with unusually large basal part. Saccus largely membranous, provided with two groups (apical and anterodorsal) of short robust spines and some spinulae. Filum robust and dark, with pale flat lobe near the middle and distinctive angularly bent apex bearing several projections, keels and pale teeth (Figs 22, 26). Ejacapodeme pigmented, with long digitiform projection having small terminal capitulum.

Female. Similar to male unless mentioned otherwise. Total body length $1.58-2.18 \mathrm{~mm}$. Frons with dark spots behind lunule less distinct, lighter pigmented. Face entirely yellowish white, without brown stripes. Ctenidial spine on $f_{1}$ very reduced as in male but $f_{3}$ without posteroventral row of short erect setae. Wing measurements: length 1.66-2.16 $\mathrm{mm}$, width 0.51-0.75, $\mathrm{Cs}_{3}: \mathrm{Cs}_{4}=1.65-2.00, \mathrm{r}-\mathrm{mldm}-\mathrm{cu}: \mathrm{dm}-\mathrm{cu}=2.47-3.00$.

Abdomen. Preabdominal terga wider, transverse; sterna narrower. T1-T2 brown but T2 anteromedially paler; both T3 (in contrast to that of male) and T4 yellow with broad 
brown band along lateral and posterior margins; T5 brown-banded only posteriorly, otherwise yellow. Preabdominal sterna all yellowish white, finely setose.

Postabdomen (Figs 27, 33). T6 large, long and pale, posteriorly narrowed and setose, with dark marginal band and robust posterior setae. $\$ 6$ very light, suboblong, little wider than long, setose in posterior half. Tergosternum $\mathrm{T} 7+\mathrm{S} 7$ unpigmented dorsomedially (Fig. 27), dark dorsolaterally following the outline of original T7; its ventromedial part (original S7) rounded trapezoidal, pale, anteriorly poorly delimited (Fig. 33), with 3 pairs of setae at posterior margin. T8 (Fig. 27) narrow, elongately oblong, very pale, with light rounded triangular pigmentation, being darker only posteriorly. S8 (Fig. 33) small and relatively narrow, with deep posteromedial cleft and and fine setae. Internal sclerotization of female genital chamber (Fig. 31) consisting of two pairs of posterior, pale and twisted sclerites (ventral pair larger) and 1 anterior, transverse, relatively strong, looped sclerite. Ventral receptacle (Fig. 30) on short duct, rounded subcylindrical, weakly sclerotized and indistinctly striated. Spermathecae $(1+1)$ short pyriform (Figs 28, 34), with robust curved spines on surface except for terminal area. T10 short and transverse and pale (Fig. 27), with a pair of long setae and sparse micropubescence in posterior half. $\$ 10$ longer than T10, rounded pentagonal, with posterior two-thirds micropubescent (Fig. 33). Cerci short and with rich moderate setae.

\section{Discussion:}

Stiphrosoma pectinatum sp. n. retains plesiomorphic spermathecae and a very short gonostylus as has $S$. sabulosum and also shares with this species the reduction of ctenidial spine on $f_{1}$ and lobe-shaped process (although pale) on filum of distiphallus. It differs from it (and other Stiphrosoma species) by long-pectinate arista, colouring of notum (brown with yellow stripes), minute ctenidial spine (Fig. 29), shortly $S$-shaped postgonite and unique apex of filum. In contrast to $S$. sabulosum it has short robust spines in saccus, ventrally pale female $T 7+S 7$, almost unpigmented $T 8,2$ pairs of internal female sclerites etc.

\section{Biology:}

Most collections of this species have been made by sweeping but specimens have also been taken with an aspirator (pooter). There are two sequential records of capture in a Malaise trap (Colesville, MD; Guelph, ON) and at a light (Plummers Island, MD).

The long series from Tennessee represent the majority of specimens of this otherwise quite rare species. Here, $S$. pectinatum was found in association with the locally less cor-'mon $S$. balteatum while sweeping. It has also been found in association with the mor common S. setipleurum (Sault Ste. Marie, ON) where they were taken from the thatc layer under Phalaris arundinacea (Poaceae). Sweeping of a patch of Impatiens capensis anc of Carex aquatilis has yielded single specimens while streamside vegetation is implicatec. in West Virginia. The immature stages of $S$. pectinatum are not known.

\section{Distribution:}

This is a decidedly eastern North American species ranging from Ontario to Nova Scotia in Canada and then Michigan and Indiana to New York and Georgia in the USA. 


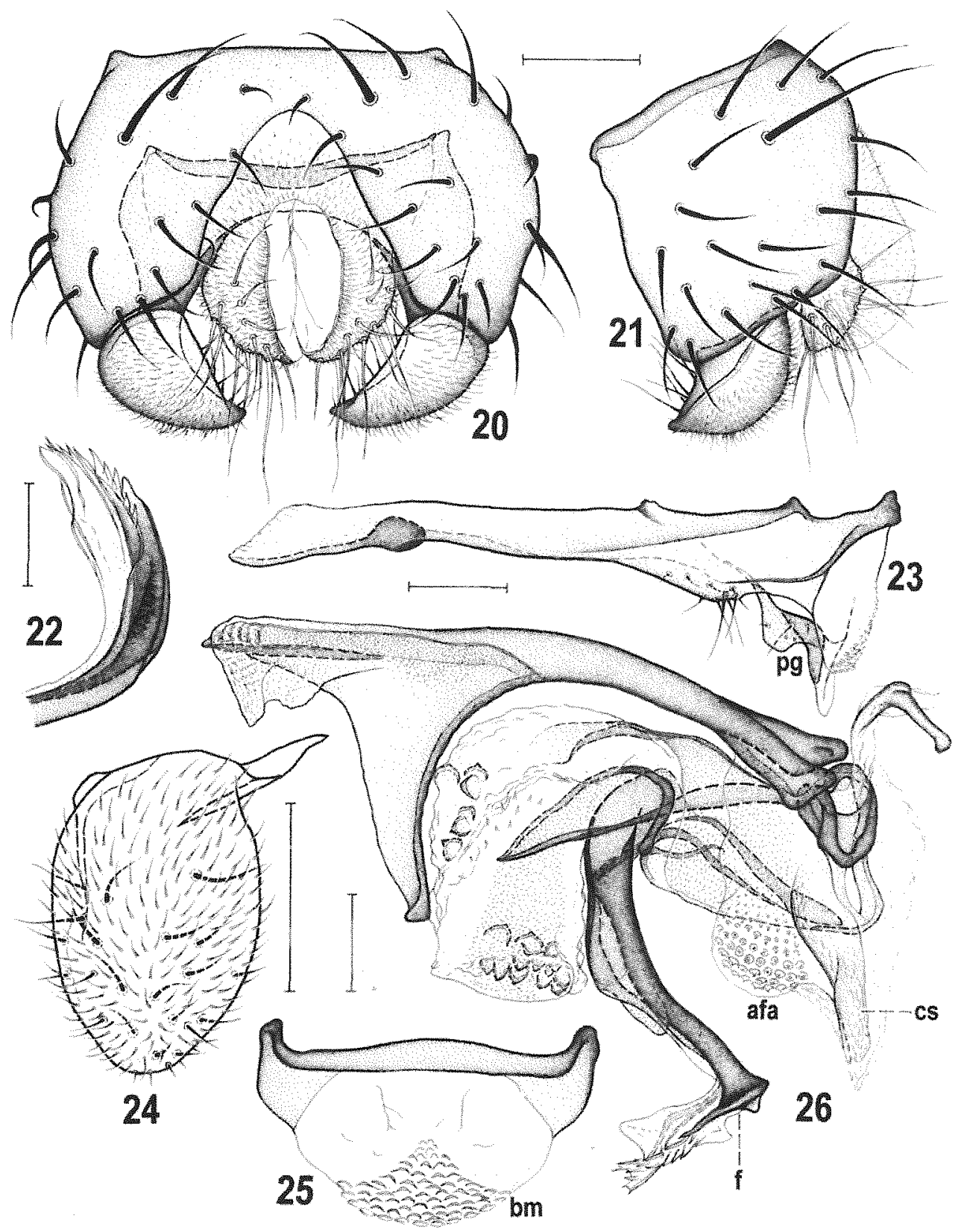

Figs 20-26: Stiphrosoma pectinatum sp. n., male paratype (USA: Tennessee). 20 - external genitalia caudally; 21 - ditto laterally; 22 - apex of filum ventrally; 23 - hypandrium and associated structures laterally; 24 - gonostylus ventrolaterally (widest extension view); 25 - transandrium and basal membrane caudally; 26 - aedeagal complex laterally. Scales $=0.05 \mathrm{~mm}$. For abbreviations see text. 


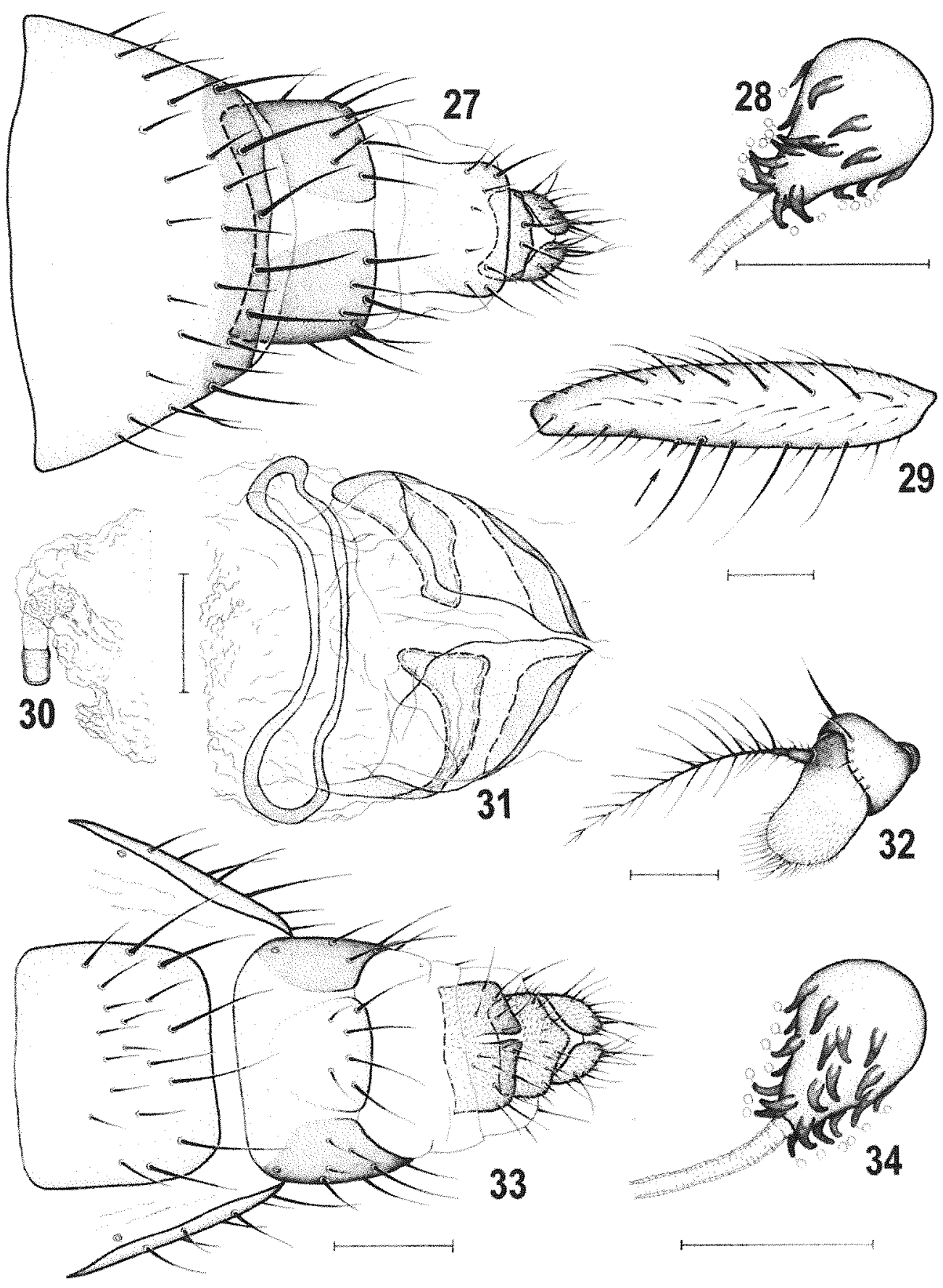

Figs 27-34: Stiphrosoma pectinatum sp. n., female paratype (USA: Tennessee). 27 - postabdomen dorsally; 28 - spermatheca; 29 - $f_{1}$ posteriorly; 30 - ventral receptacle laterally; 31 - internal sclerites ventrally; 32 - antenna laterally; 33 - postabdomen ventrally; 34 - spermatheca. Scales: Figs 27, 29, 32-33 = $0.1 \mathrm{~mm}$; others $=0.05 \mathrm{~mm}$. 
Stiphrosoma lucipetum sp. n.

(Figs 35-47, 191)

\section{Type material:}

Holotype male labelled: "BAHAMAS, N. Bimini, April 1968, G. M. Stokes, light trap" (USNM, intact). Paratypes: BAHAMAS: North Bimini, same data as for holotype, 11 males 6 females (USNM, SMOC); same locality, ii.1968, light trap, 2 males (USNM) all G. M. Stokes leg. BELIZE: Twin Cays, 7.iii.1984, mangrove swamp, Malaise trap, 6 males, W. N. Mathis leg. (USNM). COSTA RICA: Prov. Punta[renas]: Manglar, Rio Corcovado, 0 m, 22.iii.1995, 1 female, F. Alvaro leg. (INBC). CUBA: Cayo Largo, Archipiélago de los Cannareos, 24.-29.xii.1994, 1 male, Andreas Stark leg., (Universität Bielefeld, M. v. Tschirnhaus, X-1174) (ZSMC); USA: Florida: River Co., Vero Beach, 12.xii.1980, litter in mangrove swamp, 1 male, L. E. Watrous leg. (DEBU); Monroe Co., Big Pine Key, 10.iv. 1970, 1 male, Malaise trap, 1 male (USNM); Lee Co., Sanibel I[slan]d., 11.v.1973, Malaise trap, 1 female (USNM) all W. W. Wirth leg.; Sarasota, 23.iv.1936, 1 male, [-] leg. (USNM); Marcos I[slan]d, iv.1975, in black mangrove impounded forest, 1 male, C. M. Courtney leg. (USNM); Plantation Key, 25.ii.1956, at light, 1 male (USNM); Key Largo, 26.ii.1956, at light 1 female (USNM) both R. A. Morse leg. Several paratypes with genit. prep.

Etymology: The species is named "lucipetum" (= L. attracted to light) owing to its affinity for light sources which is an otherwise infrequent phenomenon in Anthomyzidae.

\section{Description:}

Male. Total body length 1.74-2.56 mm; general colour ochreous-brown and yellow; body strikingly bristly (more than in all known congeners). Head (Fig. 42) distinctly higher than long. Frons orange to dark ochreous; orbit lightest, yellow to whitish yellow and microtomentose; frontal triangle narrow, reaching to anterior third of frons and usually paler than areas between it and orbits; ocellar triangle dark brown; lunule concolorous with anterior margin of frons. Occiput bicolorous - laterally with yellow, ventrally broadened band (but eye posteriorly very narrowly brown margined), central area above foramen ochreous or pale brown and bare except for 2 ventrally covergent silvery white microtomentose bands reaching from vti to foramen; yellow lateral bands may be reduced in darkest specimens, so that occiput is mostly brown, except microtomentose stripes and yellow ventral part below foramen. Face narrow, brown, with dark brown pattern consisting of 4 longitudinal stripes ( 2 medial and 2 lateral bordering parafacialia); parafacialia (except brown margin) pale yellow, gena (including postgena) whitish yellow to white and both silvery white microtomentose; mouthparts yellow to ochreous. Cephalic chaetotaxy: pvt small, usually meeting medially; vti longest of cephalic setae; vte, oc and posterior ors subequal, slightly shorter than vti; 2 strong ors, anterior long although shorter than posterior; 2 (rarely 3) microsetulae in front of anterior ors; $1-2$ pairs of medial microsetulae near anterior corner of frontal triangle; vi about as long as anterior ors; subvibrissa two-thirds or more of vi length; peristomal setae (5-7) unusually strong, 1-4 anterior ones as long as subvibrissa; postgena with several setulae in 2 perpendicular rows; postocular microsetulae minute, in single row. Eye elongately suboval; its longest (oblique) diameter about 1.5 times as long as shortest; smallest genal height 0.11-0.12 times as long as shortest eye diameter. Antenna yellow to dark ochreous; 1 st 
flagellomere usually paler than pedicel, uniformly coloured, anteroventrally with long white cilia. Arista 1.7-1.8 times as long as antenna, ochreous to pale brown, long-pectinate (Fig. 42).

Thorax not or indistinctly narrower than head. Mesonotum bicolorous, yellow to ochreous orange and pale brown. Typically there are 7 pale brown vittae: 1 narrow medial between ac microsetae, 2 very narrow covering dc lines (all three reaching to anterior margin of scutum), 2 broader lateral ranging from prs to pa setae and 2 short ones between the latter and dc lines and covering only posterior fourth or third of scutum; area between dc lines posterior to anterior dc seta also brownish and humeral-notopleural band paler (ochreous) but not sharply contrasting with lateral vitta or dorsal pleural band; scutellum pale brown with sides usually paler ochreous. Some of scutal vittae can be widened (often medial stripe) or posteriorly confluent integrating the short posterior vitta. Pleural part of thorax yellow to pale yellow (ventrally), with broad dorsal pale brown band having diffuse ventral margin. Mesonotum finely microtomentose, subshining. Thoracic chaetotaxy richer and stronger than in all relatives: prs small but longer than in other Stiphrosoma species; $2 \mathrm{dc}$, anterior strong, longer than npl but shorter than posterior dc; 6-7 dc microsetae in front of anterior dc, 2-3 of them markedly longer than other thoracic microsetae; ac microsetae in 6 rows in front of suture, 4 rows reaching behind anterior dc and 2 medial rows behind posterior dc; $2 \mathrm{sc}$, basal unusually very long (as long as or longer than anterior $\mathrm{dc}$ ); numerous microsetae covering area between $\mathrm{dc}$ line and prs-pa line; 2 robust stpl (anterior shorter) and $4-7$ additional setulae in dorsal half of sternopleuron and several longer setae ventrally. Scutellum subtriangular, with distinctly flattened disc.

Legs very densely setulose, pale yellow to darkly yellow, sometimes with slightly darker knees and tibiae but all tarsal segments unicolorous. $f_{1}$ with ctenidial spine short, about as long as maximum width of $t_{1} . f_{2}$ with posteroventral erect setae in proximal third distinctly longer than in other congeners; ventroapical seta on $t_{2}$ relatively strong. $f_{3}$ with very dense posteroventral row of setae, $10-15$ in distal half short and thickened; $t_{3}$ with strongly reduced ventroapical seta; hind basitarsus with ventrobasal setae small and hardly discernible among other ventral setulae.

Wing (Fig. 191) with pale ochreous-brown membrane and veins. $C$ with well developed small spines between apices of $R_{1}$ and $R_{2+3}$. $R_{2+3}$ slightly bent in parallel to $C$ and apically very slightly to indistinctly upcurved to it; $R_{4+5}$ almost straight; $M$ very slightly bent or sinuate. Discal $(\mathrm{dm})$ cell short, relatively strongly widened distally, $\mathrm{r}-\mathrm{m}$ situated in basal two-fifths to half of $\mathrm{dm}$ cell. $\mathrm{CuA}$, relatively long, slightly bent, ending near wing margin; $A_{1}$ short, ending far from it. Alula narrow and anal lobe well developed. Wing measurements: length $1.66-2.26 \mathrm{~mm}$, width $0.59-0.79 \mathrm{~mm}^{-\mathrm{Cs}_{3}}: \mathrm{Cs}_{4}=0.96-1.14, \mathrm{r}-\mathrm{ml}$ dm-cu : $\mathrm{dm}-\mathrm{cu}=2.23-2.59$. Haltere ochreous with pale brown knob.

Abdomen. Terga with rather variable brown and yellow (or ochreous) pattern. T1-T2 ochreous with brownish sides and posterior margin of T2, in darker specimens almost entirely brown. T3-T5 ochreous yellow, with brown band along posterior and lateral margins, T4 and T5 sometimes also posteromedially darkened. T3-T5 densely setose over most of surface, setae on T5 longest. Preabdominal sterna S2-S5 pale yellow, becoming wider posteriorly, finely densely setulose. T6 largest of known relatives, forming transverse, pale brown, bare, on right side dilated, dorsal sclerite. S6 and S7 usually with 
2 setae. 66 pale brown, with robust dark brown heavily sclerotized anterior marginal band continued on ventral projection. S7 and often also anterior margin of S8 ochreous yellow in contrast to dark $S 6$ and $S 8$, the latter relatively long, densely setose.

Genitalia. Epandrium (Figs 35-36) brown, shorter than high, sparsely setose, with largest setae dorsomedially; dorsal side of epandrium convex; anal fissure narrowly triangular. Cercus small, finely setose. Medandrium (Fig. 35) weakly sclerotized, relatively small. Gonostylus (Fig. 41) large, elongately subtriangular in widest extension view, with rounded apex and a shallow emargination at posterior margin; micropubescence covering outer side except for anterior marginal area; longest setae situated at anterior margin of inner side. Hypandrium (Fig. 37) anteriorly slender, posteriorly relatively robust and with 2 characteristic lateral setae near ventral margin (see Figs 37-38). Transandrium broad, ventrally sinuously margined (Fig. 38); basal membrane with minute transverse tubercles. Pregonite (Fig. 37) small but complex, with small ventral flat projections and 2 longer setae besides several small setulae. Postgonite (Fig. 37) robust, strongly sinuously bent, with several microsetulae proximally and 1 anterior seta distally, and hyaline flattened apex. Aedeagal complex (Fig. 40). Robust phallapodeme with deeply forked base and large, wing-like broadened apex. Aedeagal part of folding apparatus relatively small, finely densely tuberculate (also dorsally); connecting sclerite slender, membranous, finely granulose. Phallophore very small; basal part of distiphallus dorsally sclerotized and finely granulose, ventrally hyaline and densely setulose. Saccus of distiphallus finely setulose dorsally and anteriorly and with 6-8 sclerotized spine-like tubercles. Filum dark, long and slender, having 1 sharp tooth near its middle (Fig. 39) and finely serrate membranous apex (Figs 39-40). Ejacapodeme pale, with simple digitiform projection without distinct capitulum.

Female. Similar to male unless mentioned otherwise. Total body length $2.22-2.70 \mathrm{~mm}$. Face as in male but dark marking often paler. Posteroventral setae in proximal third of $\mathrm{f}_{2}$ somewhat shorter; $\mathrm{f}_{3}$ without thickened posteroventral setae. Wing measurements: length $2.14-2.54 \mathrm{~mm}$, width $0.73-0.95 \mathrm{~mm}, \mathrm{Cs}_{3}: \mathrm{Cs}_{4}=0.91-1.14, \mathrm{r}-\mathrm{mldm}-\mathrm{cu}: \mathrm{dm}-\mathrm{cu}$ $=2.05-2.70$.

Abdomen with preabdominal terga yellow and brown, T2-T5 shorter and more transverse than in related species. T1 largely yellow with only lateral parts brown; T2 entirely brown or pale brown, often with darker posterior margin. T3-T5 yellow, each with broad brown band along posterior and lateral margins and medially with longitudinal dark band (wider on T3, narrower on T4 and T5) so that yellow areas look like 2 large spots situated at anterior margin of terga. T3-T5 with rich setae reaching to anterior fourth of tergal disc. S2-S5 pale yellow, finely densely setulose, becoming wider posteriorly, S5 the widest.

Postabdomen short and broad (Figs 43, 45). T6 very broad and densely setose, with thick setae at posterior margin, pale yellow with charcteristic dark pattern (Fig. 43). S6 transversely trapezoidal, finely sparsely setose. Tergosternum $T 7+S 7$ dorsally short, dark but dorsomedially interrupted by unpigmented membrane; its ventral side pale pigmented with original $S 7$ completely integrated (its position only indicated by darker setulose posteromedial area - see Fig. 45). T8 plate-shaped, with highly characteristic dark pattern resembling a robust $X$ and with setae restricted to posterior margin (Fig. 43). S8 relatively wide, posteriorly tapered and with deep posteromedial cleft (Fig. 45). Genital 
chamber (Fig. 44) with two pairs of pale crooked sclerites (posterior pair larger) and with well developed anterior looped sclerite being ventrally medially compressed. Ventral receptacle (Fig. 47) subcylindrical, weakly sclerotized and on short duct. Spermathecae $(1+1)$ very shortly pyriform (Fig. 46), with strongly narrowed base and dense robust thorn-like spines. T10 (Fig. 43) short, small, hyaline, with scarce micropubescence at posterior margin and 1 pair of dorsal setae. S10 (Fig. 45) larger than T10, triangular and with deep anterior incision. Cerci small but rather slender, with longest setae apically and subapically.

\section{Variability:}

The specimens from Belize are distinctly darker coloured (e.g. with frons and occiput almost brown, with reduced yellow areas) than those from Bahamas or Florida. However, a single female from Costa Rica is extreme in this respect, with head darker brown than pattern on thorax, having lightest areas pale brown (instead of yellow), including antenna, mouthparts, gena etc. Other parts of body (thorax, legs, abdomen) of this female resemble specimens from Belize. Inasmuch as its postabdominal structures are identical with those in typical specimens, we consider this dark-headed female only an aberrant specimen of S. lucipetum.

\section{Discussion:}

S. lucipetum sp. n. forms with $S$. pullum sp. n. a sister-pair of southern species which share a number of peculiar features in the male genitalia, some of which can be considered synapomorphic, viz., pregonite short, with only 2 long setae; hypandrium with 1-2 posterolateral setae; basal membrane with pigmented and unpigmented areas; basal part of distiphallus setulose; filum of distiphallus with a small pale process far from apex of filum; postgonite with seta inserted preapically. These two species are also characterized by rich setosity of body, including unusually strong anterior peristomals (as long as subvibrissa). S. lucipetum can be distinguished from $S$. pullum by bicolorous body, 6 rows of ac microsetae, male $S 7$ ochreous yellow in contrast to brown S6, S8 and epandrium, and by the form of gonostylus, postgonite, longer filum etc. The female postabdomen of $S$. lucipetum is characterized by distinctive pigmentation of ventral part of $T 7+S 7$, $\mathrm{x}$-shaped dark mark on T8, and by shortly pyriform spermathecae with very dense and robust spines.

\section{Biology:}

Apparently this is a coastal species and is likely associated with mangrove habitats as indicated on three independent collection labels (Belize, Florida). Likely, the microhabitat involves graminoids of some description. The additional behavior of attraction to lights is only otherwise recorded for S. pectinatum.

\section{Distribution:}

This is a widely distributed species ranging from the Bahamas to Florida, Belize and the Pacific coast of Costa Rica. 


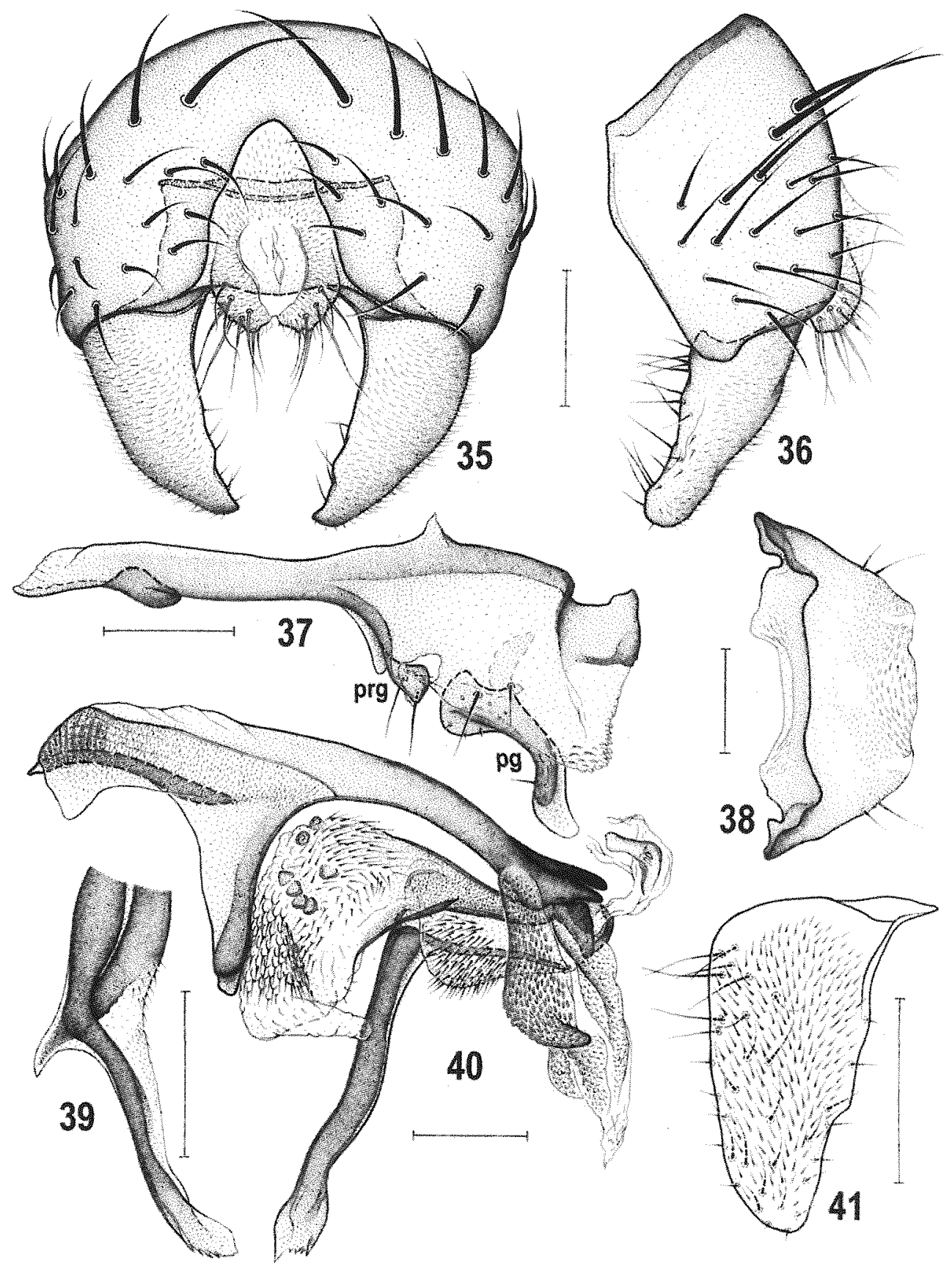

Figs 35-41: Stiphrosoma lucipetum sp. n., male patatype (Bahamas). 35 - external genitalia caudally; 36 ditto laterally; 37 - hypandrium and associated structures laterally; 38 - transandrium and basal membrane caudally; 39 - apex of filum anteroventrally; 40 - aedeagal complex laterally; 41 - gonostylus posterolaterally (widest extension view). Scales $=0.1 \mathrm{~mm}$. 


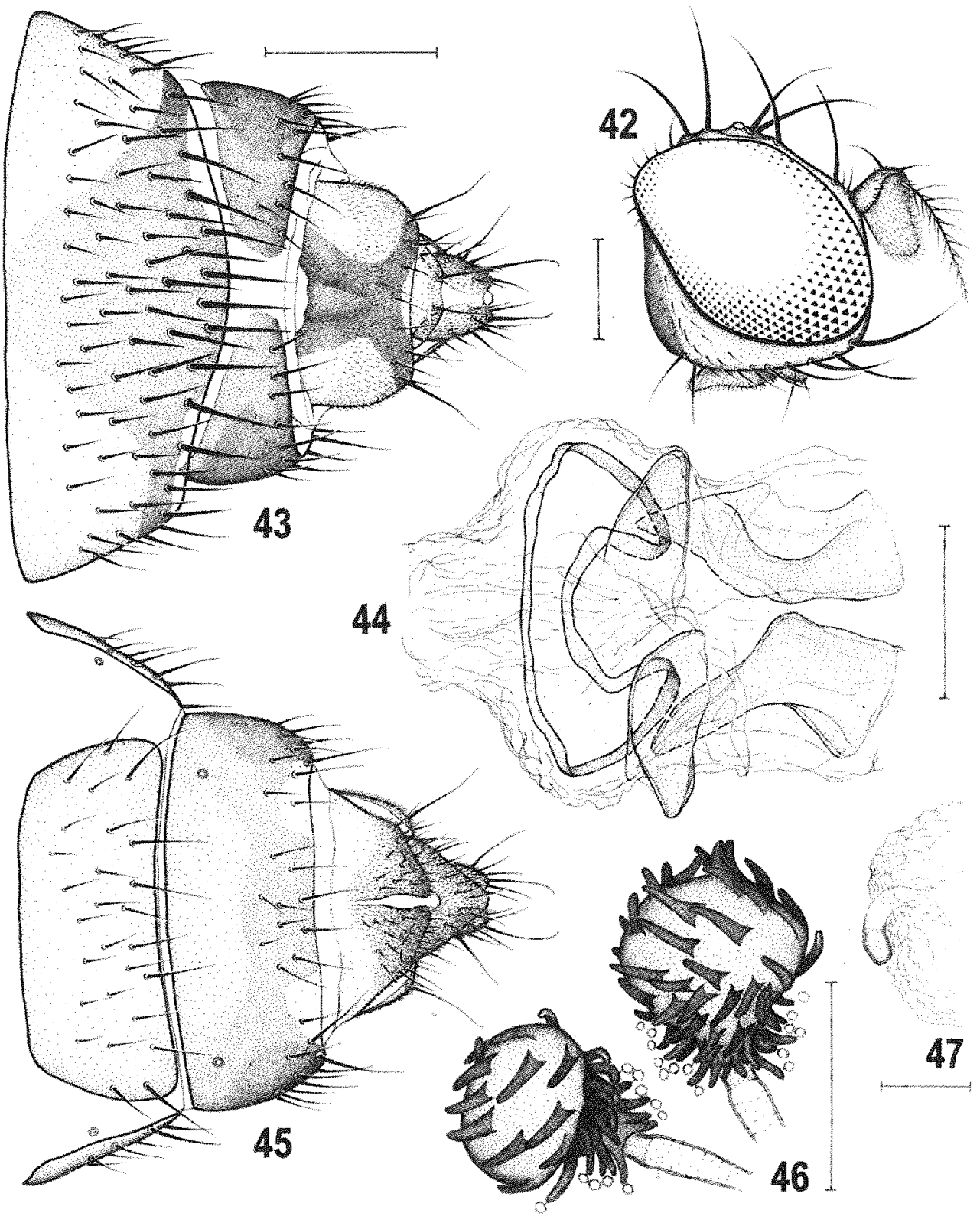

Figs 42-47: Stiphrosoma lucipetum sp. n., male holotype (42), female paratype (43-47) (Bahamas). 42- head laterally; 43 - postabdomen dorsally; 44 - internal sclerites ventrally; 45 - postabdomen ventrally; 46 - spermathecae; 47 - ventral receptacle laterally. Scales: Fig. $44=0.1 \mathrm{~mm}$; Figs $46-47=0.05 \mathrm{~mm}$; others $=$ $0.2 \mathrm{~mm}$. 
Stiphrosoma pullum sp. n.

(Figs 48-54, 192)

\section{Type material:}

Holotype male labelled: “COSTA RICA: Prov. Guanacaste, Punta Coyote, Estero Coyote, 0 m, 9 DEC 2002, Y. Cardenas, Red de Golpe. L N 196225398025 \#72710" (obverse), "INB0003565167 INBIOCRI COSTA RICA" (reverse). (INBC, genit. prep.; left wing, right hind tibia and tarsus detached and preserved with genit.).

Etymology: The name "pullum" (= L. dark) refers to the extraordinarily dark colour of the species.

\section{Description:}

Male. Total body length $2.06 \mathrm{~mm}$; general colour dark brown, with only small parts of body pale brown to yellow; body relatively bristly, though less than in S. lucipetum. Head distinctly higher than long. Frons largely dark brown, only orbit ochreous yellow and densely silvery white microtomentose; frontal triangle anteriorly very narrowed, almost reaching to margin of frons and slightly paler than dark brown areas between it and orbits; ocellar triangle large, dark brown and subshiny in contrast to dull remainder of frons; lunule pale yellow. Occiput dark brown except for 2 medial, ochreous, ventrally covergent, silvery white microtomentose bands reaching from vti to foramen; ventral margin of occiput whitish yellow. Face brown, with darker narrow marginal stripe bordering parafacialia and anterior part of gena; parafacialia (except brown margin) pale yellow, gena (including postgena) whitish yellow to dirty white and both silvery white microtomentose; mouthparts ochreous, palpus pale brown, clypeal margin brown. Cephalic chaetotaxy: pvt small, with apices crossed; vti, vte, oc and posterior ors subequal, longest of cephalic setae; 2 strong ors, anterior shorter than posterior; 2 microsetulae in front of anterior ors; 1 pair of almost invisible medial microsetulae near anterior corner of frontal triangle; vi relatively short, slightly shorter than anterior ors; subvibrissa inserted unusually far from vi and not longer than two-thirds of vi length; peristomal setae (4-5) relatively strong, 2-3 anterior ones as long as subvibrissa; postgena with several setulae in 2 perpendicular rows; postocular microsetulae minute, in single dense row. Eye elongately suboval; its longest (oblique) diameter about 1.6 times as long as shortest; smallest genal height about 0.1 times as long as shortest eye diameter. Antenna ochreous-brown but scape yellow; 1 st flagellomere paler than pedicel, somewhat darkened below base of arista, anteroventrally with long ochreous cilia. Arista 1.6 times as long as antenna, dark brown, long-pectinate, with rays longer than in $S$. lucipetum.

Thorax hardly narrower than head. Mesonotum including scutellum dark brown and uniformly greyish brown microtomentose, only anteromedially with 2 longitudinal grey microtomentose spots reaching to suture. Humeral callus (postpronotum) yellow; notopleural area pale brown. Pleural part of thorax brown (darker dorsally), ochreous only above fore coxa and around haltere. Thoracic chaetotaxy: prs small, shorter than in $S$. lucipetum; $2 \mathrm{dc}$, anterior strong, longer than npl but shorter than posterior $\mathrm{dc} ; 5 \mathrm{dc}$ microsetae in front of anterior dc, 1 of them markedly longer than other thoracic microsetae; ac microsetae in 4 rows in front of suture, in 2 rows behind anterior $\mathrm{dc}$, the latter reaching to level of posterior $\mathrm{dc} ; 2 \mathrm{sc}$, basal very long (slightly longer than anterior $\mathrm{dc}$ ); area between dc line and prs-pa line with less numerous microsetae than in S. lucipetum; 
2 robust stpl (anterior almost as long as posterior!) and 4-5 additional setulae in dorsal half of sternopleuron (including 1 setula in front of anterior stpl) and several longer setae ventrally. Scutellum large, rounded subtriangular, with distinctly flattened disc.

Legs densely setulose as in $S$. lucipetum but unusually dark: femora and tibiae largely brown; coxae, trochanters and bases of femora yellow; knees, apices of tibiae and tarsi ochreous except for pale brown basal and apical segments. Ctenidial spine on $f_{1}$ small, slightly shorter than maximum width of $t_{1} . f_{2}$ with posteroventral erect setae in proximal third shorter than in $S$. lucipetum; $t_{2}$ with ventroapical seta long and strong and with short but distinct anteroapical seta in addition. $f_{3}$ with posteroventral row of setae, 9-10 of which in distal two-thirds short and thickened; $t_{3}$ without distinct ventroapical seta; no enlarged ventrobasal setulae on hind basitarsus.

Wing (Fig. 192) unusually dark, with brown membrane and veins. $C$ with small break distal to humeral cross-vein and with well developed small spines between apices of $R_{1}$ and $R_{2+3} . R_{2+3}$ bent in parallel to $C$ and apically indistinctly upcurved to it; $R_{4+5}$ very slightly bent; $M$ almost straight. Discal (dm) cell short, slightly widened distally; $r-m$ situated in basal two-fifths of dm cell. CuA unusually long (longer than $r-m / d m-c u$ sector on $M$ ), almost straight, ending near wing margin; $A_{1}$ short, ending far from it. Alula narrow but like anal lobe well developed, both these and posterior margin of wing very densely and long ciliate. Wing measurements: length $2.10 \mathrm{~mm}$, width $0.69 \mathrm{~mm}, \mathrm{Cs}_{3}: \mathrm{Cs}_{4}=1.08, \mathrm{r}-$ $\mathrm{m} \backslash \mathrm{dm}-\mathrm{cu}: \mathrm{dm}-\mathrm{cu}=3.33$. Haltere with dark yellow stem and whitish knob.

Abdomen. Preabdominal terga broad and transverse, becoming longer posteriorly (T5 longest), all dark brown except $\mathrm{T} 1$ somewhat paler medially. T1-T2 with distinct but short setae, T3-T5 densely setose over most of surface, setae in T5 longest. Preabdominal sterna S2-S5 pale yellow, S2-S4 becoming wider posteriorly and finely setulose; S5 slightly narrower than $\$ 4$ but densely setulose. T6 forming transverse, bare, on right side dilated and dark brown pigmented dorsal sclerite narrowly fused on left side to synsternum S6-S8. All postabdominal sterna dark brown like epandrium. S6 bare, larger than usual and with robust dark anterior ledge continued as relatively short ventral process. S7 also narrowly dark margined anteriorly and with 2 minute setulae. S8 relatively long, densely setose.

Genitalia. Epandrium (Figs 48-49) dark brown, slightly shorter than high, lower and more densely setose than in $S$. lucipetum, with 2 pairs of long and strong setae (laterally and dorsomedially); dorsal side of epandrium convex; anal fissure subtriangular, well delimited. Cercus small, finely setose. Medandrium (Fig. 48) similarly constructed as in S. lucipetum but higher and narrower. Gonostylus (Fig. 51) smaller, narrower (both in lateral and widest extension view) and more acutely triangular, with more slender and anteriorly bent apex than that of $S$. lucipetum and with micropubescence and setosity similar to that species. Hypandrium (Fig. 50) very similar to that of S. lucipetum but darker, posteriorly robust and widened, with lateral setae ( 2 on left, 1 on right side) near ventral margin above postgonite longer (see Figs 50, 54). Transandrium broader than in S. lucipetum, ventrally more straight-margined (Fig. 54); basal membrane with small tubercles arranged in two groups separated by medial unpigmented area. Pregonite (Fig. 50) small, with fewer (3-4) but longer setae than in S. lucipetum. Postgonite (Fig. 50) smaller, less sinuous and darker than in $S$. lucipetum with simple rounded apex, a few proximal microsetulae and 1 anterior subapical seta. Aedeagal complex (Fig. 53). 


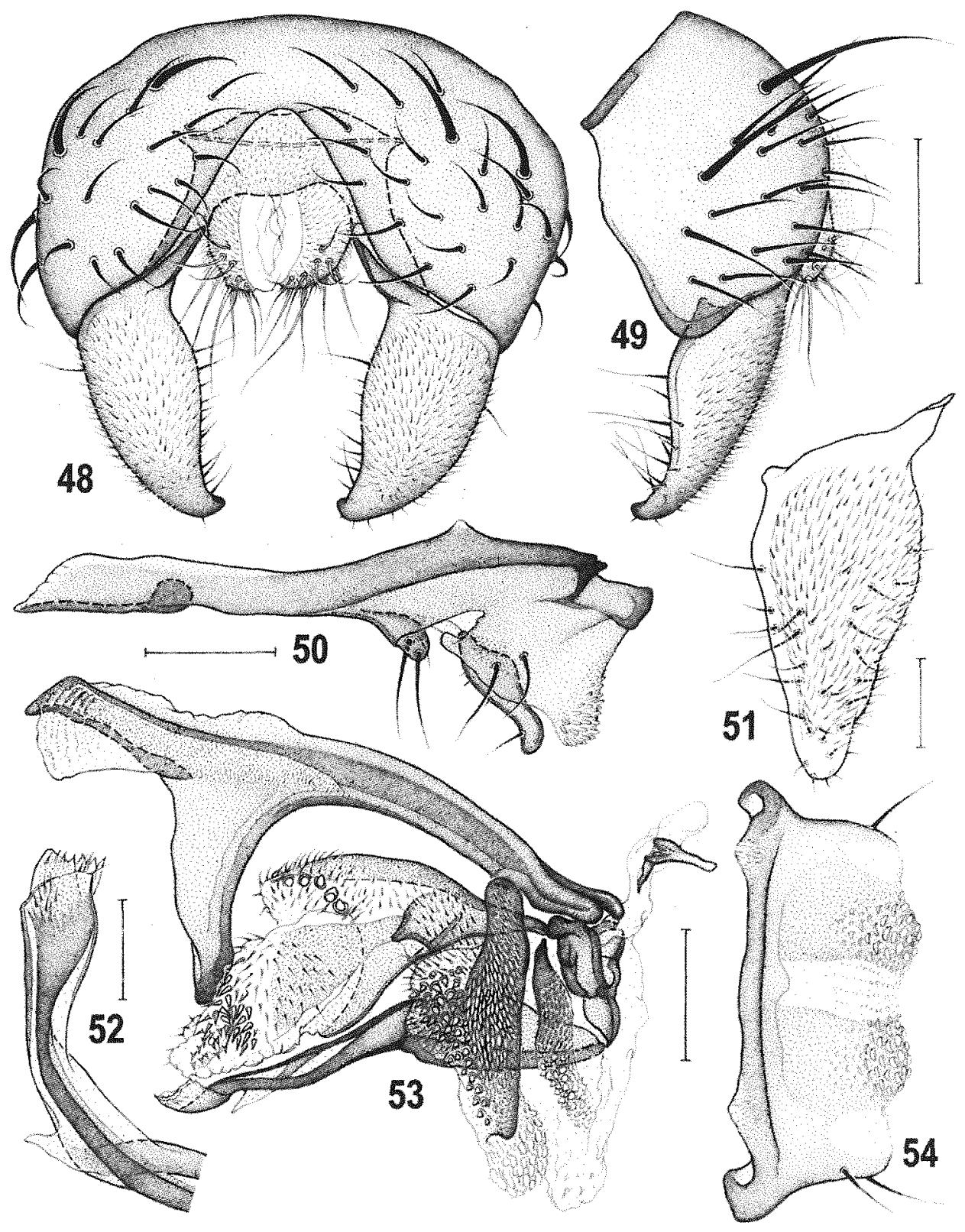

Figs 48-54: Stiphrosoma pullum sp. n., male holotype (Costa Rica). 48 - external genitalia caudally; 49 - ditto laterally; 50 - hypandrium and associated structures laterally; 51 - gonostylus posterolaterally (widest extension view); 52 - apex of filum ventrally; 53 - aedeagal complex laterally; 54 - transandrium and basal membrane caudally. Scales: Figs $51-52=0.05 \mathrm{~mm}$, others $=0.1 \mathrm{~mm}$. 
Phallapodeme robust as in $S$. lucipetum. Aedeagal part of folding apparatus larger than that of $S$. lucipetum, dark and covered by both short robust spines (anteriorly) and dense, fine elongate tubercles (the latter posteriorly and also dorsally); connecting sclerite dark, dorsally unusually heavily sclerotized, ventrally finely tuberculate. Phallophore short but complex and ventrally projecting; basal part of distiphallus well sclerotized and partly finely setulose. Saccus of distiphallus finely setulose over most of surface, and with 6 spine-like tubercles anterodorsally and with a group of smaller acute spines subapically. Filum dark, markedly shorter than in S. lucipetum, composed of 2 ribbon-shaped sclerites, with hyaline tooth in distal third (see Fig. 52) and flattened, finely serrate hyaline apex provided with some subapical spinulae. Ejacapodeme small, slender, darker than in $S$. lucipetum, with simple digitiform projection.

Female unknown.

\section{Discussion:}

S. pullum sp. n. is closely related to $S$. lucipetum sp. n. (see discussion under that species) but can be easily recognized from all known congeners by very dark body, including pleurae, most of legs and wings. Moreover, it possesses an unique feature, a small break on $\mathrm{C}$ distal to humeral cross-vein. Its genitalia are unusually heavily sclerotized and dark pigmented, including hypandrium and associated structures, aedeagal part of folding apparatus, connecting sclerite and even basal membrane.

\section{Biology:}

Nothing is known of the biology of this species.

Distribution:

This is one of only two species of Stiphrosoma known to occur in Costa Rica.

\section{Stiphrosoma setipleurum sp. n.}

(Figs 55-67, 193)

\section{Type material:}

Holotype male labelled: "ONT: SSMarie, Bristol Pl.Pk., 01.viii.1997, KNBarber, sweeps/pooter, Phalaris arundinacea, $46^{\circ} 30.8^{\circ} \mathrm{N} 84^{\circ} 16.6^{\circ} \mathrm{W}$ " (DEBU, intact). Paratypes:

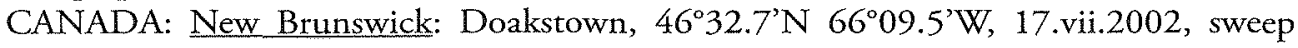
streamside vegetation on steep hillside at rest area, 1 female, J. Forrest $\& \mathrm{~T}$. A. Wheeler leg. (LEMQ). Nova Scotia: Cape Bret[on] H[ighlands]. N[ational]. P[ark]., Pleasant Bay, 17.viii.1984, ex. damp meadow, 1 female, R. Martin leg. (CNCI). Ontario: Baptiste Lake, $45^{\circ} 10^{\prime} \mathrm{N} 78^{\circ} 00^{\prime} \mathrm{W}$, sweep near lake shore, 25.vii.2000, 1 female, J. Forrest leg. (LEMQ); Bruce Peninsula N. P., bank of Crane River nr. Hwy. 6, 45 08.9'N $81^{\circ} 28.1^{\prime} \mathrm{W}$; 31.vii.1997, sweeps/pooter, Calamagrostis \& Carex, 1 female, K. N. Barber leg. (DEBU);

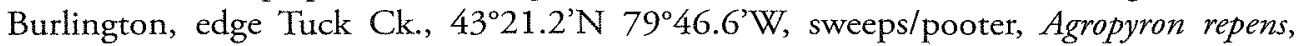
20.vii.1997, 1 female, 16.viii.1998, 1 female (DEBU); same locality but pooter, Bromus inermis, 16.vii.1997, 2 males 5 females (DEBU, SMOC), 18.vii.1997, 4 males 7 females (including 1 pair in copula) (DEBU), 20.vii.1997, 9 males 8 females (including 1 pair in copula) (DEBU, AMNH, SMOC, USNM); same locality but 16.vii.1997, sweeps/pooter, Bromus inermis, 2 males (DEBU, SMOC); same locality but sweeps/pooter, Bromus 
inermis, 15.vii.1997, 3 males 4 females, 16.vii.1997, 7 females, 18.vii.1997, 4 males 14 females, 20.vii.1997, 7 males 12 females, 16.viii.1998, 1 female; same locality but pooter, Phalaris arundinacea, 16.vii.1997, 5 males 7 females, 18.vii.1997, 2 males 5 females (including 1 pair in copula), 20.vii.1997, 1 male 2 females (DEBU); same locality but 18.vii.1997, pooter, Phleum pratense, 10 males 2 females (including 1 pair in copula), 20.vii.1997, 2 males 4 females (including 1 pair in copula) (DEBU); same locality but 16.vii.1997, pooter, Poa pratensis, 1 male 6 females, 18.vii.1997, 6 males 8 females, 20.vii.1997, 1 male 3 females (DEBU); same locality but 18.vii.1997, pooter, various grasses, 5 males 12 females (including 3 pairs in copula) (DEBU); same locality but 19.viii.1998, sweeps/pooter, grasses edge of park, 5 males, 21.viii.1998, 1 male 1 female (DEBU); same locality but 16.viii.1998, sweeps/pooter, grasses incl. Bromus/Phalaris, 2 males (DEBU); same locality but 14.vii.2002, sweeps/pooter, grasses nr. creek, 1 male (DEBU); same locality but pooter, mowed long grasses, 14.vii.2002, 1 male 2 females, 1.viii.2003, 3 males 1 female (DEBU) all K. N. Barber leg.; Fergus, Grand R. floodplain, $43^{\circ} 41.5^{\prime} \mathrm{N} 80^{\circ} 23.2^{\prime} \mathrm{W}$, 17.vii.1997, sweeps/pooter, Bromus inermis, 1 male 9 females (DEBU); same locality but $43^{\circ} 41.3^{\circ} \mathrm{N} 80^{\circ} 23.4^{\circ} \mathrm{W}, 17$. viii.1998, graminoids, 4 males 3 females (DEBU) all K. N. Barber leg.; Fergus, 30.vii.1994, riverside vegetation, 1 male 2 females, J. Roháček leg. (SMOC); Guelph, University Arboretum, 19.viii.1994, sifting grass and Carex tufts, 1 female, J. Roháček leg. (SMOC); Guelph, 2.viii.1980, 1 male, 9.vii.1981, 1 female, 28.viii.1983, 1 male (DEBU); same locality but Malaise trap, 24.vi14.vii.1981, 1 female, 1-20.vii.1982, 1 female (DEBU) all K. N. Barber leg.; Halton Reg., Milton, Derry Rd. \& $4^{\text {th }}$ Line, 12-16.vii.2001, grass field, yellow pans, 1 male 2 females, S. Paiero leg. (DEBU - 00172043, 00172198, 00172391), 9-11.vii.2001, 1 female (DEBU - 00174918), 27.viii-4.ix.2001, 1 female, S. M. Paiero leg. (DEBU 00174927); Hamilton, 10-13.vii.1980, Malaise trap, 1 male, M. Sanborne leg. (DEBU); Lancaster, Hwy \#401, interchange, $45^{\circ} 08.1^{\prime} \mathrm{N} 74^{\circ} 29.6 \mathrm{~W}$, 9.viii.2000, pooter, mixed grasses, 3 females (DEBU); Manitoulin Is., - $2.2 \mathrm{~km} \mathrm{~N}$ Cold Springs, Perch Ck @ Hwy $540,45^{\circ} 53.2^{\circ} \mathrm{N} 82^{\circ} 06.3^{\prime} \mathrm{W}$, 1.viii.1997, sweeps/pooter Calamagrostis canadensis, 18 males 35 females (including 3 pairs in copula), (DEBU, SMOC), 4.vii.1999, 1 male (DEBU); Manitoulin Is., Conc. 6, $0.5 \mathrm{~km}$ W Hwy 6, 4537.2' $\mathrm{N} 82^{\circ} 00.2^{\prime} \mathrm{W}$, 28.vii.1997, pooter, Phalaris arundinacea, 1 female (DEBU) ; Manitoulin Is., $3.3 \mathrm{~km} \mathrm{E}$ Spring Bay, Hwy $542 @$ Tracy Rd., 4543.90'N 82¹6.48'W, 30.viii.2004, pooter, roadside/fenceline grasses, 2 females (DEBU), all K. N. Barber leg.; Ottawa, 19.vii.1954, 1 female, 22.vii.1954, 1 female, W. R. M. Mason leg. (CNCI); Ottawa, 13.vii.1963, 1 female (CNCI), 15.vii.1964, among grass roots, 1 female (CNCI) all J. R. Vockeroth leg; Ottawa, 15.vii.1938, 1 female, A. Brooks leg. (CNCI); Prescott, 2.vii.1980, 1 fe-

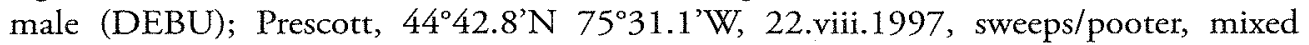
grasses, 1 female (DEBU); S[ault] S[te.] Marie, S. of Algoma U[niversity] College, $46^{\circ} 29.9^{\prime} \mathrm{N} 84^{\circ} 17.2^{\prime} \mathrm{W}$, pooter, mostly Calamagrostis canadensis, 28.vii.2001, 1 female, 29.vii.2001, 1 female, 5.viii.2001, 1 female (DEBU); S[ault] S[te.] Marie, Birchwood

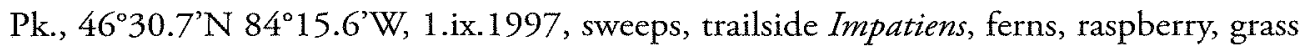
under Betula/Acer, 1 female (DEBU); same locality but 25.viii.1997, pooter, graminoids and Impatiens, used in lab-rearing, killed 20.ix.2002, 1 male 1 female; same data but dead 20.ix.2002, 1 male (DEBU) all K. N. Barber leg.; same data as for holotype, 7 males 14 females (including 1 pair in copula) (DEBU, SMOC); same data but 27.vii.1997, 1 male 5 females, 8.viii.1997, 9 males 14 females (DEBU); same locality but $46^{\circ} 30.8^{\prime} \mathrm{N}$ 
84 16.6'W, 14.viii.1999, sweeps, low veg. including grasses, 1 female; same locality but 29.viii.1999, sweeps, Phalaris arundinacea, 1 male 1 female (DEBU); same locality but sweeps/pooter, Calamagrostis canadensis, 27.vii.1997, 1 male, 1.viii.1997, 2 males 3 females, 2.viii.1997, 2 male 3 females (including 1 pair in copula) (DEBU); S[ault] S[te.] Marie, Finn Hill, pooter, Carex stipata stipata, $46^{\circ} 31.65^{\prime} \mathrm{N} 84^{\circ} 17.34^{\prime} \mathrm{W}, 30 . v i 1.2004$, 1 female (DEBU); S[ault] S[te.] Marie, Ft. Creek Cons. Area, $46^{\circ} 32.5^{\prime} \mathrm{N} 84^{\circ} 20.8^{\prime} \mathrm{W}$, 7.viii.2001, sweeps, graminoids under canopy, 2 females (DEBU) all K. N. Barber leg.; S[outh] March, 5.viii.1967, 1 male, J. R. Vockeroth leg. (CNCI). Quebec: Knowlton Ldg., 12.vii.1968, 1 female, J. R. Vockeroth leg. (CNCI); Messines, 10.vii.1947, 1 male, W. R. M. Mason leg. (CNCI); Trois Rivières, western outskirts, 25.viii.1994, forest, swept, eclector, 1 female, M. v. Tschirnhaus leg. (Universität Bielefeld X989) (ZSMC, in alcohol); E of Rimouski, $48^{\circ} 29^{\prime} \mathrm{N} 68^{\circ} 27^{\prime} \mathrm{W}$, sweep along Hwy 20, 29.vii.2001, 1 female, S. Boucher leg. (LEMQ); Ste--Anne-de-Bellevue, Stoneycroft Pond, $45^{\circ} 25.8^{\prime} \mathrm{N} 73^{\circ} 56.4^{\prime} \mathrm{W}$, sweeping grass, 5.vii.2000, 1 male, J. Forrest leg. (LEMQ); Wakefield, 1.vii.1959, 1 male 1 female, J. R. Vockeroth leg. (CNCI). USA: Illinois: Galeria, 6.vii.1917, 1 female, [-] leg. (INHS - 40,165). Indiana: LaFayette, ex. Elymus Cage 1, 23.v.1916, 2 females, 28.v.1916, 1 male 2 females (USNM); LaFayette, 25.v.1916, from Elymus Cage 1,4 males 3 females (USNM) all J. M. Aldrich leg. Massachusetts: Catoctin, Mt. Park, Chestnut wood, 15.vi.1991, 1 male 2 females, M. Barták leg. (MBP, SMOC). Michigan: Ironwood, Mt. Zion Ski Area, $46^{\circ} 28.5^{\prime} \mathrm{N} 90^{\circ} 10.2^{\prime} \mathrm{W}, 22 . v i i .1999$, sweeps, low veg. in cut under Acer, 1 male 6 females, K. N. Barber leg. (DEBU); Midland Co., 6-23.1952, 1 male (USNM); Saginaw Co., 2.vi.1949, 1 female (USNM) all R. R. Dreisbach leg. New York: Lake Placid, 2000', 19.vii.1962, 1 male 2 females, J. R. Vockeroth leg. (CNCI). Pennsylvania: Blue Knob St. Park, Bedford Co., 28.vii.1972, 1 female, D. Dee Wilder leg. (CASC). West Virginia: Bluefield, 17.vi.1970, 1 female (USNM); Ritchie Co., North Bend St. Pk., 23.vi.1970, 1 female (USNM) all G. Steyskal leg. Several paratypes with genit. prep.

\section{Other $S$. setipleurum material not designated as paratypes:}

CANADA: Ontario: Fergus, Grand R. floodplain, 17.vii.1997, sweeps/pooter, Bromus inermis, $43^{\circ} 41.5^{\prime} \mathrm{N} 80^{\circ} 23.2^{\prime} \mathrm{W}, 1$ female (DEBU); S[ault] S[te.] Marie, Birchwood Pk., $46^{\circ} 30.7^{\prime} \mathrm{N} 84^{\circ} 15.6^{\prime} \mathrm{W}, 25 . v i i i .1997$, pooter, graminoids and Impatiens, used in lab-rearing, dead 20.ix.2002, 1 female (DEBU) both K. N. Barber leg. USA: Indiana: LaFayette, 24.v.1916, from Elymus Cage 1, 1 male (USNM); LaFayette, 13.vii.1913, 1 female (USNM) all J. M. Aldrich leg.

Etymology: The name refers to the setose mesopleuron of the new species.

\section{Description:}

Male. Total body length $1.78-2.38 \mathrm{~mm}$; bicolorous, yellow and brown. Head slightly higher than long. Frons yellow, orbits paler and white microtomentose; frontal triangle narrow, reaching to anterior third of frons, slightly paler and more glittering than darker yellow and dull remainder of frons; ocellar triangle with brown spot between ocelli; occiput yellow, medially and ventrally lighter; face and mouthparts yellowish white, proboscis ochreous; parafacialia and gena white and silvery white microtomentose. Cephalic chaetotaxy: pvt small, crossed; vte distinctly shorter than vti; vti and oc longest of cephalic setae; 2 ors, posterior only slightly shorter than vti; anterior ors distinctly shorter, about 
as long as vte; 2 microsetulae in front of anterior ors, posterior twice longer than anterior; only 1 medial pair of minute setulae in front of frontal triangle; vi strong but shorter than vti; subvibrissa variable, always distinctly shorter and weaker than vi; peristomal setulae (6-9) often (in larger specimens) in two rows; also postgena with several setulae; postocular setulae minute, in single row. Eye elongately ovoid; its longest (oblique) diameter 1.5-1.6 times as long as shortest; smallest genal height about 0.12 times as long as shortest eye diameter. Antenna orange yellow, slighter darker at base of arista and on inner side of 1 st flagellomere having long (as long as dorsal rays of arista) white cilia anteroventrally. Arista 1.9-2.0 times as long as antenna, brown with paler basal segments, moderately pectinate.

Thorax very slightly narrower than head, bicolorous. Mesonotum including scutellum largely yellow but with brown lateral vitta (as in S. balteatum - see Fig. 77), anteriorly reaching to level of hu, posteriorly extending to laterobasal corner of scutellum; humeral and notopleural areas pale yellow. Pleural part of thorax pale to whitish yellow except for dorsal brown longitudinal band extending from cervix to base of abdomen. Mesonotum sparsely microtomentose, subshining to almost dull. Thoracic chaetotaxy: 1 small prs, about as long as longest $\mathrm{dc}$ microseta; 2 strong $\mathrm{dc}$, anterior long though shorter than robust posterior $\mathrm{dc}$ which is longer than apical sc; $4-6 \mathrm{dc}$ setulae in front of anterior dc seta; ac microsetae variable in number, in $2-4$ rows on suture, posteriorly in 2 rows reaching behind level of posterior dc; basal sc weaker and much shorter than anterior dc; posterodorsal corner of mesopleuron with distinct setulae (Fig. 63) but their number variable; sternopleuron also richly setulose including dorsal half, with usual $2 \mathrm{stpl}$ (posterior markedly longer) and 1 microseta in front of anterior stpl. Scutellum rounded triangular, with disc more or less flat.

Legs yellow, only apical tarsal segments brown in distal half. $f_{1}$ with robust ctenidial spine being twice or more longer than width of $\mathrm{t}_{1}$; mid basitarsus with a small dark seta ventrobasally; $f_{3}$ with a dense row of short thickened posteroventral setae (only 11-14) in distal three-fifths of femur; $\mathbf{t}_{3}$ with short thick ventroapical seta; hind basitarsus with 2 (rarely 1) ventroproximal black setae (often longer than ventroapical seta on $t_{3}$ ).

Wing (Fig. 193) with pale brownish membrane and veins. $R_{2+3}$ long, bent, parallel to $C$, with apex upcurved to $C ; R_{4+5}$ slightly bent; $M$ almost straight. Discal $(\mathrm{dm})$ cell moderately long, slightly widened distally; $\mathrm{r}-\mathrm{m}$ situated in basal third of $\mathrm{dm}$ cell. $\mathrm{CuA}_{1}$ usually slightly bent and ending near wing margin; $A_{1}$ short, ending far from wing margin; alula narrow and anal lobe well developed. Wing measurements: length $1.70-2.18 \mathrm{~mm}$, width $0.59-0.75 \mathrm{~mm}, \mathrm{Cs}_{3}: \mathrm{Cs}_{4}=1.17-1.48, \mathrm{r}-\mathrm{mldm}-\mathrm{cu}: \mathrm{dm}-\mathrm{cu}=3.42-4.27$. Haltere dirty white, stem usually darker, with ochreous tinge.

Abdomen brown and yellow. T1-T3 brown, medially or anteromedially narrowly to broadly yellow; $\mathrm{T} 4$ and $\mathrm{T} 5$ usually with yellow anterior half (in T4 yellow part could be reduced, shorter), with broad brown band along posterior and lateral margins. Preabdominal sterna pale yellow, becoming wider posteriorly and all densely finely setulose. T6 reduced to a small subtriangular, pale and bare remnant on right side. $\$ 6$ yellow but with thickened brown anterior margin and 2 (rarely more) setulae; $S 7$ entirely yellow, with 1-3 setulae. $S 8$ more setose, dark brown, sharply contrasting with yellow $\$ 7$ and epandrium.

Genitalia. Epandrium (Figs 55-56) slightly higher than long, not very broad, with very dense setae, 1-2 pairs (dorsomedial and dorsolateral) markedly longer than others. Dorsal side of epandrium almost straightened; anal fissure semi-ellipsoid. Cercus (Figs 55-56) 
relatively small but projecting. Medandrium (Fig. 55) moderate, simple, weakly sclerotized. Gonostylus (Fig. 59) large, as long as epandrium height, slightly tapered distally and rounded apically, with densely micropubescent outer side; setae on inner side rather short. Hypandrium (Fig. 58) relatively robust and well sclerotized. Transandrium simple, slightly sinuous; basal membrane ventrally with a group of small hyaline tubercles (Fig. 57). Pregonite (Fig. 58) shortly projecting and dark, with a number of setulae (11-12); postgonite (Fig. 58) dark, straight but with strongly posteriorly bent pale flat apex and with 1 anterior setula near middle. Aedeagal complex. Phallapodeme slender, with less widened apex, usual forked base, robust fulcrum and pale dorsal keel. Aedeagal part of folding apparatus laterally sculptured by small lenticular tubercles; connecting sclerite narrow and poorly delimited from surrounding membranes. Aedeagus (Fig. 61) with small, frame-like phallophore and large distiphallus. Saccus voluminous, except basal sclerites membranous, anterodorsally with 3 robust thorn-like spines and with lateral, finely tuberculate area. Filum thick, heavily sclerotized, very dark and strongly curved to the left, with complex apex provided with flat keels, 1 small digitiform process and finely spinose tip (Figs 60-61). Ejacapodeme (not illustrated) moderate, with slender, slightly bent digitiform projection teminated by weakly developed capitulum.

Female. Similar to male unless mentioned otherwise. Total body length $1.78-2.60 \mathrm{~mm}$. Chaetotaxy of legs as in male, only $f_{3}$ without posteroventral row of short thickened setae. Wing measurements: length $1.78-2.34 \mathrm{~mm}$, width $0.59-0.81, \mathrm{Cs}_{3}: \mathrm{Cs}_{4}=1.24-1.70$, $\mathrm{r}-\mathrm{mldm}-\mathrm{cu}: \mathrm{dm}-\mathrm{cu}=3.24-4.45$.

Abdomen lighter than in male; preabdominal terga wider, pale yellow with brown transverse stripe-like pattern. T1 brown but yellow anteromedially; T2 with brown stripe along lateral and posterior margins; $\mathrm{T} 3-\mathrm{T} 5$ with narrow brown stripe on only posterior margin; this stripe is usually medially interrupted (on T2 and T3), or shortened (on T4). T2-T5 sparsely shortly setose in posterior half. S2-S5 pale yellow, narrower than in male, finely densely setulose.

Postabdomen (Figs 62, 66). T6 large, only slightly tapered posteriorly, pale yellow except for dark band along posterior margin, densely setose. 56 very light, suboblong, about 1.5 times as broad as long, densely setose, with long setae at posterior and lateral margins. Tergosternum T7+S7 dorsomedially divided (Fig. 62), with dark dorsolateral areas reaching to ventral side; remnant of original $S 7$ small, rounded triangular and situated in posteromedial area between expanded (although pale) sides of T7, with about 6 ( 4 long) setae. T8 (Fig. 62) narrow, roughly pentagonal, with anteromedial corner most projecting and with triangular pigmentation. S8 (Fig. 66) short, with posteromedial cleft prolonged anteriorly to divide it medially, and with short setulae at posterior margin. Internal sclerotization of female genital chamber (Fig. 65) consisting of two pairs of posterior, pale and twisted sclerites (ventral pair substantially larger than dorsal pair which are closely attached medially) and 1 anterior, transverse, very poorly defined, looped sclerite. Ventral receptacle (Fig. 64) shortly subcylindrical, somewhat constricted near proximal end; duct moderate, finely granulose. Spermathecae $(1+1)$ elongately pyriform (Fig. 67), with small, slightly bent spines on surface set in oblique direction. T10 very pale except for dark lateral margins (Fig. 62), with a pair of long setae and sparse micropubescence on disc. S10 longer than T10, rounded triangular or slightly emarginate anteriorly, largely micropubescent (Fig. 66). Cerci relatively robust and ovoid, with rich moderate setae. 


\section{Discussion:}

The new species is best characterized by its setulose mesopleuron. The presence of mspl setulae in $S$. setipleurum should be regarded as an atavistic feature because the mesopleuron is bare in the representatives of the subfamily Anthomyzinae, with the exception of the Afrotropical apterous Apterosepsis basilewskyi Richards, 1962 in which $3 \mathrm{mspl}$ setulae are situated at the posterior margin of the mesopleuron (ROHÁčEK 1998: Fig. 23). Otherwise the setulose mesopleuron (with some longer mspl setae in addition) is only known in the fossil Protanthomyza collarti HeNnIG, 1965 (belonging to the ancestral subfamily Protanthomyzinae) and, therefore, this character is considered plesiomorphic within the family Anthomyzidae (RoHáčEK 1998). Interestingly, the female postabdominal characters of Apterosepsis (see ROHÁČEK 1998: Figs 28-32; male is unknown in this genus) are fairly similar to those of Stiphrosoma (except for completely fused and ringshaped $T 7+S 7$, simply ball-shaped spermathecae and differently formed internal looped sclerite) and, consequently, it cannot be excluded that this genus may also belong to the Stiphrosoma clade.

The relationships of $S$. setipleurum are not clear. The habitus and gonostylus look like those of $S$. balteatum, the armature of the saccus and the compact filum resemble those of the $S$. stylatum-group but the filum has a uniquely twisted apex with small subapical digitiform process. The female of $S$. setipleurum also bears several specific features, e.g. rather elongate shape of postabdomen, reduced internal looped sclerite, very characteristically spinose spermatheca (Fig. 67) and relatively robust cerci. Possibly, the Palaearctic $S$. cingulatum (Haliday, 1855) is the closest relative of S. setipleurum not only owing to identical colouration of head and thorax, but also because of very similar male genitalia (cf. hypandrium, transandrium and tuberculate armature of basal membrane, filum with small preapical process, aedeagal part of folding apparatus, female T8 and spermathecae (see RoHáčeK 1996: Figs 41-52).

\section{Biology:}

The largest series of this species were obtained by aspirating at the bases of various grasses. An attempt to localize a particular species of grass (Burlington, ON) was unsuccessful as the fly was present throughout the mosaic of a mixed graminoid assemblage on the side of a small urban stream (Phalaris, Bromus, Phleum, Poa, Elymus (=Agropyron)). It is also known from stands of Calamagrostis and Carex (Sault Ste. Marie, ON) and also from Elymus (LaFayette, IN). Many references to habitat features suggest damp soil or edges (Hoodplains?) of streams.

Large numbers can sometimes be flushed out of the thatch of these habitats including pairs in copula. S. setipleurum is often collected in association with $S$. balteatum and can be readily distinguished by the setose pleuron. The immature stages are not yet known and an initial attempt at rearing was not successful.

\section{Distribution:}

This is a fairly common species with a similar distribution to that of $S$. pectinatum but only reaching as far south as West Virginia. It should be emphasized that a concerted effort to find this species further west and north of Sault Ste. Marie (Ontario) has not been made. 


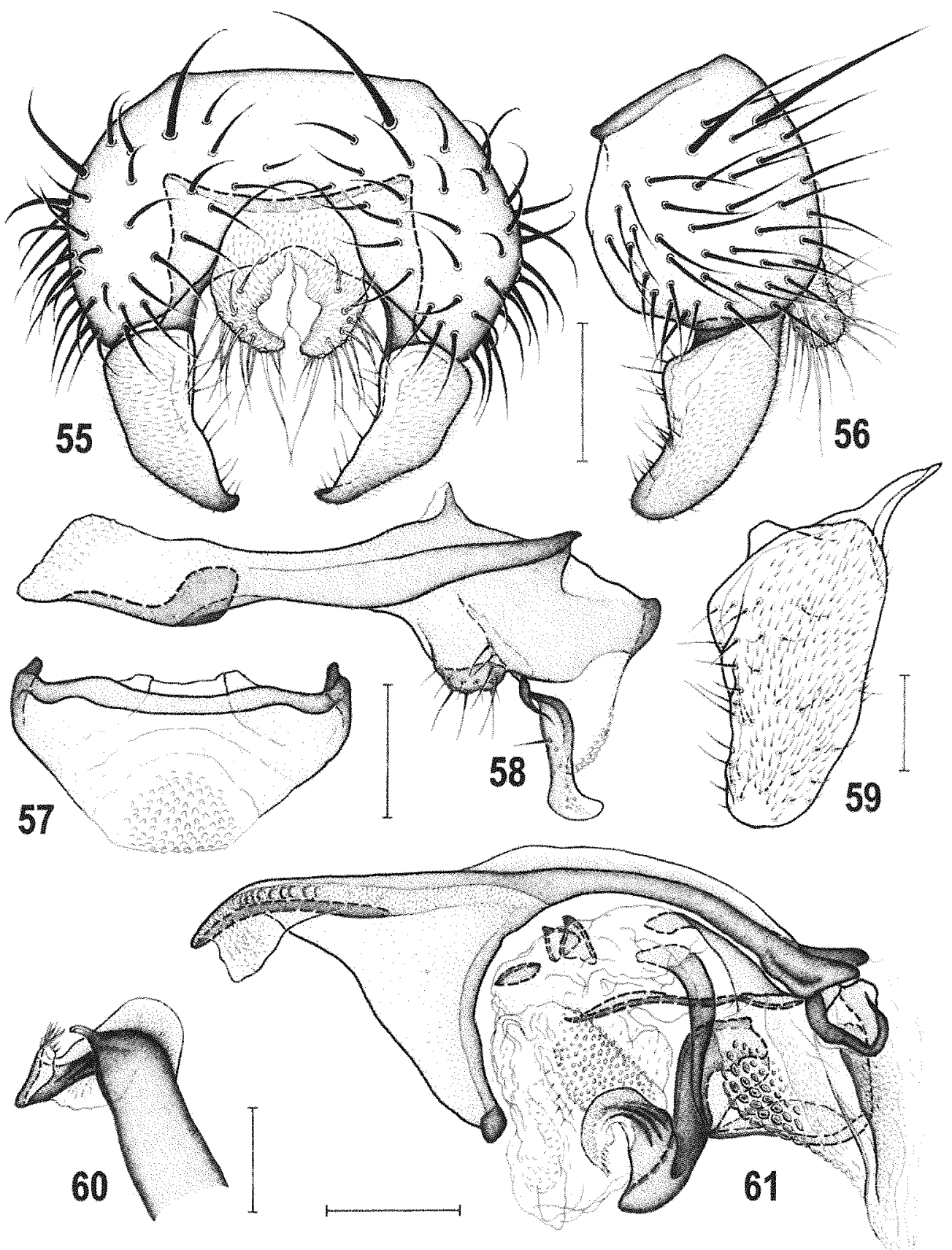

Figs 55-61: Stiphrosoma setipleurum sp. n., male paratype (Canada: Ontario). 55 - external genitalia caudally; 56 - ditto laterally; 57 - transandrium and basal membrane caudally; 58 - hypandrium and associated structures laterally; 59 - gonostylus posterolaterally (widest extension view); 60 - apex of flum ventrally; 61 - aedeagal complex laterally (ejacapodeme omitted). Scales: Figs $59-60=0.0 .5 \mathrm{~mm}$, others $=0.1 \mathrm{~mm}$. 


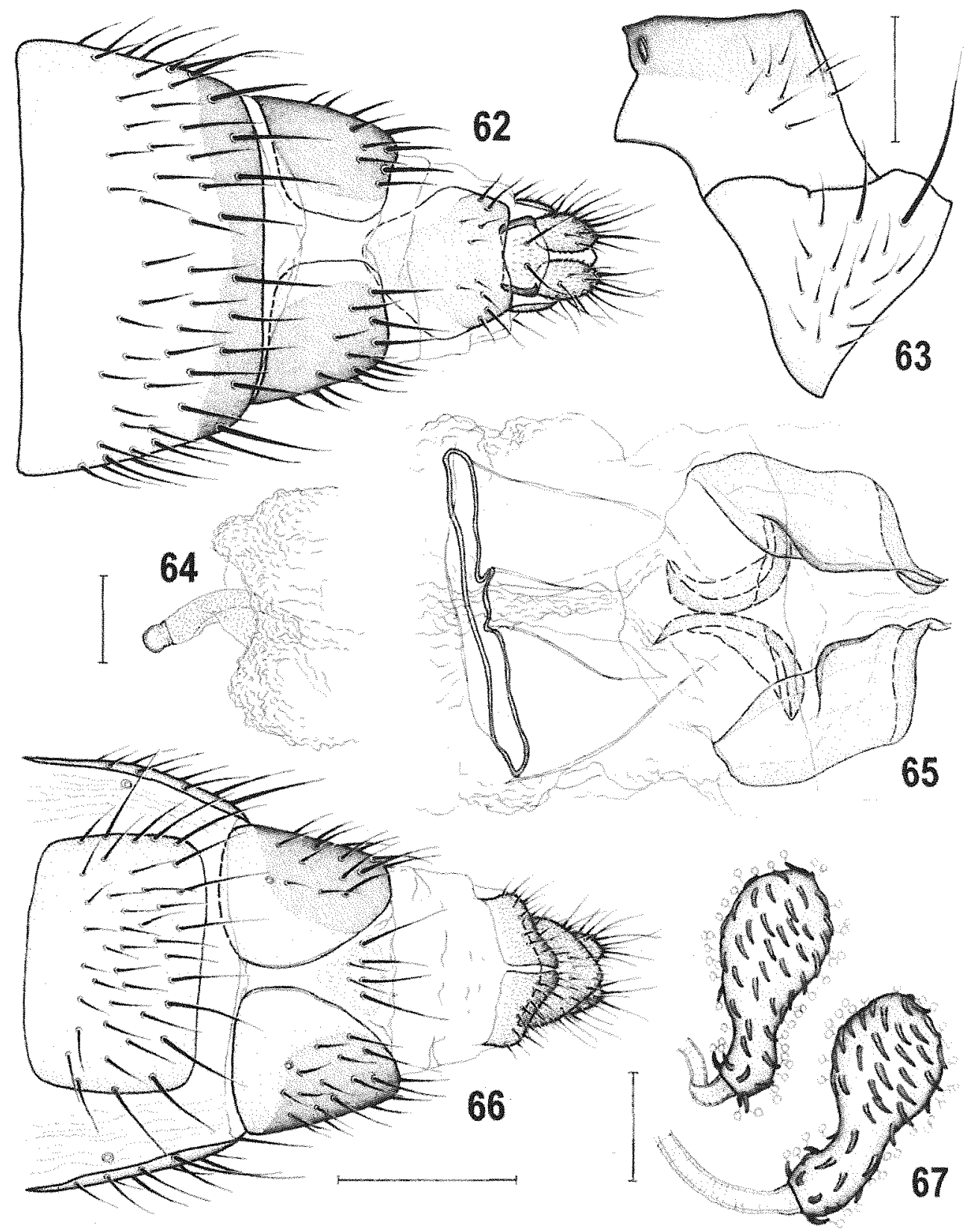

Figs 62-67: Stiphrosoma setipleurum sp. n., female paratype (Canada: Ontario). 62 - postabdomen dorsally; 63 - mesopleuron and sternopleuron laterally; 64 - ventral receptacle laterally; 65 - internal sclerites ventrally; 66 - postabdomen ventrally; 67 - spermathecae. Scales: Figs $62-63,66=0.2 \mathrm{~mm}$; others $=0.05 \mathrm{~mm}$. 


\section{Stiphrosoma balteatum sp. $\mathbf{n}$.}

(Figs 68-80, 194)

\section{Type material:}

Holotype male labelled: "ONT: Manitoulin Is., - $2.2 \mathrm{~km} \mathrm{~N} \mathrm{Cold} \mathrm{Springs,} \mathrm{Perch} \mathrm{Ck@}$ Hwy 540, 01.viii.1997, KNBarber, sweeps/pooter Calamagrostis canadensis, $45^{\circ} 53.2^{\prime} \mathrm{N}$ $82^{\circ} 06.3^{\circ} \mathrm{W}$ " (DEBU, intact). Paratypes: CANADA: Manitoba: $5 \mathrm{~km} \mathrm{~N}$ Gardenton, Tallgrass Prairie Reserve, $49^{\circ} 10.71^{\prime} \mathrm{N} 96^{\circ} 40.76^{\prime} \mathrm{W}$, pan traps in tallgrass prairie, $12-$ 17.viii.1999, 1 female, V. Crecco leg. (LEMQ). Ontario: Bruce Co., Tobermory, Parks Canada Office, $45^{\circ} 14.66^{\prime} \mathrm{N} 81^{\circ} 39.01^{\prime} \mathrm{W}$, 28.viii.2004, pooter, long grasses, 1 female (DEBU); Burlington, edge Tuck Ck., 4321.2'N 7946.6'W, sweeps/pooter, Bromus inermis, 15.vii.1997, 1 male, 16.vii.1997, 1 female, 16.viii.1998, 1 female (DEBU); same locality but 18.vii.1997, pooter, Phleum pratense, 1 male 1 female (DEBU); same locality but 20.vii.1997, pooter, Poa pratensis, 1 male 1 female (DEBU); same locality but 18.vii.1997, pooter, various grasses, 1 male 1 female (pair in copula) (DEBU); same locality but 14.vii.2002, pooter, mowed long grasses, 1 female (DEBU); same locality but pooter, Bromus inermis, 16.vii.1997, 1 female, 18.vii.1997, 1 male 1 female, 20.vii.1997, 1 male 4 females (DEBU); Burlington, Royal Botanical Gdn., $43^{\circ} 17.5^{\prime} \mathrm{N} 79^{\circ} 52.4^{\prime} \mathrm{W}, 16 . v i i .1997$, sweeps/pooter, Glyceria maxima, 6 females; same locality and date but sweeps/pooter, Calamagrostis canadensis, 1 male 1 female (DEBU); same locality and date but sweeps/ pooter, short grasses in marsh flats, 2 females (DEBU) all K. N. Barber leg.; Fathom 5 Nat. Park, Cove Is., sedge meadow, pan trap \#2, 25.vi-28.vii.1996, 1 female, T. Woodcock \& S. Marshall leg. (DEBU); Fergus, Grand R. floodplain, 17.vii.1997, sweeps/pooter, Phalaris arundinacea, $43^{\circ} 41.5^{\prime} \mathrm{N} 80^{\circ} 23.2^{\prime} \mathrm{W}, 1$ female (DEBU); same locality but $43^{\circ} 41.3^{\prime} \mathrm{N} 80^{\circ} 23.4^{\prime} \mathrm{W}, 17 . v i i i .1998$, pooter, graminoids, 1 male (DEBU) all K. N. Barber leg.; Fergus, Grand River, 30.vii.1994, riverside vegetation, 2 males, J. Roháček leg. (SMOC); Guelph, University Arboretum, 19.viii.1994, sifting grass and Carex tufts, 2 males 8 females, J. Roháček leg. (SMOC); Guelph, 3.vii.1979, 2 males, 4.vii.1979, 1 male 1 female (DEBU); same locality but 3.viii.1980, 1 female, 22.viii.1980, 1 female, 23.vii.1982, 1 male (DEBU); same locality but 1-20.vii.1982, Malaise trap, 1 male (DEBU) all K. N. Barber leg.; Halton Reg., Milton, Derry Rd. \& $4^{\text {th }}$ Line, grass field, yellow pans, 9-11.vii.2001, 1 female (DEBU - 00172125), 12-16.vii.2001, 9 females (DEBU - 00172027, 00172035, 00172068, 00172382, 00172389, 00172393, 00172427, 00172433, 00172436), 29.vii-5.viii.2001, 9 males 14 females (DEBU - 00172201, 00172214-18, 00172221-22, 00172225, 00172228, 00172230, 00172235, 00172237, 00172239-40, 00172250, 00172267, 00172269-71, 00172290-91, 00172303) all S. Paiero leg., 9-11.vii.2001, 1 male 1 female, S. M. Paiero leg. (DEBU - 00174883, 00174902); Kanata, 17.viii.1997, K. N. Barber, sweeps of low veg. on moist trail, 1 female (DEBU); same data as for holotype, 11 males 13 females (including 1 pair in copula) (DEBU, SMOC); same data but 4.vii.1999, 1 male 3 females (DEBU); Manitoulin Is., Conc. $6,0.5 \mathrm{~km}$ W Hwy 6, 45 37.2’ N 82 00.2'W, 28.vii.1997, pooter, Phalaris arundinacea, 6 males 2 females (DEBU); Manitoulin Is., $0.7 \mathrm{~km} \mathrm{~N}$ Michael's Bay Pk., $45^{\circ} 36.5^{\prime} \mathrm{N}$ $82^{\circ} 06.2^{\prime} \mathrm{W}, 28$.vii.1997, sweeps/pooter, graminoids in fen flat, 1 male (DEBU); Manitoulin

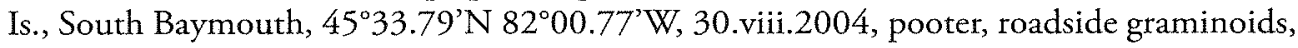
1 male 1 female (DEBU); Manitoulin Is., $3.3 \mathrm{~km}$ E Spring Bay, Hwy 542 @Tracy Rd., $45^{\circ} 43.90^{\prime} \mathrm{N} 82^{\circ} 16.48^{\prime} \mathrm{W}, 30 . v i i i .2004$, pooter, roadside/fenceline grasses, 1 male (DEBU) 
all K. N. Barber leg.; Marmora, 25.vi.1952, 1 male (CNCI); Ottawa, 12.vii.1956, 3 males 4 females, 12.vii.1964, 1 female (CNCI); same locality but 28.vi.1964, among grass roots, 1 female (CNCI) all J. R. Vockeroth leg.; Rondeau P[rovincial] Pk., Spicebush Trail, 4218'08”N 81 $51^{\prime} 13^{\prime \prime W}, 29 . v i i .2003$, sweeps, mostly Impatiens/Carex, 1 female (DEBU - 01500148); S[ault] S[te.] Marie, S. of Algoma U[niversity] College, 46 29.9'N $84^{\circ} 17.2^{\prime} \mathrm{W}, 5$.viii.2001, pooter, mostly Phalaris arundinacea, 2 females (DEBU); same locality but pooter, mostly Calamagrostis canadensis, 28.vii.2001, 2 females, 29.vii.2001, 2 males, 31.vii.2001, 1 female, 5.viii.2001, 2 females 2 males (DEBU); same locality but sweeps/pooter, Calamagrostis canadensis, 3.viii.1997, 1 male 1 female, 12.vii.2002, 3 females (DEBU); same locality but 31.vii.2002, sweeps, Carex aquatilis, 1 male (DEBU); same locality but 10.viii.2002, pooter, Carex/Calamagrostis, 1 male (DEBU); same locality but $46^{\circ} 29.88^{\prime} \mathrm{N} 84^{\circ} 17.19^{\prime} \mathrm{W}$, 4.viii.2003, pooter, Calamagrostis/Carex, 2 males 2 females (DEBU); same locality but 10.viii.2003, pooter, Carex aquatilis, 1 female (DEBU); same locality but 10.viii.2003, pooter, Calamagrostis, 1 female (DEBU); same locality but 26.viii.2003, sweeps, Carex aquatilis, 1 male (DEBU); same locality but pooter, mostly Carex aquatilis, 21.viii.2004, 5 males 8 females, 23.viii.2004, 4 males 11 females (DEBU); same locality but sweeps, trampled graminoids, mostly Carex aquatilis, 5.ix.2004, 10 males 2 females, 7.ix.2004, 1 male (DEBU); same locality but Lab-reared, Carex aquatilis, from 2 males 5 females - 4-18.viii.2002, pooter, C. aquatilis, [and various rearing data] Ovip: [date]2002, $10^{\circ} \mathrm{C} 3 . x i .2002,2^{\circ} \mathrm{C} 9 . x$ ii. $2002,20^{\circ}$ 17.iii.2003, Hatch: [date]2003, Puparium: [date]2003, Adult: [date]2003 [gender] 23 males 22 females (with puparium attached in gelatin capsule) (DEBU) all K. N. Barber leg.; S[ault] S[te.] Marie, Baseline

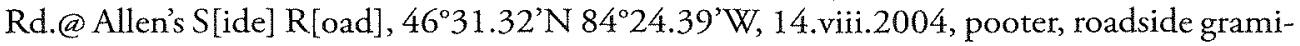
noids, 1 male (DEBU); S[ault] S[te.] Marie, Bristol PI. Pk., 46 30.8 $\mathrm{N} 84^{\circ} 16.6^{\circ} \mathrm{W}$, sweeps/ pooter, Phalaris arundinacea, 1.viii.1997, 4 males 7 females (including 1 double-mount), 8.viii.1997, 1 female (DEBU, SMOC); same locality but sweeps/pooter, Calamagrostis canadensis, 1.viii.1997, 2 females, 2.viii.1997, 2 males 3 female; same locality but 18.vii.1998, pooter, Calamagrostis canadensis, 1 male (DEBU); S[ault] S[te.] Marie, Finn Hill, $46^{\circ} 31.67^{\prime} \mathrm{N} 84^{\circ} 17.32^{\prime} \mathrm{W}$, pooter, Calamagrostis canadensis, 10.viii.2003, 39 males 43 females, 17.viii.2003, 8 males 7 females, 19.vii.2004, 12 males 9 females, 30.vii.2004, 5 males 6 females (DEBU, AMNH, CMNH, LEMQ, SMOC); same locality but $46^{\circ} 31.65^{\prime} \mathrm{N}$ 84ำ $17.34^{\prime} \mathrm{W}$, pooter, Carex stipata stipata, 30.vii.2004, 10 males 17 females, 4.viii.2004, 9 males 7 females (DEBU); same locality but $46^{\circ} 31.63^{\prime} \mathrm{N} 84^{\circ} 17.33^{\prime} \mathrm{W}, 19$. vii.2004, sweeps, Scirpus cyperinus, 3 males 2 females (DEBU); same locality but $46^{\circ} 31.63^{\prime} \mathrm{N} 84^{\circ} 17.33^{\prime} \mathrm{W}$, pooter, Carex stipata stipata, 20.vii.2004, 19 males 30 females, 21.vii.2004, 23 males 25 females, 22.vii.2004, 14 males 17 females, 23.vii.2004, 14 males 15 females, 25.vii.2004, 15 males 19 females (DEBU); same locality but 19.vii.2004, sweeps, Carex stipata stipata, 1 female (DEBU), same locality but $46^{\circ} 31.60^{\prime} \mathrm{N} 84^{\circ} 17.30^{\prime} \mathrm{W}$, pooter, Carex stipata stipata, 23.vii.2004, 1 male 1 female, 27.vii.2004, 5 females, (DEBU); samelocality but $46^{\circ} 31.57^{\prime} \mathrm{N}$ 84⒘22'W, 27.vii.2004, pooter, Carex stipata stipata, 6 males 3 females (DEBU); S[ault] S[te.] Marie, Hwy \#17 city limits, $46^{\circ} 36.58^{\prime} \mathrm{N} 84^{\circ} 17.83^{\prime} \mathrm{W}, 16 . v i i i .2004$, sweeps, Calamagrositis canadensis in wet area, 2 females (DEBU); $2 \mathrm{~km}$ E Sowerby, Hwy 17 @ Harris Ck., $46^{\circ} 17.6^{\prime} \mathrm{N} 83^{\circ} 21.3^{\prime} \mathrm{W}$, 1.viii.1997, sweeps, floodplain grasses, 1 female (DEBU) all K. N. Barber leg.; Essex Co., Windsor, Ojibway Prairie, burnt prairie, yellow pans, 10-13.vii.2001, 1 female (DEBU - 01114977); Windsor, Ojibway Prairie, burnt prairie, yellow pans, 25-28.ix.2001, 1 female (DEBU - 01113152) all S. M. Paiero leg. 
Quebec: Lac Phillipe, “ $45^{\circ} 37^{\circ} \mathrm{N} 76^{\circ} \mathrm{W}$ ”, 2.ix.1968, 1 female, J. R. Vockeroth leg. (CNCI); Old Chelsea, Summit King Mt., 1150', 15.vii.1965, Malaise trap, mounted from alcohol, 1 male, [-] leg. (CNCI); Ste.-Anne-de-Bellevue, Stoneycroft Pond, sweeping grass, $45^{\circ} 25.8^{\prime} \mathrm{N} 73^{\circ} 56.4$ 'W, 18.viii.2000, 1 female, J. Forrest leg. (LEMQ). USA: "MAS", sp.4, USNM, 1 female, [-] leg. (USNM). District of Columbia: Deanwood, 9.vi.1991, near brook, 5 males 6 females, M. Barták leg. (MBP, SMOC). Illinois: White Heath, 27.vi.1955, 1 female, M. R. Wheeler leg. (AMNH). Massachusetts: Catoctin, Mt. Park (Lantz), 15.vi.1991, edge of wood, 1 male 1 female, meadow nr. pond, 1 female, M. Barták leg. (MBP). Michigan: E. Lansing, 28.vii.1941, 1 female, B. Wilson leg. (USNM); Honor, 9.vii.1941, o*, 1 male, C. W. Sabrosky leg. (USNM); Livingston Co., 26.vii.1943, 1 female (USNM); Midland Co., 10.vii.1952, 1 female (USNM); Montcalm Co., 27.vi.1953, $0^{t}, 1$ male (USNM); Saginaw Co., 18.vi.1952, 1 female (USNM) all R. R. Dreisbach leg. New York: Roch[ester?], 30.vii.1942, 1 male, H. Stalker leg. (USNM). Ohio: Portage Co., Battaglia Bog, 4 mi. NE Kent, 19.vii.1999, swept from Carex oligosperma, 1 male, B. A. Foote leg. (CMNH). Tennessee: Cades Cove, GSMNP, sweeps, 2.vi.1979, 2 males (DEBU), 5.vi.1979, 8 males 10 females (DEBU, SMOC); Townsend, 2.vi.1979, sweeps, 1 male leg. (DEBU) all M. J. Sharkey leg. Wisconsin: Washburn Co., T39N R12W B33, 20.vii.1953, 1 male 1 female, R. H. Jones leg. (USNM). Several paratypes with genit. prep.

\section{Other S. balteatum material not designated as paratypes:}

CANADA: Ontario: Guelph, 3.ii.1979, 1 male, K. N. Barber leg. (DEBU); Halton Reg., Milton, Derry Rd. \& $4^{\text {th }}$ Line, 29.vii-5.viii.2001, grass field, yellow pans, 1 male, S. Paiero leg. (DEBU - 00172207), 27.viii-4.ix.2001, 2 males 2 females, S. M. Paiero leg. (DEBU - 00174921, 00174928-29, 00174932); Marmora, 16.vii.1952, 1 female (CNCI); Ottawa, 16.vii.1952, 1 female (CNCI) all J. R. Vockeroth leg.; Ottawa, [].x.1959, em[erged] [-].iii.1960, ex. larvae in stalks of Aster novale-]angliae, 1 female, E. Rockburne leg. (CNCI); S[ault] S[te.] Marie, S. of Algoma U[niversity] College, $46^{\circ} 29.9^{\prime} \mathrm{N} 84^{\circ} 17.2^{\prime} \mathrm{W}, 19 . v i i i .2002$, pooter, Carex aquatilis, used in lab-rearing, dead 30.x.2002, 1 male, killed 28.x.2002, 1 female, dead 22.x.2002, 1 female, killed 9.xi.2002, 2 females (DEBU); same locality but $46^{\circ} 29.88^{\prime} \mathrm{N} 84^{\circ} 17.19^{\prime} \mathrm{W}, 26 . v i i i .2003$, sweeps, Calamagrostis, 1 female (DEBU); S[ault] S[te.] Marie, Finn Hill, 46 $31.67^{\prime} \mathrm{N}$ $84^{\circ} 17.32^{\prime} \mathrm{W}$, pooter, Calamagrostis canadensis, 10.viii.2003, 1 female, 30.vii.2004, 1 male (DEBU); same locality but $46^{\circ} 31.63^{\prime} \mathrm{N} 84^{\circ} 17.33^{\prime} \mathrm{W}$, pooter, Carex stipata stipata, 23.vii.2004, 1 female, 25.vii.2004, 1 male 2 females (DEBU) all K. N. Barber leg. USA: Michigan: E. Lansing, 24.vii.1941, 1 male, B. Wilson leg. (USNM); Saginaw Co., 18.vi.1952, 1 male, R. R. Dreisbach leg. (USNM). Tennessee: Cades Cove, GSMNP, sweeps, 2.vi.1979, 3 males, 5.vi.1979, 6 males 7 females (including 1 pair in copula) (DEBU); Townsend, 2.vi.1979, sweeps, 1 female (DEBU) all M. J. Sharkey leg.

Etymology: The name refers to the transversely banded female preabdominal terga (balteatus $=$ L. belted $)$.

\section{Description:}

Male. Total body length 1.47-1.87 mm; bicolorous, yellow and brown. Head as long as high, largely yellow. Frons yellow, orbits paler and white microtomentose in anterior two-thirds; frontal triangle poorly delimited, reaching to anterior third of frons; ocellar 
triangle with brown spot between ocelli; occiput yellow, medially and ventrally lighter than laterally; face and mouthparts pale yellow, only proboscis ochreous to pale brown; parafacialia and gena white, silvery white microtomentose and narrowly orange-ochreous margined. Cephalic chaetotaxy: pvt small, crossed; vte slightly shorter than vti; vti and oc subequal and longest of cephalic setae; 2 ors, posterior almost as long as vti; anterior ors shorter than vte; 2 microsetulae in front of anterior ors, posterior twice longer than anterior; only 1-2 medial pairs of microsetulae in front of frontal triangle; vi strong and almost as long as vti; subvibrissa variable, always markedly shorter and weaker than vi; peristomal setulae (5-6), in single row; postgena with several setulae shorter than peristomals; postocular setulae minute and numerous, in single row. Eye subellipsoid; its longest (oblique) diameter 1.5-1.6 times as long as shortest; smallest genal height about 0.1 times as long as shortest eye diameter. Antenna yellow, somewhat darkened at anterior margin of 1 st flagellomere having long (slightly shorter than dorsal rays of arista) white cilia anteroventrally. Arista about 1.9 times as long as antenna, brown, moderately pectinate as in S. setipleurum.

Thorax slightly narrower than head, bicolorous. Mesonotum including scutellum largely yellow, with brown lateral vitta (Fig. 77), anteriorly reaching to level of hu, posteriorly extending to cover laterobasal corner of scutellum; humeral and notopleural areas pale yellow. Pleural part of thorax pale to whitish yellow except for dorsal brown longitudinal band extending from cervix to base of haltere. Mesonotum very sparsely microtomentose, subshining. Thoracic chaetotaxy: 1 small prs; 2 strong dc, anterior long though shorter than robust posterior $\mathrm{dc}$ which is longer than apical sc; $4-6 \mathrm{dc}$ setulae in front of anterior dc seta but hindmost of them sometimes markedly enlarged; ac microsetae variable in number, 4 rows on suture, posteriorly in 2 rows usually reaching to level of posterior dc; basal sc weaker and much shorter than anterior dc; sternopleuron sparsely setulose including a few setulae in dorsal half and with usual 2 stpl (posterior markedly longer) and 1 microseta in front of anterior stpl. Scutellum rounded triangular, with disc more or less flat (Fig. 77).

Legs yellow including tarsi, only apical tarsal segments with darkened distal third (distinctly paler than in $S$. setipleurum). $\mathrm{f}_{1}$ with strong ctenidial spine twice or more longer than width of $t_{1}$; mid basitarsus with small dark setula ventrobasally; $f_{3}$ with variable row of 12-18 posteroventral setae, $5-11^{\circ}$ of them in distal two-thirds short and thickened. $t_{3}$ with short ventroapical seta; hind basitarsus with 2-3 ventroproximal black setae (1-2 of them longer than ventroapical seta on $t_{3}$ ).

Wing (Fig. 194) with pale brownish membrane and veins. Costal spinulae well developed. $R_{2+3}$ long, sinuous, parallel to $C$, with apex upcurved to $C ; R_{4+5}$ slightly bent; $M$ almost straight. Discal $(\mathrm{dm})$ cell moderate, slightly widened distally; $r-m$ in basal third of $\mathrm{dm}$ cell. $\mathrm{CuA}_{1}$ slightly bent and almost reaching wing margin; $\mathrm{A}_{1}$ short, ending far from wing margin; alula narrow and anal lobe well developed. Wing measurements: length $1.42-2.05 \mathrm{~mm}$, width $0.47-0.64 \mathrm{~mm}, \mathrm{Cs}_{3}: \mathrm{Cs}_{4}=1.28-1.58, \mathrm{r}-\mathrm{mldm}-\mathrm{cu}: \mathrm{dm}-\mathrm{cu}=3.14-$ 3.89. Haltere with dirty white knob and darker yellowish stem.

Abdomen brown and yellow. T1-T3 brown, anteromedially narrowly to broadly pale yellow; T4 largely pale yellow, with broad brown band along lateral and posterior margins. T5 with broad brown band at posterior margin. Preabdominal sterna lightly yellow, becoming wider posteriorly, densely finely setulose. T6 reduced to short, pale, bare and 
band-like sclerite on right side. $\$ 6$ yellow but with narrow brown anterior margin and 2 (rarely more) setulae; S7 entirely yellow, with 2-3 setulae. S8 more setose, dark brown except for yellow area at anterior margin on its left side.

Genitalia. Epandrium (Figs 68-69) yellow, shorter than high and moderately broad, with relatively dense and strong setae, 2 pairs (dorsomedial and lateral) longer than others. Dorsal side of epandrium almost straight; anal fissure rounded triangular. Cercus (Figs 68-69) relatively small and slender. Medandrium (Fig. 68) moderate, weakly sclerotized. Gonostylus (Fig. 72) large, almost as long as epandrial height, tapered distally, with slightly concave anterior margin and apex bent inwardly; outer side micropubescent except for apical and anterior areas (Fig. 69), inner side with long setae. Hypandrium (Fig. 71) slender, weakly sclerotized, dilated posteriorly. Transandrium simple, slightly double sinuous; basal membrane ventrally with a narrow group of elongate tubercles (Fig. 70). Pregonite (Fig. 71) small but projecting ventrally, with about 8 fine setae; postgonite (Fig. 71) narrow, slightly bent, dark except simple membranous apex, with 1 long seta near middle. Aedeagal complex. Phallapodeme slender, with slightly widened apex, slender fulcrum and usual forked base. Aedeagal part of folding apparatus laterally with numerous lenticular tubercles; connecting sclerite long and finely granulose. Aedeagus (Fig. 74) with short, frame-like phallophore and robust distiphallus. Saccus voluminous, membranous and unarmed; its hyaline surface only finely tuberculate. Filum robust and dark, with long projection in distal third being connected with apex by flat membrane; distal third strongly bent and apex armed by 2 pointed processes and numerous small spines and teeth (Figs 73-74). Ejacapodeme pigmented, with simple digitiform projection.

Female. Similar to male unless mentioned otherwise. Total body length 1.74-2.66 mm. Frons usually with 1 , but sometimes with 2-3 pairs of microsetulae medially in front of frontal triangle. Proboscis usually darker, pale brown. $f_{3}$ without posteroventral row of short thickened setae. Wing measurements: length $1.74-2.46 \mathrm{~mm}$, width $0.57-0.81, \mathrm{Cs}_{3}$ $: \mathrm{Cs}_{4}=1.32-1.45, \mathrm{r}-\mathrm{m} \backslash \mathrm{dm}-\mathrm{cu}: \mathrm{dm}-\mathrm{cu}=2.75-4.09$.

Abdomen lighter than in male; preabdominal terga wider, largely pale yellow, all with brown stripe on posterior margins. $\mathrm{T} 1$ and $\mathrm{T} 2$ with posterior dark stripe usually medially interrupted or (in T2) narrowed; T3-T5 (and T6) with narrow posterior brown stripe complete, more rarely medially narrowed on T3. T2-T5 sparsely shortly setose in posterior third to half, otherwise bare. $\$ 2-\$ 5$ whitish yellow, becoming wider posteriorly (S5 largest), evenly finely densely setulose. (Note: Specimens freshly dried often have dark brown spots in pleural part of preabdomen below lateral margins of terga - these are caused by dark inner content of abdomen and are invisible in specimens preserved in alcohol or in abdomens cleared).

Postabdomen (Figs 75, 79). T6 large, long, posteriorly tapered, pale yellow with dark posterior margin and setose only in posterior half. $S 6$ light, relatively broad and transverse, widened posteriorly, finely setose. Tergosternum $\mathrm{T} 7+\mathrm{S} 7$ with unpigmented dorsomedial triangle (Fig. 75), dark dorsolaterally but pale yellow ventrally; its original S7 reduced to small posteromedial triangular area with only 2 pairs of weak setae. T8 (Fig. 75) narrow, suboblong with indistinct anterior margin, very pale, with dense small setae. S8 (Fig. 79) larger than T8, medially divided, shortly setulose. Internal sclerotization of female genital chamber (Fig. 78) consisting of two pairs of posterior, pale flat sclerites (ventral pair larger, complex, bipartite) and 1 anterior, transverse, relatively strong, 
looped sclerite. Ventral receptacle (Fig. 76) on short duct, subcylindrical with knob-like end, weakly sclerotized and indistinctly striated. Spermathecae $(1+1)$ pyriform (Fig. 80) with narrow proximal end, armed with long curved spines being transversely attached to surface on broad distal part. T10 small and transverse, pale with darkened lateral margins (Fig. 75), with a pair of long setae and very sparse micropubescence. S10 much longer than T10, rounded triangular, with posterior half micropubescent (Fig. 79). Cerci small but elongate and with rich moderate setae.

\section{Discussion:}

S. balteatum sp. n. strikingly resembles $S$. setipleurum in colouration, in similar chaetotaxies of head, thorax and legs (including strong ctenidial spine), and in epandrium, gonostylus, and divided female S8. However, these similarities are only indicative of the relationships of these two species - no distinct synapomorphy was found. S. balteatum differs from $S$. setipleurum not only by the bare mesopleuron but also by a number of features in the male and female genitalia. The most characteristic are the large saccus of distiphallus having only inconspicuous hyaline tubercles in membrane and the peculiar robust filum bearing a slender bent projection in apical third and distinctive spinulose apex; there are also distinct differences in the shape and pigmentation of the female $\mathrm{T} 7+57$, internal sclerites (see e.g. more robust looped sclerite) and spermathecae in contrast with the latter species.

\section{Biology:}

S. balteatum is the most commonly collected species of yellow Stiphrosoma in northeastern North America. Most records indicate an association with various graminoids (Calamagrostis, Phalaris, Bromus, Phleum, Poa, Carex) while the mixed collections with Impatiens are likely more suggestive of soil moisture preferences (see Biology under $S$. setipleurum). Of particular interest, is the direct evidence of rearing from larvae in stalks of Symphyotrichum (= Aster) novae-angliae. This composite occurs in similar open habitats to those of various graminoids mentioned here suggesting a wider potential host range available to this species and perhaps others or simply an opportunistic spillover to a sufficient host.

Laboratory rearing of $S$. balteatum successfully produced 44 individual adults from eggs obtained from wild-caught adults ( 2 males, 5 females) collected from the bases of Carex aquatilis (4-19.viii.2002). Two wild-caught females survived for the period of on or before 19.viii. to 9.xi. when they were killed and oviposition terminated representing a survival period of at least 82 days (likewise, data for 1 male -72 days, 2 females - 64 and 70 days, while 1 male and 1 female escaped). Oviposition was easily elicited in small cages inverted on moist, white sand and short sections of Carex aquatilis and continued through the period of 15.viii. to 26.x. However, unlike S. stylatum (see below), eggs obtained this way did not hatch even after several weeks at $20^{\circ} \mathrm{C}$, but fully embryonated larvae (movement of mandibles) could be seen through the chorions. This suggested an "egg" diapause so they were stepped down through lower temperatures $\left(10^{\circ} \mathrm{C}\right.$ for 36 days and $2^{\circ} \mathrm{C}$ for 98 days). Upon return to $20^{\circ} \mathrm{C}$, larvae hatched in 2-5 days (mean 3.7 \pm 0.1 s.e., $\mathrm{n}=44$ ). Subsequently, larvae were presented with moist sections of $C$. aquatilis (collected in autumn, frozen, then thawed and often softened with hot water). 


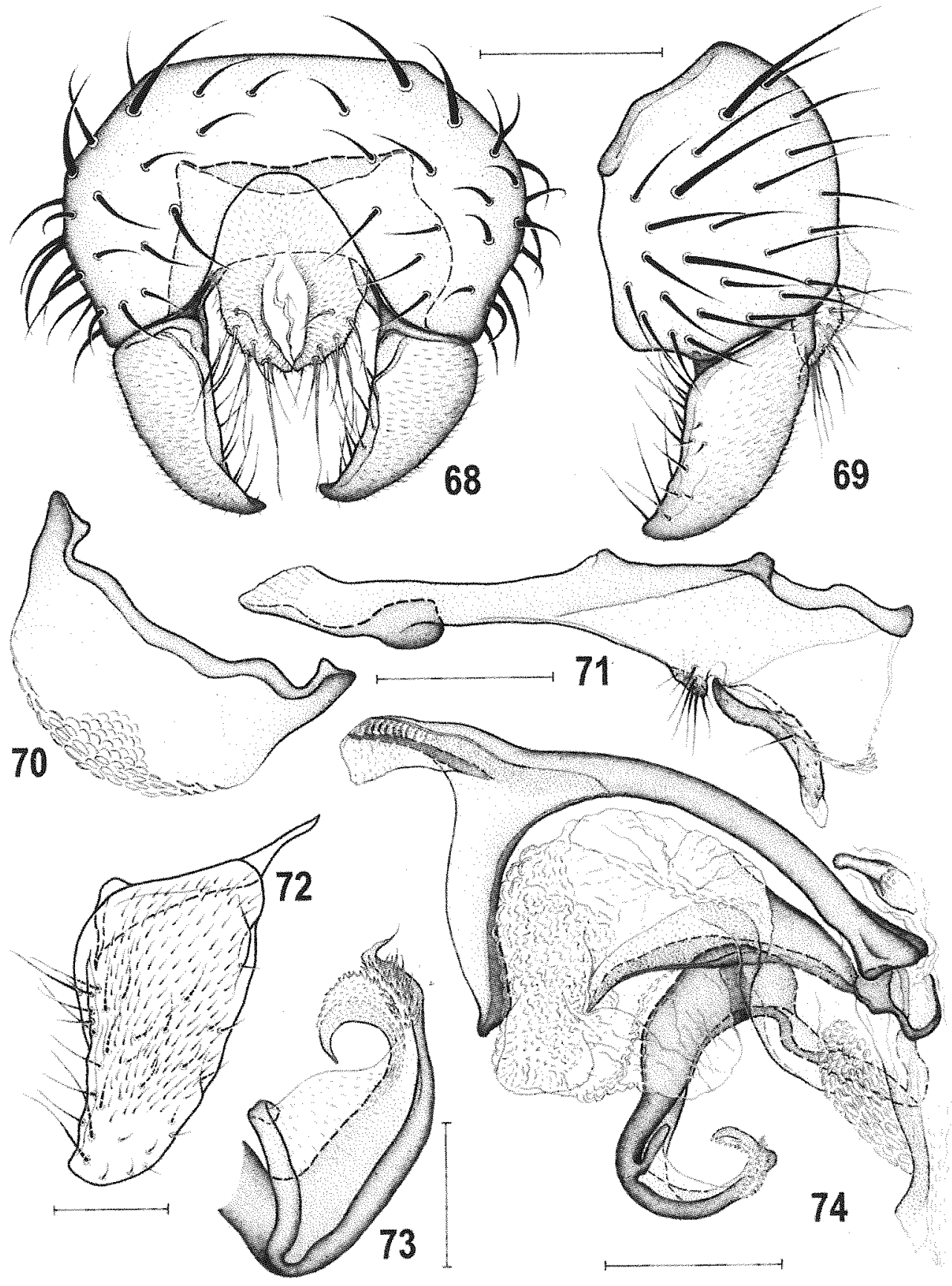

Figs 68-74: Stiphrosoma balteatum sp. n., male paratype (Canada: Ontario). 68 - external genitalia caudally; 69 - ditto laterally; 70 - transandrium and basal membrane caudally; 71 - hypandrium and associated structures laterally; 72 - gonostylus posterolaterally (widest extension view); 73 - apex of filum lateroventrally; 74 - aedeagal complex laterally. Scales: Figs $72-73=0.05 \mathrm{~mm}$, others $=0.1 \mathrm{~mm}$. 


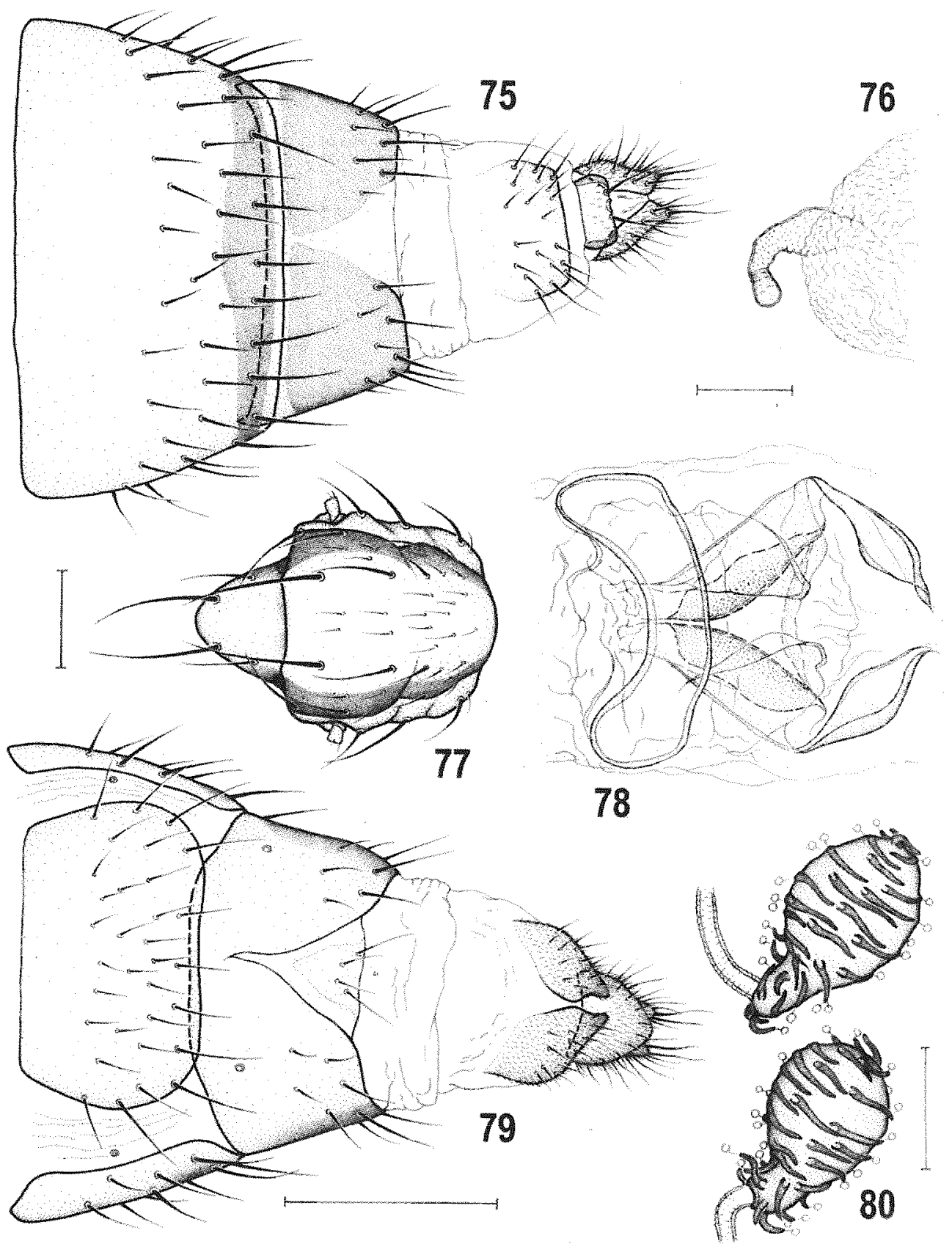

Figs 75-80: Stiphrosoma balteatum sp. n., female paratype (Canada: Ontatio). 75 - postabdomen dorsally; 76 - ventral receptacle laterally; 77 - thorax dorsally; 78 - internal sclerites ventrally; 79 - postabdomen ventrally; 80 - spermathecae. Scales: Figs $75,77,79=0.2 \mathrm{~mm}$; others $=0.05 \mathrm{~mm}$. 
Development from neonate larva to puparium required 18-27 days (mean 23.5 \pm 0.3 s.e., $\mathrm{n}=44$ ) while puparium to adult required $11-13$ days (mean $12.5 \pm 0.1$ s.e., $\mathrm{n}=44$ ). The gender ratio was nearly even $(23: 21)$. No attempts were made to compare the suitability of different graminoid leaf blades (e.g. Calamagrostis canadensis) as larval food but females would oviposit on them. The immature stages will be described at a later date.

Six specimens bear an unidentified parasitic mite ( 1 fly with 2 mites) on the dorsal surface of the abdomen (5 - Manitoulin Island, ON; 1 - Washburn Co., WI). Comparing the collections on Manitoulin Island, 5 of 41 specimens of $S$. balteatum bear a mite while 2 of the 57 specimens of $S$. setipleurum (1 with 3 mites) bear mites.

\section{Distribution:}

Another mostly eastern species, $S$. balteatum is not yet known from the maritime provinces of Canada but extends westward to Manitoba. It is known only as far south as Tennessee and west to Wisconsin in the United States.

\section{Stiphrosoma hirtum sp. n.}

(Figs 81-93, 195-205)

\section{Type material:}

Holotype male (f. brach.) labelled: „SK: Weyburn, 20.vii.1999, KNBarber, pooter, railside, Agropyron smithii, $49^{\circ} 39.5^{\prime} \mathrm{N} 103^{\circ} 51.1^{\prime} \mathrm{W}^{\prime \prime}$ (DEBU, intact). Paratypes (all f. brach. or intermediate forms unless noted otherwise): CANADA: Alberta: [loc.?], [-].vi.1971, ex. brome grass, CNC Lot.71-251, 2 females f. macropt., R. D. Dixon leg. (CNCI); Drumbeller, $51^{\circ} 27.5^{\prime} \mathrm{N} 112^{\circ} 42.2^{\prime} \mathrm{W}, 15 . v i i .1999$, pooter, railside Agropyron smithii, 1 male 3 females, K. N. Barber leg. (DEBU); Dunvegan, n. shore of Peace River, 13.vii.1997, sweep grasses at edge of agricultural field, 1 female f. macropt., (LEMQ); Dunvegan, $N$ shore of Peace River, 13.vii.1997, sweep grasses along agricultural field, 1 female (LEMQ) both T. A. Wheeler leg.; Ft. Edmonton Pk., 53³0.3'N 11334.2'W, 14.vii.1999, pooter, sidewalk $A$. smithii/B. inermis, 2 males 13 females 5 females $\mathrm{f}$. macropt., K. N. Barber leg. (DEBU, SMOC); $4 \mathrm{~km}$ SE Grimshaw, 13.vii.1997, sweep vegetation at edge of wheat field, 2 females f. macropt., S. Boucher leg. (LEMQ); Hanna, 51 38.1'N 111 $56.4^{\circ} \mathrm{W}$, 16.vii.1999, pooter, roadside Agropyron smithii, 2 males 2 females, K. N. Barber leg. (DEBU); High Prairie, 17.vii.1961, 2 females, A. R. Brooks leg. (CNCI); Lancaster Park, 28.vii.1963, 2 males 1 female 2 females f. macropt., J. R. Vockeroth leg. (CNCI);

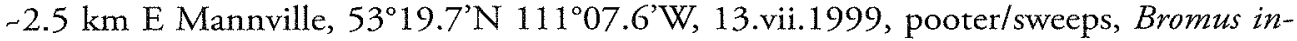
ermis, 3 females, K. N. Barber leg. (DEBU). Manitoba: $13 \mathrm{~km}$ E Erickson, 31.vii.1983, 6 males 43 females 3 females f. macropt. (DEBU) 5 males 5 females (CNCI); $19 \mathrm{~km}$ SE Gladstone, Hwy \#16, 5009.3'N 9841.9'W, 11.vii.1999, roadside sweeps/pooter, B. inermis/A. smithii, 1 female 1 female f. macropt. (DEBU); $10 \mathrm{~km} \mathrm{E} \mathrm{Neepawa,} \mathrm{Hwy}$ $\# 16,50^{\circ} 13.5^{\circ} \mathrm{N} 99^{\circ} 18.1^{\prime} \mathrm{W}, 11$.vii.1999, roadside, pooter, $B$. inermis / A. smithii, 1 male (DEBU); Prevda, Jct. Hwys. 1 \& 506, 25.vii.1994, base of Agropyron smithii, 3 males 9 females (DEBU); $3 \mathrm{~km}$ E Souris@RR crossing, 24.vii.1994, base of Agropyron smithii, 2 males 4 females 2 females f. macropt. (DEBU) all K. N. Barber leg. Ontario: $5 \mathrm{~km} \mathrm{NW}$ Dinorwic, Jct. Hwys. $17 \& 77$, side of rail bed, 26.vii.1994, base of Agropyron smithii, 2 females (DEBU); $40 \mathrm{~km}$ S Ignace, Hwy\#17, 49 15.6' $\mathrm{N} 91^{\circ} 07.9^{\circ} \mathrm{W}, 10 . v i 1.1999$, sweeps/ 
pooter, roadside, Agropyron smithii, 4 males 4 females 2 females $\mathrm{f}$. macropt. (DEBU, SMOC) all K. N. Barber leg.; Iroquois Falls, among grass roots, 5.vii.1987, 1 female, 6.vii.1987, 1 female 1 female f. macropt., J. R. Vockeroth leg. (CNCI); Manitoulin Is., -2.2 km N Cold Springs, Perch Ck. @ Hwy 540, 4553.2'N 8206.3'W, 1.viii.1997, sweeps/pooter, Calamagrostis canadensis, 1 female (DEBU); Rossport, base of Agropyron smithii, 26.vii.1994, 1 male 5 females 2 females f. macropt., 28.viii.1995, 1 female, 5.viii.1996, 1 female (DEBU); S [ault] S[te.] Marie, Finn Hill, $46^{\circ} 31.67^{\prime} \mathrm{N} 84^{\circ} 17.32^{\prime} \mathrm{W}$, pooter, Calamagrostis canadensis, 10.viii.2003, 5 males 9 females, 17.viii.2003, 1 female, 19.vii.2004, 2 males 3 female (DEBU); same locality but $46^{\circ} 31.65^{\prime} \mathrm{N} 84^{\circ} 17.34^{\prime} \mathrm{W}$, 30.vii.2004, pooter, Carex stipata stipata, 1 female (DEBU) all K. N. Barber leg. Saskatchewan: Antler @ RR crossing, 24.vii.1994, base of Agropyron smithit, 3 males 19 females 3 females f. macropt., K. N. Barber leg. (DEBU); Assiniboia, on ground among grass roots, 25.vi.1955, 2 males 1 female 2 female f. macropt., 26.vi.1955, 4 males 22 females 6 female f. macropt., J. R. Vockeroth leg. (CNCI); North Battleford, 13.vii.1999, 52 $45.7^{\prime} \mathrm{N} 108^{\circ} 17.4^{\prime} \mathrm{W}, 1$ male 1 female (DEBU); $-15 \mathrm{~km}$ W Rosetown, Hwy.7@RR crossing, 19.vii.1994, grasses incl. Agropyron smithii, 5 males 20 females 2 females f. macropt. (DEBU); Saskatoon, 20.vii.1994, base of Agropyron smithii, 38 males 129 females 8 females f. macropt. (DEBU, AMNH, CASC,EMUS, LEMQ, SMOC, USNM) all K. N. Barber leg.; Sturgis, 51 ${ }^{\circ} 56^{\prime} \mathrm{N} 102^{\circ} 32^{\prime} \mathrm{W}$, 1.vii. 1955,5 males 4 females 11 females f. macropt., J. R. Vockeroth leg. (CNCI); Weyburn, RR station, 24.vii.1994, base of Agropyron smithii, 1 male 15 females 5 female f. macropt. (DEBU); same data as for holotype, 8 males 5 females 10 females f. macropt. (DEBU, SMOC) all K. N. Barber leg.; Willow Bunch, 29.vii.1955, 9 females, A. R. Brooks leg. (CNCI). USA: Colorado: Steamboat Springs, el. 6300 feet, 15.viii.1948, 1 female, "Bryant Lot." [leg.?] (CASC); Deckers, 24.viii.1950, 1 female, M. R. Wheeler leg. (AMNH). Minnesota: $-6.5 \mathrm{~km}$ W Deer River, Hwy \#2, mi. 164, 47 19.7’ N 93⒌2'W, 22.vii.1999, pooter, railside A. smithii, 3 females, K. N. Barber leg. (DEBU). Montana: Bozeman, Mont. Exp. Sta., 1.vii.1916, 3 males 2 females 2 females f. macropt. (2 with Anthomyza pallida Zett. Det. H.L.S.), [-] leg. (USNM). North Dakota: $-9.3 \mathrm{~km}$ E Leeds, $48^{\circ} 16.8^{\prime} \mathrm{N} 99^{\circ} 18.5^{\prime} \mathrm{W}$, 21.vii.1999, pooter, roadside Agropyron smithii, 1 male 1 female f. macropt. (DEBU); $9 \mathrm{~km}$ N Bowbells, $48^{\circ} 53.7^{\prime} \mathrm{N} 102^{\circ} 15.1^{\prime} \mathrm{W}$, pooter, roadside Agropyron smithii, 1 female (DEBU) all K. N. Barber leg. Utah: Cache Co, W. Hodges Canyon, 28-31.vii.1978, 1 female f. macropt., Hanson, Knowlton leg. (EMUS). Some paratypes with genit. prep.

\section{Other $S$. hirtum material examined but not designated as paratypes:}

CANADA: Lancaster Park, 28.vii.1963, 2 males 6 females, J. R. Vockeroth leg. (CNCI). Ontario: $40 \mathrm{~km} \mathrm{~S}$ Ignace, Hwy\#17, $49^{\circ} 15.6^{\circ} \mathrm{N} 91^{\circ} 07.9^{\prime} \mathrm{W}, 10 . v i i .1999$, sweeps/pooter, roadside, Agropyron smithii, 1 male (abdomen missing), K. N. Barber leg. (DEBU). Saskatchewan: Assiniboia, on ground among grass roots, 25.vi.1955, 1 female, 26.vi.1955, 2 females, J. R. Vockeroth leg. (CNCI); Saskatoon, 20.vii.1994, base of Agropyron smithii, 1 male 1 female (DEBU); same data as for holotype, 1 female (DEBU) all K. N. Barber leg. USA: Montana: Bozeman, Mont. Exp. Sta., 1.vii.1916, 1 male 2 females 1 female f. macropt. (USNM).

Etymology: The species is named for its densely setose male abdominal sterna (hirtus = L. bristly). 


\section{Description:}

Male. Total body length $1.75-1.91 \mathrm{~mm}$; general colour yellow to pale ochreous-yellow. Head about as long as high. Frons yellow, with orbits yellowish white; frontal triangle narrow, reaching anterior half to third of frons, whitish microtomentose but slightly glittering in contrast to dull, dark yellow stripes between frontal triangle and orbits. Face (prefrons) and ventral margin of gena dark or ochreous-yellow; parafacialia and gena yellowish white. Occiput with a pair of convergent, whitish micropubescent stripes. Mouthparts yellow. Cephalic chaetotaxy: pvt small, strongly crossed; vti slightly longer than vte; 2 long ors, posterior almost as long as vti; 1-2 microsetulae in front of anterior ors; oc slightly divergent and even longer than ors; only 1 pair of microsetulae medially, in front of frontal triangle; subvibrissa slightly to distinctly shorter than vi; 3-5 (usually 4) peristomal setulae; postocular setulae minute, in single row. Eye with longest diameter about 1.5 times as long as shortest; gena narrow, its smallest height $0.12-0.13$ times as long as shortest eye diameter. Antenna yellow; 1 st flagellomere usually paler and with long white cilia on anteroventral margin. Arista about 1.7 times as long as antenna, blackish except for basal segments, shortly pectinate.

Thorax slightly (intermediate forms) to distinctly (f. brach.) narrower than head, yellow to ochreous yellow, only a narrow medial stripe in anterior half of mesonotum and small spots around anterior spiracle and below wing base dark ochreous. Mesonotum slightly shining. Thoracic chaetotaxy: prs reduced to microseta; 2 long postsutural dc, anterior shorter than posterior; 3-4 dc microsetae in front of anterior dc; ac microsetae forming 2 rows between $\mathrm{dc}$ (rarely with 1-2 additional microsetae between anterior dc), extending to level of posterior dc but sometimes shorter; basal sc short and weak, apical sc only slightly shorter than posterior dc; 2 stpl, anterior weak and half or less of length of strong posterior stpl; $1-3$ additional setulae in dorsal half of sternopleuron, sometimes $1 \mathrm{mi-}$ croseta also in front of anterior stpl; its ventral part with usual hair-like setae. Scutellum subtriangular, dorsally slightly convex.

Legs pale yellow. $f_{1}$ with small ctenidial spine being slightly shorter than maximum width of $t_{1}$ and with usual posteroventral and posterodorsal rows of thin setae. $f_{3}$ with a long row of short posteroventral setae (14-16), those in distal half more or less thickened. $t_{3}$ without ventroapical seta and hind basitarsus with only fine setulae ventroproximally (Fig. 89).

Wing polymorphic (Figs 201-205). Macropterous form unknown in male sex. Male wing usually strongly shortened, narrowed and apically acute (f. brach.) or somewhat longer but also narrow and with straight posterior margin (intermediate forms - Figs 204-205). All longitudinal veins complete. $C$ with enlarged setulae between $R_{1}$ and $R_{2+3}$; Sc distinct in most reduced wings; $R_{2+3}$ slightly bent or sinuous; $R_{4+5}$ straight or slightly bent; $M$ distally more or less bent posteriorly; $\mathrm{r}-\mathrm{m}$ in basal third to middle of $\mathrm{dm}$ cell; $\mathrm{dm}$-cu usually absent in $\mathrm{f}$. brach. but often present in intermediate forms. CuA almost reaching wing margin but $A_{1}$ very shortened. Alula and anal lobe strongly reduced. Wing measurements ( $\mathrm{f}$. brach. and intermediate forms): length 0.81-1.67 mm, width 0.18$0.51 \mathrm{~mm}, \mathrm{Cs}_{3}: \mathrm{Cs}_{4}=1.55-2.11, \mathrm{r}-\mathrm{mldm}-\mathrm{cu}: \mathrm{dm}-\mathrm{cu}$ (if dm-cu is present) $=3.11-3.75$. Haltere yellowish white, in $\mathrm{f}$. brach. small.

Abdomen yellow to pale ochreous, at most T3-T5 with somewhat darker ochreous posterolateral margins. T2-T5 with relatively long and dense setosity. T5 reduced, submem- 
branous and bare. S2-S5 becoming wider posteriorly and provided with dense short setae being strikingly thicker in posteromedial areas (Fig. 93). Postabdominal sterna darker yellow, 56 with ochreous brown anterior margin and, like S7, bare; S8 long, with evenly distributed setae.

Genitalia. Epandrium (Figs 81-82) slightly higher and much broader than long, with relatively long and dense setae, 1 dorsomedial pair longer than others. Dorsal side of epandrium slightly convex; anal fissure oval. Cercus (Figs $81-82$ ) relatively small in comparison with epandrium. Medandrium (Fig. 81) large and weakly sclerotized. Gonostylus (Fig. 86) of medium size, with rather straight anterior margin, convex posteriorly and with rounded ventral corner; outer side of gonostylus micropubescent except for anterior and apical areas; longest setae concentrated on inner side anteriorly. Hypandrium (Fig. 83) moderate, weakly sclerotized except for dorsal part and ventromedial swelling. Transandrium simple, slightly bent; basal membrane ventrally provided with numerous transverse tubercles. Pregonite (Fig. 83) angularly projecting and distally dark, with a cluster of 11-13 setulae; postgonite slightly bent, well sclerotized and pigmented except for light, dilated but flat apex, with 1 distinct seta at middle of anterior margin (Fig. 83). Aedeagal complex. Phallapodeme with laterally widened apex and broad, shortly forked base. Aedeagal part of folding apparatus laterally sculptured by rounded flat excrescences and tubercles; connecting sclerite distinct, finely granulose. Aedeagus (Fig. 85) with small frame-like phallophore; distiphallus composed of voluminous, membranous saccus provided with numerous hyaline tubercles and flat spines and several pigmented spines ( 3 in apical half and 3 basally) and relatively slender, but heavily sclerotized filum. Distal end of filum twisted, dilated and its apex armed by several teeth and very fine spinulae (Figs 84-85). Ejacapodeme pigmented, with characteristically dilated apex (capitulum) of digitiform projection.

Female. Similar to male unless mentioned otherwise. Total body length $2.06-2.54 \mathrm{~mm}$ (macropterous specimens larger on average). $f_{1}$ with ctenidial spine usually distinctly longer, as long as or slightly longer than maximum width of $t_{1} ; f_{3}$ without posteroventral row of short thickened setae. Wing more polymorphic than in male, ranging from strongly brachypterous to macropterous forms. Brachypterous and intermediate forms (Figs 195-198) as described for male. Macropterous form with wing fully developed though distinctly smaller than in other normally winged species of Stiphrosoma. $\mathrm{R}_{2+3}$ slightly bent posteriorly; $\mathrm{R}_{4+5}$ and $\mathrm{M}$ very slightly convergent distally; $\mathrm{dm}$ cell long, with $\mathrm{r}-\mathrm{m}$ situated near its proximal third; dm-cu present (Figs 199-200) or absent as in $S$. artum. $\mathrm{CuA}_{1}$ and $\mathrm{A}_{1}$ well developed but not reaching wing margin. Wing measurements (f. macropt.): length 1.51-1.87 mm, width 0.53-0.68, $\mathrm{Cs}_{3}: \mathrm{Cs}_{4}=1.68-2.28, \mathrm{r}-\mathrm{mldm}-\mathrm{cu}$ : $\mathrm{dm}-\mathrm{cu}$ (if dm-cu is present) $=3.27-3.84$. Wing measurements (f. brach. and intermediate forms): length $0.87-1.59 \mathrm{~mm}$, width $0.18-0.47, \mathrm{Cs}_{3}: \mathrm{Cs}_{4}=1.41-2.54, \mathrm{r}-\mathrm{mldm}-\mathrm{cu}$ : $\mathrm{dm}-\mathrm{cu}$ (if dm-cu is present) $=3.00-4.40$.

Abdomen. Preabdominal terga wider, transverse; sterna narrower. T3-T5 with distinct transverse brownish stripes at posterior margins being medially narrowly (T5) to broadly (T3 in particular) interrupted; sometimes posterior margin of T2 also darkened.

Postabdomen (Figs 87, 92) ochreous yellow. T6 large, posteriorly narrowed and densely setose. 56 much smaller and narrower that that of $S$. artum, suboblong, posteriorly slightly wider than anteriorly. Tergosternum $T 7+S 7$ seemingly divided (unpigmented) dorsomedially (Fig. 87), ventrally embedding spiracles (Fig. 92); its ventromedial part 
(corresponding to original S7) subtriangular, pale, poorly delimited, with only 2 pairs of setae. T8 (Fig. 87) rounded triangular with angularly tapered anterior corner and distinctly triangular pigmentation and with setae in posterior half. S8 (Fig. 92) as usual in the genus, short, with narrow posteromedial cleft and short setulae. Internal sclerotization of female genital chamber (Fig. 91) consisting of two pairs of posterior bent sclerites attached to $S 8$ and 1 anterior, transverse, looped sclerite. Ventral receptacle (Fig. 90) weakly sclerotized, rounded subcylindrical with surface finely transversely striated, borne on short duct. Spermathecae $(1+1)$ slender, elongately pyriform (Fig. 88), with narrow proximal part provided with dark, slender projecting spines, and broad distal part having these spines transversely attached to surface. T10 short and transverse (Fig. 87), with a pair of long setae and without micropubescence. S10 longer than T10, rounded pentagonal, with posterior two-thirds micropubescent (Fig. 92). Cerci conical, relatively short and with rich but short setae.

\section{Discussion:}

Stiphrosoma hirtum sp. $\mathrm{n}$. is a wing-polymorphic species having the brachypterous form predominant in the majority of populations. Previously, in the genus Stiphrosoma, only $S$. sabulosum has been known to have a brachypterous form. However, $S$. hirtum sp. n. (and $S$. artum sp. n. described below) differs dramatically from $S$. sabulosum by yellow colour, complete longitudinal veins (even in strongly reduced wings) and postabdominal characters. $S$. hirtum and $S$. artum form a sister-pair of closely allied species as is demonstrated by almost identical appearance and similar male genitalia and female postabdomen. However, $S$. hirtum is clearly the more advanced of these two judging from the modified male sternal chaetotaxy, postgonite, ejacapodeme and spermathecae. $S$. hirtum can be recognized from $S$. artum safely only by distinctly shorter ctenidial spine (particularly in male), hind tibia without ventroapical seta, fine ventral setae on hind basitarsus, male preabdominal sterna with dense thickened setae and bare male S6 and S7. There are further diagnostic features in the male genitalia - shorter and wider gonostylus, longer postgonite with dilated apex, distinctive armature of saccus, form of apex of filum etc. and also in female postabdomen - $S$. hirtum has distinctly smaller S6, few setae on remnant of S7 and slender, elongate spermathecae.

\section{Biology:}

S. hirtum seems to be a common terricolous species in western Canada associated with the grass Pascopyrum (= Agropyron) smithii where it occupies the lowest stratum close to the ground. This generalization is at least partly an artifact of the concentration of sampling on this common and distinctive western grass that can be identified from a car window in an effort to compile distributional data. Bromus inermis also commonly grows with $P$. smithii and yields specimens of $S$. hirtum but at an apparently lower rate. Subsequent collections in central Ontario have implicated Calamagrostis canadensis as a potential host plant in habitats which do not support $P$ smithii (Sault Ste. Marie - Finn Hill, Manitoulin Island - Perch Creek) or B. inermis. The record from Carex stipata stipata is from a meadow habitat where this sedge grows in conjunction with $C$. canadensis and other graminoids. Searches were directed at the base of this sedge but there is a high probability of lateral movement from the grass. Rarely, S. hirtum can be taken with sweeps of appropriate habitat (not reflected in label data - Rosetown, SK). 

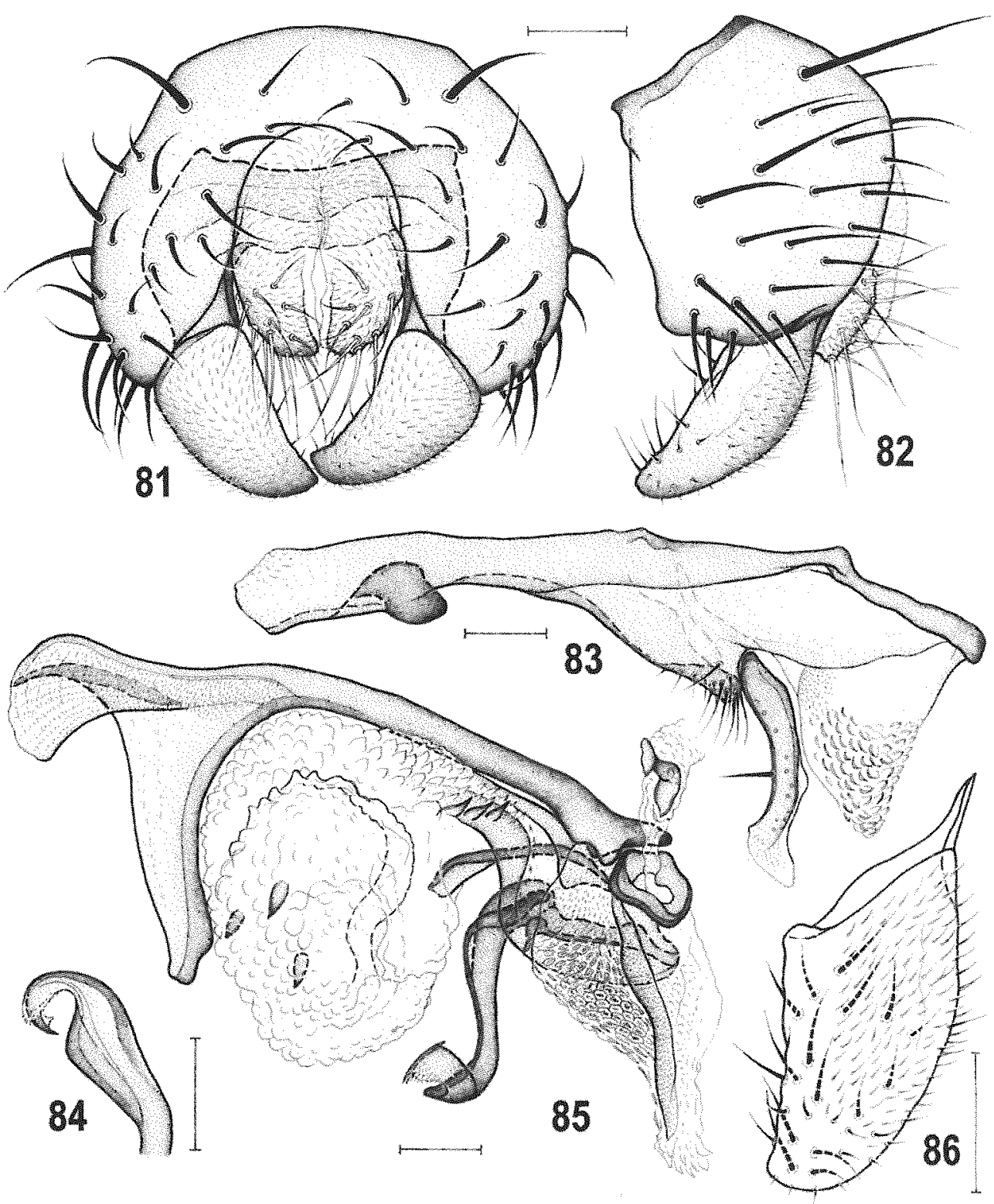

Figs 81-86: Stiphrosoma hirtum sp. n., male paratype (Canada: Saskatchewan). 81 - external genitalia caudally; 82 - ditto laterally; 83 -- hypandrium and associated structures laterally; 84 - apex of filum lateroventrally; 85 - aedeagal complex laterally; 86 - gonostylus posteroventrolaterally (widest extension view). Scales $=0.05 \mathrm{~mm}$. 


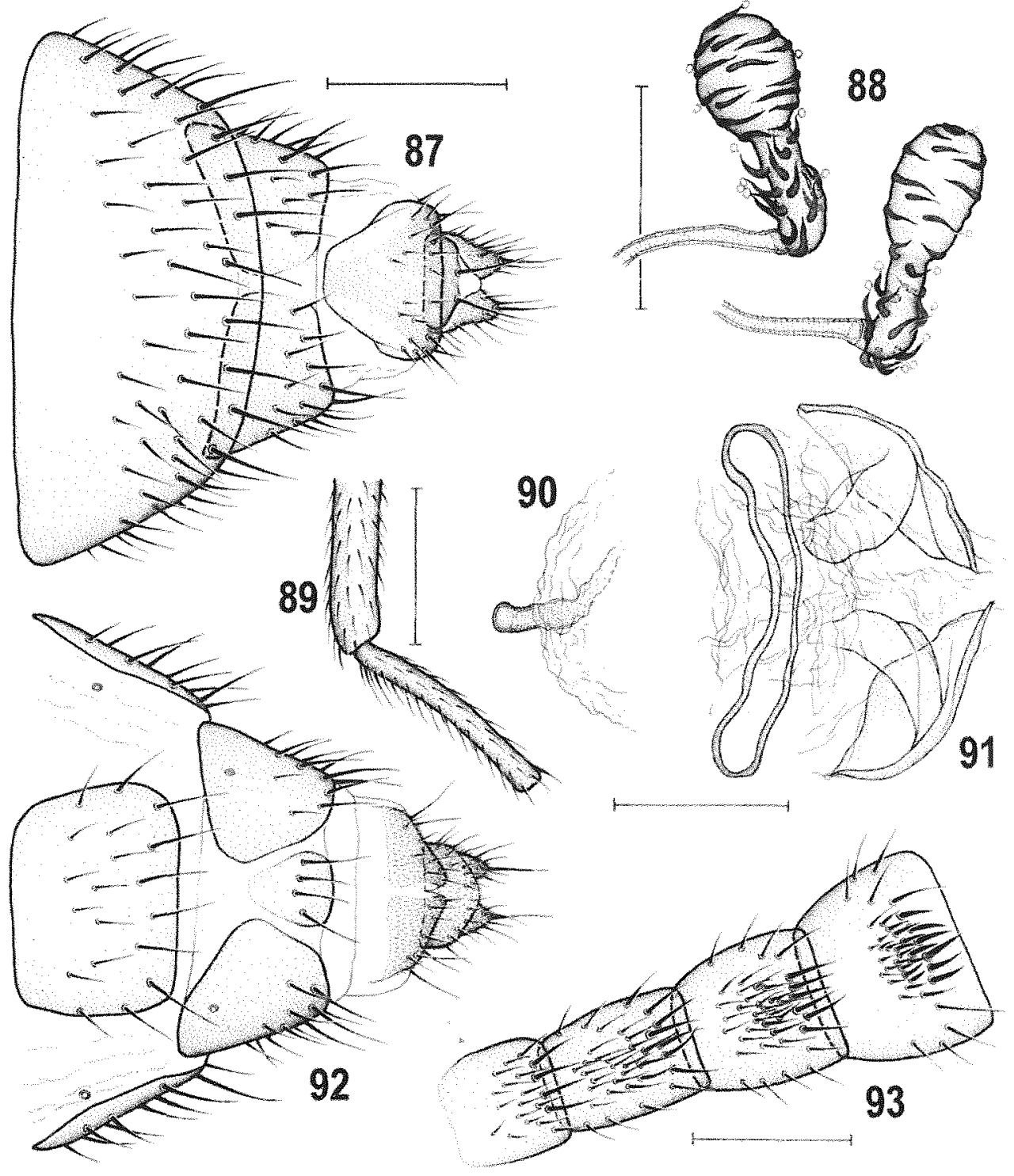

Figs 87-93: Stiphrosoma hirtum sp. n., male (93) and female (87-92) paratypes (Canada: Saskatchewan). 87 - female postabdomen dorsally; 88 - spermathecae; 89 - apex of $\mathrm{t}_{3}$ and hind basitarsus posteriorly; 90 - ventral receptacle laterally; 91 - internal sclerites ventrally; 92 - postabdomen ventrally; 93 - male S2-S5 ventrally. Scales: Figs $88,90-91=0.1 \mathrm{~mm}$; others $=0.2 \mathrm{~mm}$. 
S. hirtum has been collected with other species of Stiphrosoma including S. artum (SK), S. balteatum, S. sabulosum, S. humerale, and $S$. setipleurum (ON). It seems reasonable to consider $S$. hirtum as the primary species in well drained grassland in the west while the eastern equivalent is a combination of $S$. sabulosum, $S$. balteatum and $S$. setipleurum in what are usually moister soils where $S$. hirtum is less common.

\section{Distribution:}

Known from Canada (Alberta, Manitoba, Ontario, Saskatchewan) and the United States (Colorado, Minnesota, Montana, North Dakota, Utah). In particular, the eastern limit of distribution has not yet been determined as the cryptic habit and habitat makes this species especially difficult to find in the east. The association with $C$. canadensis in Ontario provides potential for substantial extension of the known distribution.

\section{Stiphrosoma artum sp. n.}

(Figs 94-108, 206-208)

\section{Type material:}

Holotype male (f. brach.) labelled: „SK: Weyburn, 20.vii.1999, KNBarber, pooter, railside, Agropyron smithii, 49 39.5'N 103'51.1 'W" (DEBU, intact). Paratypes: CANADA: Alberta: $S$ of Onefour, $49^{\circ} 00.7^{\circ} \mathrm{N} 110^{\circ} 26.6^{\circ} \mathrm{W}, 14-16 . v i i .1997$, Malaise trap, 1 female $\mathrm{f}$. macropt., J. E. O'Hara leg. (LEMQ). Saskatchewan: same data as for holotype, 1 male f. brach. 1 female f. macropt. (DEBU, genit. prep.). USA: North Dakota: Hwy \#2, mi. 339, W of Grand Forks, $47^{\circ} 56.0^{\prime} \mathrm{N} 97^{\circ} 27.0^{\circ} \mathrm{W}, 21$.vii.1999, pooter/sweeps, roadside vegetation incl. Bromus/Agropyron, 1 male f. brach., 1 male 1 female f. macropt. K. N. Barber leg. (DEBU, genit. prep.).

Etymology: The name refers to the narrow wings, gonostylus and postgonite of the species (artus $=$ L. narrow).

\section{Description:}

Male. Total body length 1.62-1.75 mm; general colour yellow to pale ochreous-yellow, with pale brownish transverse spots on preabdominal terga. Head as long as high. Frons yellow, with orbits yellowish white; frontal triangle poorly delimited, reaching anterior half of frons, ocellar triangle usually with distinct pale brown spot between ocelli; dull areas between frontal triangle and orbits less distinct than in S. hirtum, other parts of head as in latter species. Cephalic chaetotaxy same as in S. hirtum, only in male holotype a microseta in front of anterior ors unusually long (twice as long as in paratypes). Eye oval, with longest diameter about 1.5 times as long as shortest; smallest genal height about 0.15 times as long as shortest eye diameter. Antenna yellow as in S. hirtum; arista about 1.9 times as long as antenna.

Thorax slightly narrower than head. Mesonotum generally yellow but a diffuse lateral band and (sometimes) very narrow medial stripe in anterior half of mesonotum darker ochreous as also is dorsal band across pleura clearly contrasting with very light notopleural area. Thoracic chaetotaxy similar to that of S. hirtum but ppl and prs usually distinctly longer though fine; ac microsetae in 2 rows of variable length (in holotype ending only between anterior and posterior $\mathrm{dc}$, in one paratype reaching up to prescutellar level); 2 
usual stpl and 1 microseta in front of anterior stpl, plus several other setulae in dorsal half of sternopleuron. Scutellum as in S. hirtum.

Legs pale yellow. Ctenidial spine on $f_{1}$ distinctly longer and thicker than in S. hirtum, markedly longer than maximum width of $t_{1} . f_{3}$ with short thickened setae (only 12-14) in posteroventral row; $t_{3}$ with distinct black ventroapical seta and hind basitarsus with 2-3 thickened setae ventroproximally (Fig. 102).

Wing polymorphic (Figs 207-208), including brachypterous, intermediate and macropterous forms. Macropterous form (rarer) with wing more broad and apically rounded, similar to those of macropterous females of $S$. hirtum but dm-cu always absent (Fig. 208). $\mathrm{CuA}_{1}$ ending in wing margin; $\mathrm{A}_{1}$ short, not reaching wing margin. Alula and anal lobe distinct. Brachypterous and intermediate forms with wing similar to male $S$. hirtum, narrow apically acute (Fig. 207); $R_{2+3}$ very slightly sinuous; $R_{4+5}$ and $M$ straight or slightly bent, subparallel or distally a bit divergent. Cell $\mathrm{dm}$ always open because $\mathrm{dm}$-cu absent. $\mathrm{CuA}_{1}$ and $\mathrm{A}_{1}$ distinct and ending close to wing margin. Alula and anal lobe reduced. Wing measurements (f. macropt.): length $1.51 \mathrm{~mm}$, width $0.56 \mathrm{~mm}, \mathrm{Cs}_{3}: \mathrm{Cs}_{4}=1.47$. Wing measurements (f. brach. and intermediate forms): length $0.99-1.15 \mathrm{~mm}$, width $0.26-0.38$ $\mathrm{mm}, \mathrm{Cs}_{3}: \mathrm{Cs}_{4}=1.45-1.64$. Haltere completely pale yellow, smaller in $\mathrm{f}$. brach.

Abdomen yellow but in contrast to $S$. hirtum T2-T5 with distinct pale brown stripes along posterior margins, those on T5 (sometimes also on T4) complete, others narrowly to broadly interrupted medially. S2-S5 densely finely setulose (Fig. 108). T5 reduced to a small, transverse, pale yellow and bare remnant behind T5. S6-S8 ochreous. S6 with brownish anterior marginal stripe and 3 setae; S7 with 2 setae; S8 long, with a number of setae.

Genitalia. Epandrium (Figs 94-95) slightly higher and much broader than long, with relatively long and dense setae, 1 dorsomedial pair longer than others; dorsal side of epandrium straight and anal fissure rounded triangular (Fig. 94). Cercus (Figs 94-95) relatively small but more projecting ventrally than in S. hirtum. Medandrium (Fig. 94) weakly sclerotized, narrower than that of S. hirtum. Gonostylus (Fig. 97) of medium size, somewhat longer and narrower than in $S$. hirtum with distinctly concave anterior margin and sparser micropubescence. Hypandrium (Fig. 96) more weakly sclerotized than that of S. hirtum. Transandrium simple (Fig. 100), almost straight; basal membrane ventrally provided with a group of transverse tubercles. Pregonite (Fig. 96) angular but less projecting and with fewer (only 7-8) setulae than in S. hirtum; postgonite slightly bent, distinctly shorter than that of $S$. hirtum and with tapered flat apex (Fig. 96). Aedeagal complex. Phallapodeme more slender, paler and weaker sclerotized with less dilated apex. Aedeagal part of folding apparatus with fewer lenticular tubercles; connecting sclerite similar to that of S. hirtum. Aedeagus (Fig. 98) with small frame-like phallophore. Membranous saccus of distiphallus large, differently armed than in S. hirtum, with small to minute hyaline spines on surface plus single large dark spine in the middle of dorsal side. Filum slender, but heavily sclerotized, slightly longer than in $S$. hirtum, its distal end curved, dilated and provided with very fine spinulae on apical margin (Figs 98-99). Ejacapodeme pale pigmented, with simple digitiform projection.

Female. Similar to male unless mentioned otherwise. Total body length $1.94-2.14 \mathrm{~mm}$ Peristomal setulae more numerous (up to 8). Thoracic colour more uniform, with darkened areas less visible or indistinct. $f_{1}$ with ctenidial spine strong and long as in male; $\mathrm{f}_{3}$ without posteroventral row of short thickened setae. Setae on $t_{3}$ and hind basitarsus similar to those of male. Wing (only macropterous forms found in material examined) 
with dm-cu absent (Fig. 206). Wing measurements (f. macropt.): length 1.43-1.71 mm, width 0.46-0.56, $\mathrm{Cs}_{3}: \mathrm{Cs}_{4}=1.61-1.77$.

Abdomen. Abdominal sclerites relatively densely setose but setae on sterna fine. Preabdominal terga wider and more transverse; sterna paler, narrower and becoming wider posteriorly. T2-T5 with similar dark pattern as in male.

Postabdomen (Figs 101, 107) ochreous, somewhat darker than in S. hirtum. T6 large, posteriorly narrowed, with dense and longer setae than in S. hirtum. S6 distinctly larger and more transverse than that of $S$. hirtum. Tergosternum $T 7+S 7$ unpigmented dorsomedially (Fig. 101), ventrally with very indistinctly separated part corresponding to original S7 being more setose than in S. hirtum (Fig. 107). T8 (Fig. 101) rounded oblong but with triangular pigmentation and with setae in posterior half. S8 (Fig. 107) short, darker than in S. hirtum, with narrow posteromedial cleft prolonged anteriorly to divide it in two parts. Internal sclerotization of female genital chamber (Fig. 105) consisting of two pairs of posterior bent sclerites which are more or less fused and distinctly darker and more sclerotized than in $S$. hirtum and of 1 anterior looped sclerite (less transverse than in $S$. hirtum). Ventral receptacle (Fig. 104-105) as in S. hirtum but shorter. Spermathecae $(1+1)$ pyriform, more robust (Figs 103,106) than in S. hirtum, with shorter and wider proximal as well as distal parts, both similarly armed as those of $S$. birtum. T10 subtriangular but only its anterior half pigmented; surface of T10 sparsely micropubescent and with usual pair of long setae (Fig. 101). S10 longer than T10, semicircular, with posterior two-thirds micropubescent and shortly setulose (Fig. 107). Cerci relatively short, less tapered apically than those of S. hirtum.

\section{Discussion:}

Stiphrosoma artum sp. n. is another wing-polymorphic species of the genus. In contrast to the closely related $S$. hirtum it is generally darker yellow, with more distinct darker pattern on thorax and abdomen (diagnostic for males in particular), posterior cross-vein $(\mathrm{dm}-\mathrm{cu})$ always absent, finely setulose male sterna and differs as well in number of male and female genitalic characters (see under $S$. hirtum). Besides the latter, the distinct setae on hind tibia and basitarsus (see key) are the best features to recognize S. artum.

\section{Biology:}

$S$. artum is a rare species living at the bases of grasses. The typical series was aspirated from a strip of pure, unmowed Pascopyrum (= Agropyron) smithii between a railway and the mowed lawn of a local museum. In this site, S. hirtum was much more abundant and the primary subject of the collection as $S$. artum was not yet recognized. The North Dakota specimens were similarly collected in an unmowed margin (mixture of $P$. smithii and Bromus inermis) between a roadside drainage ditch and a cultivated agricultural field where $S$. hirtum was not evident. The Alberta site was short-grass prairie occasionally grazed by cattle with the Malaise trap placed on the edge of a patch of woody vegetation (J. E. O'Hara, pers. comm.). This single collection in a Malaise trap would appear to be a rare event, even though a macropterous specimen, when considering the absence of any such records for the much more ubiquitous $S$. hirtum.

\section{Distribution:}

Hirtherto only recorded from western Canada (Alberta, Saskatchewan) and the USA (North Dakota). 


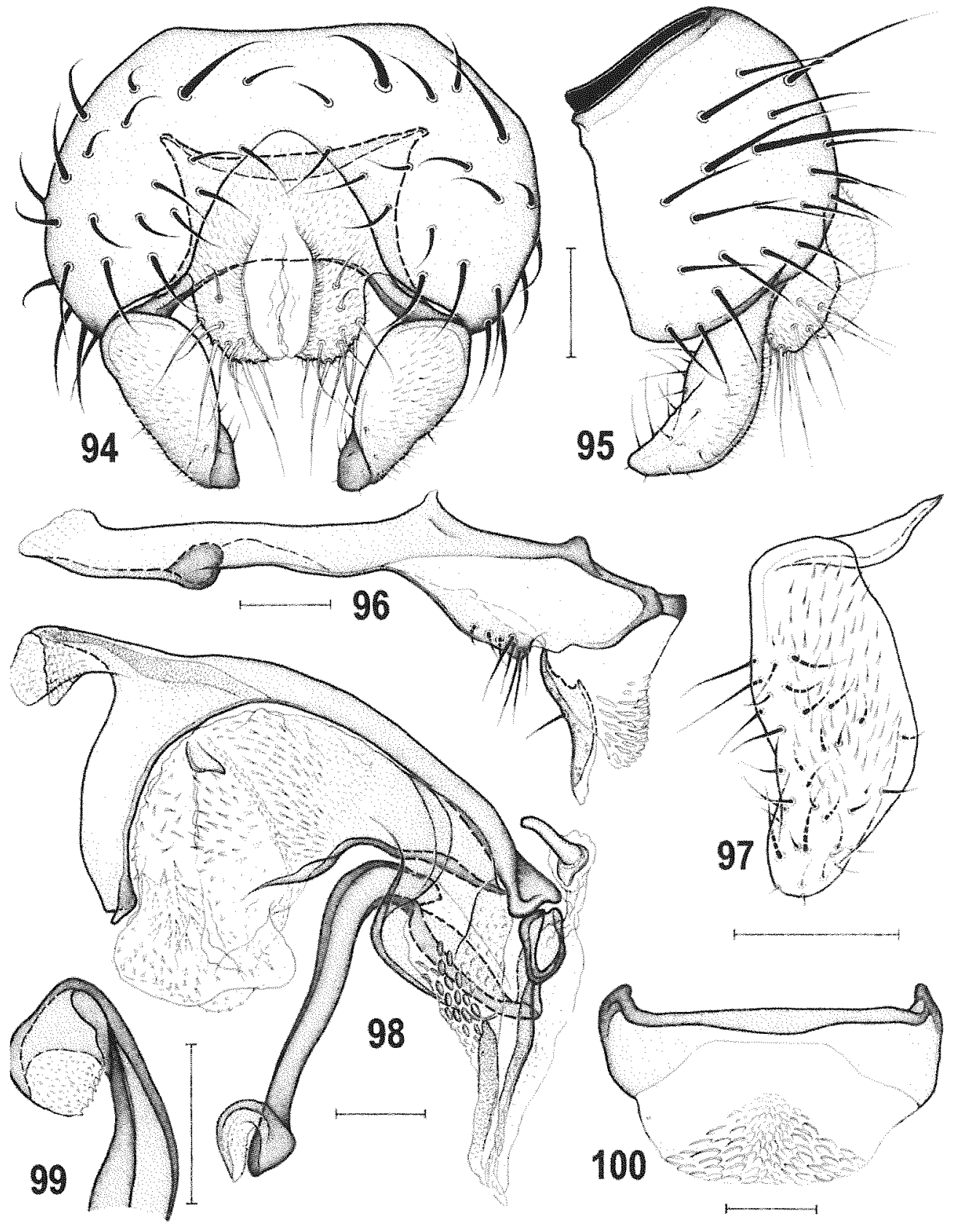

Figs 94-100: Stiphrosoma artum sp. n., male paratype (Canada: Saskatchewan). 94 - external genitalia caudally; 95 - ditto laterally; 96 - hypandrium and associated structures laterally; 97 - gonostylus posterolaterally (widest extension view); 98 - aedeagal complex laterally; 99 - apex of filum lateroventrally; 100 - transandrium and basal membrane caudally. Scales $=0.05 \mathrm{~mm}$. 


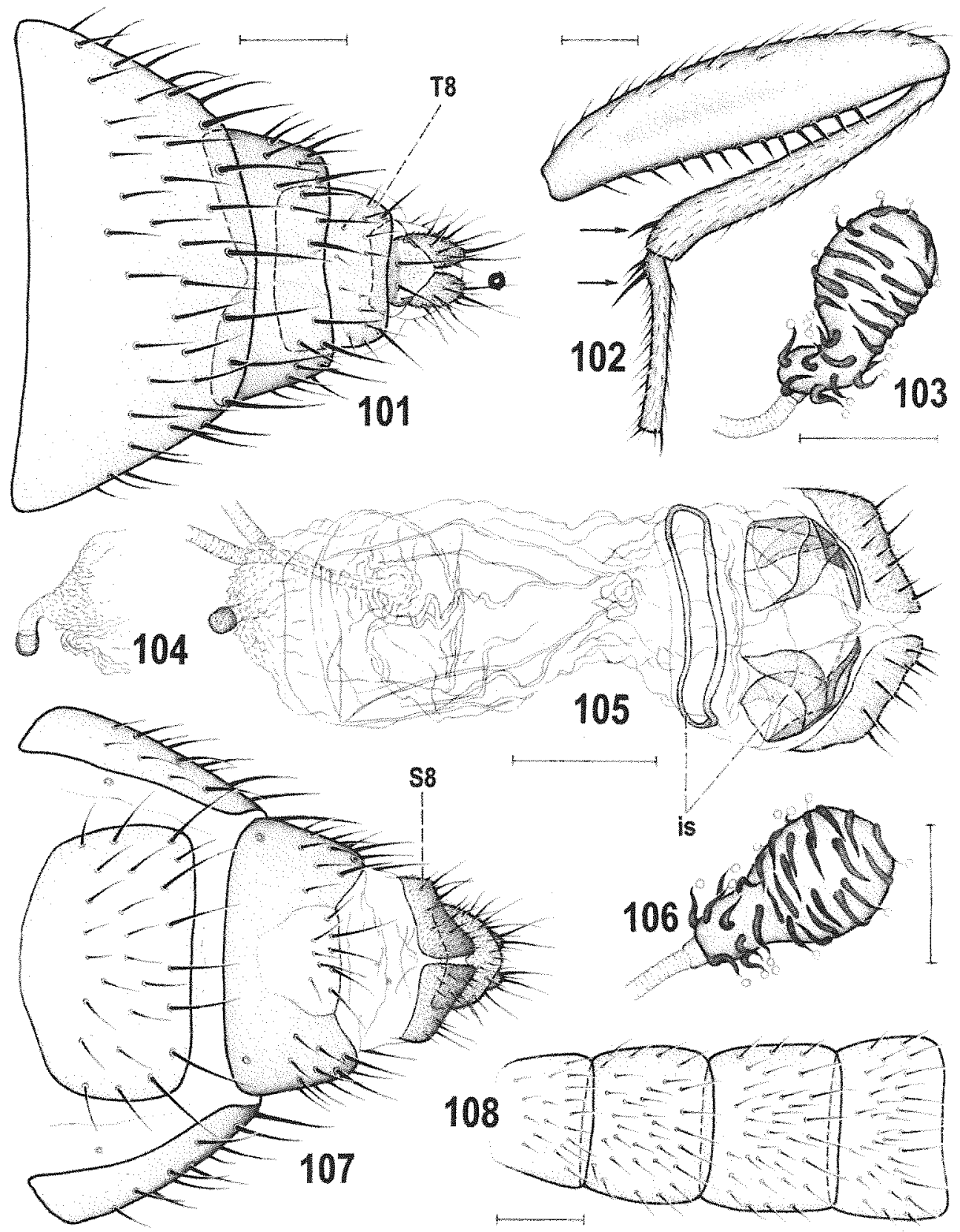

Figs 101-108: Stiphrosoma artum sp. n., male $(102,108)$ and female $(101,103-107)$ paratypes (Canada: Saskatchewan), 101 - female postabdomen dorsally; 102 - male $f_{3}, t_{3}$ and hind basitarsus posteriorly; 103 - spermatheca; 104 - ventral receptacle laterally; 105 - female genital chamber and S8 ventrally; 106 - spermatheca; 107 - postabdomen ventrally; 108 - male S2-S5 ventrally. Scales: Figs 103, $106=0.05 \mathrm{~mm}$; others $=0.1 \mathrm{~mm}$. For abbreviations see text. 


\section{Stiphrosoma belvum sp.n.}

(Figs 109-120, 209)

\section{Type material:}

Holotype male labelled: "High Prairie, Alta. 17.7 1961, A. R. Brooks" (CNCI, genit. prep.). Paratypes: CANADA: Alberta: same data as for holotype, 1 female (CNCI, genit. prep.). USA: Montana: Pipestone Pass, 29.vii.1923, 1 female, A. L. Melander leg. (USNM, genit. prep.).

Etymology: The name refers to the largely yellowish body of the species (helvus $=$ L. yellowish).

\section{Description:}

Male. Total body length $2.02 \mathrm{~mm}$; general colour yellow, with ochreous to pale brown pattern on thorax and abdomen. Head somewhat higher than long, largely yellow. Frons pale yellow, with yellowish white and white microtomentose orbits and with semicircular yellow to orange dull area in anterior third of frons. Frontal triangle short, hardly reaching to anterior third of frons; ocellar triangle small, with orange brown spot between ocelli. Occiput yellow, with whitish ventral marginal area below foramen and with pale yellow medial area above foramen ornamented by 2 usually whitish microtomentose stripes. Face narrow, whitish yellow to yellow, only marginal stripes bordering parafacialia and anterior part of gena orange to ochreous; parafacialia (except for orange margin) and gena white to yellowish white and silvery white microtomentose; mouthparts yellow. Cephalic chaetotaxy: pvt small, strongly crossed; vte distinctly shorter than vti, the latter longest of cephalic setae; oc and posterior ors almost as long as vti; 2 ors, anterior strong although distinctly shorter than posterior; 1-2 microsetulae (anterior very minute or absent) in front of anterior ors; $1-2$ pairs of medial microsetulae in front of frontal triangle; vi slightly longer than anterior ors; subvibrissa weak, two-thirds or less of vi length; only 4-5 peristomal setulae, but several setulae also on postgena; postocular microsetulae very minute, in single row. Eye subellipsoid; its longest diameter 1.4-1.5 times as long as shortest; smallest genal height about 0.11 times as long as shortest eye diameter. Antenna yellow with 1st flagellomere pale to whitish yellow but ochreous darkened around insertion of arista and with long white cilia anteroventrally. Arista 1.9-2.0 times as long as antenna, brown and relatively shortly pectinate.

Thorax narrower than head. Mesonotum yellow including scutellum, with pale brown lateral vitta extending over almost entire length of scutum (from level of hu seta to basal corner of scutellum); humeral and notopleural areas light yellow. Pleural part of thorax pale yellow to whitish yellow with narrow, light brown dorsal band extending from cervix to base of abdomen. Mesonotum sparsely microtomentose, subshining. Thoracic chaetotaxy: prs weak but longer than in S. stylatum and as long as enlarged microseta in front of anterior dc; $2 \mathrm{dc}$, anterior relatively long, posterior very long (longest of thotacic setae); 4-5 dc microsetae in front of anterior dc; ac microsetae in 4 rows anteriorly, in 2 rows behind anterior $\mathrm{dc}$ and reaching slightly behind level of posterior $\mathrm{dc} ; 2 \mathrm{sc}$, basal sc shorter than anterior dc, apical sc long but shorter than posterior dc; 2 usual stpl (anterior shorter and weaker) and 1 microseta in front of anterior stpl; 3 additional setulae in dorsal half of sternopleuron and more longer setae ventrally. Scutellum rounded triangular, with flattened disc. 
Legs pale to whitish yellow, only apical tarsal segments (fore tarsi) or their distal parts (mid and hind tarsi) darkened, yellow to ochreous. $f_{1}$ with ctenidial spine slightly longer than maximum width of $t_{1}$. Ventroapical seta on $t_{2}$ relatively short. $f_{3}$ with posteroventral row of setae, 7 in distal half thickened; $t_{3}$ with short dark ventroapical seta; hind basitarsus with 2 short dark ventrobasal setae, the most distal longer.

Wing (Fig. 209) with pale ochreous membrane and veins. $\mathrm{R}_{2+3}$ long, bent in parallel to $C$ and apically slightly upcurved to it; $R_{4+5}$ slightly bent posteriorly; $M$ almost straight. Discal $(\mathrm{dm})$ cell relatively long and narrow, $r-m$ situated in basal third of $\mathrm{dm}$ cell. CuA very slightly bent, ending near wing margin but its apical part unpigmented; $A_{1}$ short, ending far from it. Alula narrow; anal lobe well developed. Wing measurements: length $1.91 \mathrm{~mm}$, width $0.67 \mathrm{~mm}, \mathrm{Cs}_{3}: \mathrm{Cs}_{4}=1.24, \mathrm{r}-\mathrm{m} \backslash \mathrm{dm}-\mathrm{cu}: \mathrm{dm}-\mathrm{cu}=4.25$. Haltere yellow, with whitish knob.

Abdomen pale yellow with light brown belts on preabdominal terga. T1 yellow, with darkened posterior corners; T2-T5 pale yellow, each with pale brown to brown posterior marginal band being darkest and widest (longest) on T3 and T4; T5 with posterior marginal band as large as on T4 but faded, particularly laterally. Preabdominal sterna S2-S5 whitish yellow, narrow, becoming wider posteriorly, finely setulose. T6 reduced to short, pale, bare, transversely band-like sclerite widened on right side of abdomen. 66 yellow, short, with narrow pale brown anterior marginal stripe continued as slender projection on ventral side of postabdomen. $S 7$ yellow and yet more narrowly dark bordered anteriorly; S6 with 3, S7 with 5 distinct setae; S8 more setose, pale brown, darker than epandrium.

Genitalia. Epandrium (Figs 109-110) slightly shorter than high and relatively narrow, densely setose, with 2 pairs of strong and long dorsolateral setae. Dorsal side of epandrium convex; anal fissure almost semicircular but its dorsal margin poorly delimited. Cercus (Figs 109-110) relatively small. Medandrium (Fig. 109) relatively narrow, weakly sclerotized. Gonostylus (Fig. 115) about as long as epandrial height, more robust and wider than in all relatives of the $S$. stylatum-group, with apex slightly bent in anterior and also posterior view, gradually tapered towards a rounded apex in widest extension view; its outer side largely micropubescent except for apex and narrow anteroproximal area, inner side with relatively short setae. Hypandrium (Fig. 112) weakly sclerotized but more robust than in relatives of the $S$, stylatum-group, dilated and widened posteriorly. Transandrium simple, almost straight ventrally; basal membrane with small ventromedial group of hyaline transverse tubercles (Fig. 113). Pregonite (Fig. 112) lower than in all relatives, forming small lobe with about 5 longer and 4 shorter setae; postgonite (Fig. 112) distinctive, short and S-shaped, with dark basal part and hyaline narrowed apex and with 1 anterior seta in proximal half. Aedeagal complex. Phallapodeme slender but with somewhat wing-like widened apex, pale pigmented fulcrum and deeply forked base. Aedeagal part of folding apparatus laterally with large group of dense tubercle-like structures; connecting sclerite very slender, proximally darkened. Aedeagus (Fig. 114) with short, frame-like phallophore and robust distiphallus. Saccus voluminous, with only proximal end and ventral slender plate sclerotized and pigmented, otherwise membranous hyaline and armed by 6 robust dark spines (larger and more acute than in relatives) scattered in membrane and by lateral row of short dark tubercle-like spines in basal third but without fine hairs or setulae. Filum slender, dark, compact, composed of two closely 
attached band-like sclerites and with apex twisted, long, narrow and provided with small sharply pointed teeth and minute spinulae (Figs 111, 114). Ejacapodeme pigmented, with relatively thick projection having well developed capitulum.

Female. Similar to male unless mentioned otherwise. Total body length $2.26-2.31 \mathrm{~mm}$. Face as in male but margins of parafacialia paler. $f_{3}$ without thickened posteroventral setae but hind basitarsus with ventrobasal setae longer than in male. Discal (dm) cell broader; $\mathrm{r}-\mathrm{m}$ situated in basal two-fifths of $\mathrm{dm}$ cell. Wing measurements: length $1.98-2.26 \mathrm{~mm}$, width 0.73-0.81 mm, $\mathrm{Cs}_{3}: \mathrm{Cs}_{4}=1.40-1.46, \mathrm{r}-\mathrm{mldm}-\mathrm{cu}: \mathrm{dm}-\mathrm{cu}=3.33-3.41$.

Abdomen pale yellow, with transverse dark (pale brown to brown) belts on preabdominal terga. T1 yellow, with brownish posterior corners; T2-T5 pale or whitish yellow, each with brown stripe on posterior margin being medially shortened to almost interrupted (in T2-T3 in particular). T2-T5 shortly setose, except for their anterior third, with longest setae in posterior corners of T4 and T5. S2-S5 whitish yellow, narrower than in male, becoming wider posteriorly, S5 widest (as wide as S6), all finely setose.

Postabdomen (Figs 116-117) relatively narrow. T6 large, not very transverse, posteriorly slightly tapered, pale yellow with dark, medially attenuated stripe at posterior margin, densely setose in posterior two-thirds. $\$ 6$ pale yellow, relatively narrow, finely setose, with long setae on posterior and lateral margins. Tergosternum $T 7+S 7$ with unpigmented dorsomedial area (Fig. 116), dark only dorsolaterally, pale yellow ventrally; its original S7 reduced to posteromedial triangular area anteriorly delimited by distinct lines, posteriorly hardly separated from rest of tergosternum and bearing (in contrast to species of the S. stylatum-group) a number (4 longer and about 6 shorter) of thin setae (Fig. 117). T8 (Fig. 116) simple, suboblong pale plate, with small setae in posterior rounded corners. S8 (Fig. 117) unusually short, with posteromedial incision, very shortly setulose. Internal sclerotization of female genital chamber (Fig. 119) complex, consisting of (probably) two pairs of posterior, largely coalesced sclerites (medial pair larger and darker) and 1 anterior, transverse, looped slender sclerite. Ventral receptacle (Fig. 120) on longer slender duct, rounded subcylindrical, finely transversely striated; accessory gland with subterminally dilated duct. Spermathecae (1+1) pyriform (Fig. 118) with strikingly narrowed and long proximal end, armed with dark, very slender and curved spines being transversely attached to surface on broad distal part. T10 small, laterally pigmented, otherwise membranous (Fig. 116), with a pair of long setae and very fine micropubescence restricted to medial area. $S 10$ broader than $\mathrm{T} 10$, relatively long, rounded subtriangular, anteriorly emarginate, micropubescent over entire surface (Fig. 117). Cerci small, short, with rich moderate setae.

\section{Discussion:}

S. helvum sp. n. seems to be a somewhat aberrant species related to the $S$. stylatum-group which includes the following four species, viz. S. stylatum, S. minor, S. vittatum and $S$. sororium. It can be considered a sister taxon of this monophyletic group characterized by synapomorphies listed under $S$. stylatum below. S. helvum lacks these features but bears several highly diagnostic characters, viz. the $S$-shaped postgonite, reduced number of tubercles in the basal membrane, saccus unhaired but with dark robust spines, filum with elongate curved and pointed apex with spinulose tip, more setose remnant of female $S 7$, large internal sclerites in the female genital chamber, extremely shortened female $S 8$ and spermathecae resembling those of $S$. laetum and $S$. bumerale. 

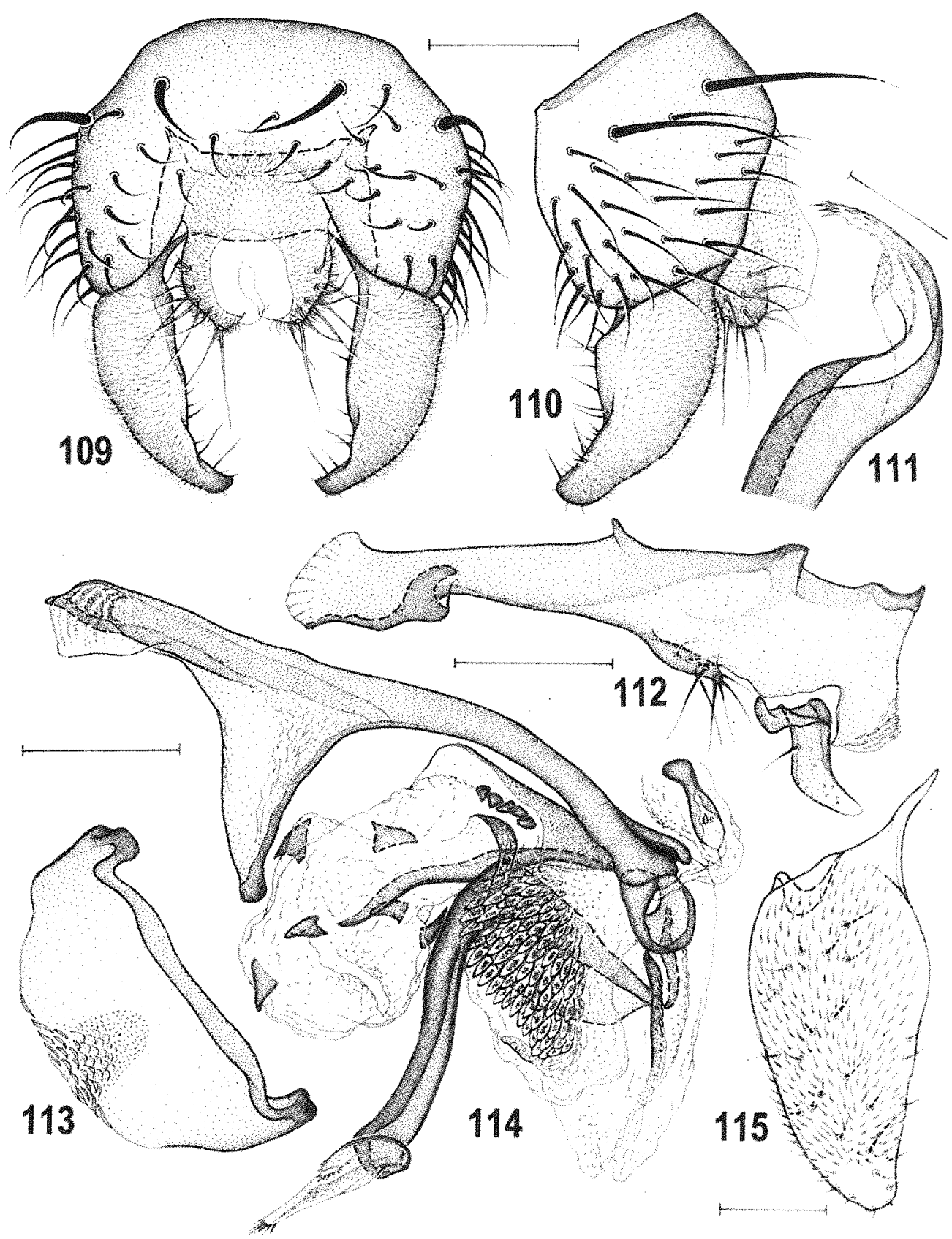

Figs 109-115: Stiphrosoma helvum sp. n., male holotype (Canada: Alberta). 109 - external genitalia caudally; 110 - ditto laterally; 111 - apex of filum ventrally; 112 - hypandrium and associated structures laterally; 113 - transandrium and basal membrane caudally; 114 - aedeagal complex laterally; 115 - gonostylus posterolaterally (widest extension view). Scales: Figs $111,115=0.05 \mathrm{~mm}$, others $=0.1 \mathrm{~mm}$. 


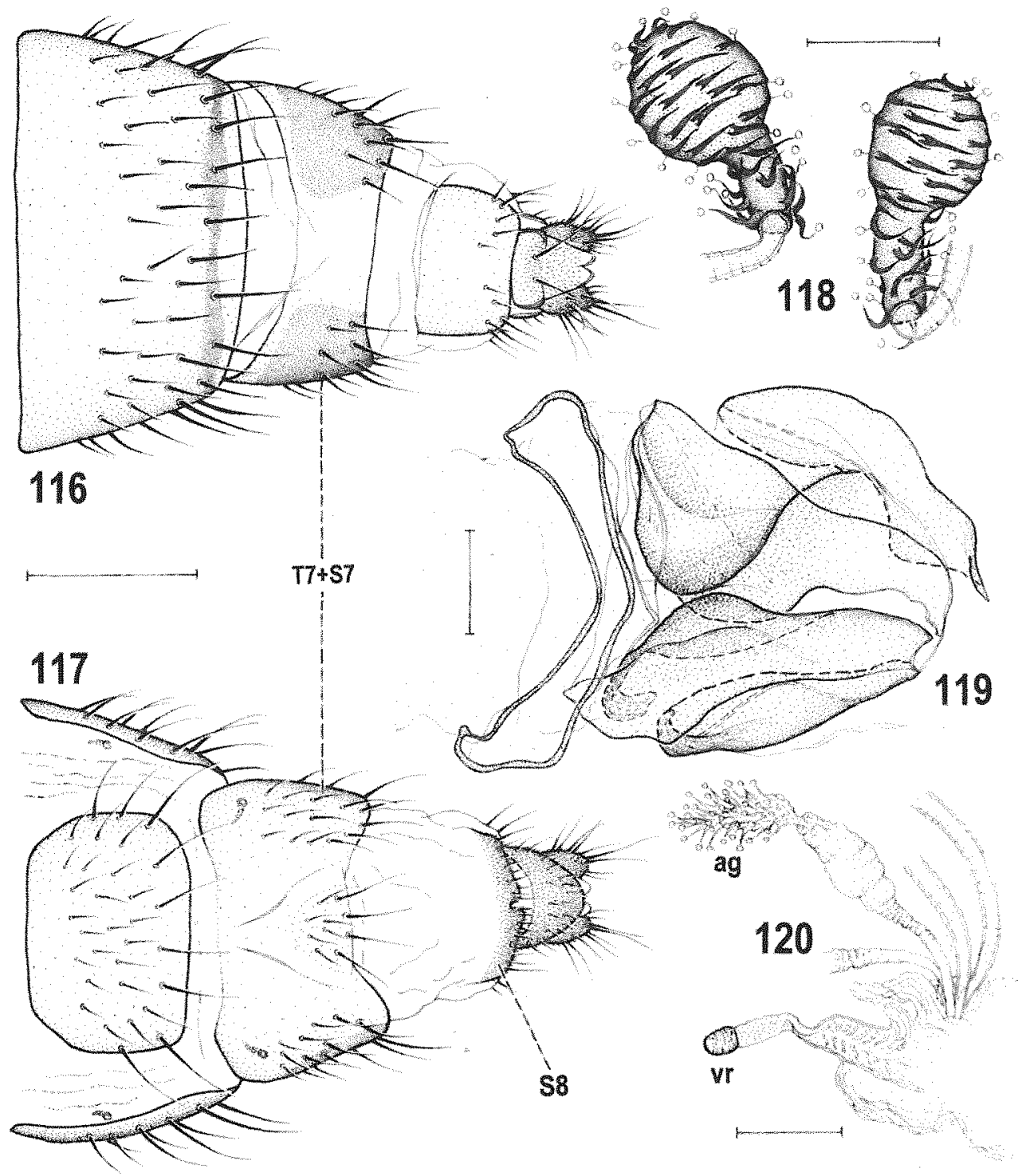

Figs 116-120: Stiphrosoma helvum sp. n., female paratype (Canada: Alberta). 116 - postabdomen dorsally; 117 - ditto ventrally; 118 - spermathecae; 119 - internal sclerites ventrally; 120 - ventral receptacle and accessory gland laterally. Scales: Figs $116-117=0.2 \mathrm{~mm}$; others $=0.05 \mathrm{~mm}$. For abbreviations see text.

\section{Biology:}

Nothing is known of the biology of this species.

\section{Distribution:}

Known only from central Alberta (Canada) and southwestern Montana (USA). 


\section{Stiphrosoma stylatum sp. n.}

(Figs 121-133, 210)

\section{Type material:}

Holotype male labelled: „Lab-reared, Carex aquatilis, from $6 \circ$ - ONT: SSMarie, S. of Algoma U. College, 31.vii-18.viii.2002, pooter, C. aquatilis, KNBarber, $46^{\circ} 29.9^{\prime} \mathrm{N}$ $84^{\circ} 17.2^{\circ} \mathrm{W}^{\prime \prime}$ and „20 $0^{\circ}$;6L: 8D; 50-70\% RH, moist 3-cm sections $C$. aquatilis, in $5 \mathrm{~cm}$ plates. Ovip: 04-15.viii.2002. Puparium: 03.xi.2002. Adult: 11.xi.2002 o" (DEBU, intact). Paratypes: CANADA: Manitoba: Int[ernational] Peace Gardens, Turtle Mtn. For. Res., 7.viii.1958, 1 male, J. G. Chillcott leg. (CNCI). Ontario: Fergus, Grand River, 30.vii.1994, riverside vegetation, 1 male, J. Roháček leg. (SMOC); Ottawa, 13.vii.1963, 1 female, J. R. Vockeroth leg. (CNCI); same data as for holotype (except for different rearing data), 32 males 46 females (DEBU, AMNH, CNCI, SMOC, USNM); S[ault] $\mathrm{S}$ [te.] Marie, S. of Algoma U. College, $46^{\circ} 29.9^{\circ} \mathrm{N} 84^{\circ} 17.2^{\circ} \mathrm{W}, 31 . v i \mathrm{i}-18 . v i i i .2002$, pooter, Carex aquatilis, used in lab-rearing, killed 19.viii., 13.ix., 9.xi.2002 or dead 7.xi.2002, 4 females (DEBU); same locality, sweeps, Carex aquatilis, 12.vii.1997, 1 male, 3.viii.1997, 1 female (DEBU); same locality but 29.vii.1998, sweeps/pooter, Carex aquatilis, 1 female (DEBU); same locality but 3.viii.1997, sweeps/pooter, Calamagrostis canadensis, 1 female (DEBU) all K. N. Barber leg.; same locality but $46^{\circ} 29.88^{\circ} \mathrm{N} 84^{\circ} 17.19^{\circ} \mathrm{W}$, pooter, mostly Carex aquatilis, 21.viii.2004, 1 male 1 female, 23.viii.2004, 1 male 1 female, 5.ix.2004, 1 female (DEBU); same locality but 5.ix.2004, sweeps, trampled graminoids, mostly Carex aquatilis, 6 males 2 females (DEBU) all K. N. Barber leg. USA: Minnesota: Aitkin Co., $14 \mathrm{mi} \mathrm{W}$ of Willow River, 46.334 N 93.096 W, 26.vii.1995, 1 male 1 female, D. E. Hansen leg. (DEBU). Utah: Hyde Park, 16.vi.1938, 1 female, D. E. Hardy $\&$ G. S. Stains leg. (EMUS). Several paratypes with genit. prep.

Other S. stylatum material not designated as paratypes (damaged):

CANADA: Ontario: same data as for holotype (except for different rearing data) 3 females, K. N. Barber leg. (DEBU); S[ault] S[te.] Marie, S. of Algoma U. College, $46^{\circ} 29.9^{\circ} \mathrm{N} 84^{\circ} 17.2^{\circ} \mathrm{W}, 31 . v i i-18 . v i i i .2002$, pooter, Carex aquatilis, used in lab-rearing, dead 24.x.2002, 1 female (DEBU, abdomen lost).

Material of $S$. cf. stylatum (questionable status):

CANADA: Manitoba: Max Lake, Turtle Mtn. For. Res., 30.vii.1958, 1 female, J. G. Chillcott leg. (CNCI). Ontario: S[ault] S[te.] Marie, S. of Algoma U. College, $46^{\circ} 29.9^{\circ} \mathrm{N}$ $84^{\circ} 17.2^{\prime} \mathrm{W}$, 31.vii-18.viii.2002, pooter, Carex aquatilis, used in lab-rearing, killed 16.ix.2002, 1 female, K. N. Barber leg. (DEBU). USA: Maine: Narrows Mt. Desert, 27.vii.1919, 1 male C. W. Johnson leg. (USNM). Utah: Corinne, on celery, 9.vii.1949, 1 female, G. F. Knowlton leg. (USNM).

Etymology: The species is named for its very long and slender gonostylus.

\section{Description:}

Male. Total body length 1.74-2.15 mm; general colour yellow, with pale brown to brown pattern on thorax and abdomen. Head slightly higher than long. Frons yellow, with yellowish white orbits and frontal triangle reaching to anterior third of frons; ocellar triangle brown; in contrast to $S$. minor there is usually a small V-shaped pale brown pattern be- 
tween lunule and frontal triangle. Occiput yellow, with medially divided paler and white microtomentose medial area above foramen and with 2 subtriangular darker (ochreous brown) spots laterally to the latter; dorsal and lateral margins of occiput yellow to ochreous, paler than these spots. Face narrow, with brown pattern formed by 4 longitudinal stripes (medial pair sometimes partly coalesced, lateral forming boundary between face and parafacialia); parafacialia (except brown margin) and gena yellowish white and silvery white microtomentose; mouthparts yellow. Cephalic chaetotaxy: pvt small, strongly crossed; vte slightly shorter than vti; oc and posterior ors almost as long as vti; 2 ors, anterior strong although distinctly shorter than posterior; 1-2 microsetulae in front of anterior ors; only 1 pair of medial microsetulae in front of frontal triangle; vi slightly shorter than posterior ors; subvibrissa weak, two-thirds or less of vi length; only 4-5 peristomal setulae, but several setulae also on postgena; postocular microsetulae very minute, in single row. Eye subellipsoid; its longest diameter 1.4-1.5 times as long as shortest; smallest genal height about 0.13 times as long as shortest eye diameter. Antenna yellow with 1 st flagellomere pale to whitish yellow but more or less darkened around insertion of arista and with long white cilia anteroventrally. Arista 1.9 times as long as antenna, dark brown with paler basal segments and relatively shortly pectinate.

Thorax narrower than head. Mesonotum yellow including scutellum, with pale brown narrow stripe between medial ac setulae and lateral vitta extending (in contrast to $S$. minor) front of suture up to level of hu seta; humeral and notopleural areas whitish yellow. Pleural part of thorax pale yellow with brown dorsal band extending from cervix to base of abdomen. Mesonotum sparsely microtomentose, subshining. Thoracic chaetotaxy: prs very small (yet weaker than in $S$. minor); $2 \mathrm{dc}$, anterior relatively long but distinctly shorter than posterior; 5-6 dc microsetae in front of anterior dc; ac microsetae in 4 rows anteriorly, in 2 rows behind anterior $\mathrm{dc}$ and reaching sometimes behind level of posterior $\mathrm{dc} ; 2 \mathrm{sc}$, basal sc relatively long (as long as anterior $\mathrm{dc}$ ), apical sc very long (as long as posterior dc); 2 usual stpl (anterior markedly shorter) and 1 microseta in front of anterior stpl; 3-4 additional setulae in dorsal half of sternopleuron and more longer setae ventrally. Scutellum rounded triangular, with flattened disc.

Legs pale yellow, but distal half of apical tarsal segments brown. $f_{1}$ with ctenidial spine longer than maximum width of $t_{1}$. Ventroapical seta on $t_{2}$ relatively short. $f_{3}$ with posteroventral row of setae, $8-9$ in distal half thickened; $t_{3}$ without ventroapical seta; hind basitarsus with 2-3 short dark ventrobasal setae being thicker than in S. minor.

Wing (Fig. 210) with pale ochreous membrane and veins. $R_{2+3}$ long, bent in parallel to $\mathrm{C}$ and apically slightly upcurved to it; $\mathrm{R}_{4+5}$ slightly bent posteriorly; $\mathrm{M}$ almost straight or very slightly bent. Discal $(\mathrm{dm})$ cell moderate, widened distally, both $\mathrm{r}-\mathrm{m}$ and $\mathrm{dm}$-cu relatively long, $\mathrm{r}-\mathrm{m}$ situated in basal two-fifths of $\mathrm{dm}$ cell. CuA slightly bent, ending near wing margin; $A_{1}$ short, ending far from it. Alula narrow; anal lobe well developed. Wing measurements: length $1.88-2.15 \mathrm{~mm}$, width $0.62-0.73 \mathrm{~mm}, \mathrm{Cs}_{3}: \mathrm{Cs}_{4}=1.18-1.59, \mathrm{r}-\mathrm{ml}$ $\mathrm{dm}-\mathrm{cu}: \mathrm{dm}-\mathrm{cu}=3.00-3.87$. Haltere with dirty white knob and yellow stem.

Abdomen pale to whitish yellow with brown patterned terga. T1 pale brown or ochreous but whitish yellow anteromedially; $\mathrm{T} 2$ and $\mathrm{T} 3$ with brown lateral areas and medial (anteriorly wider) yellow triangular area, larger in T3; T4 and T5 with only short (narrow) posterior marginal band brown, or $T 4$ also laterally brown margined. Preabdominal sterna S2-S5 whitish yellow, narrow, becoming wider posteriorly, finely setulose. T6 re- 
duced to small, pale bare transversely triangular temnant on right side of abdomen. S6 yellow, short, with very slender ventral projection and very narrow brown anterior marginal stripe; S7 yellow and both usually with 2 setae; S8 brown and setulose, contrasting with yellow epandrium.

Genitalia. Epandrium (Figs 121-122) shorter than high and relatively narrow, densely setose, with 2 pairs of dorsolateral setae longer than others. Dorsal side of epandrium convex; anal fissure rounded triangular but its dorsal margin poorly delimited. Cercus (Figs 121-122) relatively small. Medandrium (Fig. 121) large but very weakly sclerotized. Gonostylus (Fig. 127) very long, longer than epandrial height, only slightly tapered distally and with broadly rounded apex; in lateral view with concave anterior margin (Fig. 122); its outer side largely micropubescent except for apex and narrow anterior area, inner side with long anterior setae. Hypandrium (Fig. 123) slender, weakly sclerotized, dilated posteriorly. Transandrium simple, slightly double sinuous; basal membrane (longer than in S. minor) ventrally with a group of hyaline transverse tubercles (Fig. 124). Pregonite (Fig. 123) moderate, forming rounded lobe with a number of fine setae (12-14); postgonite (Fig. 123) narrow, distinctly bent, with somewhat dilated and rounded membranous apex and with 1 short seta in proximal third. Aedeagal complex. Phallapodeme slender including simple apex, slender pale pigmented fulcrum and deeply forked base. Aedeagal part of folding apparatus laterally with large group of small dark tubercles; connecting sclerite very slender, distally tapered and darkened. Aedeagus (Fig. 126) with frame-like phallophore (longer than in most relatives) and robust distiphallus. Saccus voluminous, dorsally and ventrally proximally sclerotized and pigmented, otherwise membranous hyaline and armed by 3 pairs of short thick and dark spines (on left side) and finely haired (mainly on right side) but its apex unarmed. Filum slender, dark, compact and curved, with apex widened and provided with small sharply pointed processes, spines and teeth (Figs 125-126). Ejacapodeme pale pigmented, with slender digitiform projection having small, slightly projecting capitulum.

Female. Similar to male unless mentioned otherwise. Total body length $1.78-2.70 \mathrm{~mm}$. Head with brown markings often paler, e.g. V-shaped pattern at fore margin of frons sometimes pale and poorly visible. Face typically with simple broad brown band and margins of parafacialia at most ochreous or orange; in pale or immature specimens face paler (ochreous) pigmented. Thoracic pattern as in male, but lateral vitta sometimes paler (particularly in lab-reared specimens). $\mathrm{f}_{1}$ with ctenidial spine usually shorter than in male, about as long as tibial width. $f_{3}$ without thickened posteroventral setae but hind basitarsus with ventrobasal short setae as in male. Wing measurements: length 1.71-2.64 $\mathrm{mm}$, width 0.60-0.85 mm, $\mathrm{Cs}_{3}: \mathrm{Cs}_{4}=1.26-1.45, \mathrm{r}-\mathrm{m} \backslash \mathrm{dm}-\mathrm{cu}: \mathrm{dm}-\mathrm{cu}=3.11-3.91$.

Abdomen pale yellow, with dark pattern on terga. Usually T1 ochreous yellow, darker laterally; T2-T5 pale or whitish yellow, with pale to dark brown stripe on posterior margin which can also be extended on lateral margins or (in pale specimens) medially interrupted. In the reared specimens only lighter form has been observed, often with dark marginal markings distinctly paler than in wild females.

Postabdomen (Figs 128, 131). T6 large but transverse, posteriorly tapered, yellow with dark, medially interrupted band at posterior margin, shortly setose. S6 light, roughly transversely oval, finely setose, with long setae on posterior and lateral margins. Tergosternum $\mathrm{T} 7+\mathrm{S} 7$ with unpigmented dorsomedial area (Fig. 128), dark only dorso- 
laterally, pale yellow ventrally; its original S7 reduced to posteromedial semicircular area bearing usually $4-5$ (Fig. 131), more rarely 6-9, thin setae. T8 (Fig. 128) wider posteriorly, with indistinct anterior margin, pale, with small setae. S8 (Figs 131, 133) shorter than T8, undivided but posteromedially emarginate, shortly setulose. Internal sclerotization of female genital chamber (Figs 132-133) complex, consisting of three pairs of posterior, partly coalesced flat sclerites (medial pair smaller and darker) and 1 anterior, transverse, looped sclerite being strongly bent dorsally. Ventral receptacle (Fig. 130) on short duct, subcylindrical with rounded end, finely transversely striated. Spermathecae $(1+1)$ pyriform (Fig. 129) with narrow proximal end, armed with dark, curved spines being transversely attached to surface on broad distal part. T10 small, subtriangular but only anteriorly pigmented, otherwise membranous (Fig. 128), with a pair of long setae and sparse micropubescence. S10 slightly broader than T10, rounded triangular, with posterior half micropubescent (Fig. 131). Cerci small, short, with rich moderate setae.

\section{Variability:}

The reared specimens (particularly females) are usually smaller than wild-caught specimens of the parent generation and others collected from the same locality (frons to haltere length of only critical-point dried specimens have been measured to avoid influence of distention of abdomen and to include specimens with genitalic preparations: range, mean \pm standard error, one-way ANOVA: reared males - 0.850-1.150 mm, $1.027 \pm$ $0.013 \mathrm{~mm}, \mathrm{n}=31$, wild males $-0.875-1.200 \mathrm{~mm}, 1.097 \pm 0.036 \mathrm{~mm}, \mathrm{n}=8, \mathrm{~F}=5.079$, $\mathrm{p}=0.030$; reared females $-0.925-1.200 \mathrm{~mm}, 1.077 \pm 0.010 \mathrm{~mm}, \mathrm{n}=45$, wild females $-1.075-1.350 \mathrm{~mm}, 1.225 \pm 0.025 \mathrm{~mm}, \mathrm{n}=12, \mathrm{~F}=42.979, \mathrm{p}<<0.001)$. They are also usually lighter, with less distinct brown pattern on the adominal terga. However, similarly pale specimens were also found among specimens captured in wild. Lowest values of body and wing length given in the above description were taken from reared specimens but they may rarely also occur in wild populations. Interestingly, size and colouring seem to be less affected by conditions of lab-rearing in males than in females.

\section{Discussion:}

The new species is very similar and closely allied to $S$. minor sp. n. These species form a sister-pair characterized by very similar colouring of head and thorax, chaetotaxy and general structure of the male genitalia. A number of genitalic characters (including epandrium with dorsally poorly delimited anal fissure; elongate shape of gonostylus; slender hypandrium; saccus haired in addition to a few thick spines; filum relatively compact, with short, flat and finely dentate apex) are considered apomorphic and demonstrate close relationships of $S$. stylatum and S. minor to another sister-pair, viz. S. vittatum and S. sororium (see below).

Because of the large external resemblance of $S$. stylatum sp. n. and S. minor sp. n. it is sometimes difficult to separate these species by non-genitalic characters. There are small differences in darker markings on frons, occiput, male face, mesonotum, apical tarsal segments and preabdominal terga, it is true, but some of them may be variable. More reliable diagnostic criteria can be found in the male genitalia, e.g. in the male $S 6$, gonostylus, postgonite, basal membrane below transandrium, apex of filum of distiphallus etc. (see key). 
In addition to the type series some other specimens have been examined which do not fit the above description in some respect. They may represent aberrant individuals lying close to the limits of the variation of $S$. stylatum or belong to another closely allied taxon. As this question is unsolvable because of the limited material, these specimens are listed separately to be available for future study as and when new material is acquired.

\section{Biology:}

This species is collected only sporadically and not yet in large series despite its relatively wide geographic distribution. It is known to be sympatric with $S$. balteatum, and more rarely with $S$. setipleurum, S. pectinatum, and S. humerale in Ontario (Sault Ste. Marie, Algoma University College). This collection site stays moist late into the season and borders a small depression of Typha. There is a fairly pure component of Carex aquatilis here while the co-dominant graminoids are Calamagrostis canadensis and Phalaris arundinacea. Six females collected from the bases of Carex aquatilis from this site (31. vii. to 18.viii.2002) were used to attempt rearing and production of immature stages for description. Laboratory rearing of $S$. stylatum followed the outline provided under $S$. balteatum and produced 82 individual adults from eggs. The 6 females lived in captivity until being killed or found dead and their survival time ranged from 1 to 83 days (1, $26,29,67,81,83$ days). As in $S$. balteatum, prolonged survival is possible for adults in the laboratory. Oviposition continued through the period of 4.viii. to 10.x. but unlike $S$. balteatum (see above), eggs obtained this way hatched within a short period (time not measured as eggs handled in batches of 4-11 days exposure to females). Larvae were provided with moist sections of $C$. aquatilis collected in late-summer or autumn, and presented either fresh or frozen, then thawed (as for $S$. balteatum). Timing of development from neonate larva to puparium formation also was not possible with these groups of eggs. However, development from puparium to adult required $8-11$ days (mean $9.3 \pm 0.1$ s.e., $\mathrm{n}=80$ with two outliers of 6 and 7 days removed as judged to have had pupariation date overlooked). The gender ratio was approximately 1:1.5 (33 males, 49 females).

The previously noted size difference (see above) between reared and wild-caught specimens suggests suboptimal rearing conditions for $S$. stylatum. Except for the difference in timing of larval feeding (egg diapause in $S$. balteatum required delay and exclusive use of frozen/thawed Carex) the rearing procedures were the same for these two species. Only one point of comparison is possible, that being development time from puparium formation to adult eclosion. The ranges for these two species are barely overlapping $(S$. stylatum - 8-11 days; S. balteatum - 11-13 days; only 3 specimens requiring 11 days) and their means differ by about 2.2 days ( 9.3 and 12.5 , respectively). If nothing more, this provides physiological or ecological evidence that these two species function differently in a yet unknown way in the same habitat. The immature stages will be described at a later date.

\section{Distribution:}

A wide distribution (USA: Minnesota, Utah and Canada: Ontario, Manitoba) comprised of sparse collection records describes what is known for $S$. stylatum. Undoubtedly it is being overlooked over a large part of the continent. 


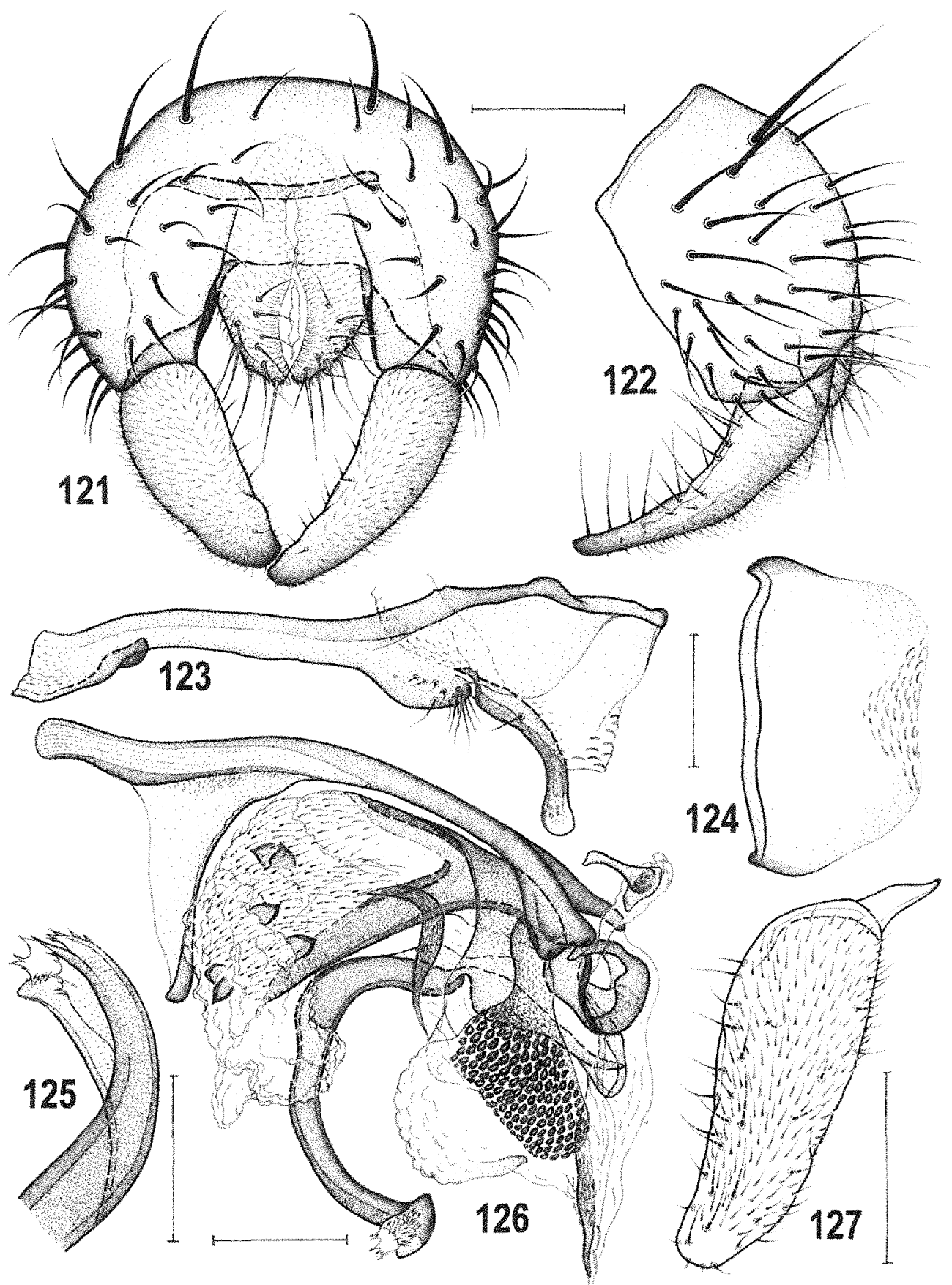

Figs 121-127: Stiphrosoma stylatum sp. n., male paratype (Canada: Ontario). 121 - external genitalia caudally; 122 - ditto laterally; 123 - hypandrium and associated structures laterally; 124 - transandrium and basal membrane caudally; 125 - apex of filum ventrally; 126 - aedeagal complex laterally; 127 - gonostylus posterolaterally (widest extension view). Scales: Figs $125,127=0.05 \mathrm{~mm}$, others $=0.1 \mathrm{~mm}$. 


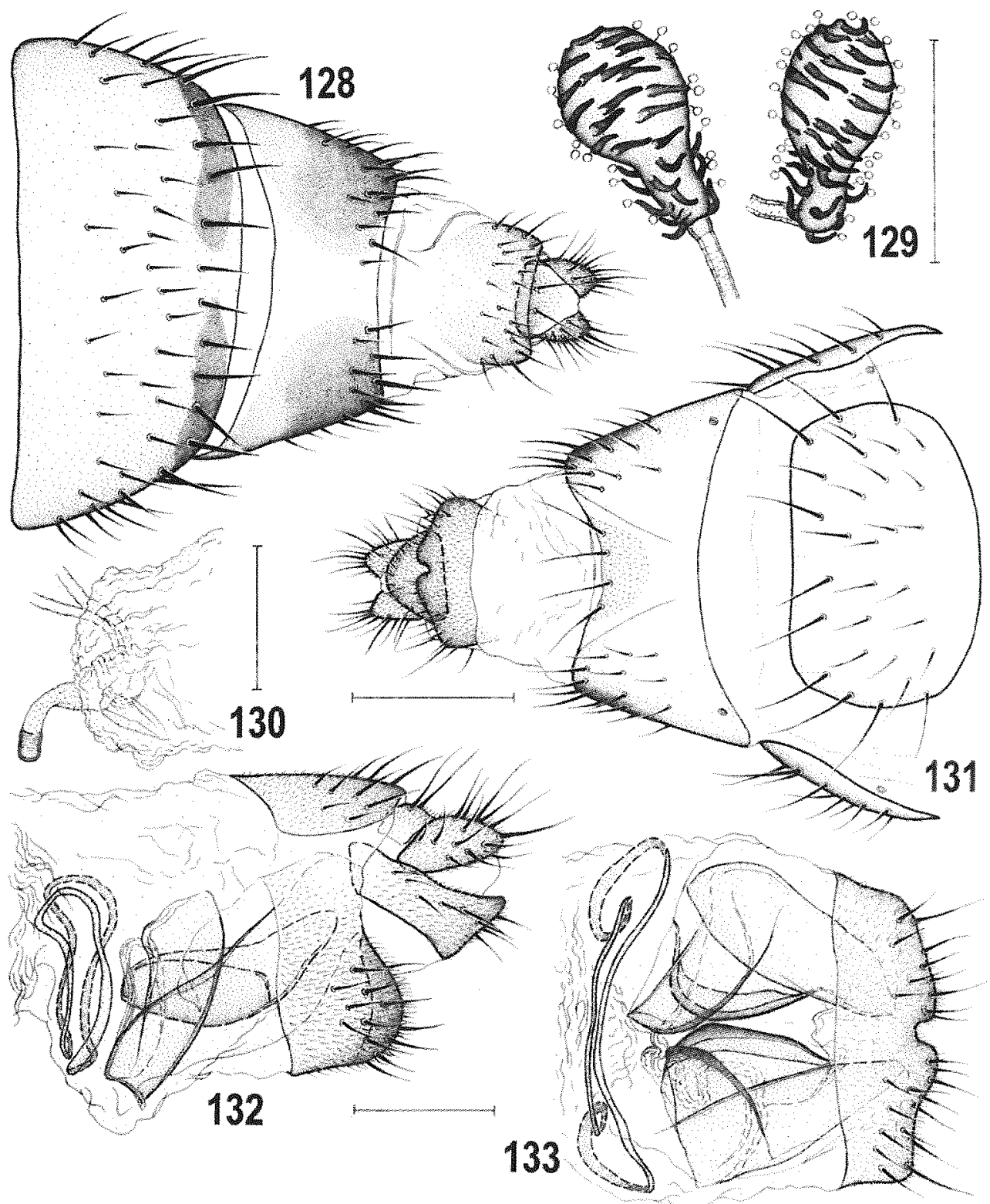

Figs 128-133: Stiphrosoma stylatum sp. n., female paratype (Canada: Ontario). 128 - postabdomen dorsally; 129 - spermathecae; 130 - ventral receptacle laterally; 131 - postabdomen ventrally; 132 - apex of postabdomen laterally; 133 - internal sclerites and S8 ventrally. Scales: Figs $128,131=0.2 \mathrm{~mm}$, others = $0.1 \mathrm{~mm}$. 


\section{Stiphrosoma minor sp. n.}

(Figs 134-141, 211)

\section{Type material:}

Holotype male labelled: "Ramsey Cn.-ARIZ Huachuca Mts. 10.IV.675500'D.M.Wood" (CNCI, genit. prep.). Paratypes: USA: Arizona: Santa Cruz Co., Patagonia, $31.53^{\circ} \mathrm{N}$ 110.77 W, 15.i.1994, Malaise trap, 1 male, B. V. Brown \& E. Wilk leg. (LEMQ, genit. prep.); Santa Cruz Co., Sycamore C[anyo]n, Ruby Rd, 11-13.vi.1982, 1 male, W. J. Hanson leg. (EMUS, genit. prep.).

Etymology: The name refers to the smaller gonostylus of the species in comparison with that of S. stylatum (minor = L. smaller).

\section{Description:}

Male. Total body length 1.74-1.87 mm; general colour yellow to ochreous yellow, with some brown markings. Head distinctly higher than long. Frons yellow, with pale yellow orbits; frontal triangle poorly visible, probably reaching to anterior third frons; ocellar triangle brown between ocelli; no darker pattern behind lunule. Occiput yellow, paler medially above foramen. Face narrow, ochreous, with single brown medial stripe and narrow lateral margins; parafacialia and gena pale to whitish yellow and silvery white microtomentose, gena ventrally narrowly pale brown margined; mouthparts yellow. Cephalic chaetotaxy as in S. stylatum but pvt with only apices crossed; vte almost as long as vti and also oc and posterior ors of the same length. Eye size and shape as in S. stylatum; smallest genal height about 0.12 times as long as shortest eye diameter. Antenna uniformly yellow or orange; 1 st flagellomere anteroventrally with white ciliation (slightly shorter than longest rays of arista). Arista dark brown with ochreous basal segments, about twice length of antenna, relatively shorty pectinate.

Thorax very slightly narrower than head. Mesonotum including scutellum yellow to ochreous yellow, with more or less distinct narrow pale brown medial stripe reaching to level of posterior $\mathrm{dc}$ and with somewhat darkened lateral spot extended from suture to postalar seta (i.e. distinctly shorter than in S. stylatum); humeral and notopleural areas distinctly lighter, whitish yellow and contrasting with brown dorsal band across pleural part of thorax; rest of pleuron pale yellow. Mesonotum subshining, sparsely microtomentose. Thoracic chaetotaxy: prs small and weak, about as long as longest dc microseta in front of anterior dc; other setae as in S. stylatum but medial rows of ac microsetae reaching (at most) to level of posterior dc. Scutellum as in $S$. stylatum.

Legs completely yellow, including apical tarsal segments. $f_{1}$ with short and weak ctenidial spine, slightly shorter than maximum width of $t_{1}$. Ventroapical seta on $t_{2}$ short as in $S$. stylatum. Posteroventral row on $\mathrm{f}_{3}$ composed of fewer setae than in $S$. stylatum, with only 5-6 in apical two-fifths thickened; $t_{3}$ as in $S$. stylatum but hind basitarsus with weaker ventrobasal setulae.

Wing (Fig. 211) very similar to that of $S$. stylatum including $\mathrm{R}_{2+3}, \mathrm{R}_{4+5}$ and both cross-veins; $\mathrm{M}$ almost straight; $\mathrm{dm}$ cell somewhat shorter than in $S$. stylatum; $\mathrm{CuA}$ almost reaching wing margin. $A_{1}$, alula and anal lobe as in S. stylatum. Wing measurements: length 1.90$2.06 \mathrm{~mm}$, width $0.69-0.76 \mathrm{~mm}, \mathrm{Cs}_{3}: \mathrm{Cs}_{4}=1.31-1.50, \mathrm{r}-\mathrm{mldm}-\mathrm{cu}: \mathrm{dm}-\mathrm{cu}=2.53-2.94$. Haltere darker than in $S$. stylatum, ochreous yellow, with pale brown tinge on stem. 
Abdomen yellow with brown pattern on terga. $\mathrm{T} 1$ ochreous yellow, only laterally darkened. T2 and T3 with subtriangular brown spots covering posterolateral area on each side; T4 and T5 with brown transverse band along posterior margin, usually shortened (narrowed) in the middle. Preabdominal sterna pale yellow, narrow but becoming wider posteriorly ( 55 largest) and all, except for S1, finely setulose. T6 reduced to unpigmented (poorly visible) and bare remnant on right side. S6 (Fig. 137) yellow with brown and heavily sclerotized anterior marginal stripe (twice thicker than that of $S$. stylatum) and 2-3 setae; S7 yellow to ochreous, with 1-2 setae; S8 more setose and brown, contrasting in colour with both $\mathrm{S} 7$ and yellow epandrium.

Genitalia. Epandrium (Figs 134-135) shorter than high and relatively broad (wider than in S. stylatum) densely setose, with 2 pairs of dorsolateral setae longer than others. Dorsal side of epandrium convex; anal fissure rounded triangular but its dorsal margin poorly delimited. Cercus (Figs 134-135) relatively larger and more projecting that in S. stylatum. Medandrium (Fig. 134) large and weakly sclerotized. Gonostylus (Fig. 141) shorter than epandrial height, slender, more tapering towards apex than in S. stylatum, and in lateral view distinctly concave anteriorly; its outer side largely micropubescent except for apex and narrow anterior area, inner side with long anterior setae. Hypandrium (Fig. 136) slender, weakly sclerotized, less dilated posteriorly that in S. stylatum. Transandrium simple, slightly double sinuous; basal membrane markedly shorter that in $S$. stylatum, ventrally with a group of small hyaline tubercles and spines (Fig. 139). Pregonite (Fig. 136) smaller and less projecting than that of $S$. stylatum, with fewer (9-10) fine setae; postgonite (Fig. 140) similar to that of $S$. stylatum but shorter and with less dilated unpigmented apex. Aedeagal complex. Phallapodeme more robust than in S. stylatum, and with dilated, ventrolaterally projecting corners of apex. Aedeagal part of folding apparatus laterally with large group of small spine-like dark tubercles; connecting sclerite slender, dark, distally tapered. Aedeagus (Fig. 140) with frame-like phallophore (shorter than in S. stylatum) and large distiphallus. Saccus generally similar to that of $S$. stylatum but proximally less sclerotized, but armed by more (about 8) short thick and dark spines (on left side) and less densely haired on right side. Filum closely resembling that of $S$. stylatum, but its apex finely pubescent and densely spinulose (Figs 138, 140). Ejacapodeme pigmented, with digitiform projection pointed.

Female unknown.

\section{Discussion:}

S. minor sp. $\mathrm{n}$. is undoubtedly the closest relative of $S$. stylatum. It differs from the latter species by the robust ventral projection of male $S 6$, shorter and more pointed gonostylus, lower pregonite, narrower apex of postgonite, different apex of filum and ejacapodeme. The female of $S$. minor is unknown but it will probably be very similar to that of $S$. stylatum.

\section{Biology:}

The Patagonia site is within the Patagonia-Sonoita Creek Preserve (The Nature Conservancy) with the Malaise trap located on the edge of a grassy meadow (horse grazing remediation) and cottonwood-willow riparian forest $(-50 \mathrm{~m}$ from Sonoita Creek; B. V. Brown, pers. comm.). Similar riparian elements and graminoids are likely in the other two recorded sites.

\section{Distribution:}

Known only from southern Arizona, USA. 

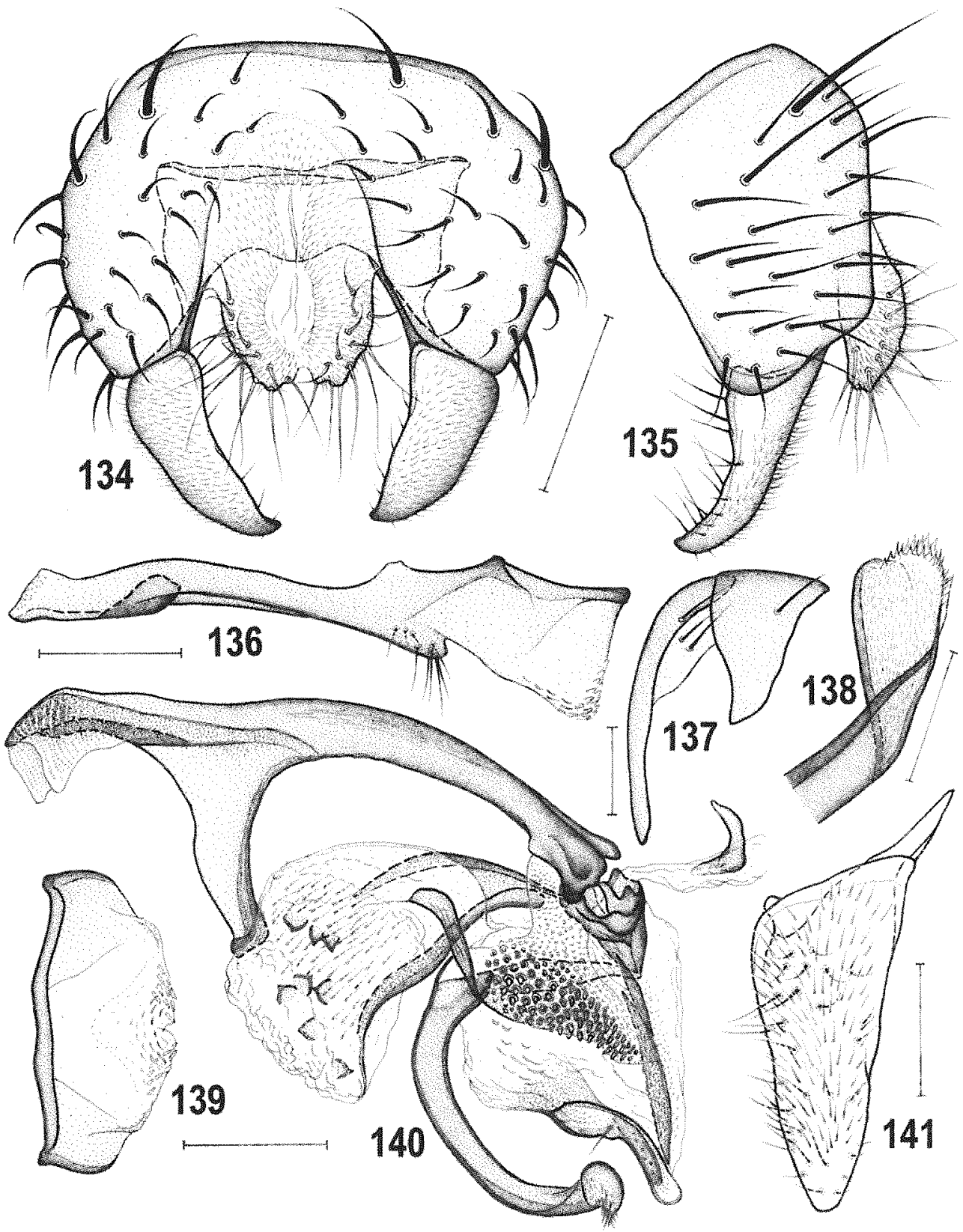

Figs 134-141: Stiphrosoma minor sp. n., male paratype (USA: Arizona). 134 - external genitalia caudally; 135 - ditto laterally; 136 - hypandrium and associated structures laterally; 137 - S6-S7 ventrally; 138 - apex of filum ventrally; 139 - transandrium and basal membrane caudally; 140 - aedeagal complex laterally; 141 - gonostylus posterolaterally (widest extension view). Scales: Figs 138, $141=0.05 \mathrm{~mm}$, others = $0.1 \mathrm{~mm}$. 


\section{Stiphrosoma vittatum sp. n.}

(Figs 142-154, 212)

Type material:

Holotype male labelled: "CA: Marin Co., Point Reyes, 19.iv.1980, S. A. Marshall" (DEBU, intact). Paratypes: USA: California: same data as for holotype, 1 male (DEBU); Mendocino Co., Ukiah, 5.viii. 1953, 1 male (headless) (CASC); San Mateo Co., Redwood City, 16.iii.1969, 1 female (CASC); San Francisco, vic. Lake Merced, 4.v.1967, 1 female (CASC) all P. H. Arnaud leg.; Santa Cruz Co., Santa Cruz, 17.vii.1940, 2 males, B. Brookman leg. (CASC); U. California, Riverside, i.1983, Malaise trap, 1 female, D. Yu leg. (DEBU); Riverside, 5.v.1935, 1 male (headless), A. L. Melander leg. (USNM); same locality, 23.iv.1962, 1 female, S. Frommer leg. (UCRC); Los Angeles Co., Arcadia Arboretum, 18.ix.1949, 1 male, 12.x.1949, 1 female, 24.xii.1949, 1 female, all M. R. Wheeler leg. (AMNH, SMOC); same locality, 15.x.1949, 1 male, A. L. Melander leg. (USNM); Los Angeles Co., San Gabriel Riv., 18.ix.1949, 1 male (labelled "Anthomyza vittata Mel M.S.", AMNH); Los Angeles Co., Pasadena, 24.iv. 1950, 1 female (AMNH); Rio Hondo, 8.ii.1950, 1 female (AMNH) all M. R. Wheeler leg.; Rio Hondo, 14.xii.1949, 1 male, A. L. Melander leg. (USNM); Rosemead, 22.ii. 1950, 2 males 1 female (USNM, SMOC); Morro Bay, 27.vii.1940, 1 female (USNM) all A. L. Melander leg.; San Diego Co., Rancho Santa Fe, 14.i.1959, collected by vacuum cleaner in alfalfa field, 1 female, E. I. Schlinger leg. (UCRC); Yuba Co., Sierra Foothill Field Sta., 3 mi N Smartville, 2.v.1980, 1 female, J. A. Powell leg. (EMEC). Several paratypes with genit. prep.

\section{Other $S$. vittatum material not designated as paratypes:}

USA: California: Rosemead, 22.iii.1950, 1 male (missing head and abdomen), A. L. Melander leg. (USNM).

Etymology: The name refers to the longitudinally banded mesonotum of the new species $($ vitta $=$ L. band $)$ and acknowledges a manuscript name suggested by A. L. Melander.

\section{Description:}

Male. Total body length $1.55-2.18 \mathrm{~mm}$; general colour yellow and brown. Head slightly higher than long. Frons whitish yellow, with narrow yellow frontal triangle (poorly visible) reaching to anterior third of frons; ocellar triangle brown to dark brown. Occiput largely brown laterally, with yellow, ventrally tapered, medial area above foramen having a pair of whitish microtomentose stripes, and with yellow ventral part below foramen. Face narrow, with brown pattern consisting of 3-4 longitudinal stripes ( 3 if medial pair coalesced; lateral pair forming boundary between face and parafacialia); parafacialia (except brown margin) and gena (including postgena) yellowish white and silvery white microtomentose; mouthparts yellow. Cephalic chaetotaxy: pvt small, meeting or crossed medially; vti longest of cephalic setae; vte, oc and posterior ors slightly shorter than vti; 2 ors, anterior strong although shorter than posterior; 1-2 microsetulae in front of anterior ors; only 1 pair of medial microsetulae in front of frontal triangle; vi almost as long as posterior ors; subvibrissa weak, two-thirds or less of vi length; 5-6 peristomal setulae; also postgena with several setulae; postocular microsetulae minute, in single row. Eye elongately suboval; its longest (oblique) diameter 1.4-1.5 times as long as shortest; smallest genal height about 0.12 times as long as shortest eye diameter. Antenna yellow; 
1st flagellomere pale to whitish yellow but brownish darkened around base of arista and with long white cilia anteroventrally. Arista 1.8-1.9 times as long as antenna, dark brown, shortly pectinate.

Thorax slightly narrower than head. Mesonotum with 3 brown and 2 yellow longitudinal stripes: medial brown stripe reaching from cervix and posteriorly widened on scutellum; lateral vitta anteriorly shorter (beginning at foremost dc setula) but broader, posteriorly narrowed to cover lateral sides of scutellum; yellow stripe between medial and lateral brown vittae also prolonged on scutellum; humeral and notopleural areas whitish yellow. Pleural part of thorax pale yellow with broad brown dorsal band extending from cervix to base of haltere. Mesonotum sparsely microtomentose, subshining. Thoracic chaetotaxy: prs very small (as long as longest dc microseta); $2 \mathrm{dc}$, anterior longer than anterior $\mathrm{npl}$ but distinctly shorter than posterior dc; 5-7 dc microsetae in front of anterior dc; ac microsetae in 4 rows anteriorly, in 2 rows behind anterior $\mathrm{dc}$ posteriorly ending at or behind level of posterior dc; $2 \mathrm{sc}$, basal relatively long (as long as anterior $\mathrm{dc}$ ), apical strong and as long as posterior dc; 2 stpl (anterior markedly shorter and weaker) and 1 microseta in front of anterior stpl; 2-4 additional setulae in dorsal half of sternopleuron and more longer setae ventrally. Scutellum rounded triangular, with flattened disc.

Legs pale yellow, at most apex of last tarsal segments darker yellow (as viewed from sharp apical angle). $f_{1}$ with ctenidial spine slightly to distinctly shorter than maximum width of $t_{1}$. Ventroapical seta on $t_{2}$ normal. $f_{3}$ with posteroventral row of setae, 8-9 in distal half thickened; $t_{3}$ without distinct ventroapical seta; hind basitarsus with 2-3 short and weak ventrobasal setae.

Wing (Fig. 212) with pale ochreous-brown membrane and veins. $R_{2+3}$ long, bent in parallel to $C$ and apically slightly upcurved to it; $R_{4+5}$ slightly bent posteriorly; $M$ almost straight or very slightly bent. Discal $(\mathrm{dm})$ cell relatively long, slightly widened distally, $\mathrm{r}-\mathrm{m}$ situated in basal third to two-fifths of $\mathrm{dm}$ cell. CuA slightly bent, ending near wing margin; $A_{1}$ short, ending far from it. Alula narrow; anal lobe well developed. Wing measurements: length $1.70-2.22 \mathrm{~mm}$, width $0.57-0.75 \mathrm{~mm}, \mathrm{Cs}_{3}: \mathrm{Cs}_{4}=1.44-1.56, \mathrm{r}-\mathrm{m} \backslash \mathrm{dm}$ $\mathrm{cu}: \mathrm{dm}-\mathrm{cu}=2.64-3.29$. Haltere with whitish knob and yellow stem.

Abdomen. Terga mostly brown, only T4-T5 with whitish yellow pattern. T1 short, entirely brown. T2 and T3 also brown, at most somewhat lighter dorsomedially; T4 and T5 brown, each with a pair of anterior pale yellow semicircular spots which may be anteromedially coalesced. Preabdominal sterna S2-S5 pale yellow, becoming wider posteriorly, finely setulose. T6 reduced to short, pale brown, transversely band-like sclerite (bare or with 1-2 pairs of microsetulae) being wider on right side. S6-S8 brown; S6 with dark brown heavily sclerotized anterior marginal band continued on ventral projection; S6 with 3-5, S7 usually with 3 setae; S8 dark brown, setose, contrasting with pale yellow epandrium.

Genitalia. Epandrium (Figs 142-143) slightly longer than that of S. sororium, moderately setose, with dorsolateral seta longer than others. Dorsal side of epandrium convex; anal fissure rounded triangular, poorly delimited dorsally, relatively large. Cercus (Figs 142143) moderate, finely setose. Medandrium (Fig. 142) weakly sclerotized, narrower than in S. sororium. Gonostylus (Fig. 148) slender and narrow, tapered in distal two-thirds, with apex rounded; micropubescence extended over most of outer side except for anterior margin and apex; setae at anterior margin of inner side relatively long (cf. Fig. 143). 
Hypandrium (Fig. 144) slender and weakly sclerotized. Transandrium distinctive, with slender, characteristically bent posterior ledge (Fig. 145); basal membrane ventrally with small medial group of small transverse tubercles. Pregonite (Fig. 144) slightly projecting ventrally, similar to $S$. sororium with numerous (about 10 ) fine setae, mainly internally. Postgonite (Fig. 144) simple, slightly bent, with 1 seta near middle and hyaline rounded apex. Aedeagal complex (Fig. 147). Phallapodeme moderate, with slender fulcrum, deeply forked base and wing-like, laterally widened apex. Aedeagal part of folding apparatus armed by numerous dense spines (longer than in $S$. sororium); connecting sclerite slender, long, finely granulose. Aedeagus (Fig. 147) with short, frame-like phallophore and robust distiphallus with well sclerotized base. Saccus voluminous, membranous, very finely haired (mainly on right side), with 4 short and broad spines in the middle and 2 additional ones at apex. Filum slender, dark, strongly curved, with band-like sclerites largely fused together; its apex terminated in a number of fine hyaline teeth (Figs 146147). Ejacapodeme with digitiform projection with preapically toothed capitulum.

Female. Similar to male unless mentioned otherwise. Total body length $1.78-2.30 \mathrm{~mm}$. Head with brown markings often paler, e.g. on occiput. Face typically with simple broad pale brown band and margins of parafacialia (in immature specimens face ochreous), more rarely dark striped as in male. Thoracic pattern with lateral vitta sometimes paler brown or narrower. $f_{1}$ with ctenidial spine sometimes slightly longer but never exceeding maximum tibial width. $\mathrm{f}_{3}$ without thickened posteroventral setae. Wing measurements: length $1.90-$ $2.38 \mathrm{~mm}$, width 0.65-0.83 mm, $\mathrm{Cs}_{3}: \mathrm{Cs}_{4}=1.33-1.54, \mathrm{r}-\mathrm{mldm}-\mathrm{cu}: \mathrm{dm}-\mathrm{cu}=2.47-3.33$.

Abdomen pale yellow, with brown pattern on terga. $T 1$ usually largely yellow, brown only laterally; T2 ochreous yellow, brown along posterior and lateral margins; T3-T5 pale or whitish yellow, with brown band along lateral and posterior margins and with medial stripe coalesced with posterior band but sometimes shortened anteriorly (not reaching anterior margin of terga); the medial dark pattern together forms longitudinal band across middle of T3-T5. T4 and T5 with setae also in anterior third, not only posteriorly. S2-S5 whitish yellow, finely setulose, S5 the widest as usual.

Postabdomen (Figs 149, 153). T6 large, yellow with a pair of brown spots at posterior corners, shortly densely setose. S6 suboblong, distinctly narrower than in S. sororium, with longer setae at lateral and posterior margins. Tergosternum $\mathrm{T} 7+\mathrm{S} 7$ dorsally dark brown but medially unpigmented and seeming divided (Fig. 149); ventrally pale yellow and its original S7 reduced to small, poorly delimited area carrying 4-5 longer fine setae. T8 (Fig. 149) distinctly smaller than in $S$. sororium but with similar dark pattern being anteriorly tapered and indistinctly margined. S8 (Fig. 153) somewhat longer than that of S. sororium, with usual posteromedial cleft. Internal structures of female genital chamber (Fig. 152) formed by two pairs of posterior pale sclerites (ventral pair larger, subtriangular) and 1 anterior, very slender, tranversely compressed looped sclerite. Ventral receptacle (Fig. 151) simply subcylindrical, on longer duct than that of $S$. sororium. Accessory gland elongately bag-like, with finely granulose internal structure. Spermathecae (Figs $150,154)$ shortly pyriform, with more robust base and thicker curved spines (transversely attached to surface on broad distal part) than those of S. sororium. T10 (Fig. 149) small, bare, unpigmented except for small stripes leading to bases of 2 dorsal setae. S10 unusually short, anteriorly with small medial triangular lobe (Fig. 153). Cerci very short, shortly setose, with lateral setae slightly longer than (thicker) apical setae. 


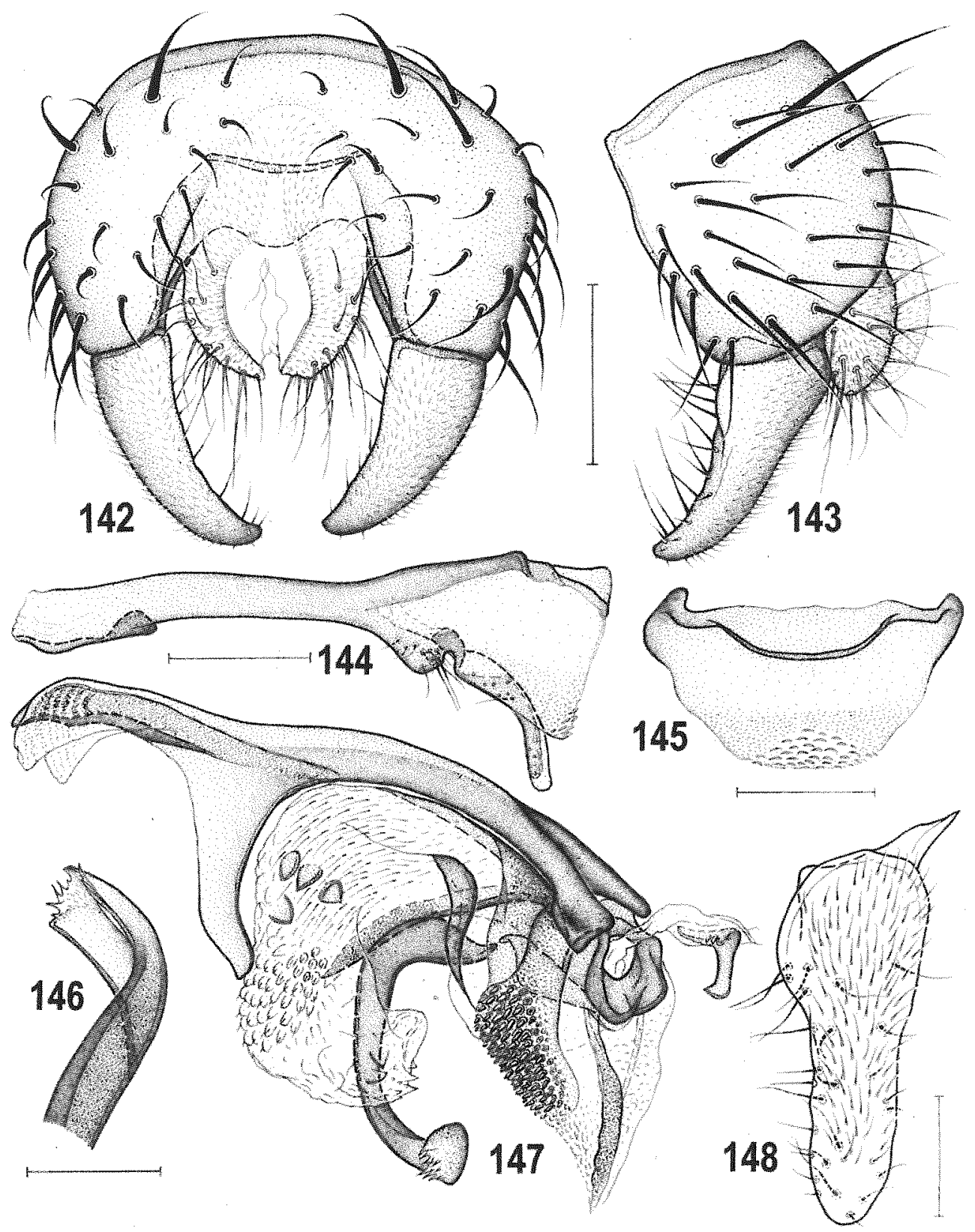

Figs 142-148: Stiphrosoma vittatum sp. n., male paratype (USA: California). 142 - external genitalia caudally; 143 - ditto laterally; 144 - hypandrium and associated structures laterally; 145 - transandrium and basal membrane caudally; 146 - apex of filum ventrally; 147 - aedeagal complex laterally; 148 - gonostylus posterolaterally (widest extension view). Scales: Figs $146,148=0.05 \mathrm{~mm}$, others $=0.1 \mathrm{~mm}$. 


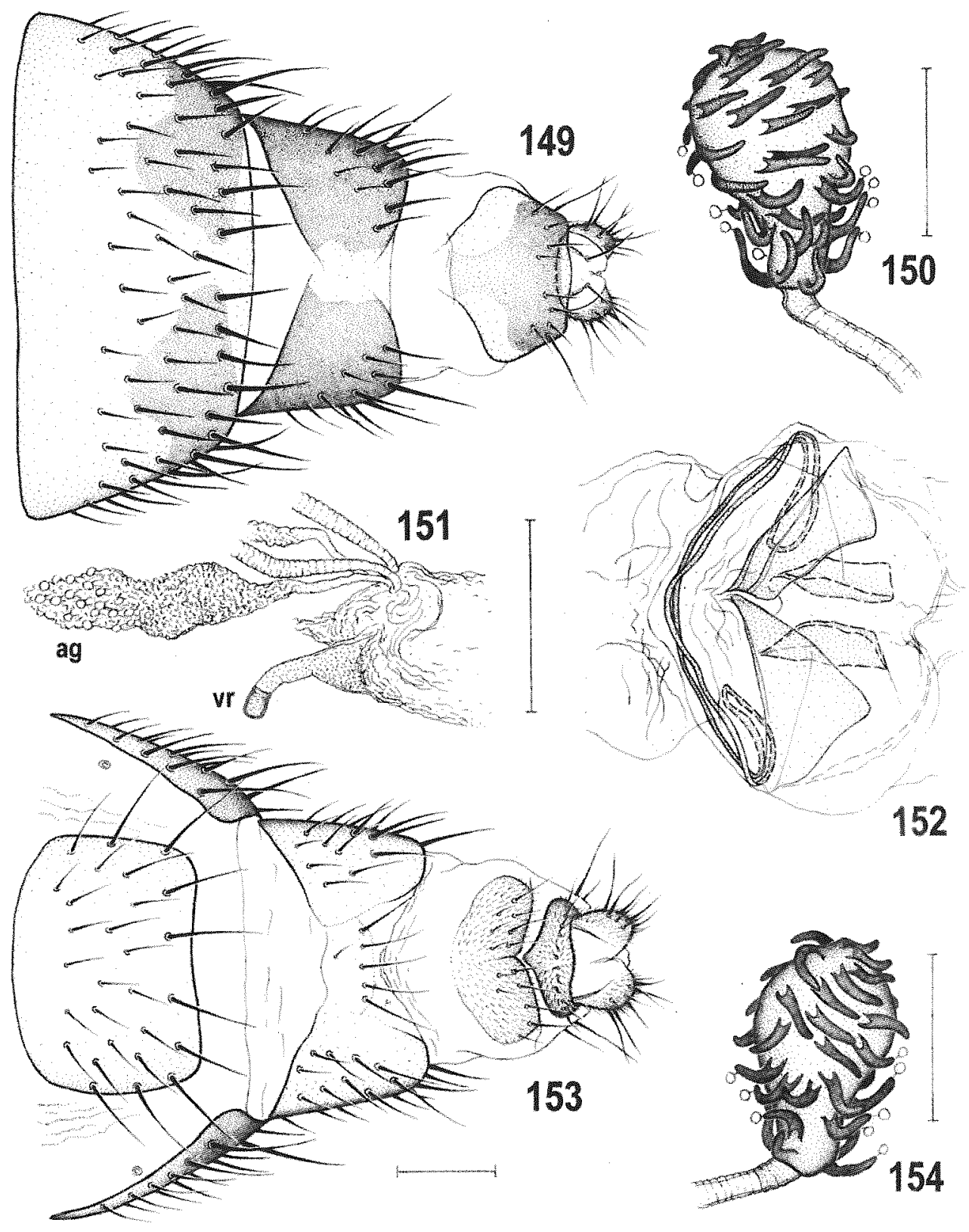

Figs 149-154: Stiphrosoma vittatum sp. n., female paratype (USA: California). 149 - postabdomen dorsally; 150 - spermatheca; 151 - ventral receptacle and accessory gland laterally; 152 - internal sclerites ventrally; 153 - postabdomen ventrally; 154 - spermatheca. Scales: Figs $150,154=0.05 \mathrm{~mm}$, others $=0.1 \mathrm{~mm}$. 


\section{Discussion:}

S. vittatum sp. $\mathrm{n}$. forms with $S$. sororium sp. n. a sister-pair of very closely related species as is demostrated by the following features: mesonotum with broad medial brown band; gonostylus tapered in the middle, saccus with tuberculate area on anterior surface in distal third; female T8 with T-shaped to Y-shaped dark pattern. These species can be recognized by the features given in the key. For the male $S$. vittatum the shape of gonostylus, modified transandrium (see Fig. 145) and armature of saccus are the most diagnostic; the female can be identified by the T-shaped dark pattern of $S 8$ and by the very slender, tape-shaped looped sclerite.

\section{Biology:}

The only specific information comes in the implication of alfalfa fields as a potential habitat. It could be just as plausible that this species occurs widely in hedgerows of similarly disturbed habitats and poorly maintained urban areas. Moisture may be a limiting factor and references to water bodies are evident in the label data.

\section{Distribution:}

Known only from USA: California but widely distributed within the state.

\section{Stiphrosoma sororium sp. n.}

(Figs 155-167, 213)

\section{Type material:}

Holotype male labelled: "MEX. Chis. 7200 ft., S. Crist. las Casas, 1. June 1969, Malaise Trap" [-] leg. (CNCI, intact). Paratypes: same data as for holotype, 3 males 5 females (CNCI, SMOC, 1 male headless, 2 males 2 females with genit. prep.); MEXICO: Chiapas: San Cristobal de las Casas, 7087', 17.v.1969, 2 females, B. V. Peterson leg. (CNCI, 1 with genit. prep.).

Etymology: The species is named „sororium" (= L. sisterly) because it is considered a sister-species of $S$. vittatum.

\section{Description:}

Male. Total body length 1.70-1.99 mm; general colour darker than in S. vittatum, brown and yellow. Head slightly higher than long. Frons yellow, with dark-yellow frontal triangle being laterally well delimited by narrow brownish stripes meeting at anterior margin of frons; ocellar triangle dark brown; orbits pale yellow and whitish microtomentose; lunule whitish yellow. Occiput largely brown, only medially with ochreous yellow area above foramen having a pair of whitish microtomentose stripes, and with small brightly yellow dorsolateral marginal spots and narrow ventral area below foramen. Face narrow, yellow, with brown pattern consisting of 3 longitudinal stripes ( 1 medial and 2 lateral forming boundary between face and parafacialia); parafacialia (except brown margin) and gena (including postgena) pale yellow but only parafacialia and anterior part of gena silvery white microtomentose; mouthparts yellow. Cephalic chaetotaxy: pvt small, meeting or crossed medially; vti longest of cephalic setae; vte, oc and posterior ors subequal, almost as long as vti; 2 ors, anterior strong although shorter than posterior; 2 microsetulae 
in front of anterior ors; 1 pair of medial microsetulae (often very reduced and invisible) near tip of frontal triangle; vi slightly shorter than posterior ors; subvibrissa weak, twothirds of vi length; 4-5 peristomal setulae; postgena also with several setulae; postocular microsetulae minute, in single row. Eye elongately suboval; its longest (oblique) diameter about 1.5 times as long as shortest; smallest genal height about 0.1 times as long as shortest eye diameter. Antenna with pedicel orange yellow; 1 st flagellomere whitish yellow but pale brown around base of arista, anteroventrally with white cilia as long as dorsal rays of arista. Arista 1.9-2.0 times as long as antenna, dark brown, shortly pectinate.

Thorax narrower than head. Mesonotum patterned by 3 brown and 2 yellow longitudinal stripes as in $S$. vittatum but in contrast to the latter species lateral sides of scutellum not darkened but yellow to ochreous, contrasting with broad brown medial band. Pleural part of thorax yellow to pale yellow with broad brown band as in S. vittatum. Mesonotum finely microtomentose, somewhat duller than in S. vittatum. Thoracic chaetotaxy: prs small (slightly longer than $\mathrm{dc}$ microsetae); $2 \mathrm{dc}$, anterior long, longer than anterior $\mathrm{npl}$ but shorter than posterior dc; 5-6 dc microsetae in front of anterior dc; ac microsetae in 4 rows anteriorly, in 2 rows more posteriorly, reaching behind level of posterior dc; $2 \mathrm{sc}$, also basal relatively long (slightly shorter than anterior dc), apical as long as posterior dc; $2 \mathrm{stpl}$ (anterior shorter and weaker) and 1 microseta in front of anterior stpl; 3-4 additional setulae in dorsal half of sternopleuron and several longer setae ventrally. Scutellum rounded triangular, with flattened disc.

Legs pale yellow, but last tarsal segments brown (Fig. 163). $f_{1}$ with ctenidial spine slightly to distinctly shorter than maximum width of $t_{1}$. Ventroapical seta on $t_{2}$ normal. $f_{3}$ with posteroventral row of setae, 6-8 in distal two-fifths short and thickened; $t_{3}$ without distinct ventroapical seta; hind basitarsus with 2 short and weak ventrobasal setae.

Wing (Fig. 213) relatively long, with pale ochreous-brown membrane and veins. $R_{2+3}$ long, bent in parallel to $C$ and apically very slightly upcurved to it; $R_{4+5}$ slightly bent posteriorly; $M$ almost straight or very slightly bent. Discal (dm) cell relatively long and narrow, moderately widened distally, $r-m$ situated in about basal third of $\mathrm{dm}$ cell. $\mathrm{CuA}$ slightly bent, ending near wing margin; $A_{1}$ short, ending far from it. Alula and anal lobe well developed. Wing measurements: length $2.06-2.32 \mathrm{~mm}$, width $0.69-0.77 \mathrm{~mm}, \mathrm{Cs}_{3}$ $: \mathrm{Cs}_{4}=1.41-1.81, \mathrm{r}-\mathrm{m} / \mathrm{dm}-\mathrm{cu}: \mathrm{dm}-\mathrm{cu}=3.35-3.78$. Haltere with yellowish white knob and ochreous-brown stem.

Abdomen. Terga largely brown, only T4-T5 with yellow to ochreous pattern which may be reduced. T1-T3 entirely brown. T4 and T5 brown, each with a pair of anterior yellow or ochreous semicircular spots which can be small or darkened (also in holotype). Preabdominal sterna S2-S5 pale yellow, becoming wider posteriorly, finely setulose. T6 reduced to short, small, pale brown, bare, crescent-shaped dorsal sclerite. S6-S7 ochreous, both usually with 2 setae. $S 6$ with dark brown heavily sclerotized anterior marginal band continued on ventral projection. S8 dark brown, setose, contrasting with yellow epandrium.

Genitalia. Epandrium (Figs 155-156) moderate, shorter and narrower than that of S. vittatum, with finer setae except for long and strong dorsolateral seta. Dorsal side of epandrium convex; anal fissure rounded triangular, poorly delimited dorsally, narrower than in S. vittatum (Fig. 155). Cercus resembling that of S. vittatum, finely setose. Medandrium (Fig. 155) very weakly sclerotized, relatively broad. Gonostylus (Fig. 157) slightly longer 
than in S. vittatum, also narrower proximally but tapered in the middle and apex broadly rounded; micropubescence restricted to dorsal three-fifths of outer side and setae on inner side shorter than in S. vittatum. Hypandrium (Fig. 158) slender and very similar to that of $S$. vittatum. Transandrium forming simple transverse band (Fig. 160); basal membrane as in S. vittatum. Pregonite (Fig. 158) more projecting ventrally than in S. vittatum. Postgonite (Fig. 158) also similar but with hyaline apex distinctly widened. Aedeagal complex (Fig. 161). Phallapodeme more slender, with shorter basal fork than that of S. vittatum. Aedeagal part of folding apparatus armed by shorter spines than in S. vittatum, connecting sclerite slender as in the latter species. Phallophore and basal part of distiphallus resembling those of $S$. vittatum. Saccus of distiphallus less densely haired than in $S$. vittatum, with only 2 dark robust spines in distal half (Fig. 161). Filum very similar to that of $S$. vittatum including armature of apex but with fine tubercle-like teeth in addition (Fig. 159). Ejacapodeme with digitiform projection terminated by simply rounded capitulum.

Female. Similar to male unless mentioned otherwise. Total body length $1.78-2.38 \mathrm{~mm}$. Face with simple broad brown band (often dorsally forked); margins of parafacialia yellow to ochreous, never brown. Mesonotum with lateral vitta sometimes paler brown but always distinct. $\mathrm{f}_{3}$ without thickened posteroventral setae, other pedal chaetotaxy as in male. Wing measurements: length $2.26-2.62 \mathrm{~mm}$, width $0.73-0.97 \mathrm{~mm}, \mathrm{Cs}_{3}: \mathrm{Cs}_{4}=$ $1.25-1.59, \mathrm{r}-\mathrm{m} \backslash \mathrm{dm}-\mathrm{cu}: \mathrm{dm}-\mathrm{cu}=2.90-3.33$.

Abdomen with more extensive brown pattern on terga than in S. vittatum. T1 brown except for yellow anterior marginal stripe; T2 entirely brown, sometimes with darker posterior margin. T3-T5 brown, each with a pair of large yellow semicircular spots situated at anterior margin but not coalesced anteromedially; thus the medial brown pattern on preabdomen looks like serrate longitudinal band formed by 3 coalesced triangles in middle of T3-T5. T4 and T5 with setae also in anterior third, not only posteriorly. S2-S5 whitish yellow, finely setulose, becoming wider posteriorly, S5 the widest.

Postabdomen (Figs 162,166). T6 pale yellow with dark spots in posterior corners as in $S$. vittatum but its shape less tapered posteriorly. $S 6$ wider and anteriorly narrowed in contrast to that of $S$. vittatum. Tergosternum $T 7+S 7$ also resembling that species in dorsal pigmentation (Fig. 162) but its ventral side different, having pale, posteriorly distinctly delimited remnant of S7 (see Fig. 166). T8 with conspicuous dark pattern being anteriorly narrow and sharply margined and posteriorly divided by pale medial area (Fig. 162). S8 shorter than in S. vittatum (Fig. 166). Female genital chamber (Fig. 165) with two pairs of posterior pale sclerites (larger pair rounded) and 1 looped sclerite being V-like compressed and more robust than that of S. vittatum. Ventral receptacle (Fig. 164) narrower cylindrical, and on shorter duct than in S. vittatum. Spermathecae pyriform (Fig. 167), with narrower basal part and with longer and more slender curved spines (transversely attached to surface on broad distal part) than those of $S$. vittatum. T10 (Fig. 162) hyaline, poorly delimited except for lateral margin, with some micropubescence and usual pair of dorsal setae. S10 larger and anteriorly simply margined in comparison to that of S. vittatum (Fig. 166). Cerci short, but apical setae longer than in S. vittatum.

\section{Discussion:}

The new species is very similar and closely related to $S$. vittatum (see under that species) and the differences from the latter species are enumerated in the description and the most important are given in the key. 


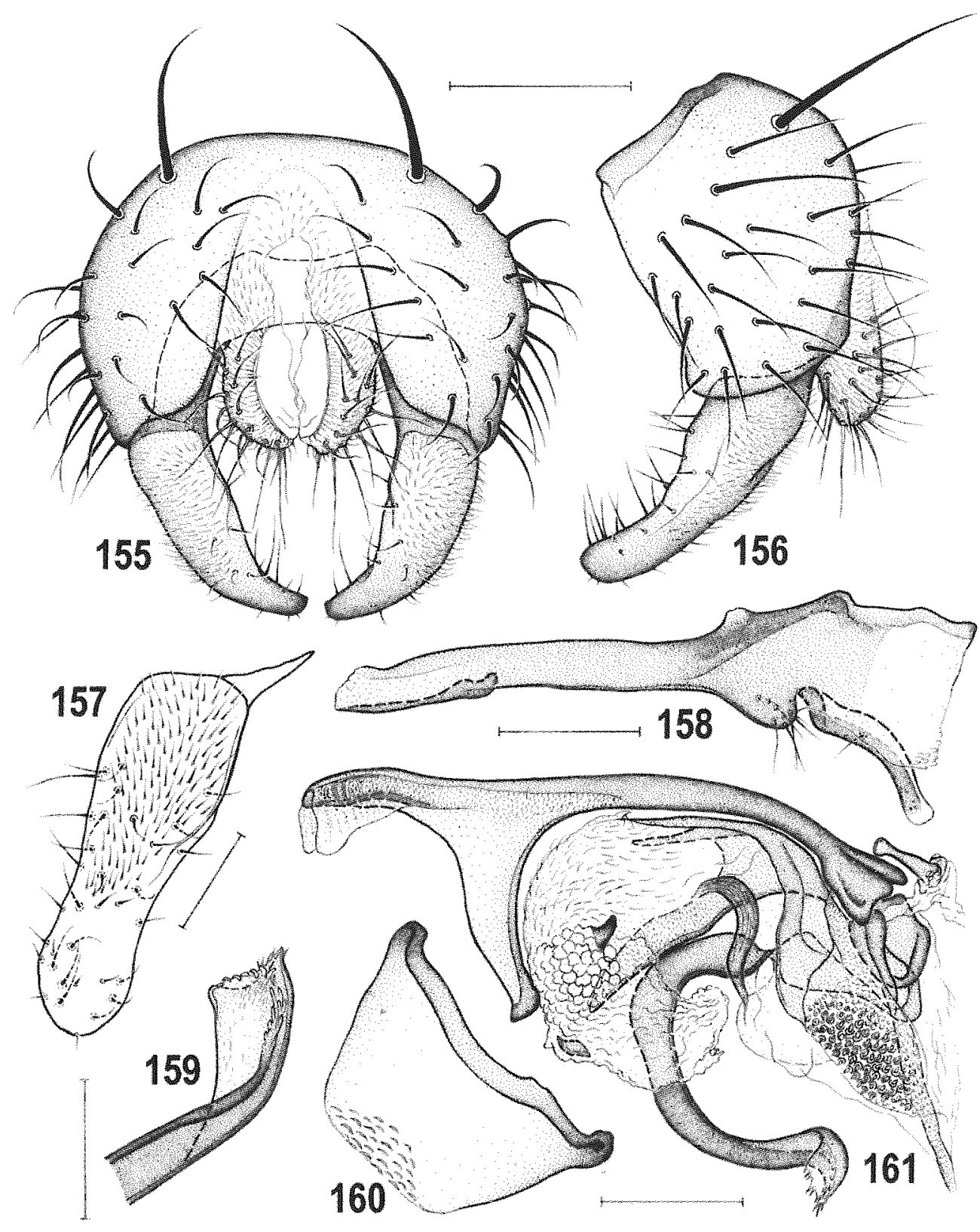

Figs 155-161: Stiphrosoma sororium sp. n., male paratype (Mexico). 155 - external genitalia caudally; 156 - ditto laterally; 157 - gonostylus posteroventrolaterally (widest extension view); 158 - hypandrium and associated structures laterally; 159 - apex of filum ventrally; 160 - transandrium and basal membrane caudally; 161 - aedeagal complex laterally. Scales: Figs $157,159=0.05 \mathrm{~mm}$, others $=0.1 \mathrm{~mm}$. 


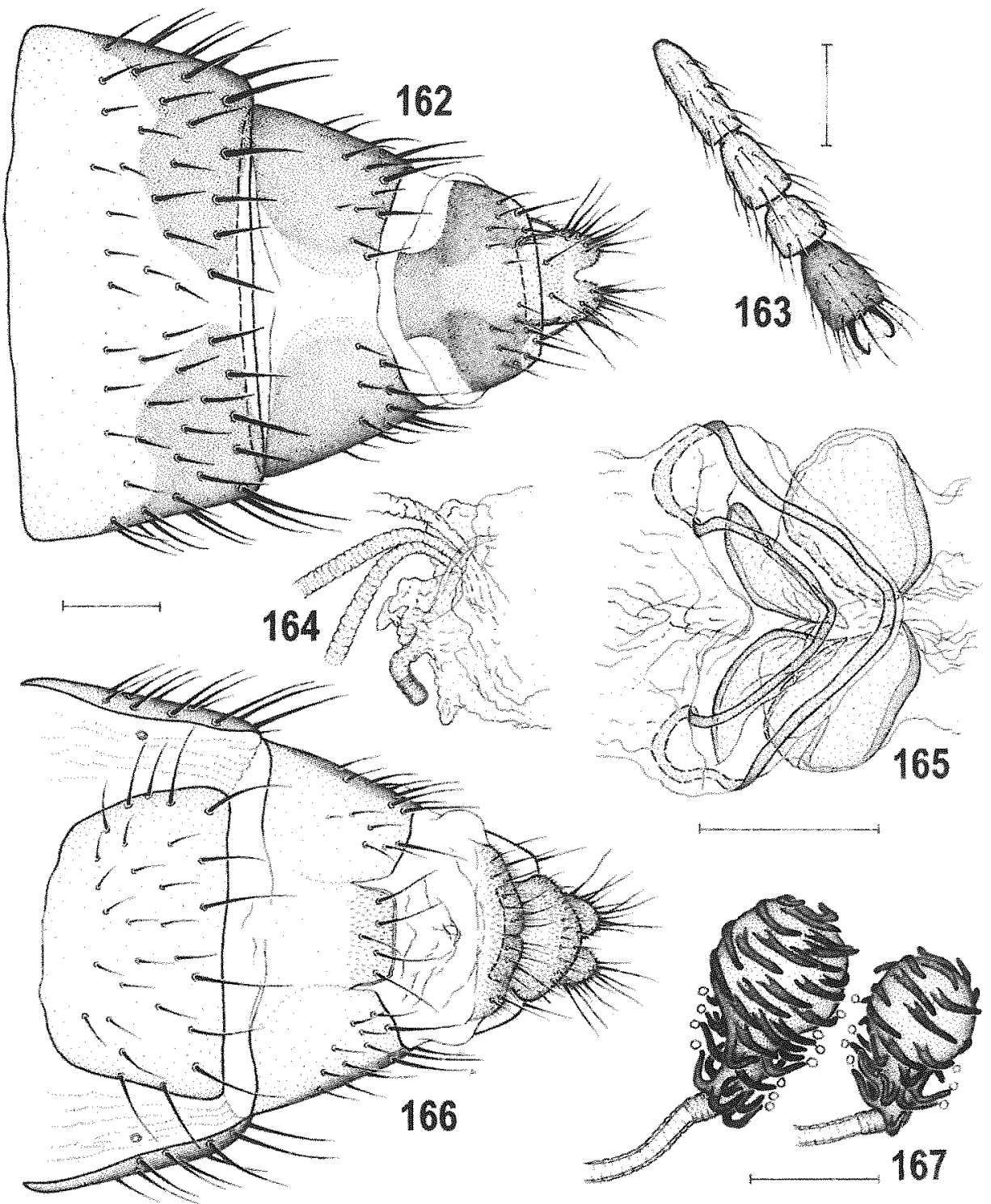

Figs 162-167: Stiphrosoma sororitum sp. n., female paratype (Mexico). 162 - postabdomen dorsally; 163 - apical segments of fore tarsus dorsally; 164 - ventral receptacle laterally; 165 - internal sclerites ventrally; 166 - postabdomen ventrally; 167 - spermathecae. Scales: Fig. $167=0.05 \mathrm{~mm}$, others $=0.1 \mathrm{~mm}$.

\section{Biology:}

S. sororium is as yet known from a single collection in a Malaise trap and (probably) sweeping low vegetation in Chiapas. The elevation of 7087-7200' is the highest recorded for any New World Stiphrosoma.

\section{Distribution:}

The species is only recorded from Mexico: Chiapas. 


\section{Stiphrosoma bumerale sp.n.}

(Figs 168-179, 214)

Type material:

Holotype male labelled: "ONT: SSMarie, Bristol PI.Pk., 27.vii.197, KNBarber, sweeps/ pooter, Phalaris arundinacea, $46^{\circ} 30.8^{\prime} \mathrm{N} 84^{\circ} 16.4^{\prime} \mathrm{W}$ ” (DEBU, intact). Paratypes: CANADA: Alberta: Dunvegan, n. shore of Peace River, 13.vii.1997, sweep grasses at edge of agricultural field, 3 males 4 females (LEMQ); Dunvegan, N. shore of Peace River, 14.vii.1997, sweep grasses along agricultural field, 2 males (LEMQ) all T. A. Wheeler leg.; Dunvegan, N. side Peace River, 11-25.vii.1995, pan traps in grasses, 2 females (LEMQ); $4 \mathrm{~km}$ SE Grimshaw, 13.vii.1997, sweep vegetation at edge of wheat field, 1 female (LEMQ) all S. Boucher leg. British Columbia: Creston, 8.ix.1947, 1 male, D. B. Waddell leg. (CNCI); Cultus Lake Prov. Pk., Teapot Hill Trail, $49^{\circ} 01.72^{\prime} \mathrm{N}$ $121^{\circ} 59.71^{\prime} \mathrm{W}, 50-200 \mathrm{~m}, 24 . v i i .2002$, sweeps, forest path, 1 male, M. v. Tschirnhaus leg. (Universität Bielefeld, Ca-1511) (ZSMC, in alcohol); Kaslo, 25.vi.[-], 1 male, R. P. Currie leg. (USNM); Mt. Robson Prov. Pk., Hwy \#16, small road towards Mt. Robson, $53^{\circ} 03^{\circ} \mathrm{N} 119^{\circ} 15^{\prime} \mathrm{W}, 6 . v_{i i i} 2002$, forest floor, swamp, 2 females, M. v. Tschirnhaus leg. (Universität Bielefeld, Ca-1519) (ZSMC, in alcohol); Nancy Greene Lake (Blueberry Creek), S Hwy \#3, $-24 \mathrm{kmWSW}$ Castlegar, $-49^{\circ} 14^{\circ} \mathrm{N}-118^{\circ} \mathrm{W}$, 14.viii.2002, swept, aspirated, 1 female, M.v.Tschirnhaus leg. (Universität Bielefeld, Ca 1534) (ZSMC, in alcohol); Robson, 7.vii.1966, 1 male, H. R. Foxlee leg. (UBCZ); Squamish, Diamond Head Trail, 3200', 26.viii.1953, 1 male, W. R. M. Mason leg. (CNCI); Vernon, 27.vii.1937, 1 female, D. B. Waddell leg. (CNCI). Manitoba: Prevda, Jct Hwys 1 \& 506, 25.vii.1994, base of Agropyron smithii, 2 males 2 females, K. N. Barber leg. (DEBU). Newfoundland: Pasadena, 1.viii.1984, low vegetation in field, 1 female, Lloyd Hollett leg. (CNCI). Nova Scotia: Nova Scotia: Kentville, 6.viii.1958, 1 female (CNCI); Lockeport, 2.viii.1958, 3 females (CNCI); Meat Cove, 10.vii.1983, among grass roots, 2 male 5 females (CNCI) all J. R. Vockeroth leg. Ontario: Algonquin Prov. Pk., Scott Lake, 6.viii.1994, maple forest, sweep, 1 female, S. A. Marshall leg. (DEBU); Bruce Peninsula N.P., Cameron Lk. Rd., $45^{\circ} 12.5^{\circ} \mathrm{N} 81^{\circ} 33.5^{\prime} \mathrm{W}, 30$. vii.1997, sweeps, grasses in trail, 1 female (DEBU); Bruce Peninsula N.P., Emmett Lake, $45^{\circ} 13.5^{\prime} \mathrm{N} 81^{\circ} 28.2^{\prime} \mathrm{W}, 2 . v i i .1999$, sweeps, mostly graminoids, open area under Acer/Quercus, 1 female (DEBU) both K. N. Barber leg.; Iroquois Falls, among grass roots, 5.vii.1987, 1 female, 6.vii.1987, 3 males, J. R. Vockeroth leg. (CNCI); Rossport, base of Agropyron smithii, 26.vii.1994, 1 male 10 females, 13.ix.1994, 3 males 1 female, 28.viii.1995, 3 males 3 females (DEBU, AMNH, SMOC, USNM); S[ault] S[te.] Marie, S of Algoma U[niversity] College, $46^{\circ} 29.9^{\prime} \mathrm{N}$ $84^{\circ} 17.2^{\prime} \mathrm{W}, 17 . v i i .2001$, sweeps, mostly Carex aquatilis, 1 female, 31.vii.2002, sweeps, Calamagrostis canadensis, 1 male (DEBU); S[ault] S[te.] Marie, Birchwood Park, mixed forest, 27.viii.1986, 2 females, 13.viii.1986, 1 female; same locality but 5.ix.1987, rotten mushrooms, 1 female (DEBU) all K. N. Barber leg. Quebec: $13 \mathrm{~km}$ SW Baie Trinité, $-1 \mathrm{~km}$ W Pointe-des-Monts lighthouse, 24.viii.1994, ornamental lawn, swept, eclector, 1 female, M. v. Tschirnhaus leg., Universität Bielefeld X-987 (ZSMC, in alcohol); Godbout, 24.viii.1994, dunes near ferry dock, swept, eclector, 1 male, M. v. Tschirnhaus leg. (Universität Bielefeld, X-988) (ZSMC, in alcohol). Saskatchewan: Beaver Creek Cons. Area, $13 \mathrm{~km}$ S Saskatoon, $51^{\circ} 58.6^{\prime} \mathrm{N} 106^{\circ} 43.0^{\prime} \mathrm{W}, 12$. vii.1999, sweeps, mostly grasses under Betula/Populus, 1 male, K. N. Barber leg. (DEBU). USA: Michigan: 
Ironwood, Mt. Zion Ski Area, 46'28.5'N 90'10.2'W, 22.vii.1999, sweeps, low veg. in cut under Acer, 2 females, K. N. Barber leg. (DEBU). New Hampshire[?]: "White Mts., Morrison", 2 females (USNM). North Carolina: Mt. Mitchell, 12.viii.1957, 1 female, L. A. Kelton leg. (CNCI). Tennessee: Gr[eat] Sm[okey] Mt. Nat. Park, Collins Gap, 5700' 22.viii.1957, 1 female, J. G. Chillcott leg. (CNCI).

Palaearctic: LATVIA: Melturu sils, 5.viii.2004, 3 males (IBUL, SMOC); Nicgale, 22.vii.2004, 1 male (IBUL) all A. Karpa leg. NORTH KOREA: S slope of Paekdu Mt., 16.viii.1989, 1 male 2 females; Pakdusan, Samjion $40 \mathrm{~km} \mathrm{NW,} \mathrm{17.viii.1989,} 1$ female; Paekdusan, Onsupjong, 19.viii.1989, 1 male, all M. Kozánek leg. (MBP, SMOC). RUSSIA: Siberia: Altai Region, Teltskoya Lake, 16-20.vii.1991, pan traps in mossy wet area beside field, 2 males 2 females, S. A. Marshall leg. (DEBU). A number of paratypes with genit. prep.

Other $S$. bumerale material not designated as paratypes (most badly damaged):

CANADA: Alberta: Dunvegan, n. shore of Peace River, 13.vii.1997, sweep grasses at edge of agricultural field, 1 female, T. A. Wheeler leg. (LEMQ); Nancy Greene Park, [-].viii.1980, sweep, 1 female, S. Marshall leg. (DEBU); Vernon, 12.vii.1937, 1 male, D. B. Waddell leg. (CNCI, only genit. prep. remaining). USA: Vermont: $12 \mathrm{~km} \mathrm{SW}$ Waterbury, Camel Hump Trail, $44.3^{\circ} \mathrm{N} 72.7^{\circ} \mathrm{W}, 26 . v i i i .2001$, sweep, 1 male, S. E. Brooks leg. (LEMQ, only genit. prep. remaining). Virginia: Highlands Co., Locust Spgs., Beaver Pond, 1.vii.1982, W. Mathis \& O. S. Flint leg., 1 female (USNM). Washington: Whatcom Co., 4.5 mi E Glacier, North Fork Nooksack River, 1300', 19.vii.1978, 1 female, Nancy Herman leg. (AMNH).

Etymology: The name of the species refers to the yellow humerus (= postpronotum) contrasting with the dark brown mesonotum and acknowledges a manuscript name suggested by G. E. Shewell.

\section{Description:}

Male. Total body length 1.71-2.30 mm; bicolorous, brown to dark brown (dorsally) and yellow (pleural and ventral part). Head slightly higher than long. Frons yellow but frontal triangle (reaching to anterior third of frons) pale to dark brown including ocellar triangle; lunule yellow. Orbit anteriorly (in front of posterior ors) pale yellow and whitish microtomentose, posteriorly (behind posterior ors) pale brown to brown. Occiput largely dark brown, only medial ventrally narrowed area pale brown to ochreous yellow and provided with 2 ventrally convergent silvery grey microtomentose stripes meeting at foramen; ventral portion of occiput (below upper margin of foramen) yellowish white and sharply demarcated from dark brown remainder of occiput. Face narrow, with brown pattern consisting of 2 medial longitudinal stripes (paler in Palaearctic specimens) and 2 lateral marginal ochreous-brown stripes bordering parafacialia and also gena; parafacialia, gena (except for brown margin) and postgena yellowish white and silvery white microtomentose; mouthparts whitish yellow to yellow. Cephalic chaetotaxy: pvt small but crossed; vti and oc longest of cephalic setae, posterior ors slightly shorter; vte usually shorter than posterior ors; 2 strong ors, anterior distinctly to markedly shorter than posterior; usually only 1 microsetula in front of anterior ors; $1-2$ pairs of medial microsetulae in front of frontal triangle; vi about as long as posterior ors; subvibrissa two-thirds or less of vi length and much weaker; $4-5$ short and pale peristomal setae and some weak setae also on postgena; postocular microsetulae minute, in 
single row. Eye suboval; its longest (oblique) diameter about 1.5 times as long as shortest; smallest genal height 0.09-0.10 times as long as shortest eye diameter. Antenna with yellow pedicel and yellowish white 1 st flagellomere having anterodorsal corner (around base of arista) ochreous or brownish darkened; 1st flagellomere with long white cilia on apex. Arista about 1.9 times as long as antenna, dark brown and relatively shortly pectinate.

Thorax slightly narrower than head. Mesonotum largely brown to dark brown, contrasting with whitish yellow humerus (postpronotum) and, in Palaearctic specimens, yellow notopleural area; scutellum brown but its apical part (up to half) paler brown. Pleural part of thorax yellow to whitish yellow, with dark brown dorsal band, usually widened anteriorly (to cover entire propleuron), narrowed around mesothoracic spiracle and widened again posteriorly below wing insertion. Mesonotum sparsely microtomentose, rather shining. Thoracic chaetotaxy: prs small, as long as or shorter than longest dc microseta; 2 strong dc, anterior long (usually longer than posterior $\mathrm{npl}$ ), posterior dc longest of thoracic setae (longer than apical sc); 3-5 dc microsetae in front of anterior dc, hindmost of them markedly enlarged; ac microsetae in 4 rows in front of suture, in 2 (medial) rows behind anterior dc, usually reaching slightly beyond posterior $\mathrm{dc} ; 2 \mathrm{sc}$, basal shorter and weaker than anterior dc; apical sc long but shorter than posterior dc; $2 \mathrm{stpl}$ (anterior shorter) and 1 microseta in front of anterior stpl; several (3-4) additional setulae in dorsal half of sternopleuron in addition to several longer setae ventrally. Scutellum rounded triangular, with relatively flat disc.

Legs entirely yellow. $f_{1}$ with robust ctenidial spine being markedly longer than maximum width of $t_{1}$; fore basitarsus with a few longer hairs ventrobasally. $t_{2}$ with usual ventroapical seta. $f_{3}$ with a long row of posteroventral setae, but only 8-10 in distal twofifths shortened and thickened; $t_{3}$ with reduced ventroapical seta (better developed in Palaearctic specimens); hind basitarsus with 2 distinct ventrobasal setae.

Wing (Fig. 214) with pale brownish membrane and yellowish brown veins. $\mathrm{R}_{2+3}$ long, bent in parallel to $C$ and apically slightly upcurved to it; $R_{4+5}$ slightly bent to almost straight; $M$ straight. Discal $(\mathrm{dm})$ cell relatively narrow; $r-m$ situated in front of basal third of $\mathrm{dm}$ cell. $\mathrm{Cu} \mathrm{A}_{1}$ slightly bent, almost reaching wing margin; $\mathrm{A}_{1}$ short, ending far from it. Alula small and narrow; anal lobe well developed. Wing measurements: length $1.51-2.20 \mathrm{~mm}$, width $0.48-0.75 \mathrm{~mm}, \mathrm{Cs}_{3}: \mathrm{Cs}_{4}=1.27-1.58, \mathrm{r}-\mathrm{mldm}-\mathrm{cu}: \mathrm{dm}-\mathrm{cu}=3.25-$ 4.12. Haltere white, stem partly ochreous tinged.

Abdomen. Preabdominal terga completely brown, all large and broad, becoming longer posteriorly (T5 longest), sparsely shortly setose. Preabdominal sterna yellow, becoming wider posteriorly ( 55 widest). T6 reduced, short and very transverse but brown pigmented only laterally, thus seemingly divided in two small, widely separated, plates. S6-S8 brown, partly coalesced; S6 very short and transverse with strongly sclerotized and dark brown anterior marginal ledge; S7 longer but also anteriorly (more narrowly) dark margined; both S6 and S7 with 2 setae each; S8 large and more setose.

Genitalia. Epandrium (Figs 168-169) about as long as high but broad, distinctly wider than that of $S$. laetum, with relatively sparse setae, 2 dorsolateral setae markedly enlarged; dorsal margin of epandrium straight; anal fissure low and broad, almost semicircular. Cercus rather short but thick, finely setose. Medandrium (Fig. 168) lower than that of S. laetum, with projecting dorsal corners. Gonostylus (Fig. 171) similar to that of $S$. laetum, in lateral view shorter and markedly broader, particularly in apical third; micropubescence covering large part of outer side except for anterior and distal marginal areas; longer setae situated at anterior margin of inner side. Hypandrium (Fig. 170) ro- 
bust, similar to that of $S$. laetum. Transandrium broad, also resembling that of $S$. laetum but with strongly sinuous ventral band-like ledge (Fig. 174); basal membrane broad, with numerous transverse tubercles. Pregonite (Fig. 170) forming low, slightly projecting lobe, with numerous (more than 10) setae being slightly longer than in S. laetum. Postgonite (Fig. 170) resembling that of S. laetum, with slighly wider apex. Aedeagal complex (Fig. 173). Phallapodeme robust, with broader proximal part than in S. laetum. Aedeagal part of folding apparatus membranous, with short dense spines concentrated near its middle; connecting sclerite slender, dorsally dark and sclerotized, ventrally membranous. Phallophore short, frame-shaped; basal part of distiphallus membranous except for dorsal and ventral sclerites. Saccus of distiphallus voluminous and armed by numerous short thick spines and dense spinulae basally (as in $S$. laetum but with denser spines in anterior group, see Fig. 173). Filum also very similar to that of S. laetum including curved apex provided with a clump of setulae and numerous small hyaline teeth (Fig. 172). Ejacapodeme dark, with digitiform projection having bluntly cut capitulum.

Female. Similar to male unless mentioned otherwise. Total body length $1.75-2.78 \mathrm{~mm}$. Face as in male but with medial dark stripes often coalesced forming single longitudinal band. Scutellum with apex to apical half yellow; often also elongate spots surrounding posterior dc pale brown to yellow (sometimes prolonged up to anterior dc). Ctenidial spine on $f_{1}$ yet longer than in male. $f_{3}$ without thickened posteroventral setae but short ventroapical seta on $t_{3}$ better developed. Wing measurements: length $1.71-2.54 \mathrm{~mm}$, width 0.55-0.87 mm, $\mathrm{Cs}_{3}: \mathrm{Cs}_{4}=1.15-1.58, \mathrm{r}-\mathrm{m} / \mathrm{dm}-\mathrm{cu}: \mathrm{dm}-\mathrm{cu}=3.11-4.36$.

Abdomen with T1-T5 more transverse than in male, all uniformly brown to dark brown, or T1 somewhat pale medially. T5 longest of preabdominal terga. S2-S5 yellow, narrower than in male, becoming wider posteriorly; S5 the widest but narrower than S6. Terga with thicker setae than sterna.

Postabdomen (Figs 175, 178). T6 uniformly dark brown, with short setae (Fig. 175), as in S. laetum but S6 distinctly smaller than in that species, sparsely shortly setose. Tergosternum $\mathrm{T} 7+\mathrm{S} 7$ dorsally short and dark but dorsomedially divided; its ventral side pale pigmented and remnant of original S7 forming unpigmented posteromedial triangular area with 4-6 setae (Fig. 178). T8 dark, anteriorly narrowed, more symmetrical than that of S. laetum (Fig. 175). S8 narrower than T8, with anterior margin indistinct and usual posteromedial cleft (Figs 178-179). Internal structures of genital chamber (Figs $177,179)$ complex and well sclerotized, with 3 pairs of partly fused sclerites, all distinctly different from those of $S$. laetum (e.g. dorsal pair markedly smaller, all sclerites without tubercles) and with very slender, transversely compressed looped sclerite. Ventral receptacle (Fig. 177) similar to $S$. laetum. Spermathecae $(1+1)$ elongately pyriform (Fig. 176), with spines transversely attached to surface denser, shorter and thicker than in S. laetum. T10 (Fig. 175) short, small, hyaline except for lateral margins, with 2 short dorsal setae and without micropubescence. S10 larger than T10, roughly pentagonal with shallowly emarginate anterior margin and micropubescent in posterior half (Fig. 178). Cerci small, closer to each other than in $S$. laetum, with short setae apically.

\section{Variability:}

The species is rather variable in the colouration of head and thorax. Particularly, the Palaearctic specimens generally have a more extensively yellow frons (frontal triangle smaller and paler brown), a lighter medial occipital area above foramen and a paler face (with pale brown dark medial stripe[s]). Apart from the humeral callus, their notopleural area is 
yellow and the female scutellum has the yellow colour restricted to the extreme apex. Pale brown to yellow spots near the posterior $\mathrm{dc}$ on the female mesonotum are variable both in the Nearctic and Palaearctic specimens, ranging from almost invisible to short yellow bands between scutellum and anterior dc. However, the extent of the variability is not precisely known in the Palearctic populations because of the limited material available for study. Therefore a possibility that the latter represent a separate subspecies cannot be excluded.

\section{Discussion:}

S. humerale sp. n. is most closely allied to the European species S. laetum (MEIGeN, 1830). These two species form a distinctive sister-pair, characterized by highly similar male genitalia (e.g. armature of saccus, setose apex of filum, reduced aedeagal part of folding apparatus) and female postabdomen (shape of $T 7+S 7, T 8,3$ pairs of strong internal sclerites). These resemblances are so striking that specimens of $S$. humerale from North Korea were erroneously considered by RoHÁČEK (1996) to be very dark specimens of Stiphrosoma laetum. The new species can be easily recognized from all New World species and also from S. laetum by its dark brown mesonotum, having only humeral and (in the Palaearctic) notopleural areas yellow (see key). S. humerale also differs from S. Laetum by broader epandrium and gonostylus, different transandrium, more sclerotized connecting sclerite, more dentate apex of filum, different female internal sclerites, S10 and smaller female cerci.

\section{Biology:}

Little is known of the biology of this species. Seldom are series of specimens obtained although sweeping grasses on the edge of an agricultural field (Dunvegan, AB) yielded 8 specimens. Searching among grass roots has been particularly successful in Meat Cove (NS). Similar searches with an aspirator at the bases of Pascopyrum (= Agropyron) smithii yielded several specimens over several occasions (Rossport, ON). In the latter locality, the primary focus was to record $S$. hirtum but $S$. humerale was present in much lower densities. Additional collections have been made in association with the graminoids Phalaris arundinaceae, Calamagrostis canadensis and Carex aquatilis and other species of Stiphrosoma (S. pectinatum, S. balteatum, S. setipleurum, and S. stylatum). Generally, the habitats in North America are drier than those reported for the closely related Palaearctic S. laetum (cf. RoHÁčEK 1996) as suggested by the Dunvegan and Rossport sites. One female has been taken from rotten mushrooms in early September. In the Palaearctic Region, specimens were collected in moist mixed forests with rich herbaceous undergrowth (Latvia - A. Karpa, pers. comm. 2004) and in the wet mossy margin of a field in pan traps (W. Siberia: Altai region).

\section{Distribution:}

This is as yet the only indisputably naturally Holarctic species of Stiphrosoma known. S. humerale ranges from Newfoundland to British Columbia but is not yet known from New Brunswick, Prince Edward Island, and points further north in Canada. In the United States, it is known mostly from the northeast (Michigan, North Carolina, New Hampshire?, Tennessee, Vermont, Virginia) with a single female from West Virginia in the west. In the Old World, this species is known from Latvia (westernmost records), western Siberia and North Korea, the latter records previously reported under the name S. laetum (see RоHÁčEK 1996). The new records from Latvia indicate that S. humerale is probably widespread in the temperate belt of the Palaearctic Region as well. 


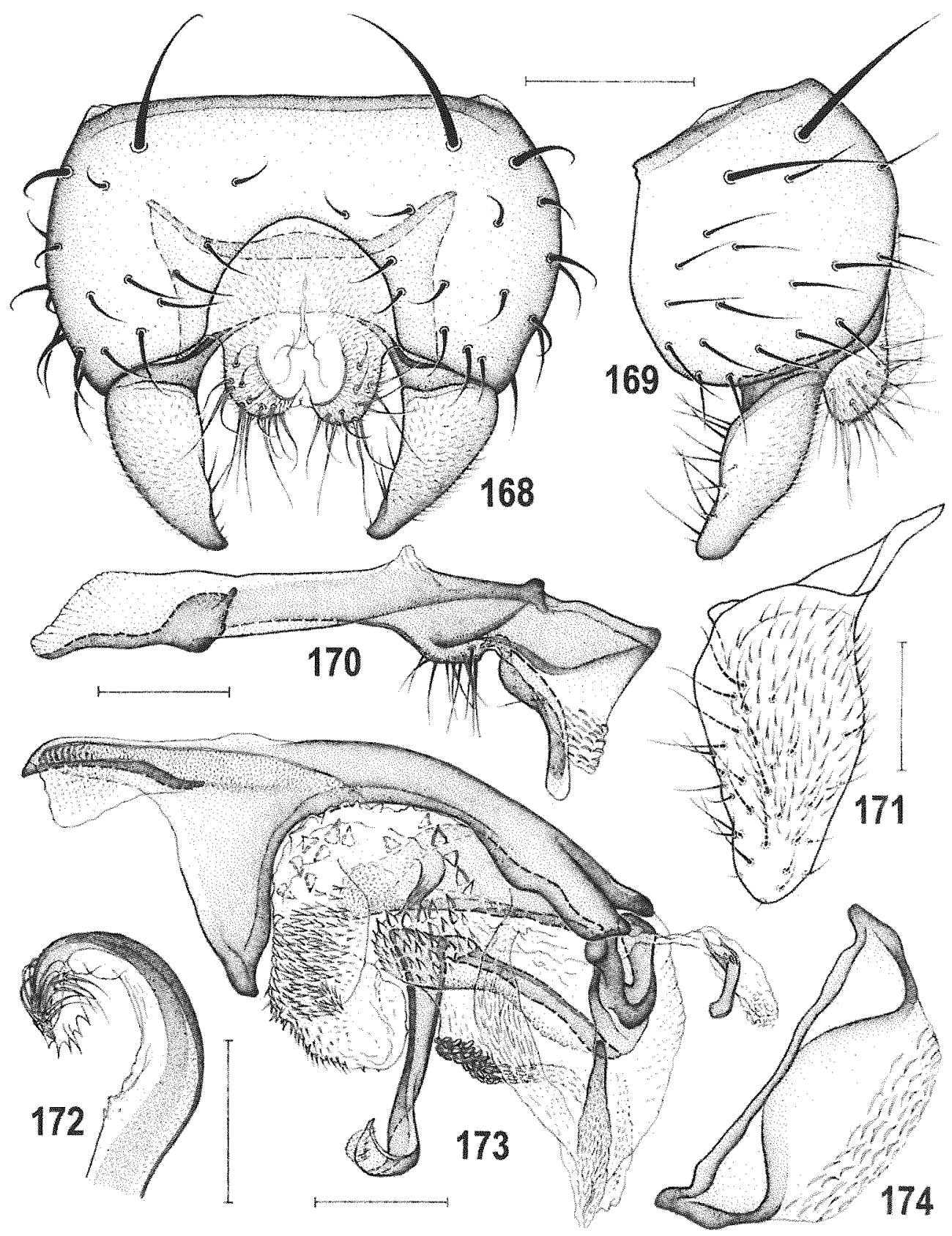

Figs 168-174: Stiphrosoma humerale sp. n., male paratype (Canada: Ontario). 168 - external genitalia caudally; 169 - ditto laterally; 170 - hypandrium and associated structures laterally; 171 - gonostylus posterolaterally (widest extension view); 172 - apex of filum anteroventrally; 173 - aedeagal complex laterally; 174 - transandrium and basal membrane caudally. Scales: Figs 171-172 $=0.05 \mathrm{~mm}$, others $=0.1 \mathrm{~mm}$. 


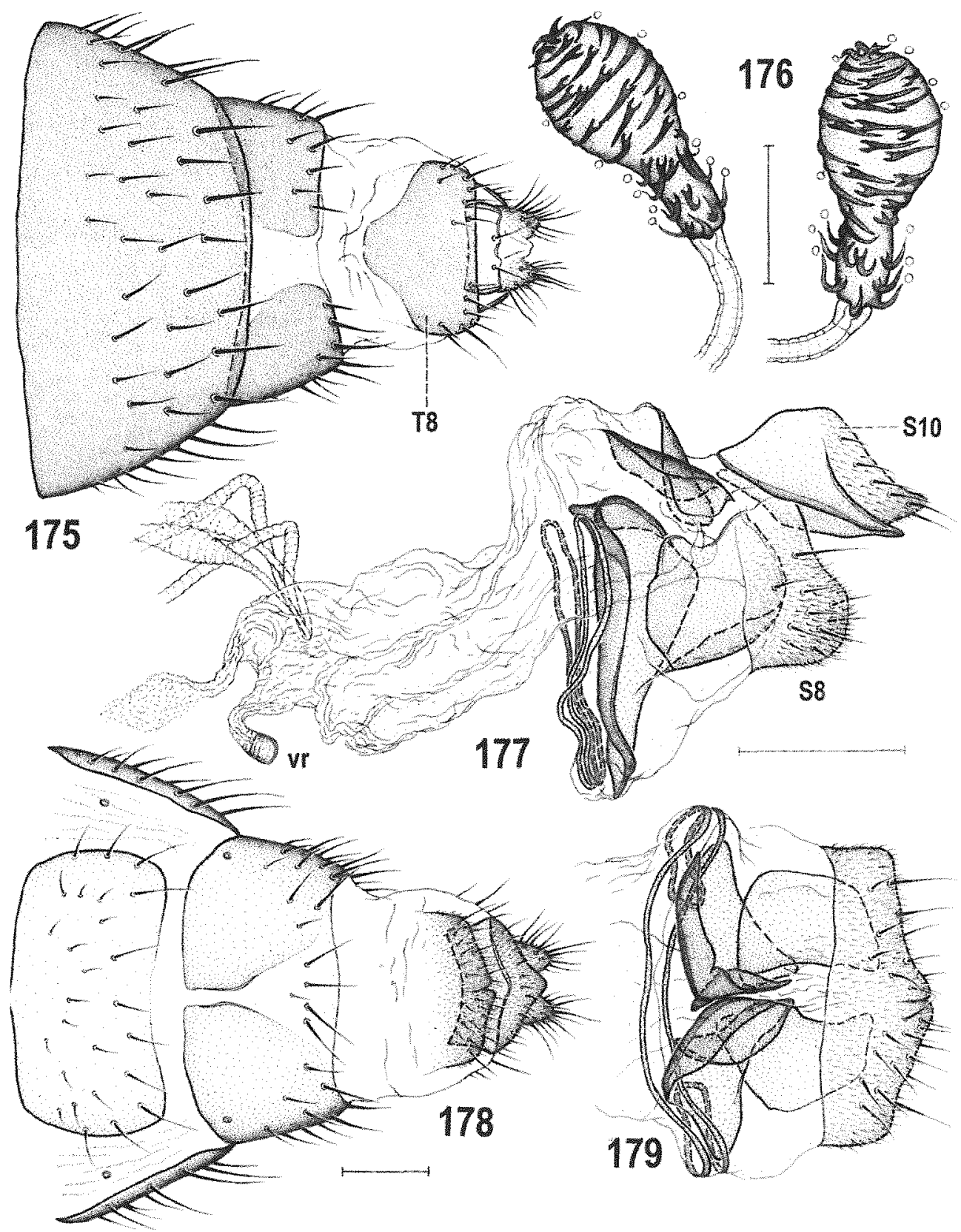

Figs 175-179: Stiphrosoma bumerale sp. n., female paratype (Canada: Ontario). 175 - postabdomen dorsally; 176 - spermathecae; 177 - female genital chamber, $\$ 8$ and S10 laterally; 178 - pastabdomen ventrally; $179-$ internal sclerites and $S 8$ ventrally. Scales: Fig. $176=0.05 \mathrm{~mm}$, others $=0.1 \mathrm{~mm}$. For abbreviations see text. 


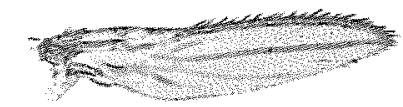

\section{0}
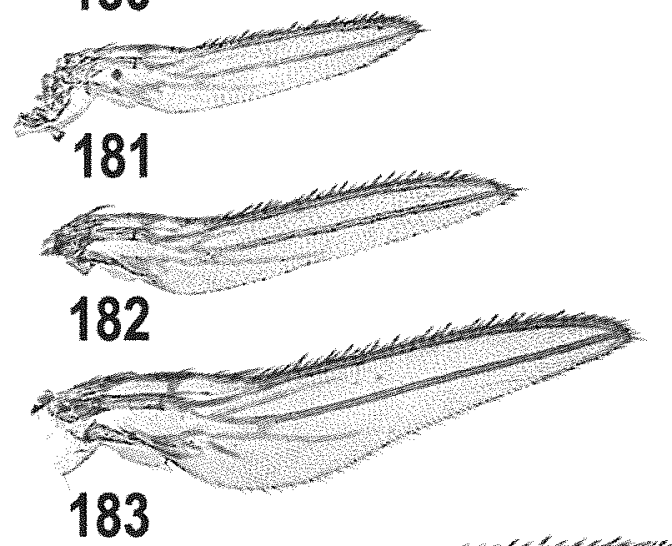

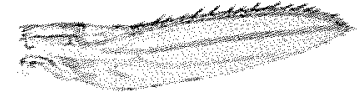

186
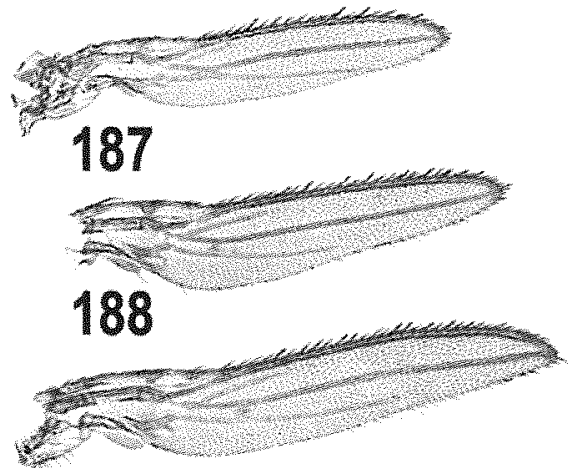

189

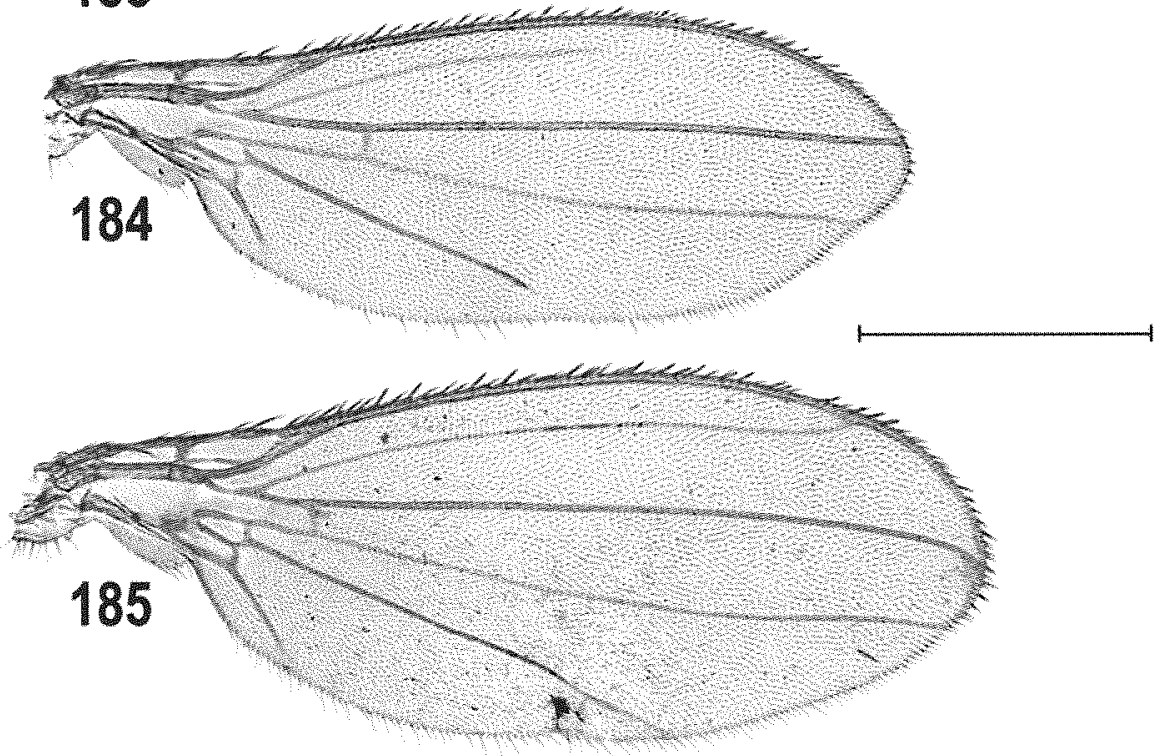

Figs 180-189: Stiphrosoma sabulosum (HaLIDAY), wings (Fig. 185 USA: Michigan, others Canada: Ontario). 180-183 - f. brach., female; 184-185 - f. macropt., female (185 - aberrant with apex of $\mathrm{R}_{4+5}$ deflected toward M); $186-189-$ f. brach., male. Scale $=0.5 \mathrm{~mm}$. 

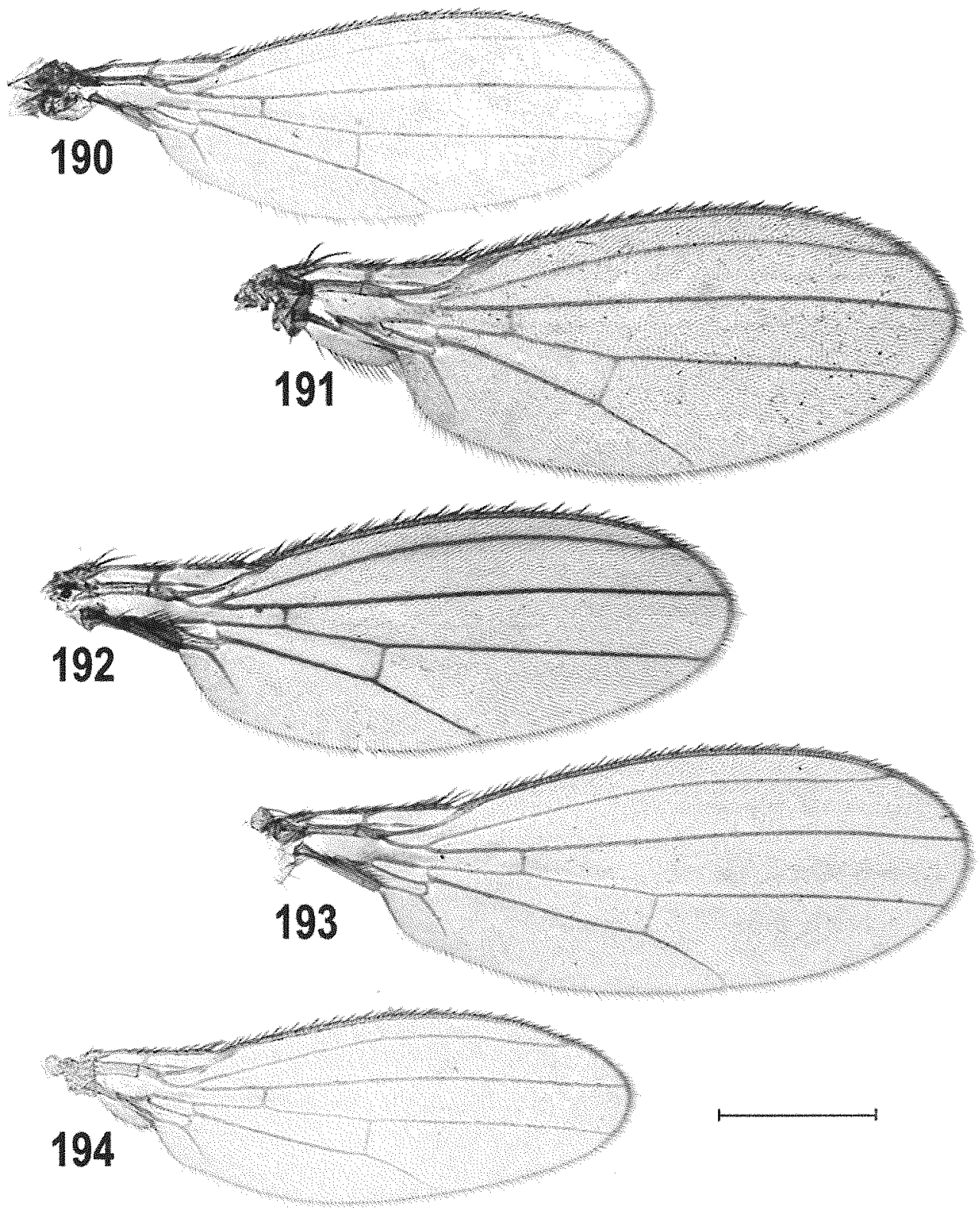

Figs 190-194: Stiphrosoma species, wings. $190-$ S. pectinatum sp. n., male paratype (USA: Tennessee); 191 - S. lucipetum sp. n., male paratype (Bahamas); 192 - S. pullum sp. n., male holotype (Costa Rica); 193 -S. setipleurum sp. n., male paratype (Canada: Ontario); $194-S$. balteatum sp. n., male paratype (Canada: Ontario). Scale $=0.5 \mathrm{~mm}$. 


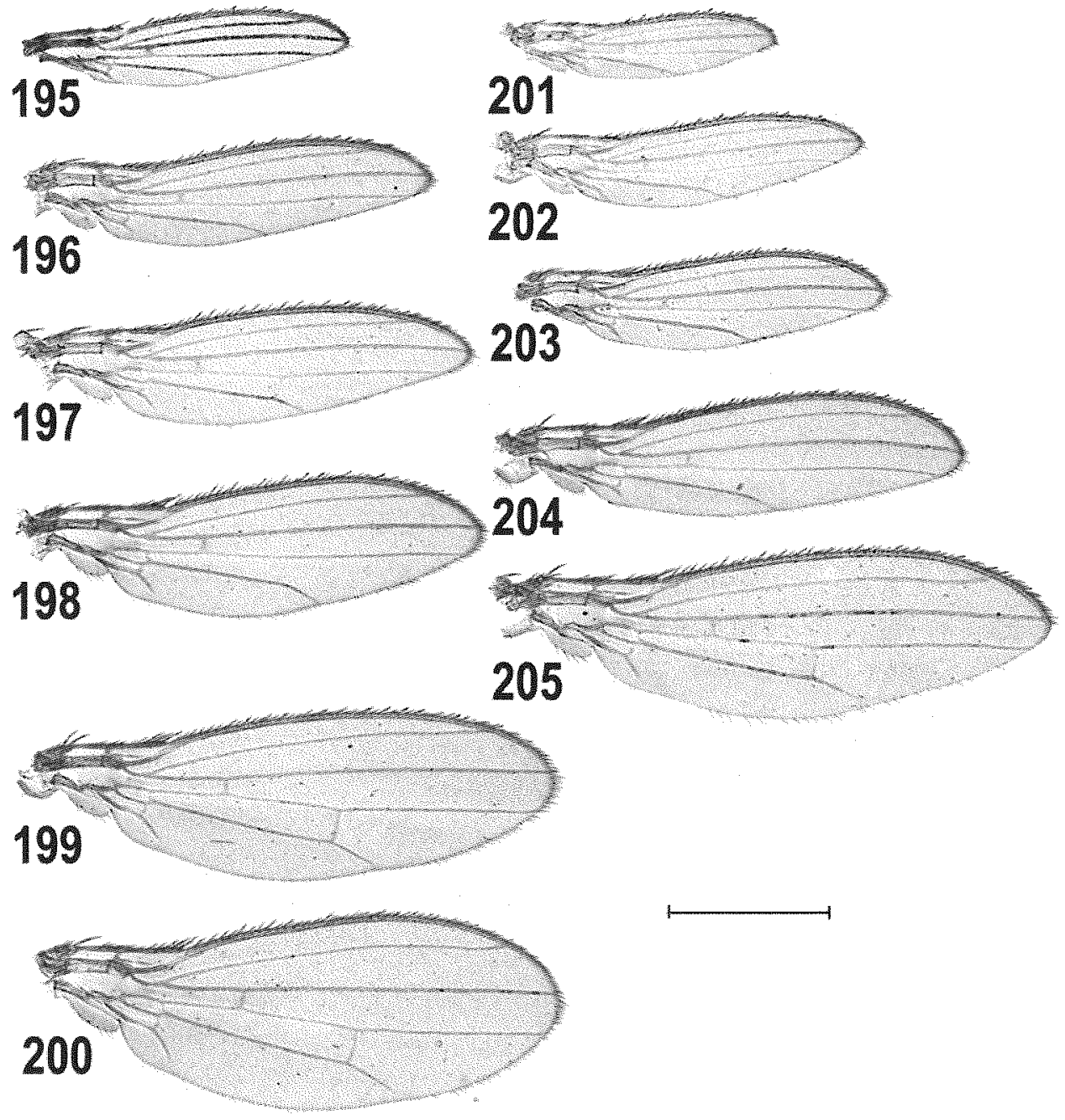

Figs 195-205: Stiphrosoma hirtum sp. n., wings (Figs 195-202 Canada: Saskatchewan, Figs 203, 205 Canada: Manitoba, Fig. 204 Canada: Ontario). 195-198 - f. brach. and intermediate, female paratypes; 199-200-f. macropt., female paratypes; 201-205- f. brach. and intermediate, male paratypes. Scale $=0.5 \mathrm{~mm}$. 

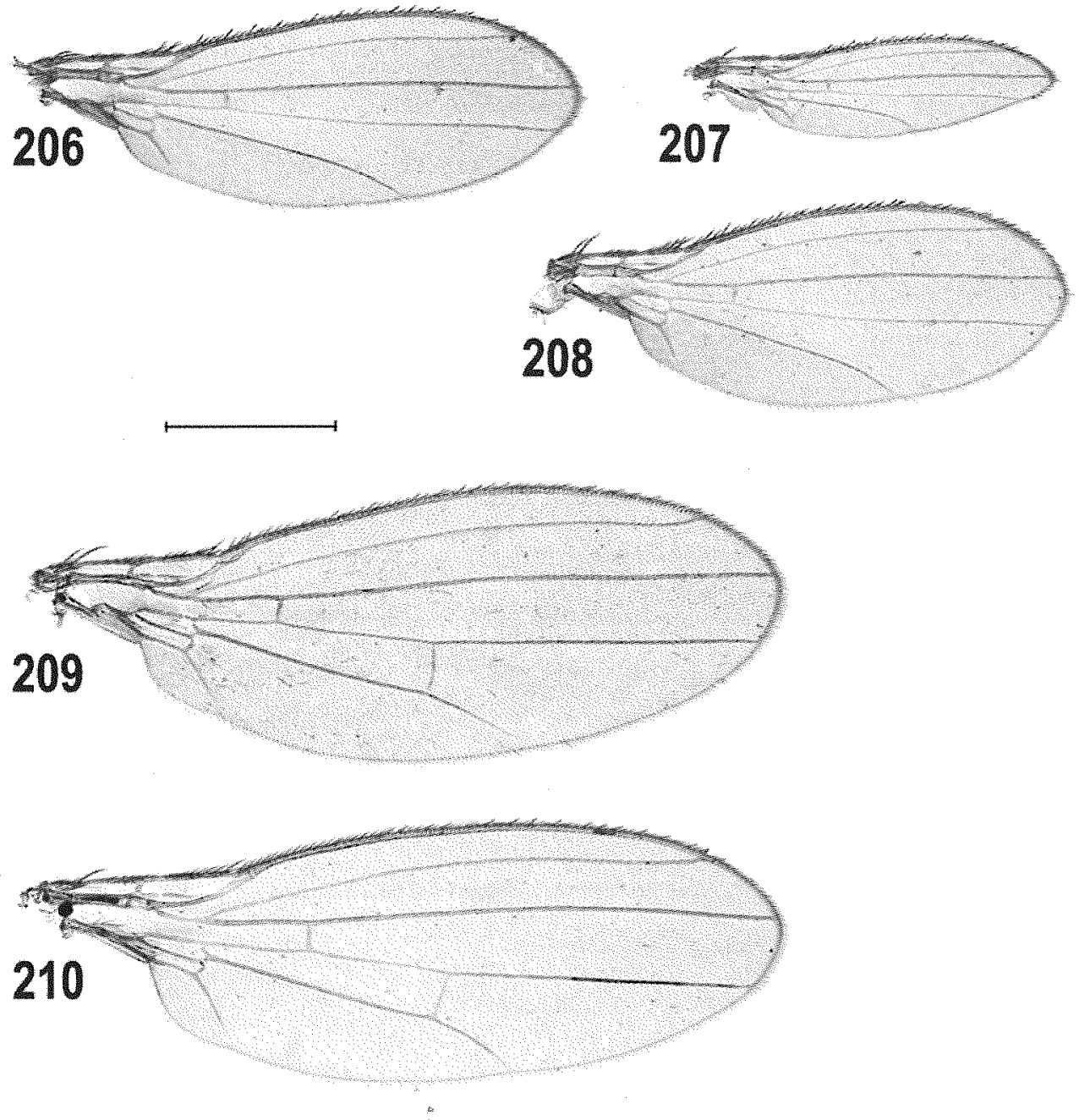

Figs 206-210: Stiphrosoma species, wings. 206-208 - S. artum sp. n. 206 - f. macropt., female paratype (USA: North Dakota); 207 - f. brach., male paratype (Canada: Saskatchewan); 208 - f. macropt., male paratype (USA: North Dakota). 209 - S. heluum sp. n., female paratype (Canada: Alberta); 210 - S. stylatum sp. n., male paratype (Canada: Ontario). Scale $=0.5 \mathrm{~mm}$. 


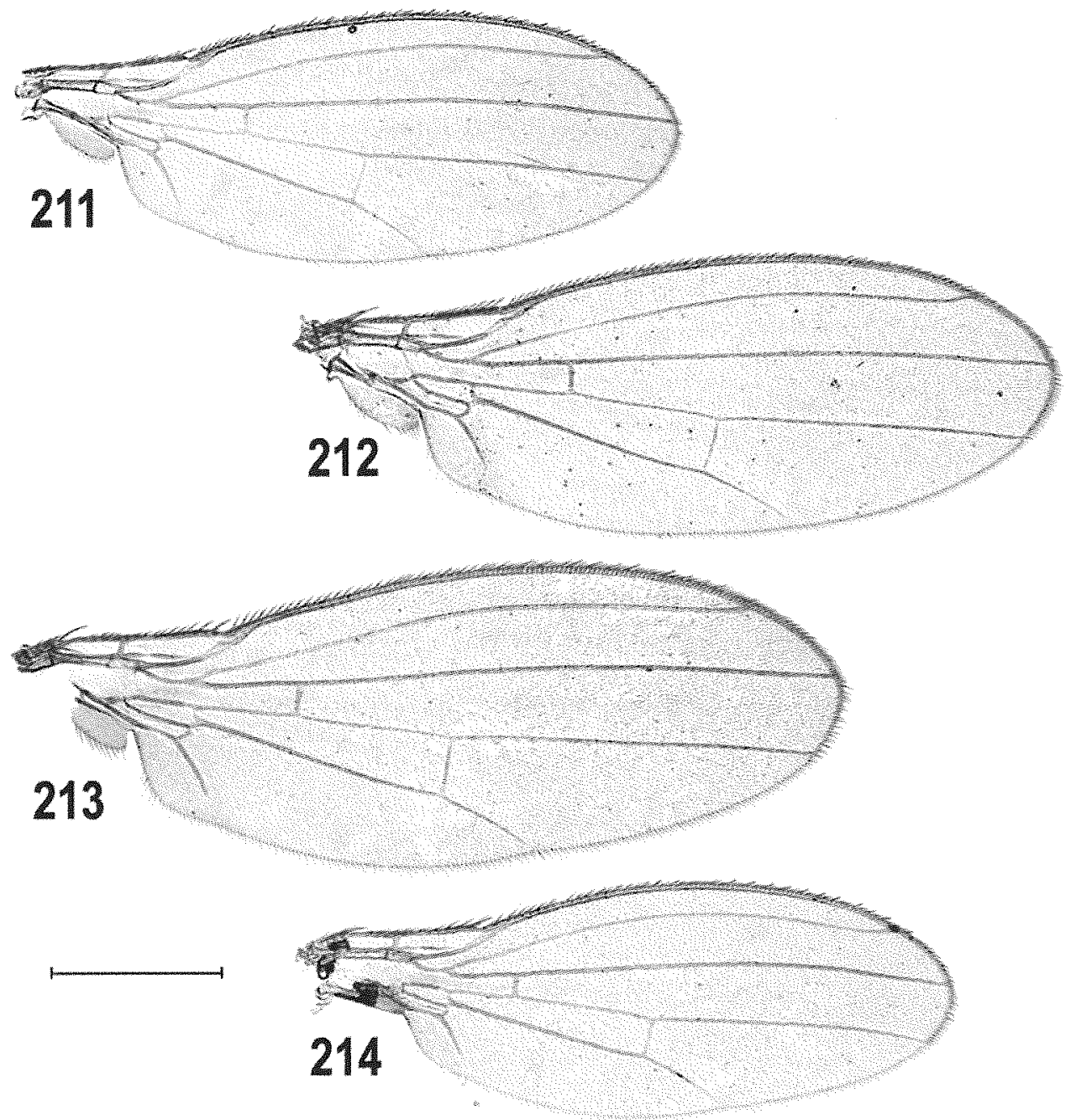

Figs 211-214: Stiphrosoma species, wings. $211-S$. minor sp. n., male paratype (USA: Arizona); $212-S$. vittatum sp. n., male paratype (USA: California); 213 - S. sororium sp. n., female paratype (Mexico); 214 $-S$. bumerale sp. n., male paratype (Canada: Ontario). Scale $=0.5 \mathrm{~mm}$. 
Phylogenetic considerations and biogeographic implications

$$
\text { Phylogeny }
$$

The relationship of the genus Stiphrosoma to other potentially related genera of Anthomyzidae (Chamaebosca, Mumetopia, Cercagnota, Apterosepsis) is difficult to evaluate, chiefly because of the lack of information about structures of the female postabdomen in Chamaebosca and of the male genitalia in Apterosepsis. Inasmuch as the sister-group of Stiphrosoma cannot be determined on the basis of the present knowledge about character distribution within these genera, the cladogeny of Stiphrosoma is reconstructed following a generalized outgroup accumulating plesiomorphies of all these genera.

The majority of recognized synapomorphies (see Fig. 215, characters 1-7) supporting the monophyly of Stiphrosoma are relatively weak because they occur in parallel in some other (even unrelated) genera of the family. Despite this fact, Stiphrosoma seems to be a fairly compact group characterized not only by the distinctive male and female genitalia (character 7 - dorsally divided female $\mathrm{T} 7+\mathrm{S} 7$ - is considered a strong synapomorphy) but also by the terricolous habits (association with lower parts of grass-like vegetation) of most Stiphrosoma species.

Reconstruction of the phylogenetic relationships of the species within the genus Stiphrosoma also proved to be difficult. There are too many characters affected by parallel evolution or convergency as well as characters whose polarity cannot be unambiguously determined. This has resulted in a complicated mosaic distribution of characters, particularly the external ones. Therefore characters of the male and female genitalia have been preferentially selected for the cladistic analysis which generated the (most parsimonious) cladogram presented here (Fig. 215). The analysis revealed several distinctly monophyletic, well substantiated groups:

(1) the very distinctive $S$. lucipetum-group formed only by two subtropical-tropical species, S. lucipetum and S. pullum (but some additional species can be expected in the Neotropical Region) and characterized by unique male genitalia (Fig. 215, characters 14-15) and unusually bristly appearance;

(2) the $S$. hirtum-group, containing two Nearctic wing polymorphic species, S. hirtum and S. artum (Fig. 215, characters 21-22);

(3) the largest and well supported $S$. stylatum-group comprising two sister-pairs, viz. S. stylatum + S. minor and S. vittatum + S. sororium (Fig. 215, characters 11b, 27a-30);

(4) the S. laetum-group with two species, the Holarctic S. humerale and the European $S$. laetum (Fig. 215, characters 24-26).

Another species-pair, formed by the Nearctic S. setipleurum and the Palaearctic S. cingulatum, seems to be less distinct, despite similar male genitalia (including similarly formed apex of filum) because the recognized synapomorphies are relatively weak (Fig. 215, characters 17-18).

Apart from these more or less distinct monophyletic groups or species-pairs, there are several other species whose positions are less clear. S. helvum, for example, appears to be allied to the $S$. stylatum-group but the only synapomorphy (Fig. 215, character 23) 
demonstrating a sister-group relationship to the latter group is not very convincing. The $S$. hirtum-group, $S$. stylatum-group $(+S$. helvum) and $S$. laetum-group remain as an unresolved trichotomy within a relatively weakly supported monophyletic clade. On the other hand, all these species plus $S$. balteatum (absence of strong spines in saccus in this species interpreted as a secondary reversal of character 10, see Fig. 215) seem to represent a distinctly monophyletic group provided that the distinctive arrangement of spines on the surface of the spermatheca is considered a strong synapomorphy (Fig. 215, character 16 ). The sister-pair $S$. setipleurum $+S$. cingulatum is probably the sister-group to the latter clade but this statement is supported by only a single synapomorphy (Fig. 215 , character 12). The phylogenetic affinity of the E. Palaearctic species S. fissum is particularly obscure (not only because of the reversal of character 10 but also owing to its primitive, shortly pyriform spermathecae) and, consequently, it is tentatively placed together with the $S$. lucipetum-group and the previously discussed clade in another unresolved trichotomy (cf. Fig. 215, character 11a). The two remaining species of Stiphrosoma differ from the above species (apart from $S$. fissum) in having the primitive (plesiomorphic), shortly pyriform spermathecae of the same type also known in Mumetopia. Of these, $S$. pectinatum seems to belong to the same clade as all other Stiphrosoma species except for S. sabulosum; the monophyly of this clade is supported by synapomorphies 8-10 (Fig. 215). S. sabulosum, albeit appearing to be highly derived, retains several features which are considered plesiomorphic, such as dark pleurae, sclerotized and dark ventral part of female $\mathrm{T} 7+\mathrm{S} 7$, and saccus without robust spines. Moreover it has some structures similar to those occuring in the related genus Mumetopia (viz. shape and armature of spermatheca, ventral receptacle, female T8 and S8). On the other hand, the absence of the ctenidial spine on $f_{1}$ in $S$. sabulosum is an apomorphic feature because this spine is considered a ground plan character of the family Anthomyzidae and is known in all other species of Stiphrosoma. The strongly shortened ctenidial spine in S. pectinatum apparently evolved independently.

\section{Biogeography}

The majority of the known species of Stiphrosoma are distributed in the temperate belt of both the Nearctic and Palaearctic Regions. There are only 2 species (S. lucipetum and $S$. pullum) recorded from the tropics of Central America, both belonging to the $S$. lucipetum-group, which plausibly is of Neotropical origin but later expanded (S. lucipetum only) into southern Nearctic areas.

The species-rich $S$. stylatum-group plus the related $S$. helvum, and S. hirtum-group include species widespread throughout most of Nearctic Region, including extreme southern (S. vittatum + S. sororium sister-pair), central and western areas (S. stylatum $+S$. minor sister-pair, $S$. helvum and also $S$. hirtum-group) but with only $S$. stylatum and $S$. hirtum partly penetrating to eastern Nearctic areas (up to Manitoba, Ontario). This pattern is highly interesting because the other Nearctic species, viz. S. balteatum, S. setipleurum and S. pectinatum, which seem to be restricted to eastern North America, all belong to different clades (see Fig. 215) and are not closely related to the groups discussed above. Two species have their closest relatives in the Palaearctic Region: $S$. setipleurum is allied to $S$. cingulatum (widespread in N. and $\mathrm{C}$. Europe and reaching east as far as the $\mathrm{Ob}$ region in Siberia); $S$. humerale, considered 
a naturally Holarctic species (widespread in the Nearctic, E. Palaearctic, and reaching as far as Latvia in the W. Palaearctic), is the sister-species of S. laetum (distributed in N. and C. Europe). Apart from the E. Palaearctic $S$. fissum, which has no indisputable relative among the Nearctic species, the most problematic is to evaluate the biogeography of S. sabulosum. The Holarctic distribution of $S$ sabulosum may not be natural (it may have been introduced from Europe recently) but if this is true and if its position in the cladogram (see Fig. 215) is correct, it must represent a remnant of a very old clade whose representatives reached the W. Palaearctic area long before the ancestors of the other Palaearctic species.

Because most Stiphrosoma species are only known from the temperate belt of the Nearctic Region it is reasonable to consider this area an evolutionary centre of the genus. The $S$. lucipetum-group obviously is a southern offshoot of the genus which had to adapt to a markedly different habitat (mangrove swamp) and this is plausibly also reflected in their aberrant morphology. The other southern species, S. sororium, moved to higher altitudes to find suitable habitats (montane grassland). The Palaearctic taxa seem to be descendants of species which spread across the northwestern (Beringian) land bridge to the eastern Palaearctic areas and subsequently colonized the western part of the Palaearctic Region. Judging from the phylogenetic reconstruction, these colonization events probably occurred several times as indicated by the relationships of the Palaearctic species which clearly belong to several different clades (see Fig. 215).

\section{Acknowledgements}

We would like to thank the following individuals who helped to make arrangements for loans of material critical to this revision: Dr. D. A. Grimaldi and T. C. Nguyen (AMNH), Dr. B. L. Fisher and Mr. K. J. Ribardo (CASC), Dr. B. A. Foote and Dr. C. Young (CMNH), Dr. J. M. Cumming and Mr. H. Walther (CNCI), Prof. Dr. S. A. Marshall and Dr. M. Buck (DEBU), C. B. Barr (EMEC), Dr. W. J. Hanson (EMUS), Dr. A. Karpa (IBUL), Mr. M. A. Zumbado (INBC), Mr. C. Favret (INHS), Prof. Dr. T. A. Wheeler and S. Boucher (LEMQ), Prof. Dr. M. Barták (MBP), Dr. Z. H. Falin (SEMC), Dr. G. G. E. Scudder and K. M. Needham (UBCZ), Dr. D. Yanega (UCRC), Dr. W. N. Mathis and H. Williams (USNM), Dr. M. von Tschirnhaus and Dr. M. Kotrba (ZSMC).

Also, several reviewers, known and not known to us, provided comments and suggestions at various stages of preparation of the manuscript including Dr. J. R. Vockeroth (Ottawa), Prof. S. A. Marshall, and Dr. M. Buck. KNB wishes to acknowledge the in-kind support of Natural Resources Canada, Canadian Forest Service for use of laboratory and equipment and K. Baldwin, S. Meades, and Dr M. Qi for providing or confirming identifications of graminoids. JR acknowledges financial support by the grants No. 206/00/0236 and No. 206/03/0020 of the Grant Agency of the Czech Republic.

\section{References}

Andersson, H. 1984b: Family Anthomyzidae. - In: Soós Á. \& Papp L. (eds.): Catalogue of Palaearctic Diptera. Vol. 10, 402 pp. (p. 50-53), Akadémiai Kiadó, Budapest.

BÄHRMANN, R. 1987: Untersuchungen der Dipterenfauna in natur- und industrienahen Rasen-biotopen Thüringens (DDR) mittels Bodenfallen (Diptera Brachycera). - Deutsche Entomologische Zeitschrift, N.F. 34: 85-105.

Collun, J. E. 1944: The British species of Anthomyzidae (Diptera). - The Entomologist's Monthly Magazine 80: $265-272$. 
Czerny, L. 1902: Bemerkungen zu den Arten der Gattungen Anthomyza Ful. und Ischnomyia Lw. - Wiener Entomologische Zeitung 21: 249-256.

Czerny, L. 1928: 54b. Anthomyzidae. - In: Lindner, E. (ed.): Die Fliegen der palaearktischen Region. Vol. 6, pt. 1, 8 pp., E. Schweizerbartsche Verlagsbuchhandlung, Stuttgart.

Enderlein, G. 1936: 22. Ordnung. Zweiflügler, Diptera. - In: Brohmer, P; Ehrmann, P. \& Ulmer, G. (eds): Die Tierwelt Mitteleuropas 6 (2), Insekten, Teil 3, 259 pp., Quelle \& Meyer, Leipzig.

Frey, R. 1958: Zur Kenntnis der Diptera brachycera p.p. der Kapverdischen Inseln. - Societas Scientiarum Fennica. Commentationes Biologicae 18 (4): 1-61.

Haliday, A. H. 1837: Notes, etc. upon Diptera. - Entomological Magazine 4 (2): 147-152.

HALIDAY, A. H. 1855: Descriptions of insects figured, and references to plates illustrating the notes on Kerry insects. - Natural History Review 2: 59-64.

Hennig, W. 1965: Die Acalyptratae des Baltischen Bernsteins und ihre Bedeutung für die Erforschung der phylogenetischen Entwicklung dieser Dipteren Gruppe. - Stuttgarter Beiträge für Naturkunde 145: $1-215$.

LoEw, H. 1866: Ueber einige bei Danzig gefangene Dipteren, bei denen die Flügel verkümmert sind oder ganz fehlen. - Schriften der Naturforschenden Gesellschaft in Danzig, N.F, 1: 1-8.

Mergen, J. W. 1830: Systematische Beschreibung der bekannten europäischen zweiflügeligen Insekten. Vol. 6, xi +401 pp., Schulzische Buchhandlung, Hamm.

Melander, A. L. 1913: A synopsis of the dipterous groups Agromyzinae, Milichiinae, Ochthiphilinae and Geomyzinae. - Journal of the New York Entomological Society 21 (4): 283-300.

NyE, I. W. B. 1958: The external morphology of some of the dipterous larvae living in the Gramineae of Britain. - Transactions of the Royal Entomological Society of London 110: 411-487.

RrchaRDs, O. W. 1932: Some breeding and habitat records of British Diptera. - Journal of the Entomological Society of the South of England 1 (1): 11-14.

RICHARDS, O. W. 1962: Mission zoologique de III.R.S.A.C. en Afrique orientale. LXXI. Diptera. Two new East African species of Alombus Beck. and an apterous sepsid (Chloropidae and Sepsidae). - Annales du Musée Royal de l'Afrique Centrale, Tervuren, Série in $8^{\circ}$ (Sciences Zoologiques) 107: 464-468.

RонÁČ́EK, J. 1983: Faunistics of the Czechoslovakian species of Anthomyzidae and Stenomicridae (Diptera). Časopis Slezského Muzea, Opava (A) 32: 125-135.

RонÁČ́EK, J. 1984: Santhomyza gen. n., a new genus of Anthomyzidae (Diptera) from the Mediterranean area. - Bollettino del Museo Regionale di Scienze Naturali, Torino 2: 531-543.

RoHÁčEK, J. 1987: Anthomyzidae. - In: JEžEK, J. (ed.): Enumeratio insectorum bohemoslovakiae. Check List of Czechoslovak Insects II (Diptera). - Acta Faunistica Entomologica Musei Nationalis Pragae 18: 253-254.

RoHÁČ́E, J. 1996: Revision of Palaearctic Stiphrosoma, including the Anthomyza laeta-group (Diptera: Anthomyzidae). - European Journal of Entomology 93: 89-120.

RoHÁČEK, J. 1998: Taxonomic limits, phylogeny and higher classification of Anthomyzidae (Diptera), with special regard to fossil record. - European Journal of Entomology 95: 141-177.

ROHÁČEK, J. 1999: A revision and re-classification of the genus Paranthomyza CZERNY, with description of a new genus of Anthomyzidae. - Studia dipterologica 6: 373-404.

RонÁČEK, J. 2004a: Revision of the genus Amygdalops LAмB, 1914 (Diptera, Anthomyzidae) of the Afrotropical Region. - African Invertebrates 45: 157-221.

RoнÁČEK, J. 2004b: Anthomyzidae. - Fauna Europaea Service, http://www.faunaeur.org

Roháč́ck, J. \& Freidberg, A. 1993: The Anthomyzidae (Diptera) of Istael, with revision of Anagnota BeCKer. - Israel Journal of Entomology 27: 61-112.

SÉGuY, E. 1934: Anthomyzidae. - In: Diptères (Brachycères) (Muscidae Acalyptratae et Scatophagidae). - Faune de France, Vol. 28, iv + 832 pp. (p. 301-305), P. Lechevalier et fils, Paris.

Soós, Á. 1981: 58. család: Anthomyzidae - Tüskéscombú legyek. - Fauna Hungariae 149, pp. 106-117, Akadémiai Kiadó, Budapest (in Hungarian) 
SPEISER, P. 1903: Eine neue Dipterengattung mit rudimentären Flügeln, und andere dipterologische Bemerkungen. - Berliner entomologische Zeitschrift 48: 65-72.

Stackelberg, A. A. 1958: Materiali po faune dvukrylykh Leningradskoi oblasti. III. Diptera Acalyptrata, ch. 1 [List of Diptera of the Leningrad Region, III. Acalyptrata, part 1.]. - Trudy Zoologicheskogo Instituta Akademii Nauk SSSR 24: 103-191 (in Russian)

STACkelberg, A. A. 1970: 83. sem. Anthomyzidae. - In: Bei-Bienko, G. YA. (ed.): Opredelitel nasekomykh evropeiskoi chasti SSSR. - Vol. 5, pt. 2, 943 pp. (pp. 326-329), Nauka, Leningrad (in Russian).

Trojan, P. 1962: Zeszyt 54-58 Odiniidae, Clusiidae, Anthomyzidae, Opomyzidae, Tethinidae. Klucze do oznaczania owadów Polski. Część XXVIII Muchówki - Diptera. 68 pp., Państwowe Wydawnictwo Naukove, Warszawa (in Polish).

Vockeroth, J. R. 1961: The North American Species of the Family Opomyzidae (Diptera: Acalypterae). - The Canadian Entomologist 93: 503-522.

Vockeroth, J. R. 1987: 75. Anthomyzidae. - In: McAlpine J. F; Peterson, B. V.; Shewell, G. E.; Teskey, H. J.; Vockeroth, J. R. \& Wood, D. M. (eds): Manual of Nearctic Diptera. - Agriculture Canada Monograph No. 28, Vol. 2, vi+675-1332 (p. 887-890). Minister of Supply and Services Canada, Ottawa.

Wheeler, T. A. 1994: Conioscinella zetterstedti Andersson (Diptera: Chloropidae), a chloropid fly with polymorphic wing reduction, new to the Nearctic and Central Palaearctic regions. - The Canadian Entomologist 126: 1377-1381.

Wheeler, T. A.; Vockeroth, J. R. \& Boucher, S. 1999: Geomyza tripunctata Fallén, a Palaearctic opomyzid fly new to North America, with notes on range expansions in Holarctic Opomyzidae (Diptera).

- Proceedings of the Entomological Society of Ontario 130: 15-20.

ZATWARNICKI, T. 1996: A new reconstruction of the origin of eremoneuran hypopygium and its implications for classification (Insecta: Diptera). - Genus 7 (1): 103-175.

Zetterstedt, J. W. 1852: Diptera Scandinaviae. - Disposita et descripta. Vol. 11, vii + $4091-4545$ pp., Officina Lundbergiana, Lundae [= Lund].

\section{Authors' addresses:}

Dr. JINDŘICH ROHÁČEK

Department of Entomology

Silesian museum, Tyršova 1 ,

CZ-746 46 Opava

Crech Republic
KEVIN N. Barber

Great Lakes Forestry Centre

Canadian Forest Service, Natural Resources Canada, 1219 Queen St. E., Sault Ste. Marie, Ontario, P6A 2E5, Canada 
List of numbered characters used in cladogram in Fig. 215. A - apomorphic, P - plesiomorphic

(1) arista pectinate $(A)$; arista pubescent $(P)$

(2) wing relatively short to reduced $(A)$; wing long $(P)$

(3) occiput medially with a pair of convergent silvery microtomentose stripes (A); occiput medially simple (P)

(4) subvibrissa enlarged (A); subvibrissa small (P)

(5) phallapodeme with deeply forked base (A); phallopodeme with base unforked, at most emarginate (P)

(6) connecting sclerite in aedeagal part of folding apparatus well developed (A); connecting sclerite membranous $(\mathrm{P})$

(7) female tergosternum $\mathrm{T} 7+\mathrm{S} 7$ dorsomedially divided or unpigmented (A); female $\mathrm{T} 7+\mathrm{S} 7$ dorsally compact (P)

(8) pleural part of thorax yellow, at most dorsal band brown (A); pleural part of thorax largely brown (P)

(9) ventral part of female $T 7+S 7$ pale-pigmented (A); ventral part of T7+S7 dark as dorsal part $(\mathrm{P})$

(10) saccus with short robust pigmented spines $(A)$; saccus with only hyaline fine spinulae or tubercles $(P)$

(11a) gonostylus long $(\mathrm{A})$; gonostylus short $(\mathrm{P})$

(11b) gonostylus elongate and slender $(A)$; gonostylus shorter and broader $(P)$

(12) spermathecae elongately pyriform (A); spermathecae shortly pyriform (P)

(13) peristomal setulae enlarged (A); peristomal setulae small (P)

(14) hypandrium with 1-2 setae on each side (A); hypandrium bare (P)

(15) base of distiphallus densely setulose (A); base of distiphallus without setulae (P)

(16) spermathecae with long spines transversely attached to surface $(A)$; spermathecae with spines oriented longitudinally (P)

(17) hypandrium robust (A); hypandrium slender $(P)$

(18) basal membrane with longer rounded tubercles $(A)$; basal membrane with low transverse tubercles $(P)$

(19) filum compact and without projections (A); filum less compact, with at least small projection in distal third to subapically $(\mathrm{P})$

(20) looped sclerite attenuate, tape-shaped (A); looped sclerite thicker and less prolonged $(P)$

(21) female $S 8$ medially divided (A); female $S 8$ posteromedially incised (P)

(22) thorax without dark areas (A); thorax with dark (brown) areas (P)

(23) anal fissure of epandrium with dorsal margin poorly delimited (A); anal fissure with dorsal margin distinct $(\mathrm{P})$

(24) apex of filum setulose (A); apex of filum without setulae (P)

(25) basal part of saccus with small spines (A); basal part of saccus without spines (P)

(26) female internal sclerites enlarged and heavily sclerotized (A); female internal sclerites smaller and weakly sclerotized (P)

(27a) mesonotum with medial brown band $(A)$; mesonotum without medial brown band $(P)$

(27b) medial brown band on mesonotum narrowed $(\mathrm{A})$; medial brown band broad $(\mathrm{P})$

(28) $t_{3}$ with ventroapical seta absent $(A)$; $t_{3}$ with ventroapical seta present $(P)$

(29) apex of filum short, broad, flat and finely dentate (A); apex of filum long and narrowed (P)

(30) saccus finely setulose in addition to short spines $(A)$; saccus without setulae (P)

(31) occiput yellow to ochreous yellow (A); occiput brown, at least laterally (P)

(32) saccus with a tuberculate area $(A)$; saccus without tuberculate area $(P)$

(33) gonostylus narrowed in the middle (A); gonostylus gradually tapered towards apex (P)

(34) female T8 with T-shaped or Y-shaped dark pattern (A); female T8 simply pale pigmented (P) 


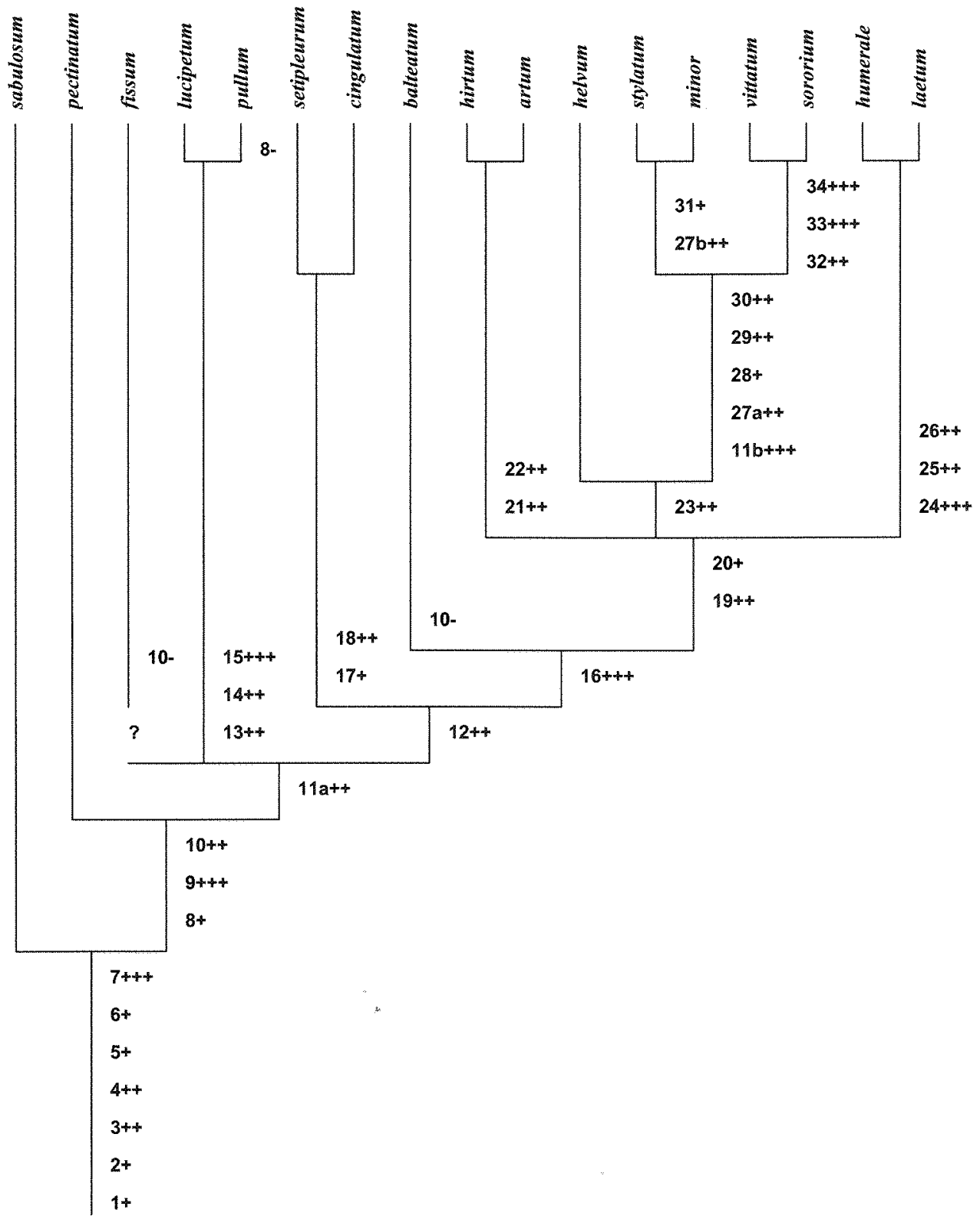

Fig. 215: Cladogram showing the inferred relationships of Stiphrosoma species. Numbers refer to the characters listed below, $(+),(++),(+++)$ indicate character weighting based on subjective assesment of the likelihood of misinterpretation of homology or polarity. Characters unique within the Anthomyzidae, considered strong evidence of synapomorphy, are given greatest weight and coded $(+++)$. Characters marked $a, b$ are postulated as transformation series, reversals are coded (-). 